

Digitized by the Internet Archive in 2007 with funding from Microsoft Corporation 


l 



\title{
THE IDEA OF GOD
}

\author{
IN THE LIGHT OF
}

\section{RECENT PHILOSOPHY}

\section{The Bifford Zectures}

DELIVERED IN THE UNIVERSITY OF ABERDEEN IN THE YEARS 1912 AND 1913

BY

\begin{abstract}
A. SETH PRINGLE-PATTISON, $\perp$ I/ LL D, D.C.L.

TELLOW OF THE BRITISH ACADEMY

EMERITUS PROFESSOR OP LOGIC AND METAPHYSICS

IA THE UNIVERSITY OF EDINBURGE
\end{abstract}

SECOND EDITION REVISED

NEW YORK OXFORD UNIVERSITY PRESS

AMERICAN BRANCH : 35 WEET 32ND STREET LONDON, TORONTO, MELBOURNE, AND BOMBAY 1920 
Copyright, 1920

by Oxford University Peess

AMERICAN BRANCH

PRINTED IN THE UNITED STATES OF AMERICA 
To

MY WIFE

AND THE DEAR MEMORY OF

RONALD

OUR YOUNGEST SON

WHO GAVE HIS LIFE WILLINGLY

AT GINCHY ON THE SOMME

6TH SEPTEMBER 1916 



\section{PREFACE}

Distractions and anxieties arising out of the war have interfered with the preparation of these Lectures for the press, but it is possible that, at certain points, the thought may have gained in maturity by the enforced delay.

Readers of this volume who listened to the Gifford Lectures in 1912 and 1913 will recognize that, in the main, the material and the treatment are the same. But $I$ have not hesitated, on occasion, to transfer a lecture or part of a lecture from its original place in the series, when the sequence of thought seemed to gain thereby in clearness and logical coherence. One or two passages also, which appeared to have little or no bearing on the argument as it ultimately took shape, have been removed. A lecture, introductory to the Second Series, criticizing two recent essays on Religion, has been omitted. It served at the time as a convenient illustration of the thesis of the previous year's course, and it was printed shortly thereafter as an article in the Hibbert Journal for October 19I3. But the discussion has not sufficient permanent importance to justify its retention here, and its inclusion would interrupt the course of what is intended to be a continuous argument. On the other hand, I have tried to develop the subject more fully at points where the original treatment had been somewhat hurried. This applies more particularly to the lecture on 'Time and 
Eternity' and to the criticism of M. Bergson's doctrine of Time and its implications in the lecture which follows. Here what was originally a single lecture has grown into two. Complete success in such a region is unattainable, but I trust that what is now offered is, in some respects, a more adequate handling of a peculiarly difficult subject. In Lecture IV, while my view of the relation of biology to physics remains unchanged, I have added some detailed criticism of recent neo-vitalist statements from which I wish to dissociate myself ; and the discussion of Pluralism in the later lectures has been extended by including a criticism of the views of Professor Howison, Dr. Rashdall, and Dr. McTaggart.

The choice of a title has caused me some difficulty. The title eventually chosen may easily be condemned as too ambitious; but it has at least the merit of comprehensiveness, and it is also the official subject of the Lectures founded by Lord Gifford. It has the disadvantage-if it be a disadvantage-that it does not indicate in advance the nature of the conclusion reached. But philosophical labels are for the most part misleading, and the conclusion will mean more to the reader if he discovers it for himself. I am especially anxious, however, that the reference to 'recent philosophy' should not lead anyone to suppose that the book is merely, or even primarily, an historical survey of opinion on the subject with which it deals. There are many names mentioned in the course of the lectures, and many theories criticized, but there is no pretence of an exhaustive survey, and not one of the names and theories actually cited is introduced on historical grounds. They are all employed as a means of illuminating, either by affinity or by force of contrast, the constructive position which is gradually built up in the course of the lectures. In short, although it consists largely of criticism, the interest of the book is neither critical 
nor historical, but constructive throughout. This method of construction through criticism is the one which I have instinctively followed in everything I have written. I do not claim that it is the best method; I simply desire that its nature be recognized.

In the present case, when contemporary discussion on the fundamental questions of philosophy and religion is peculiarly active, the necessity is almost imposed upon a writer of defining his own position by reference to divergent views and other forms of statement. And I venture to think that the value of his work is thereby increased; for only by such mutual criticism, and the resulting definition of the points of difference, can we advance towards a common understanding. Readers of this volume will note the prominence given to Professor Bosanquet's impressive statement of the Idealistic position in the two volumes of his Gifford Lectures in the University of Edinburgh. I found it especially instructive, from time to time, to make Professor Bosanquet's treatment my point of departure, because, along with the large amount of general agreement, there was at certain points a difference of emphasis, to say the least, in our ways of holding the Idealistic creed. The lecture on 'The Criterion of Value' and the two lectures on 'The Absolute and the Finite Individual ' may be mentioned as examples of what I mean.

It is possible that some readers may think that $I$ have drawn too frequently upon the poets. That is perhaps a question of temperament. But my procedure was, at any rate, quite deliberate, for I accept Wordsworth's description of poetry as 'the breath and finer spirit of all knowledge', and $\mathrm{I}$ am even ready to be persuaded by Mr. Yeats that 'whatever of philosophy has been made poetry is alone permanent'. 
In concluding this preface, I desire to thank the Senatus of the University of Aberdeen for the honour they did me in appointing me to the Lectureship. It has enabled me to bring together the reflections of many years, and I have striven, in return, to give them of my best.

To my brother, Professor James Seth, who read the lectures in manuscript, and to Professor H. R. Mackintosh, of New College, Edinburgh, and Mr. H. F. Hallett, M.A., who read the whole in proof, my warm thanks are also due for their ready help and valuable suggestions.

\section{UNIVERSITY OF EDINBURGH,}

December 20, 1916.

The reception accorded to these Lectures encourages me to hope that the book may continue to be found of service for some time. The call for a new edition has come while publishers are still hampered by difficulties of production and by the accumulations of the war. In these circumstances it has been decided to print the present edition from the plates of the American edition issued in 1917. This has made it impossible to introduce into the text more than verbal corrections, but I have been able to add, by way of appendix, a few supplementary notes referring to the more important criticisms and discussions to which the volume has given rise. Any attempt at mediation in a difficult dispute is necessarily exposed to attack from both sides, and this has happened to my attempt, in the second series of Lectures, to balance the claims of the Absolute and the individual or of monism and pluralism. But I have met with nothing to shake my confidence in the fundamental positions and lines of argument to which I had committed myself. 


\section{CONTENTS}

\section{FIRST SERIES}

\section{LECTURE I}

\section{HUME'S 'DIALOGUES CONCERNING NATURAL RELIGION'}

PAGE

Reasons for beginning with Hume . . . . . . . I

The importance attached to the 'Dialogues' by Hume himself 2

The question debated is not 'the Being but only the Nature of the Deity' . . . . . . . . . . . . 6

Demea's attempt to base religious faith on philosophical scepticism . . . . . . . . . . . . 7

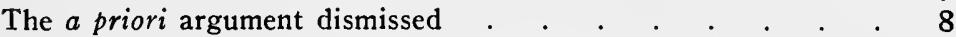

Concentration of the discussion on the argument from design .9

The criticisms of Philo and his anticipation of modern points of view . . . . . . . . . . . . . . I I

Hume's tenacious adherence to the 'speculative tenet of theism' . . . . . . . . . . . . . 14

Contrast between the order of nature and the record of human history . . . . . . . . . . . . . 16

Hypothesis of a finite God suggested but set aside . . . . 19

Surrender of the moral attributes . . . . . . . . 20

Insignificant character of the conclusion . . . . . . 2I

\section{LECTURE II}

\section{KANT AND THE IDEA OF INTRINSIC VALUE}

Hume's conclusion determined by the restricted nature of his premisses

Kant's analysis of moral experience . . . . . . . $\quad 26$

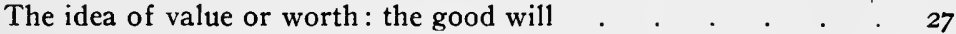

'A realm of ends': teleological view of the world of nature . 28

The 'postulates' of God and immortality . . . . . . 3I

Defects of Kant's statement . . . . . . . . . . 34

The doctrine of the self-legislative will . . . . . . 36

The idea of value in Kant's successors and throughout the nninẹteențh century 
PAGE

The philosophical antithesis between Idealism and Naturalism 40 The objectivity of values . . . . . . . . . . 42 The idealistic position not to be staked on any minor issue . . 43

\section{LECTURE III}

\section{THE NINETEENTH-CENTURY DUEL BETWEEN IDEALISM AND NATURALISM}

The protest of 'the heart' against the reason . . . . . 47

The Kantian separation between Knowledge and Belief . 48

Lange's History of Materialism and the 'flight to the ideal' . 52

Lotze's protest against materialistic dogmatism: 'the world of forms' and 'the world of values' . . . . . . 54

Ritschl's repudiation of metaphysics . . . . . . . 56

Spencer's Unknowable as the reconciliation of religion and science . . . . . . . . . . . . 58

Mr. Balfour's argument: its sceptical and constructive aspects 60 The disparagement of reason: danger of so presenting the principle of value

\section{LECTURE IV}

\section{THE LIBERATING INFLUENCE OF BIOLOGY}

The relations of philosophy and the sciences . . . . . 66

Biology and physics . . . . . . . . . . . . 68

The claim of biology to use its own categories . . . . . . 71

The organism as a self-maintaining whole . . . . . . 73

Criticism of Neo-vitalistic statements . . . . . . . . 77

Re-interpretation of the doctrine of evolution . . . . . 81

Revival of general interest in philosophy . . . . . 86

\section{LECTURE V}

\section{THE LOWER AND THE HIGHER NATURALISM}

Ambiguity of the term Naturalism . . . . . . . . . . $\quad$. 88

A defence of order and continuity against an arbitrary Supernaturalism

Illusory 'explanation' of the more developed by the less developed . . . . . . . . . . . . 9r

Transition in nature from one order of facts to another . . $\quad 93$

The question of the 'origin' of life . . , . . . . 98 
PAGE

The passage from perception and association to the conceptual reason

Continuity of process does not exclude the emergence of real differences

The meaning of potentiality $\cdot \cdot \cdot$

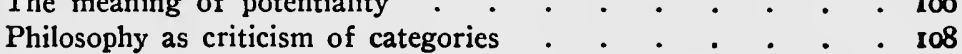

\section{LECTURE VI}

\section{MAN AS ORGANIC TO THE WORLD}

Manufactured difficulties as to the subjectivity or relativity of knowledge

Cognition conceived as the 'barren rehearsal' of a finished reality

Relatedness versus Relativity . . . . . . . . . II5

The epistemological problem in Locke, Berkeley, and Kant . . II6 The objectivity of the secondary qualities . . . . . . I20

Professor Laurie's statement of philosophical Realism . . 122

The evolution of the sense-organs as part of nature's purpose of self-revelation . . . . . . . . . . . I26

The same principle applies to the aesthetic qualities . . . $\quad$ I27

\section{LECTURE VII}

\section{ETHICAL MAN : THE RELIGION OF HUMANITY}

The ethical versus the cosmic process

The Religion of Humanity, as a merely 'subjective synthesis',

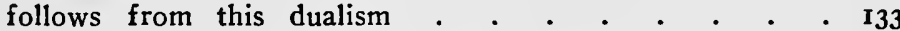

Comte's phenomenalism depends on a false idea of metaphysics Vital truths of Comte's religious doctrine: $(a)$ the central function assigned to religion in human history; $(b)$ the insistence on the moral qualities as the only fit objects of love and worship; (c) the organic life of Humanity . . I37

Humanity taken as a species of finite Absolute . . . . . 145 Impossibility of thus isolating Humanity illustrated from Comte himself . . . . . . . . . . . . 146

His subordination of the intellect to 'the heart' makes him eventually false to the scientific spirit 


\section{LECTURE VIII \\ POSITIVISM AND AGNOSTICISM}

The time-process as the progressive revelation of an eternal Reality

The human and the divine: Positivism and Christianity.$\quad$ I57

Agnosticism depends on a false ideal of knowledge . . . 158

Substance and qualities, essence and appearance . . . . 159

Confusion between the unknowable and the unfathomable . . 165

The Religion of Humanity and the worship of the Unknowable

as complementary half-truths . . . . . . . 170

\section{LECTURE IX}

\section{IDEALISM AND PAN-PSYCHISM}

Further reflections on the Agnostic fallacy . . . . . 172

General conclusion reached in these lectures . . . . . 175

The idealistic doctrine maintained does not involve Monadism or

Pan-psychism . . . . . . . . . . . 178

The motives underlying monadistic theories . . . . . 179

The desire to save spontaneity and freedom . . . . . . 183

Illusory attempt to evolve the very conditions of evolution . . 185

Such freedom becomes indistinguishable from pure contingency 186 A realm of physical law required as the milieu of the spiritual

life . . . . . . . . . . . . . 188

\section{LECTURE $\mathrm{X}$}

\section{IDEALISM AND MENTALISM}

Our conclusion does not involve Subjective Idealism or Mentalism

The circular nature of Berkeley's argument . . . . . 19r

Ferrier's demonstration of an 'infinite and everlasting Mind'

proceeds on the same lines . . . . . . . . . 193

Green's Eternal Consciousness . . . . . . . . 195

The mentalistic argument yields us at best only the empty form of the Ego

To regard the material world as self-subsistent, or as a res completa, is a moral as much as a speculative impossibility .

The larger idealistic truth admits of a frankly realistic attitude towards external nature 


\section{SECOND SERIES}

\section{LECTURE XI}

THE LOWER PANTHEISM AND THE DOCTRINE OF DEGREES OF TRUTH

The argument of the First Series reviewed . . . . . . 207

The reality of appearances . . . . . . . . . . 216

But is not this merely the pell-mell of empirical occurrence over

again? . . . . . . . . . . . . . 219

The idea of a system and a scale of values is essential . . . 220

Spinoza on degrees of 'perfection' . . . . . . . 22I

Mr. Bradley's use of the principle . . . . . . . . . . 222

Illustration from the world of Shakespeare's tragedies . . . 223

\section{LECTURE XII}

\section{THE CRITERION OF VALUE: ITS NATURE} AND JUSTIFICATION

Mr. Bradley's criterion of inclusiveness and harmony . . 226

Accepted by Professor Bosanquet in his formula of individuality and non-contradiction . . . . . . . . . 227

Formal and abstract character of such a principle . . . . 230

We must argue from the specific modes of our finite consciousness of value . . . . . . . . . . . . . 23I

Mr. Bradley's transformation of the purely logical criterion . 233

His unconvincing defence of this transformation . . . . 234

The real defence is the view taken of man as an organ of reality 235

The inevitable assumption involved . . . . . . . . 236

The real meaning of the ontological argument . . . . : 240

\section{LECTURE XIII}

\section{THE IDEAL AND THE ACTUAL}

Ideals operative in experience are themselves part of experience 243 Common neglect of this, e. g. in Hume's argument . . . 244 Descartes's argument from the idea of a Perfect Being . . 246 The cosmological argument also rises from the imperfect to the perfect . . . . . . . . . . . . . 249

The Ideal the most real thing in the world . . . . . . 251

Solution of the problem of immanence and transcendence . . 253 


\section{LECTURE XIV}

\section{THE ABSOLUTE AND THE FINITE INDIVIDUAL}

Professor Bosanquet's view of the 'formal distinctness' of selves as due to 'impotence' . . . . . . . . . . 256

The mere individual as a self-contained unit is certainly a fiction 257 Again, the true life of the finite self is a finding of itself in social and universal interests $. \quad . \quad . \quad . \quad . \quad . \quad . \quad .262$

But this in no way supports the idea of a 'confluence' or blending of selves . . . . . . . . . . . . . .

The individual as a unique expression or focalization of the universe . . . . . . . . . . . . .

Selves not 'elements' of Reality, but 'members' or incarnations of the Absolute . . . . . . . . . . . . . . 270

The 'adjectival' theory of the finite . . . . . . . 272

\section{LECTURE XV}

THE ABSOLUTE AND THE FINITE INDIVIDUAL (Continued)

Mr. Bradley's view of the plurality of souls as 'appearance and error' . . . . . . . . . . . . . 276

Resulting view of the destiny of the finite self . . . . . 280

But the individual is not simply a very complex group of universals . . . . . . . . . . . . . 282

The origin of such finite centres the only fact fitly describable as creation . . . . . . . . . . . . . 285

Real difference and a measure of independence involved . . 287

The testimony of our greatest experiences . . . . . . 289

Personality as a formed will . . . . . . . . . 29I

A world of persons the appropriate End of the Absolute as a selfcommunicating Life . . . . . . . . . . 294

Note on Professor Bosanquet's use of the social analogy . . 296

\section{LECTURE XVI}

\section{THE IDEA OF CREATION}

Ordinary idea of creation as an event in the past . . . . 299 A phenomenal regress cannot lead to a First Cause . . . 30I Cause as applied to God must be understood as Ground or Reason 302 The relation of the universe to God is organic, not accidental - 304 
Creation as an 'eternal' act 305

Creation 'out of nothing' is the denial of an independently existing matter . . . . . . . . . . . . 306 Creation as manifestation in and to conscious spirits . . . 308 No existence of God prior to and apart from such manifestation 310 A comparison with Professor Howison's Pluralism . . . 315 God must be more than primus inter pares . . . . . 320

\section{LECTURE XVII}

\section{TELEOLOGY AS COSMIC PRINCIPLE}

Finite purpose implies desire for the non-existent and the adaptation of means to ends

Do these features of the idea disqualify it as a principle of cosmic interpretation? . . . . . . . . . . . 324

The traditional argument from design . . . . . . . 325

Teleology as affected by the modern theory of organic development

The idea of purpose becomes the idea of a systematic and intelligible whole . . . . . . . . . . . . 328

The idea thus tends to pass into that of value or satisfaction $\quad .332$ Illustrated by Spinoza's treatment of the subject . . . . 333 Can value be separated from activity or effort? . . . . . . 335 The 'eternal purpose' of God . . . . . . . . 340

\section{LECTURE XVIII}

\section{TIME AND ETERNITY}

Three senses of the term 'eternal' distinguishable . . . . 343 The timelessness of truth : the Platonic world of Ideas . . . 345 'Eternal' in ordinary usage is rooted in our temporal experience 348 The perception of succession implies a consciousness of duration 350 Eternity as a totum simul . . . . . . . . . . . . 354

The stages must be seen not merely simultaneously, but as elements in a completed purpose . . . . . . . . . 358 The analogy of an artistic whole . . . . . . . . 36r The time-process must be retained, and yet transcended, in the Absolute . . . . . . . . . . . . 363 


\section{LECTURE XIX}

\section{BERGSONIAN TIME AND A GROWING UNIVERSE}

The spatialized idea of time and the illusion of determinism - 367

But the same illusion persists in M. Bergson's stress on the

contingency of the future . . . . . . . . . 370

Past, present, and future organic to one another . . . . 376

As a mere beginning, the élan vital is purely indeterminate . $\quad .378$

M. Bergson's suggestion of a theistic background . . . . 379

Progress predicable only of the parts, not of the Eternal Nature on which they draw . . . . . . . . . . 38t

Note on M. Bergson's doctrine of Time . . . . . . 383

\section{LECTURE XX}

\section{PLURALISM-EVIL AND SUFFERING}

Dr. Rashdall's theory of a limited God . . . . . . . 388

Dr. McTaggart's Absolute as a society of seli-existent persons 39I

William James's Pluralistic Universe . . . . . . . 393

His mistaken conception of the Absolute as mereiy a spectator of the world-drama . . . . . . . . . . 397

The problem of evil and sufiering . . . . . . . . 400

The arguments of Hume and Mill . . . . . . . . 401

The conception of omnipotence . . . . . . . . 403

The purely hedonistic ideal of both thinkers . . . . . 406

Failure of traditional theism to assimilate the most characteristic articles of Christian belief . . . . . . . . 409

The eternal redemption of the world . . . . . . . 412

The element of casualty and 'the arduousness of reality' . . 415

The omnipotence of atoning love . . . . . . . . 4I7 


\section{LECTURE I}

\section{HUME'S 'DIALOGUES CONCERNING NATURAL RELIGION ,}

IT is just two hundred years since the birth of the greatest Scotsman who ever applied himself to these subjects. In Academies and learned journals, even in the daily and weekly newspapers, during the past year ${ }^{1}$ we have been celebrating the bicentenary of David Hume, and recalling to mind the achievements which gave him so conspicuous a place in the history of thought. It has seemed to me therefore not inappropriate to begin these lectures by some reference to Hume's pronouncement on those ultimate questions which Lord Gifford had in view in the foundation of this lectureship. The more so as we are not left in this matter to deductions, more or less probable, from Hume's general theory of knowledge; he has dealt with the theistic problem explicitly and at length in his Dialogues concerning Natural Religion, a work to which his biography shows that he attached unusual importance as the deliberate and carefully weighed expression of his conclusions on the greatest of all themes. Although Hume's mode of stating the question, his handling of the argument, as well as the nature of his conclusions, are in many ways strikingly different from those which naturally suggest themselves to a thinker of to-day, I have thought that these very differences of formulation and of emphasis render a statement of his position valuable as a background to our further discussion. And although I do not intend these lectures to be primarily historical in character, a certain amount of historical orientation is

${ }^{1}$ The first course of lectures was delivered during the University session, I9I I-I2. 
indispensable, if only to enable us to understand how the question takes for us to-day the form it does.

The history of Hume's Dialogues is indeed curious, and the fortunes of the work have been, perhaps, hardly commensurate with the care taken by its author to ensure its survival. It was written in the maturity of Hume's powers, when he was completing his revision of his youthful conclusions in metaphysics and ethics and bidding a final farewell to philosophical speculation; and in his correspondence with Gilbert Elliot of Minto there is interesting evidence of the pains he bestowed on the balance of the argument. The terms in which he speaks of it are more appropriate to a personal document than to a purely literary performance. ' 'Tis not long ago', he writes, 'I burned an old manuscript book, wrote before I was twenty, which contained page after page the gradual progress of my thoughts on that head. It began with an anxious search after arguments to confirm the common opinion; doubts stole in, dissipated, returned; were again dissipated, returned again; and it was a perpetual struggle of a restless imagination. against inclination, perhaps against reason.'

To Philo is assigned in the Dialogues the part of the sceptical objector-what Hume here describes as the struggle of a restless inagination-and because Philo's sceptical arguments are so entirely consonant with the general tenor of Hume's philosophy, it has been too common to take his utterances as representing by themselves Hume's own attitude to the question under discussion. But this is to ignore both the carefully constructed balance of the Dialogues and their avowed and deliberate conclusion. Hume admits, in the letter already quoted, that the part of Philo is one which admirably suited his temperament. 'I must confess, Philo,' says Cleanthes in the Dialogues, 'that of all men living, the task you have undertaken of raising doubts and objections suits you best.' And when Cleanthes further. 
rallies his 'ingenious friend ' on the 'too luxuriant fertility' of his invention, which 'suppresses his natural good sense by a profusion of unnecessary scruples and objections', and on the 'strange lengths' to which his 'spirit of controversy, joined to his abhorrence of vulgar superstition' has carried him in the course of the argument, we seem to hear the echoes of one of Gilbert Elliot's letters at the time of the composition of the work. Hume replied to his correspondent that he wished his friend lived near enough to sustain in actual discussion the rôle of Cleanthes, the philosophical theist. Cleanthes, he explicitly says, is the hero of the piece, and he is anxious to see his position strengthened, if that be possible, against his own sceptical doubts in the mouth of Philo. He admits 'the strong propensity of the mind' towards the theistic conclusion, but he fears that ' unless that propensity were as strong and universal as that to believe in our senses and experience, it will be esteemed a suspicious foundation'. ' 'Tis here', he proceeds, 'I wish for your assistance; we must endeavour to prove that this propensity is somewhat different from our inclination to find our own figures in the clouds, our faces in the moon, our passions and sentiments even in inanimate matter.' There is good evidence, therefore, that Hume's purpose in the Dialogues was entirely serious, and the work as a whole is perhaps the most intimately personal expression of his views which we possess. It appears to be the outcome of something like a personal need to probe the question to the bottom, and to set down as carefully and dispassionately as possible both the positive and the negative results.

This is the view which is naturally suggested by the history of the manuscript and the deliberate publication of the volume as the philosopher's last bequest to the world he was leaving. For twenty-seven years Hume kept the manuscript by him. Rumours of the existence of such a work by 'the terrible David' had got abroad. Its negative 
results were exaggerated by a natural enough inference, and its possible appearance was regarded by the upholders of religion with undisguised panic. When Hume sounded his friend Adam Smith, whom he had made his literary executor, he found him unwilling to incur the odium of editing the book. Even his publisher, Strahan, to whom in consequence he transferred his manuscripts, declined the task. But with characteristic quiet determination the dying man had provided even for this contingency, ordaining in a last codicil to his will that, if still unpublished within two years and a half after his death, the sheets should be returned to his nephew David, 'whose duty in publishing them as the last request of his uncle must be approved by all the world'. By his nephew, therefore, the Dialogues were eventually published in 1779. The reception of the book was a somewhat ironic commentary upon the alarm of the orthodox and the elaborate precautions of the author. 'The zealots,' as Hume calls them, seem to have found the volume less formidable in reality than in apprehension. Perhaps the delicate rapier-play of the discussion, though touching to the quick the vital points of the great issue, was at too Olympian a distance from the bludgeon-work of contemporary theological controversy to cause them serious concern. A German translation, however, came into Kant's hands just as he was beginning the final draft of the Critique of Pure Reason, and his repeated references to Hume's arguments, in the Prolegomena two years later, show how carefully he had studied it. But from that time till this the Dialogues have hardly received either from friend or foe the prominence they deserve, both as the sincerest expression of Hume's personal position and as a searching analysis of the theistic problem an analysis which, in spite of its eighteenth-century mannerisms and turns of phraseology, significantly anticipates at certain points the lines on which subsequent controversy has moved. 
It is not my purpose here to follow all the windings of Hume's discussion, or even to appraise the value of the arguments used on either side of the debate. Some of the more significant of these we may have to return to later, for Hume's statement of a position is often classical. My present purpose is rather to bring out the main lines on which the discussion moves, the decisive considerations on which it turns, and, as far as possible, the precise nature of the conclusion arrived at. The very differences between Hume's method of stating the question and those which seem natural and appropriate to us, will prove, I think, instructive for our further discussion; and the strangely unsatisfying character of his conclusion, even in its most positive aspect, must at least help us to realize what we mean by the existence of God-what the idea of God stands for in our conception of the universe and in our attitude towards life.

The characters in the Dialogues are three in number, Cleanthes and Philo, already mentioned, and Demea, described in the Introduction as the representative of 'rigid inflexible orthodoxy'. Demea is introduced more as a foil to the other two than as making any serious contribution to the determination of the question. His treatment by his fellow-disputants is more or less ironic throughout, and he is represented as retiring in ill-concealed displeasure when his two opponents reveal the extent of the ground they hold in common, and before the remarkable attempt made in the concluding section to reach a frank adjustment of their differences. Demea's diatribes against 'mere human reason' and 'the infirmities of human understanding', which make the nature of God 'altogether incomprehensible and unknown to us ', are skilfully exploited by Philo at the outset of the discussion in a sceptical or agnostic interest, and it is certain that the literary play of the dialogue would suffer by Demea's absence. But the philosophical interest of the work lies in the encounter of Philo and Cleanthes, in the gradual 
development and 'progressive restatement ' of the argument between them according to the admissions of each disputant to his opponent.

The modern reader who has Hume's popular reputation in mind, and who remembers also the absolute scepticism which is the outcome of Hume's philosophy as a whole, will probably be surprised to find that 'the being of a God' is not disputed by any of the combatants. On the contrary, it is their common assumption. Philo no less than Demea emphasizes the position that 'surely where reasonable men treat these subjects, the question can never be concerning the Being, but only the Nature of the Deity.' He accepts the former as a ' fundamental truth ', as ' unquestionable and self-evident ', and recalls with approbation Bacon's scriptural classification of the atheist with the fool. But the reader's natural surprise at the unchallenged admission of so seemingly important a position is soon lessened by finding how little the admission really amounts to-to no more, indeed, than a barely formal acknowledgement. 'Nothing exists without a cause,' says Philo, by way of interpreting this fundamental article of agreement, 'and the original cause of this universe (whatever it be) we call God, and piously ascribe to him every species of perfection.' So formulated, the being of a God involves no more than Locke's jejune proposition 'Something must be from eternity',' and it is evident that everything depends on what we are warranted in concluding as to the nature of the so-called divine Being. This is the avowed subject of the Dialogues.

The debate is started by Demea, whose disparagement of human reason, in comparison with the claims of authority and revelation, gives Philo an opening for developing the thesis in a purely sceptical direction by arguments familiar to every reader of the Treatise or the Enquiry. 'It is a

'Or the 'Being is' of Parmenides and Spinoza. Cf. McTaggart, Some Dogmas of Religion, p. 187. 
pleasure to me', says Philo, 'that just reasoning and sound piety here concur in the same conclusion, and both of them establish the adorably mysterious and incomprehensible nature of the Supreme Being.' This attempt ' to erect religious faith on philosophical scepticism' (so Cleanthes accurately describes it) irresistibly recalls the similar movement in English philosophy a century later, connected with the names of Hamilton and Mansel, which found its natural sequel in the more complete Agnosticism of Herbert Spencer. Demea, like Sir William Hamilton, offers to 'cite all the divines almost, from the foundation of Christianity' in support of his conclusion that, "from the infirmities of human understanding,' the nature of God is 'altogether incomprehensible and unknown to us'. And, like Mansel, he adds, that though we "piously ascribe to him every species of perfection', ' we ought never to imagine that we comprehend the attributes of this divine Being, or to suppose that his perfections have any analogy or likeness to the perfection of a human creature. Wisdom, Thought, Design, Knowledge : these we justly ascribe to him because these words are honourable among men, and we have no other language or other conceptions by which we can express our adoration of him. But let us beware lest we think that our ideas anywise correspond to his perfections, or that his attributes have any resemblance to those qualities among men.' The reply of Cleanthes to this insidious method of argument must be accepted by any serious disputant as conclusive: "The Deity, I can readily allow, possesses many powers and attributes of which we can have no comprehension; but if our ideas, so far as they go, be not just and adequate, and correspondent to his real nature, I know not what there is in this subject worth insisting on. Is the name without any meaning of such mighty importance? Or how do you Mystics, who maintain the absolute incomprehensibility of the Deity, differ from Sceptics or Atheists, who assert that the first 
cause of all is unknown and unintelligible?' It is not, however, till late in the discussion that Demea suddenly discovers that Philo, his assiduous ally, is 'secretly a more dangerous enemy than Cleanthes himself', and soon afterwards takes occasion to leave the company.

Before his departure he had made a second attempt to bring the discussion back to 'that simple and sublime argument a priori, which, by offering to us infallible demonstration, cuts off at once all doubt and difficulty'. By this Demea means' the traditional ontological argument 'to a necessarily existent Being who carries the REASON of his existence in himself, and who cannot be supposed not to exist without an express contradiction'. But however they may differ otherwise, Philo and Cleanthes are at one in peremptorily rejecting this mode of argument as illegitimate. Hume has elsewhere anticipated Kant's famous criticism of the argument, by pointing out that existence is not an addition to the content of any idea. And the argument, at least in its traditional form, has not survived their joint attack. Here Hume is content to rest his case on the distinction, so fundamental in the Enquiry, between ' matters of fact' and 'relations of ideas'. ' Nothing that is distinctly conceivable implies a contradiction. Whatever we conceive as existent, we can also conceive as non-existent. There is no being, therefore, whose non-existence implies a contradiction. . . . The words, therefore, necessary existence, have no meaning.' Moreover, if they had any meaning, 'why may not the material universe be the necessarily existent Being?'

Hume's rejection of the conception of abstract or absolute necessity has been sustained by subsequent thought. Necessity is essentially relative, and expressible in the form of the hypothetical judgement-If $A$, then $B$. One fact may imply another, so that (on the basis of experience at least) we may reason in this logical form from the existence or nature of one set of facts to the existence or nature of another set of 
facts. But that the totality of facts which we call the universe should exist at all-or as Demea puts it, that something should exist rather than nothing-that is simply an ultimate fact to be accepted as such. There may be reasoning within this Fact as to the concatenation and mutual dependence of its parts, but with the existence of the Fact itself reasoning has nothing to do. If any one prefers to use the term universe for the sum of created or dependent beings, he may, of course, refund the universe into God as its creative source; but the position of affairs is in nowise altered, save as regards the name of the ultimate Fact. God does not reason Himself into existence; He simply is. Modern logic recognizes the ultimate categorical judgement which underlies all hypothetical judgements or logical necessities; and any attempts that have been made to rehabilitate the ontological mode of proof have really transformed it beyond recognition, and must be dealt with on their own merits. ${ }^{1}$

The vital discussion in the Dialogues turns from beginning to end round the argument from design or final causes. It is introduced in Part II by Cleanthes with a certain impatience as the only argument worthy of serious consideration. ' Not to lose any time in circumlocutions, said Cleanthes, I shall briefly explain how I conceive this matter. Look round the world: contemplate the whole and every part of it: you will find it to be nothing but one great machine, subdivided into an infinite number of lesser machines, which

\footnotetext{
${ }^{1}$ If we speak, as we may intelligibly do in another connexion, of God as necessarily existing, we mean, by the phrase, that the character of the world, as known to us, is such that it can only have its source in a Being defined as we ordinarily define God. God, in other words, is a necessary hypothesis to explain the nature of our experience. This is a logical inference of the ordinary type, and it may or may not be legitimate; but the necessity which we claim refers entirely to the relation of the conclusion to its premisses within our knowledge, and has nothing to do with the extraordinary attempt of the ontological argument to deduce existence from essence, as if God's nature could be made, in some mysterious fashion, the foundation or prius of his existence. 'I am' and ' $I$ am that I am'-the universe exists and its nature is what it is.
} 
again admit of subdivisions, to a degree beyond what human senses and faculties can trace and explain. All these various machines, and even their most minute parts, are adjusted to each other with an accuracy, which ravishes into admiration all men, who have ever contemplated them. The curious adapting of means to ends, throughout all nature, resembles exactly, though it much exceeds, the productions of human contrivance; of human designs, thought, wisdom, and intelligence. Since therefore the effects resemble each other, we are led to infer, by all the rules of analogy, that the causes also resemble; and that the Author of Nature is somewhat similar to the mind of man; though possessed of much larger faculties, proportioned to the grandeur of the work which he has executed. By this argument a posteriori, and by this argument alone, do we prove at once the existence of a Deity, and his similarity to human mind and intelligence.'

In reply to this confident and somewhat dogmatic statement, Philo, in Hume's own speculative vein, develops a number of objections calculated to weaken the force of the analogy, thereby reducing the conclusion to 'a guess, a conjecture, a presumption', or even to impugn the validity of the reasoning altogether. Some of these are repeated in his other works, and are of classical importance in the history of theistic controversy. But in Part III Cleanthes, again with a touch of impatience, brushes aside the objections as due to an affectation of scepticism on Philo's part rather than to any real difficulty in the subject-matter. It is not necessary, for example, to prove the similarity of the works of Nature to those of Art, "because this similarity is self-evident and undeniable'. 'Consider, anatomize the eye; survey its structure and contrivance; and tell me, from your own feeling, if the idea of a contriver does not immediately flow in upon you with a force like that of sensation.' There is, to his mind, something at once forced and frivolous in the objections by which it is sought to controvert or invalidate 
this obvious conclusion. Philo's 'sifting, inquisitive disposition' suffers, he suggests, 'from too luxuriant a fertility which suppresses [his] natural good sense by a profusion of unnecessary scruples and objections'. At this point we are told 'Philo was a little embarrassed and confounded', as if this shaft of Cleanthes had gone home; and for the interpretation of the Dialogues this little dramatic touch is of some significance. The statement of Cleanthes is, to a considerable extent, Hume's own criticism, as ' a practical man of common sense', ${ }^{1}$ of the speculative difficulties which he makes it his business to raise. As he is reported to have said on a memorable occasion: " Though I throw out my speculations to entertain the learned and metaphysical world, yet in other things I do not think so differently from the rest of the world as you imagine.' We find, as a matter of fact, in the concluding section of the Dialogues when, after the departure of Demea, Philo talks with Cleanthes as one man with another, that he states his frank acceptance of the argument from design in terms as strong and unqualified as those of Cleanthes himself. But for the present "while he hesitated in delivering an answer, luckily for him, Demea broke in upon the discourse, and saved his countenance'.

This diversion leaves Philo free to develop his sceptical and naturalistic vein in Parts IV to VIII, some of the most characteristic sections of the work. He elaborates the difficulty of stopping in the causal regress. 'A mental world, or universe of ideas, requires a cause as much as does a material world or universe of objects.' If we say that the different ideas which compose the reason of the Supreme Being fall into order, of themselves and by their own nature, "why is it not as good sense to say that the parts of the material world fall into order, of themselves and by their own nature?' 2 It may be permissible in science 'to explain

${ }^{2}$ He claims this title for himself in the concluding section.

${ }^{2}$ Part IV. 
particular effects by more general causes', but it cannot be satisfactory 'to explain a particular effect by a particular cause, which was no more to be accounted for than the effect itself '.

He returns to elaborate the contention that Thought is only one of a number of 'powers or energies in nature, whose effects are known, but whose essence is incomprehensible'. 'In this little corner of the world alone, there are four principles, Reason, Instinct, Generation, Vegetation.' The world resembles a living creature, an animal or a vegetable, perhaps more than it resembles a machine, ' and if $\mathrm{Cle-}$ anthes demands the Cause of our great vegetative or generative faculty, we are equally entitled to ask him the Cause of his great reasoning principle.' For, after all, 'reason, in its internal fabric and structure, is really as little known to us as instinct or vegetation '.'

In a striking paragraph Hume anticipates the evolutionary view of the gradual perfecting of organic adjustments through the progressive modification of more primitive forms. 'If we survey a ship, what an exalted idea must we form of the ingenuity of the carpenter, who framed so complicated, useful, and beautiful a machine? And what surprise must we feel, when we find him a stupid mechanic, who imitated others, and copied an art, which, through a long succession of ages, after multiplied trials, mistakes, corrections, deliberations, and controversies, had been gradually improving? Many worlds might have been botched and bungled, throughout an eternity, ere this system was struck out: much labour lost: many fruitless trials made: and a slow, but continued improvement carried on during infinite ages in the art of world-making.' 3 Applied to the human eye, as developed from the pigment spots of lower creatures, this is the argument urged by Huxley and others against Paley and his Almighty Watchmaker. And in another
${ }^{2}$ Concluding words of Part IV.
${ }^{2}$ Part VII.
- Part IV. 
section, in which he elaborates a modern version of ' the old Epicurean hypothesis' of the origin of the world 'from the eternal revolutions of unguided matter', Hume turns the tables upon the ordinary teleological theory by a statement of the modern view of adaptation and the consequent survival of the fittest. 'It is in vain to insist upon the uses of the parts in animals or vegetables and their curious adjustment to each other. I would fain know how an animal could subsist, unless its parts were so adjusted? Do we not find, that it immediately perishes whenever this adjustment ceases, and that its matter corrupting tries some new form.' 1 Hence even the old Epicurean hypothesis, he adds, 'though commonly, and I believe, justly, esteemed the most absurd system that has yet been proposed ', may be made with a few alterations to bear a faint appearance of probability.

For himself, Philo is made to say that he is attracted by the ancient theory of a world-soul, and were he obliged to defend any speculation, he esteems ' none more plausible than that which ascribes an eternal inherent principle of order to the world '.2 But the truth is 'we have no data to establish any system of cosmogony. Our experience, so imperfect in itself, and so limited both in extent and duration, can afford us no probable conjecture concerning the whole of things.' This, says Philo, is the topic on which I have all along insisted. 'Each disputant triumphs in his turn,' ' but all of them on the whole prepare a complete triumph for the Sceptic.' 'A total suspension of judgement is here our only reasonable resource.'

Amid all this fire of criticism and brilliant improvisation of vivid hypotheses, Cleanthes remains by his original thesis quite unmoved. He compliments Philo on the fertility of his invention-' So great is your fertility of invention, that

1 Part VIII (p. 428).

${ }^{2}$ Close of Part VI. And it may be noted that he repeats this as the most plausible view at the close of Part VIII, where this part of the argument reaches its conclusion. 
I am not ashamed to acknowledge myself unable, on a sudden, to solve regularly such out-of-the-way difficulties as you incessantly start upon me: though I clearly see, in general, their fallacy and error.' Looking at the subject practically, in short, as a matter for reasonable belief or disbelief, he invokes Philo's own serious and considered judgement against the 'whimsies' he has delivered, whimsies which he must be sensible 'may puzzle but cannot convince us'.' And this appeal is not in vain, for even before the final rapprochement, we find, in the significant chapter which follows, on the moral attributes of the Deity, that Philo makes this unreserved admission: ' Formerly when we argued concerning the natural attributes of intelligence and design, I needed all my sceptical and metaphysical subtilty to elude your grasp. In many views of the universe, and of its parts, particularly the latter, the beauty and fitness of final causes strike us with such irresistible force, that all objections appear (what I believe they really are) mere cavils and sophisms.' And this is more than confirmed in the frank give-and-take of the two disputants in the concluding section, where Hume seems to lay aside his sceptical mask and let us see for a few moments his individual belief on the great question in debate. 'Your spirit of controversy,' says Cleanthes in the opening of that section, ' joined to your abhorrence of vulgar superstition, carries you strange lengths, when engaged in an argument.' ' I must confess, replied Philo, that I am less cautious on the subject of Natural Religion than on any other; both because I know that I can never, on that head, corrupt the principles of any man of common-sense, and because no one, I am confident, in whose eyes I appear a man of common-sense, will ever mistake my intentions. You, in particular, Cleanthes, with whom I live in unreserved intimacy; you are sensible, that, notwithstanding the freedom of my conversation, and my

${ }^{2}$ Close of Part VII. 
love of singular arguments, no one has a deeper sense of religion impressed on his mind, or pays more profound adoration to the Divine Being, as he discovers himself to reason, in the inexplicable contrivance and artifice of Nature. A purpose, an intention, a design strikes everywhere the most careless, the most stupid thinker; and no man can be so hardened in absurd systems, as at all times to reject it.

All the sciences almost lead us insensibly to acknowledge a first intelligent Author ; and their authority is often so much the greater, as they do not directly profess that intention.' The suspension of judgement which he formerly advocated he now pronounces impossible. 'The existence of a Deity is plainly ascertained by reason.'

Inconsistent as it may appear with the general tenor of Hume's philosophy, there is no doubt that this conclusion is neither due to the literary art of the dialogue nor is it an insincere concession to public opinion. It is to be found in all his works in which the question is touched, and everywhere it is presented as the one sufficient foundation for rational religion as opposed to the 'superstition' which his soul loathed. Thus in a note appended to the Treatise he says: "The order of the universe proves an omnipotent mind. Nothing more is requisite to give a foundation to all the articles of religion.' 1 Similarly not long a fter, in a letter of I744, he defines rational religion as 'the practice of morality and the assent of the understanding to the proposition that God exists '.2 In the Enquiry, in the important section 'Of a Particular Providence and of a Future State' he says (in the transparent disguise of an Epicurean philosopher) that 'the chief or sole argument for a divine existence (which I never questioned) is derived from the order of nature'. And again, the 'Natural History of Religion' opens with a distinction between two questions in regard to religion-its

${ }^{1}$ Book I, Part III, section I4, Green and Grose's edition, p. 456.

${ }^{2}$ Hill Burton's Life of Hume, vol. i, p. 162. 
foundation in reason and its origin in human nature. 'Happily', says Hume, 'the first question, which is the most important, admits of the most obvious, at least, the clearest solution. The whole frame of nature bespeaks an intelligent Author, and no rational enquirer can, after serious reflection, suspend his belief a moment with regard to the primary principles of genuine Theism and Religion.' This is possibly more strongly phrased than Hume might at all times be willing to approve of ; but the consensus of passages from his various writings puts beyond reasonable doubt his sincere adherence to what he calls 'genuine Theism' ${ }^{1}$ and his acceptance of the argument from design as its rational basis.

Professor Huxley speaks of Hume's ' shadowy and inconsistent Theism'. Further examination will diminish our surprise at Hume's apparent inconsistency, while it diminishes at the same time our sense of the value of this 'speculative tenet of Theism ',' to which he apparently assigns so important a position as the foundation of rational piety. It will be observed that the argument in the Dialogues has been uniformly and exclusively based on the evidences of order and design in external nature, and the conclusion reached was concerned, in Hume's phrase, solely with 'the natural attributes of intelligence and design'. Similarly in the 'Natural History of Religion' he distinguishes sharply between contemplation of 'the works of nature' 3 - which irresistibly suggests 'one single being who bestowed existence and order on this vast machine and adjusted all its parts according to one regular plan or connected system'-and consideration of 'the conduct of events, or what we may call the plan of a particular providence', where the impression produced is strangely different. Two sections of the Dialogucs (Parts $\mathrm{X}$ and $\mathrm{XI}$ ) are accordingly devoted to an examination of the phenomena of human life and history as

Dialogues, Part XII.

I Ibid.

Essays, vol. ii, p. 314 (Green and Grose). 
bearing especially on 'the moral attributes of the Deity, his justice, benevolence, mercy and rectitude'. 'Here', says Philo, 'I find myself at ease in my argument.'

The discussion at this point takes its rise in a characteristic attempt of Demea to found the truth of religion on man's 'consciousness of his own imbecility and misery'. In Part $X$, he and Philo vie with one another in the darkness of the colours in which they paint the misery of human and all animal life. 'A perpetual war is kindled amongst all living creatures. Necessity, hunger, want, stimulate the strong and courageous. Fear, anxiety, terror, agitate the weak and infirm. The first entrance into life gives anguish to the new-born infant and to its wretched parent. Weakness, impotence, distress, attend each stage of that life: and 'tis at last finished in agony and horror.' And even when man by combination in societies is able to surmount all his real troubles, he immediately raises up for himself imaginary enemies, the demons of his fancy, who haunt him with superstitious terrors and blast every enjoyment of life. Society itself becomes the source of the most poignant miseries. ' Man is the greatest enemy of man. Oppression, injustice, contempt, contumely, violence, sedition, war, calumny, treachery, fraud; by these they mutually torment each other.' Whether we look at the long catalogue of physical diseases, at the mental torments of the passions and emotions, or at the labour and poverty which are the lot of the vast majority of mankind, we are driven to ask how a world like this can be traced to a Being in whom infinite power and wisdom are united with perfect goodness. 'In what respect', says Philo, 'do his benevolence and mercy resemble the benevolence and mercy of men? . . None but we Mystics, as you were pleased to call us, can account for this strange mixture of phenomena, by deriving it from attributes, infinitely perfect, but incomprehensible.' When Cleanthes unmasks the covert atheism of such an argument, 
and asks: ' To what purpose establish the natural attributes of the Deity, while the moral are still doubtful and uncertain?' Demea thinks to save the situation in the usual orthodox fashion. 'This world is but a point in comparison of the universe: this life but a moment in comparison of eternity. The present evil phenomena, therefore, are rectified in other regions and in some future period of existence. And the eyes of men, being then opened to larger views of things, see the whole connexion of general laws; and trace, with adoration, the benevolence and rectitude of the Deity, through all the mazes and intricacies of his providence.' 'No!' replies Cleanthes, with a vehement disclaimer of this crooked logic, 'these arbitrary suppositions can never be admitted contrary to matter of fact, visible and uncontroverted. Whence can any cause be known but from its known effects? Whence can any hypothesis be proved but from the apparent phenomena? To establish one hypothesis upon another, is building entirely in the air.' He is prepared, however, to deny Demea's exaggerated pessimism as contrary to experience. 'Health is more common than sickness, Pleasure than pain, Happiness than misery. And for one vexation which we meet with, we attain, upon computation, a hundred enjoyments.' But Philo reminds him (what he should have himself remembered in his pessimistic disquisitions) that it is impossible, in strictness, to estimate and compare all the pains and all the pleasures in the lives of all mankind, or of all living creatures, and to weigh the one against the other. Such a valuation of life must be matter of individual opinion, resting largely on temperament. But it is not necessary for the purposes of the argument, Philo proceeds, to decide such a question one way or another. "Why is there any misery at all in the world?... Is it from the intention of the Deity? But he is perfectly benevolent. Is it contrary to his intention? But he is almighty. Nothing can shake the solidity of this 
reasoning, so short, so clear, so decisive; except we assert that these subjects exceed all human capacity, and that our common measures of truth and falsehood are not applicable to them.'

Urged in this way, Cleanthes for the first time abandons his immovable attitude. Up to this point he has simply reiterated, in the face of every criticism and objection, the cardinal doctrine of natural religion. Now, under the pressure of the argument, he confesses that he has 'been apt to suspect the frequent repetition of the word infinite, which we meet with in all theological writers, to savour more of panegyric than of philosophy, and that any purposes of reasoning, and even of religion, would be better served, were we to rest contented with more accurate and more moderate expressions'. 'If we abandon all human analogy'-as Demea and Philo seem inclined to do-he is afraid that 'we abandon all religion, and retain no conception of the great object of our adoration. If we preserve human analogy, we must for ever find it impossible to reconcile any mixture of evil in the universe with infinite attributes.' 'But supposing the Author of Nature to be finitely perfect, though far exceeding mankind; a satisfactory account may then be given of natural and moral evil, and every untoward phenomenon be explained and adjusted. A less evil may then be chosen, in order to avoid a greater; inconveniences be submitted to, in order to reach a desirable end: and in a word, benevolence, regulated by wisdom, and limited by necessity, may produce just such a world as the present.' He invites Philo to give his opinion of this new theory. The theory is familiar to us in more recent times in J. S. Mill's posthumous essays, and may almost be said to be fashionable in contemporary thought as represented, for example, by William James, Dr. McTaggart, and others. It will therefore meet us again. At present we must limit ourselves to noting Hume's attitude towards it. 
Philo begins by repeating in a memorable passage the protest of Cleanthes against the illegitimate employment of human ignorance as a premiss in the argument of orthodox apologetics. If we are antecedently convinced, on independent grounds, of the existence of an almighty Intelligence of perfect wisdom and goodness, the narrow limits of our understanding may reasonably suggest that the puzzling phenomena which seem so hard to reconcile with such a hypothesis may have many solutions at present, and perhaps for ever, beyond our grasp. 'But supposing, which is the real case with regard to man, that this creature is not antecedently convinced of a supreme intelligence, benevolent, and powerful, but is left to gather such a belief from the appearances of things; this entirely alters the case, nor will he ever find any reason for such a conclusion. He may be fully convinced of the narrow limits of his understanding; but this will not help him in forming an inference concerning the goodness of superior powers, since he must form that inference from what he knows, not from what he is ignorant of.' Our ignorance, in short, ' may be sufficient to save the conclusion concerning the divine attributes, yet surely it can never be sufficient to establish that conclusion'. Reviewing the facts in a more measured and judicial temper than he had exhibited in backing Demea's impeachment of Nature in the preceding section, Philo's deliberate conclusion is that 'the original source of all things is entirely indifferent to all these principles, and has no more regard to good above ill [i.e. to happiness and misery] than to heat above cold, or to drought above moisture, or to light above heavy'; and what applies to natural evil ' will apply to moral, with little or no variation'. The hypothesis of a perfectly benevolent deity, of great but limited power, seems to him negatived by 'the uniformity and steadiness of general laws', which point to the unity of the Power in which they have their source.

Philo must undoubtedly be taken here as the repre- 
sentative of Hume himself. Cleanthes has appealed to him for his judgement on the case, and in the subsequent conversation with Philo he makes no return to the subject by way of controverting or even modifying the sweeping and, to most men, staggering conclusion arrived at. ${ }^{1}$ In that conversation Philo still takes the leading part, and it is remarkable; as we have already partly seen, for the extent of the agreement which it establishes between the two chief disputants, defining, as it does, the extent to which Philo, the airy sceptic, admits the contention of the more solid Cleanthes-as a matter, if not of demonstrable certainty, at any rate of reasonable belief. But the importance of this agreement has already been largely discounted by the elimination of the moral attributes of God and of the whole idea of a moral government, or moral order, of the universe. As Cleanthes expresses it, "to what purpose establish the natural attributes of the Deity while the moral are still doubtful and uncertain?' The significance of the conclusion is still further whittled away in the concluding pages, where Philo represents the whole controversy between theism and atheism as mainly verbal. The theist, while calling the supreme cause Mind or Thought, is ready to allow that the original Intelligence is very different from human reason, and the atheist ("who is only nominally so and can never possibly be in earnest') allows that the original principle of order bears some remote analogy to it.

${ }^{1}$ It must be noted, however, that in the concluding section he still refers to 'genuine Theism' as teaching that man is 'the workmanship of a Being perfectly good, wise and powerful; who created us for happiness, and who, having implanted in us immeasurable desires of good, will prolong our existence to all eternity, and will transfer us into an infinite variety of scenes, in order to satisfy those desires, and render our felicity complete and durable'. The phraseology of this curious passage strikingly recalls Kant's subsequent scheme. Cleanthes presents this doctrine as 'the most agreeable reflection which it is possible for human imagination to suggest', and Philo, admitting that 'these appearances are most engaging and alluring', adds these somewhat significant words-' and with regard to the true philosopher, they are more than appearances'. 
It is only, therefore, a question of degree, and in actual discussion it will often be found that they 'insensibly change sides,' the theist emphasizing the difference between God and man, and the atheist magnifying the analogy among all the operations of nature. What is there, then, to hinder an amicable adjustment of their differences? 'The whole of Natural Theology resolves itself', in Philo's concluding words, 'into one simple, though somewhat ambiguous, at least undefined, proposition: That the cause or causes of order in the universe probably bear some remote analogy to human intelligence.' 'The analogy, imperfect as it is, can be carried no farther than to the human intelligence; and cannot be transferred, with any appearance of probability, to the other qualities of the mind.' The proposition, as he significantly admits, is one which 'affords no inference that affects human life, or can be the source of any action or forbearance'; and, if so, 'what can the most inquisitive, contemplative, and religious man do more than give a plain, philosophical assent to the proposition, as often as it occurs; and believe that the arguments on which it is established, exceed the objections which lie against it?'

Such is the nature of the attenuated theism to which Hume on all occasions so carefully adheres, and to which he sometimes assigns a central importance in the foundation of that 'philosophical and rational' religion which he so sharply distinguishes from 'vulgar superstition'. It is here if anywhere-in the importance he assigns to it rather than in the nature of the tenet itself-that the inconsistency to which Huxley refers may be found; for how can a proposition possess any religious significance if, as Philo truly describes it here, 'it affords no inference that affects human life, or can be the source of any action or forbearance'? Involuntarily we recall the pragmatic test of truth by its practical consequences. And however much questionable matter we may find in pragmatist writers associated with this main 
contention or developed from it, we may well ask ourselves whether a proposition which has no practical consequences whatever is to be regarded as a truth at all. Is it not either meaningless or (as Hume here says) at least undefined? It is not without reason that theist and atheist so amicably shake hands over their differences, for the proposition contains nothing vital either to affirm or to deny. Certainly this is not what those who have contended for the existence of God have meant by that doctrine. To them it meant undoubtedly a doctrine which, if true, must profoundly affect our whole view of the universe and our conduct in it. 


\section{LECTURE II}

\section{KANT AND THE IDEA OF INTRINSIC VALUE}

WE have seen in the previous lecture the vague residuum of theistic belief which is all that Hume considered deducible from the evidence-a residuum, however, to which he clings through all his works with an almost curious tenacity. A proposition which 'affords no inference that affects human life or can be the source of any action or forbearance' seems a credo hardly worth contending for. If we mean by God an extra-mundane entity whose super-human intellectual powers are attested by the orderly arrangements and nice contrivances of the material scheme of things, but who is indifferent, so far as the phenomena enable us to judge, not only to human weal and woe, but also to the aspects of will and character which seem to us indubitably the highest and the best we know, the existence or non-existence of such a deity can hardly be a matter of human concern. It is surely not too much to say that the prominence given to the proof of intelligence in most of the arguments, especially the older arguments, for the existence of God, is due not so much to an interest in the merely cognitive powers-the super-human cleverness, as it were-of the world-artificer as to the feeling that, together with knowledge, we may expect to find in the Ground of things something akin to those elements of our being, rooted as they are in intelligence, in which we recognize our true dignity and worth. Whether we have just grounds for believing in such kinship is a question to be dealt with in the further course of these lectures, but certainly without it we cannot expect man to be satisfied, hardly indeed to be interested. Intelligence has, as a matter of fact, for the greater thinkers always meant more than the abstract intellect. 
But the nature of Hume's conclusion was determined by the restricted nature of the premisses from which it is deduced. It is explicitly based upon ' a contemplation of the works of nature ', ' the frame of nature ', 'that is to say, upon the order and adjustments of the material system, to the exclusion of human nature and human experience in any other than its sense-perceptive aspect. Now Hume himself points out $^{2}$ that "the first ideas of religion arose not from a contemplation of the works of nature, but from a concern with regard to the events of life, and from the incessant hopes and fears which actuate the human mind'. And although he contrasts 'the religious fictions and chimeras' thence arising with 'the genuine principles of theism ', and counsels an escape from the violence of contending superstitions 'into the calm though obscure regions of philosophy', it is in reality futile to rest a philosophical doctrine of God on a fragment of the evidence actually before us. It is possible that when we include in our survey the sentient creation and the facts of human history - ' the dread strife of poor humanity's afflicted will' 3.- the whole may appear to us, in Hume's memorable phrase, 'a riddle, an enigma, an inexplicable mystery'. But even if we risk such a result, how can we leave these facts out? They are in the very centre and foreground of the picture. It may be, moreover, that although they immensely increase the difficulty of the problem, they alone supply us with the hint of a concrete and tolerable solution.

The general problem of philosophy, as every one knows, passed from the hands of Hume to those of Kant, and to Kant may be traced the most characteristic modern forms of the theistic argument. Kant's precise position is, in my opinion, no more tenable here than is the letter of his general

1 These phrases are repeatedly used in the first two sections of the 'Natural History of Religion'.

'In the 'Natural History of Religion'. 'Excursion, Book VI. 
theory of the constitution of experience; but he largely fixed the point of view from which the question has been discussed by subsequent thinkers. The contrast with Hume stares us in the face; for it is an analysis of man's moral experience which yields Kant his assurance of the existence of God, and it is the moral attributes, or (shall we say?) the moral interests, of the Deity which he is primarily concerned to establish. That is to say, instead of the complete indifference to natural and to moral evil alike which Hume attributes to his Supreme Mind, God is for Kant primarily and essentially the author and maintainer of a moral order. The universe as a moral system is the last word of the Kantian philosophy. It is not that Kant denies those aspects of human existence which leave upon Hume, as they have left on so many thoughtful observers since the world began, the vivid impression of a moral indifference.

Streams will not curb their pride The just man not to entomb,

Nor lightnings go aside

To give his virtues room,

Nor is that wind less rough that blows a good man's barge.

The moral indifference of nature, or, as Professor Huxley more strongly phrased it, "the unfathomable injustice of the nature of things', is a problem as old as the Book of Job and older. Apart altogether from moral desert, what are we to make of the terrible contingencies of nature to which at every turn man is exposed-the agonies of the quivering flesh or the laceration of the spirit through his tenderest affections? All the apparently motiveless pain and misery of the world, on the face of it pure contingency-Hume was not the first to ask how such features of our experience are to be reconciled with the traditional conception of 'infinite benevolence, conjoined with infinite power and infinite 
wisdom'. Nor does Kant blink the facts. Indeed, when he speaks of the human lot and of the record of human history, the picture he paints is so dark that German pessimists of the nineteenth century have sought to claim him as one of themselves. ${ }^{1}$ But it is only so long as we take happiness to be man's chief end or good, and regard the universe as 'a place of pleasure', that Kant adopts this tone or allows it to be justified. If the world of time is really, as he holds it is, the training ground of the spirit, if man's painful history is but the long discipline by which a moral being is shaped out of a merely animal creature, then Kant's attitude is rather that of Browning in 'Rabbi ben Ezra'.

The process can only be rightly judged in the light of what we take to be the end in view. And it is just here that Kant introduces his new formulation of the question, not only, as already indicated, by breaking away from the hedonistic, or at least eudaemonistic, presuppositions of his century, but still more by insisting that the preliminary to all fruitful discussion is to make clear to ourselves what we mean, or can intelligibly mean, by an ultimate End. This Kant fixes through the idea of value or worth which he puts in the forefront of his ethics. This idea is fundamental, I think, in all constructive thought since Kant's time, though it may disguise itself in different forms. It is certainly dominant in contemporary discussion.

'Nothing can possibly be conceived, in the world or out of it, which can be considered good without qualification except a good will. Intelligence, wit, judgement, and the other talents of the mind, however they may be named, or courage, resolution, perseverance, as qualities of temperament, are undoubtedly good and desirable in many respects;

${ }^{2}$ For example, Von Hartmann in his Kant der Vater des modernen Pessimismus. Kant's philosophy of history is chiefly contained in the little treatise, Idee zu einer allgemeinen Geschichte in weltbürgerlicher Absicht, in his review of Herder's Ideen, and in the tract, Muthmasslicher Anfang der Menschengeschichte. 
but these gifts of nature may also become extremely bad and mischievous if the will which is to make use of them, and which therefore constitutes what is called character, is not good. It is the same with the gifts of fortune. A rational and impartial spectator can have no pleasure in the sight of the uninterrupted prosperity of a being unadorned by a single feature of a pure and good will. Hence a good will appears to constitute the indispensable condition even of being worthy of happiness. . . A good will is good not because of what it performs or accomplishes, not by its aptness for the attainment of some proposed end, but simply in virtue of its volition, that is, it is good in itself. . . Even if it should happen that, owing to special disfavour of fortune or the niggardly provision of a step-motherly nature, this will should wholly lack power to accomplish its purpose, ... it would still shine like a jewel by its own light, as something which has its whole value in itself.' 1 In these well-known words Kant formulates the idea of 'absolute value 'as revealed in the moral personality, and from this, as his $\pi$ ov $\sigma \tau \overline{\boldsymbol{\omega}}$, he proceeds to build up his theory of the universe as 'a realm of ends '- a moral system, that is to say, whose ultimate purpose or raison d'être is the realization of this supreme good in a community of ethical persons.

In the light of this idea, which appears in Kant as a fundamental certainty, 'the frame of nature', on which Hume's whole argument had been based, assumes a quite subordinate significance. 'Two things', Kant has said, 'fill the mind with ever new and increasing admiration and awe, the oftener and the more steadily we reflect upon them, the starry heavens above and the moral law within.' But he did not hesitate to subordinate the former to the latter, and to restore man as an intelligence to that central position in the scheme of things, from which Copernicus had

${ }^{2}$ The opening sentences of the first section of the Grundlegung zur Metaphysik der Sitten (Abbott's translation, pp. 9-10). 
dethroned him as an animal creature. 'Stars and systems wheeling past' would be but an unmeaning show, if they did not furnish the casket for the jewel of which he spoke. The use of the world, as Keats finely said, is to be 'the vale of soul-making'. 'Do you not see', he says in one of his letters, 'how necessary a world of pains and trouble is to school an intelligence and make it a soul? A place where the heart must feel and suffer in a thousand diverse ways. ... As various as the lives of men are, so various become their souls, and thus does God make individual beings, sparks of his own essence.' ${ }^{1}$ So to Kant the world becomes ultimately intelligible as a spiritual process-what his great contemporary, Lessing, called a divine education-in Kant's eyes, too; an education of the race, but pre-eminently for him an education of the individual for a never-ending life of progress towards the ideal. Nature, he says, otherwise regarded as a machine, receives the name of a 'realm ', a kingdom or system, when viewed in relation to rational beings as its ends. ${ }^{2}$ It acquires in that light, we may say, a unity which otherwise does not belong to it; it becomes an element in a self-supporting system. Reason demands not merely the ' is' of bare fact, but the 'ought-to-be ', the 'deserves-to-be' of absolute value. But, as Fichte was soon to put it, in the Kantian spirit, "if matter alone existed, it would be just the same as if nothing at all existed ' ${ }^{3}$ I have no desire to raise here the question at issue between Berkeleian idealism and realism, the question, I mean, whether a selfexistent material universe is or is not a contradiction in terms. It is the question of value alone with which we are concerned; and I think we may say without hesitation that, apart from the emotions which they may awaken in a rational spectator, the kaleidoscopic transformations of ex-

${ }^{1}$ Letters of John Keats, edited by Sidney Colvin, p. 256.

${ }^{2}$ Grundlegung (Abbott), p. 57 ; Werke (ed. Hartenstein), vol.v, p. 286.

${ }^{3}$ Cf. Kant, Critique of Judgment, section 86. 
ternal nature possess in themselves no trace of that intrinsic value which must belong to what Kant calls an end-in-itself. They are all summed up in Spencer's phrase, the redistribution of matter and motion; and, apart from conscious results which the process may condition, it is hard to see what interest lies for God or man in the infinite shiftings of the cosmic dust. Even if we include in our world the existence of sentient creatures, and these all happy, or, at least, with a surplus of pleasure over pain, this 'green-grazing happiness of the herd', as Nietzsche contemptuously calls it, would not give us the inherent worth which reason demands in a self-justifying end. The demand for such an end would seem to be as much a rational necessity as that which impels us to refund any phenomenon into its antecedent conditions-if it does not, indeed, represent a deeper principle of explanation, a deeper need of reason. Certainly the human mind is not content to take the universe simply as a fact or set of interrelated facts. It is not intellectual coherence alone that the philosopher seeks-the fitting together, as it were, of the parts of some gigantic puzzle. The most perfect realization of unity in variety is as naught, if there is nowhere anything to which we can attach this predicate of value. If the philosophical impulse is to be satisfied, we must be able to repeat the verdict of the divine Labourer upon his world; we must be able to say that the world is 'good' in the sense of possessing intrinsic worth or value.

Kant, the ethicist par excellence in modern philosophy, recognizes this quality exclusively in character or the moral will; and therefore this becomes for him the one end-initself, for whose realization the universe exists, and by which its existence is explained or justified. Even those who, like Professor Bosanquet, object most strongly to the too exclusive moralism of his theory, admit that his error is excusable, in so far as we get, in morality and religion, 'the 
essential and fundamental conditions' of the perfect life, to which all other excellences-intellectual or artistic, for example-' are relatively posterior and dependent'. 'Morality', says Professor Bosanquet, 'can more nearly stand alone, and its absence shakes the whole foundations of life and mind. Such absence is in respect to life as a whole, what a failure of belief in the first principles of rational system is to intelligence.' 1 Accepting this justification of Kant's procedure, we may frankly accept also the implied criticism of his too exclusive attitude. The hackneyed triad of the True, the Beautiful, and the Good is sufficient to remind us that there are at least two other phases of experience to which it would be strange to deny an intrinsic value.

When Kant proceeds to work out the consequences of $Y$ his fundamental conception, the result, as formulated in $X$ what he calls the 'Postulates of the Practical Reason', is less satisfactory than might fairly have been anticipated. The postulates are three in number. First of all, the $\emptyset$ imperative of duty involves, as its self-evident condition, the Freedom of the being on whom the command is laid. 'Thou canst because thou oughtest.' Kant is speaking of human nature in the Idea, and he says that the being who can conceive the idea of a law possesses, in virtue of that very fact, the power of realizing it. We accept such responsibility when we condemn ourselves, as we do, for our own failures. So understood, freedom and intelligence go together. Kant repeatedly puts freedom on a different footing from the other two postulates. 'It is the only one of all the ideas of the speculative reason of which we know the possibility a priori, because it is the condition of the moral law which we know.' The possibility of the other two ideas (those of God and immortality) is proved, he says, 'by the fact that freedom actually exists, for this idea is revealed

${ }^{1}$ The Principle of Individuality and Value, pp. 347-8. 
by the moral law.' ' Twice over in the Critique of Judgment, he notes, as something 'very remarkable', that in this case (and in this one case only) we have an Idea of Pure Reason 'whose object is a thing of fact and to be reckoned among scibilia'.2 Duty and freedom, in short, are for Kant not so much two facts, one of which is inferred from the other, as two ways of characterizing the same experience. ${ }^{3}$

It is in his handling of the other postulates that we begin to feel a certain meagreness and externality in the treatment. Kant starts from the conception of the summum bonum as the object of the rational will, the end, that is to say, whose realization is enjoined by the law of duty; and, in formulating it, the preacher of duty for duty's sake, who had so rigorously purged his ethics of all considerations of happiness or natural inclination, surprises us by the baldly hedonistic lines on which he rounds off his theory. Job is not to serve God for naught after all. Virtue, it is said, remains the supreme good (bonum supremum) inasmuch as it is 'the supreme condition of all our pursuit of happiness', and remains therefore the formal maxim of the will. 'But it does not follow that it is the whole and perfect

${ }^{2}$ Preface to Practical Reason (Abbott), p. 88.

${ }^{2}$ Critique of Judgment, section 91 (Bernard's translation, p. 405): - There is one rational Idea (which is susceptible in itself of no presentation in intuition and consequently of no theoretical proof of its possibility) which also comes under things of fact. This is the idea of Freedom, whose reality, regarded as a particular kind of causality, may be exhibited by means of practical laws of pure Reason, and conformably to this, in actual actions, consequently in experience. This is the only one of the Ideas of Pure Reason whose object is a thing of fact and to be reckoned among scibilia.' He notes this, both here and again on p. 413, as 'sehr merkwürdig'. Compare also p. 414: 'All belief must be grounded upon facts. . . . All facts belong either to the natural concept, which proves its reality in the objects of sense, or to the concept of freedom, which sufficiently establishes its reality through the causality of reason in regard to certain effects in the world of sense, possible through it, which it incontrovertibly postulates in the moral law.'

"We find them expressly equated in the Critique of Practical Reason: 'this consciousness of the moral law, or what is the same thing, of freedom' (Abbott, p. 135). 
good, as the object of the desires of rational finite beings; for this requires happiness also, and that not merely in the partial eyes of the person who makes himself an end, but even in the judgement of an impartial reason, which regards persons in general as ends in themselves.' Thus 'virtue and happiness together constitute the possession of the summum bonum in a person, and the distribution of happiness in exact proportion to morality (which is the worth of a person and his worthiness to be happy) constitutes the summum bonum of a possible world; hence this summum bonum expresses the whole, the perfect good '.' An unkind critic might say that although the primacy is accorded to virtue as the supreme condition, yet the definition of virtue as 'worthiness to be happy' seems, on the other hand, to put virtue in a merely instrumental relation towards happiness, as the real object of desire and the ultimate end of action. But however that may be, Kant's second and third postulates are directly deduced by him from this formula of the summum bonum. The postulate of immortality connects itself with the element of virtue or perfection; for the primary object of the moral individual must be the attainment of that conformity of his will with the moral law which would, in the eyes of a perfect and all-seeing Judge, constitute a passport to happiness. But such 'holiness' of will is 'a perfection of which no rational being of the sensible world is capable at any moment of his existence '. ${ }^{2}$. It must be found, therefore, in an infinite progress of approximation, and 'such an endless progress is possible only on the supposition of the endless duration of the existence and personality of the same rational being, which is what we mean by the immortality of the soul'. The existence of God is connected with the second element in the summum bonum; for the failure of the natural

3 Abbott, p. 206.

I Ibid., p. 218. 
system of causes and effects to realize that distribution of happiness in exact proportion to morality which Kant's formula demands, involves the existence of God as a moral governor of the universe who will ultimately effect the adjustment required. In short, 'it is morally necessary to assume the existence of God.' 1

Kant's statement of the argument for immortality does not directly concern us at present. We may confine ourselves, therefore, to the third postulate, which is our proper subject. And here criticism naturally fastens on the externalism of the conception and on the peculiarly unfortunate nature of an argument which introduces God simply as a means to the happiness of individual human beings. Surely if, as Kant insists, it is wrong to treat a human being merely as a means, it must be a false way of putting things to present God himself in this merely instrumental light-as a deus ex machina introduced to effect the equation between virtue and happiness. Formulated thus, the argument is calculated to provoke Hume's reminder that to build one hypothesis upon another, by way of avoiding the conclusion suggested by the facts accessible to us, is 'building entirely in the air'. And although Kant would reply that his conclusion is based upon a fact of another order, namely, the fundamental deliverance of the moral consciousness, he gravely misinterprets that deliverance and its implications, in consequence of the sheerly individualistic and deistic habit of thought which he shares with Hume and the eighteenth century generally. It is upon the attitude of the moral man himself that the moral philosopher should base his theory. But the temper of true virtue is not the meticulous claim which Kant formulates for doles of happiness in exact proportion to individual merit. The temper of true virtue is rather that of Spinoza's closing proposition, Beatitudo non est virtutis praemium sed ipsa virtus. It claims no wages as the reward of its well-

1 Abbott, p. 222. 
doing, least of all does it keep a moral ledger with a debit and credit account to be evenly balanced.

Glory of Virtue, to fight, to struggle, to right the wrong,Nay, but she aimed not at glory, no lover of glory she;

Give her the glory of going on, and still to be.

The real postulate or implied presupposition of ethical action is simply that we are not acting in a world which nullifies our efforts, but that morality expresses a fundamental aspect of reality, so that in our doings and strivings we may be said, in a large sense, to have the universe somehow behind us. Moral action, in short, implies the belief in a moral order, just as deliberate action of any sort implies belief in the orderly connectedness of physical nature. And of course that was the general idea which Kant intended to express - the broad idea of the universe as a divine moral order, not as a power hostile or indifferent to the life of ethical endeavour. But owing to the extraordinary hold which the individualism and the external deism of his century had over him, God seems to be introduced in Kant's moral theory almost as an after-thought, and He is connected with the law, not as its inspirer or author, but in the merely administrative capacity of Paymaster. Kant tells us, it is true, that after we have accepted the pure law of duty in ethical practice, we may go on to regard its injunctions, from the point of view of religion, as the commands of a divine lawgiver. But, as he hastens to add, the sanction thus super-added to the moral law has nothing to do with its inherent and self-imposed authority, for man can be bound only by his own law.

Here we meet Kant's great doctrine of the autonomy of the moral will as the foundation of an obligation that cannot be evaded. The self is bound by the law because the law is self-imposed; it is its own law, and is recognized as such. But Kant does not see that, in this profound doctrine, he has opened the way to a truer conception of the relation between the human and the divine than is represented by the 
painfully mechanical theory of a super-added, and strictly superfluous, ${ }^{1}$ theological sanction. The fruitful idea of the self as at once the author and the subject of moral legislation -as laying down a law not only for the single self but for all men and, indeed, as Kant says, for all rational beingsnaturally suggests the question whether such a self can still be treated as an isolated individual.

I may illustrate my argument by a reference to certain statements of Dr. Martineau upon this very point. Martineau, who was steeped, like Kant, in an inherited individualism, denies this doctrine of the autonomy of the will on the express ground that it violates the unitary and exclusive nature of personality. 'It takes two', he says, ' to establish an obligation. . . . The person that bears the obligation cannot also be the person whose presence imposes it: it is impossible to be at once the upper and the nether millstone. Personality is unitary, and in occupying one side of a given relation is unable to be also on the other.' Hence he concludes that the sense of authority means 'the recognition of another than I, . . . another Person, greater and higher and of deeper insight.' This is the God of Deism, introduced to make good the sheer individualism of the self as a 'unitary personality'; and apart from this presupposition the argument has no force. That such is the presupposition is plain from the hypothetical examples by which Martineau seeks to justify his contention. $\mathrm{He}$ supposes ' the case of one lone man in an atheistic universe', and asks whether there could 'really exist any authority of higher over lower within the enclosure of his detached personality'; and he not unreasonably concludes that 'an insulated nature ', ' an absolutely solitary individual ', cannot

${ }^{1}$ Superfluous, and indeed noxious, so far as ethics is concerned. The reference to God seems in Kant solely connected with 'the attainment of the summum bonum'-' the desired results', 'the happy consequences', which God guarantees (see Abbott, p. 226).

"Types of Ethical Theory, vol. ii, pp. 96-9. 
be conceived as the seat of authority at all. But the rejoinder is that such an individual is a pure myth, the creature of a theory, and is certainly improperly spoken of as a self or a person. If any being were shut up, in Martineau's phrase, 'within the enclosure of his detached personality,' he would be a self-contained universe in himself, or rather he would be one bare point of mere existence. If intelligences were simply mutually exclusive points of subjectivity, then indeed they could not be the seats and depositaries of an objective law; they could not be the subjects of law at all. As I have said elsewhere, " consciousness of imperfection, the capacity for progress, and the pursuit of perfection, are alike possible to man only through the universal life of thought and goodness in which he shares, and which, at once an indwelling presence and an unattainable ideal, draws him " on and always on ".' The authority claimed by what is commonly called the higher self is thus only intelligible, if the ideals of that self are recognized as the immediate presence within us of a Spirit leading us into all truth and goodness. But the immanence of the divine was an idea foreign to Kant's whole way of thinking. Instead, therefore, of revising his conception of the self in view of its legislative function, he simply tells us that, while in ethics we must regard the law as self-imposed, we may go on in religion to regard its precepts as the commands of a Supreme Being, the reason assigned for so regarding them consisting in the fact that only through such a Being, morally perfect and at the same time all-powerful, can we hope to attain the summum bonum.

But after we have discarded the eighteenth-century framework of the Kantian scheme, the central and permanently important position remains-the idea of intrinsic value as ultimately determinative in a philosophical reference, as yielding us, in the Kantian phrase, an intelligible world,

'The Philosophical Radicals and other Essays, pp. 97-8. 
which, when recognized, sets limits to the exclusive pretensions of the world of sense-perception, and defines the mode or degree of reality which belongs to that world in the total scheme of things. This conception of intrinsic value as the clue to the ultimate nature of reality is the fundamental contention of all idealistic philosophy since Kant's time. It is the living assumption at the root of the great speculative systems to which the Kantian theory immediately gave rise in Germany. This is obvious in Fichte's case, to whom the consciousness of the moral law is the ultimate evidence of his own reality, and the universe itself only the material of duty. If it lies less on the surface in Hegel, it is merely because in him Idealism is no longer militant but triumphant, and because the system as a whole is the explication of the supreme conviction on which it is built. In this respect, what the great German idealists substantially did was to enlarge and complete Kant's conception of intrinsic value by making it include all the higher reaches of human experience. The moral experience is still predominant in Fichte : the aesthetic comes to its rights in Schelling, with perhaps even an overemphasis. In Hegel the claims of the theoretical and the practical (Truth, Beauty, and Goodness) are more evenly balanced, while the stress laid on religion as the bearer of human culture, and as presenting, in its own form, the substance of philosophical truth, goes far to refute the common criticism that the intrinsic values of concrete experience are sacrificed in his system to a logical abstraction.

And if the idea of value thus operates as an assumption in Kant's immediate successors, it becomes still more markedly the watchword of Idealism in the long duel with an encroaching Naturalism, which was the engrossing concern of the nineteenth century, and which has shaped for us the specific form in which the theistic problem, as the ultimate question of philosophy, presents itself to the modern mind. All through the period mentioned, the problem of construc- 
tive thought has been the relation of our ideals or values to the ultimate ground of things. So Sidgwick, lecturing in the nineties in his carefully balanced way on "The Scope of Philosophy', defined its ' final and most important task' as the problem of ' connecting fact and ideal in some rational and satisfactory manner'. ${ }^{1}$ And at the present day, philosophical discussion is carried on more explicitly in terms of value than at any previous time. Take for example two such representative thinkers as Höffding and Windelband,-than whom it would be difficult to name two contemporary writers more balanced in judgement or more catholic in their outlook. Höffding's Philosophy of Religion lays down 'the conservation of value', or 'the conviction that no value perishes out of the world', as the characteristic axiom of religion, while the problem alike of religion and of philosophy is said to be 'the relation between what seems to us men the highest value and existence as a whole'.2 And Windelband expresses the present philosophical situation thus: 'We do not so much expect from philosophy what it was formerly supposed to give, a theoretic scheme of the world, a synthesis of the results of the separate sciences, or, transcending them on lines of its own, a scheme harmoniously complete in itself ; what we expect from philosophy to-day is reflection on those permanent values which have their foundation in a higher spiritual reality above the changing interests of the times.' 3

I have said that the debate between Naturalism and Idealism dominates the whole of the second half of the nineteenth century, and that it has bequeathed to us the peculiarly modern form of the theistic problem. We shall see in the following lecture how the formu-

${ }^{3}$ H. Sidgwick, Philosophy, its Scope and Relations, p. 30.

2pp. 6, 9-1o (English translation).

- In his lectures, published in 1909, Die Philosophie im deutschen Geistesleben des Igten Jahrhunderts, p. IIg. 
lation of the issue was determined-determined, I think, unfortunately-by specific features of the Kantian philosophy. In the meantime, if we recall briefly the larger aspects of this perennial philosophical antithesis, it will be seen that the idea of value is central and decisive throughout. It is, at bottom, the question of the divineness or the undivineness of the universe. Is the universe the expression of a transcendent Greatness and Goodness, or is it, in ultimate analysis, a collection of unknowing material facts? In the plain impressive words of Marcus Aurelius- "The world is either a welter of alternate combination and dispersion or a unity of order and providence. If the former, why do I care about anything else than how I shall at last become earth? But on the other alternative, I reverence, I stand steadfast, I find heart in the power that disposes all.' From our human point of view, this alternative must necessarily take some such form as this: "Is the spirit of the universe or the ultimate nature of things akin to what we recognize as greatest and best, or are such standards and distinctions but human parochialisms, sheerly irrelevant in a wider reference?' Somehow thus we must express it, for we have no other criterion which we can apply than the values which we recognize as intrinsic and ultimate. Hence the immediate form of the question-the form also which discloses the intensely practical interest which inspires it-is as to the relation of man and his human values or ideals to the universe in which he finds hiniself. Is our self-conscious life with its ideal ends but the casual outcome of mechanical forces, indifferent to the results which by their combinations they have unwittingly created, and by their further changes will as unwittingly destroy, or is it the expression, in its own measure, of the Power that works through all change and makes it evolution? Is the ultimate essence and cause of all things 'only dust that rises up and is lightly laid again', or is it the Eternal Love with which Dante closes his vision, " the Love 
that moves the sun and the other stars '? On the one hypothesis, as Mr. Balfour has put it in a passage of poignant beauty, with the final run-down of the solar system, as science predicts it, "man will go down into the pit, and all his thoughts will perish. The uneasy consciousness which in this obscure corner has for a brief space broken the contented silence of the universe, will be at rest. Matter will know itself no longer. "Imperishable monuments" and "immortal deeds", death itself, and love stronger than death, will be as if they had not been. Nor will anything that is be better or worse for all that the labour, genius, devotion, and suffering of man have striven through countless ages to effect.' 1 Naturalism seems to teach that when we resolve the universe, as it were, into its real constituents, it reduces itself to the ceaseless redistribution of matter and motion, what William James not inaptly describes as the 'vast driftings of the cosmic weather'.

Let us grant, for the sake of argument, that such a theory is intellectually conceivable; it would still remain incredible, because it outrages the deepest convictions on which our life is built. Our sense of value is not a matter of selfish preference or individual desire; the judgement of value is as impartial as it is unhesitating. It is as objective in its own sphere as a scientific judgement on matters of fact. On points of detail the sense of value may be open to criticism and susceptible of education, just as scientific statements are open to revision. But in its pronouncements as to what possesses value and what does not-in its recognition of the main forms of value, and in its general scale of higher and lower - it represents an unswerving conviction which is, even prima facie, at least as important an element in the philosophical question as the scientific theories on which Naturalism builds; and if the scope of these theories be shown in a truer light, it may well become of determining

${ }^{2}$ Foundations of Belief, p. 3 I. 
significance for our conception of ultimate reality. Idealism takes its stand on the essential truth of our judgements of value, and the impossibility of explaining the higher from the lower. Beauty and goodness are not born of the clash of atoms; they are effluences of something more perfect and more divine.

I would venture to dwell for a few moments on this point of the objectivity of our judgements of value. It is allimportant in the discussion of values and ideals to realize that these are in no sense private ends which we seek to impose upon the universe, and that it is not the disappointment of our selfish hopes which is the real explanation of our revulsion from the naturalistic creed. It is frequently implied in naturalistic polemic that the idealist view is no better than a sentimental clinging to the illusions of man's youth, a weak refusal to look the facts in the face and accept the world as it is. But Lotze, in a famous passage, has exposed the falsity of this ostentatious worship of truth, this ' sham heroism, which glories in renouncing what no man has a right to renounce ' ${ }^{1}$ When man confronts the world with his standards of value, his attitude is not that of a suppliant but of a judge. He does not appear as one who craves a kindness, but as one who claims a right; or rather, as invested with the authority of a higher tribunal, he pronounces sentence on the travesty of a universe which materialism offers him. It is all the more important, therefore, that in staking the idealistic position on the objective significance of human values, we should avoid, as far as possible, any expression that might seem to savour of merely personal wish. From this point of view, the title of a recent article in the Hibbert Journal ${ }^{2}$ - ' Is the Universe friendly?'-seems to

'Preface to the Mikrokosmos.

'January Igi2. My reference, I wish to add, is only to the title, and in no way to the substance of Professor Ladd's article, which I had not read at the time. The title, as stated in the opening sentences, is taken from a recorded saying of $F$. W. H. Myers. 
me to strike a false note; it has just that suggestion of the whining and pitiful which I have been deprecating. The question is rather whether the nature of the ultimately real is to be found on the lines of what we recognize as greatest and best in our own experience. So, again, the argument from human 'needs' (which in its legitimate form is identical with that which we are considering) requires to be carefully safeguarded, if it is not to invite misconception. Man. as Kant has said, is an end-in-himself ; but we must be careful to avoid expressions which would imply that human beings, as given finite personalities, constitute the final purpose or the central fact of the universe, in the sense that the whole framework of being is to be regarded as the instrument of their individual destiny. We have seen that Kant himself, in formulating his postulates, erred in this direction, first in the prominence given to happiness, and secondly, in the merely instrumental function assigned to God. Sir William Hamilton, proceeding on somewhat similar lines, was betrayed into a grosser lapse when he allowed himself to say: 'A God is, indeed, to us only of practical interest, inasmuch as he is the condition of our immortality.' ${ }^{1}$ Practical interest in a God-what a phrase and what an attitude! The glories of the outer world, the splendours and sanctities of the inner world, and no interest in God save as a security for our continued existence! I am reminded by contrast of a passage in a lecture by your own Principal, in which he deals with this theme of personal immortality in relation to Old Testament study. After arguing for the truth of the doctrine as the outcome of the highest religious experience, he continues: 'Yet while this is true, it is well for us all sometimes to pitch our religious life in terms which do not include the hope of a future. Most of the crises of religious experience may be achieved, as some of the grandest Psalms fulfil their music, without the echo of one of the far-off bells

${ }^{1}$ Lectures on Metaphysics, vol. i, p. 32. 
of heaven. A man may pass through the evangelical experiences of conversion, regeneration and redemption, without thinking any more of the future than the little child thinks, but only sure and glad that his Father is with him. The Old Testament is of use in reminding us that the hope of immortality is one of the secondary and inferential elements of religious experience.' 1

I am not arguing here against immortality any more than your Principal in the passage I have quoted; but I think that we place an exaggerated emphasis upon it, if we make it the centre and foundation of our whole world-theory. We all remember how prominent is the place held by the idea in the thought of the two greatest Victorian poets, Tennyson and Browning, and to what noble uses they turn it. But in Tennyson at least, we may perhaps admit that the emphasis tends to become unhealthy. $\mathrm{He}$ is recorded as saying in conversation that if immortality 'be not true, then no God but a mocking fiend created us. . . . I'd sink my head to-night in a chloroformed handkerchief and have done with it all.' 2 A number of passages, less violent in expression but substantially to the same effect, might be quoted from the poems. ${ }^{3}$

Against such an utterance I would venture to put, as conveying a saner and a larger view, a passage of $\mathrm{Dr}$.

'George Adam Smith, Modern Criticism and the Preaching of the Old Testament, p. 176.

${ }^{2}$ Recorded by James Knowles, Nineteenth Century, January I893. As he spoke, Knowles says, Tennyson grew 'crimson with excitement'. ' His belief in personal immortality was passionate-I think almost the strongest passion he had.'

e. g. In Memoriam, xxxiv:

'Twere best at once to sink to peace,

Like birds the charming serpent draws,

To drop head foremost in the jaws

Of vacant darkness and to cease.

Compare the lines to Fitzgerald (dedicatory introduction to Tiresias), and contrast with Tennyson's utterances the well-known words of Socrates: "If the rulers of the universe do not prefer the just man to the unjust, it is better to die than to live.' 
Hutchison Stirling's, quoted in his recently published Life. Dr. Stirling himself, it may be as well to say, held the conviction of immortality with peculiar intensity, yet he writes: 'We shall not speak of love or of one's daily meals, or of science or of Shakespeare; but he who has seen the sea and the blue of heaven, and the moon and the stars, who has clomb a mountain, who has heard a bird in the woods, who has spoken and been spoken to, who has seen a sock or a shoe of his own child, who has known a mother-he will bow the knee and thank his God and call it good, even though his lot in the end be nothingness.' ${ }^{1}$ This is to see things in a truer proportion, and philosophy is largely a question of proportion. We cannot afford to stake our whole position on anything ' secondary and inferential', however well-assured we may ourselves be of its truth. Personal immortality, as the history of the race abundantly shows, is not an absolute necessity, in the sense that without it the world becomes a sheer irrationality. There is certainly possible a disinterested devotion to ideals whose triumph, as we quite simply say, we shall not be there to see. We feel that we are sharers in a wider life, and we feel that it is good to have been admitted to share it. It is the spirit of the aged Simeon: 'Lord, now lettest thou thy servant depart in peace . . . for mine eyes have seen thy salvation.' But that our ideals themselves should perish, that nothing worth existing should have any pledge of continuance or growth, that the world of values, in short, should have no relation to the world of facts-that is the one intolerable conclusion. And just because its intolerableness has nothing to do with any private hopes or fears, we feel that the refusal to entertain it is a judgement of objective validity, that it is, in short, of the same texture as the inability to believe an intellectual contradiction.

${ }^{2}$ James Hutchison Stirling, His Life and Work, p. 251. 


\section{LECTURE III}

\section{THE NINETEENTH-CENTURY DUEL BETWEEN IDEALISM AND NATURALISM}

In the two preceding lectures we have seen how the problem of theism presented itself to Hume and Kant, the two thinkers who stand in the mid-stream of the modern philosophical movement, and whose influence may be discerned in most of its subsequent course. Neither of them can be said to have emancipated himself from the external deism of his age and environment; but in other respects the contrast between the two is so great that we seem, in passing from one to the other, to be traversing a different country and breathing a different atmosphere. The starting-point, method and goal of the reasoners seem to have little in common, when we compare Hume's critical 'contemplation of the works of nature' and its exiguous result with the Kantian argument which rests the whole case on the intrinsic worth of the moral personality. I criticized a certain externality and poverty of feeling in the formal arguments by which Kant establishes the postulates of immortality and the existence of God. But his central idea of value, as a determining factor in philosophical explanation, I took to be not only sound in itself but the fundamental contention of all idealistic philosophy since his time.

In Kant's immediate successors, I said, the idea of value operates as an assumption, and it is entirely detached by them from the special associations of the Kantian theory of knowledge. The actual phrase first occurs as a watchword in the long duel between Naturalism and Idealism which followed the collapse of the great 
idealistic systems and dominated the whole of the second half of the nineteenth century; and it reappears there in a more distinctively Kantian form. The modern formulation of the ultimate issue as between Naturalism and Idealism has, indeed, been mainly determined by two features of the Kantian philosophy-on the one hand, by the criterion of value of which we have been speaking and, on the other hand, by the abrupt separation which Kant makes between the theoretic and the practical reason-between the objective certitude, or knowledge, attainable in the scientific sphere and the subjective certitude, or faith, on which our ethical postulates rest. If the former feature furnished Idealism with her positive credo, the latter was largely responsible, as we shall presently see, for the disadvantageous conditions under which she had often to fight her battles. For, as I have already partly indicated, the principle of value may either be employed simply and directly, as an immanent presupposition rather than as matter of controversial assertion-so we find it on the whole in the greater thinkers-or it may appear as a protest of the remaining part of our nature against what it takes to be the usurpation of authority by the pure intellect. As it was phrased by Pascal, ' the heart has its reasons, of which the reason knows nothing.' It is in this latter form that the argument frequently tends to appear in the controversy with Naturalism during the period to which I have referred; and perhaps it is hardly possible when engaged in such a controversy to avoid statements which seem to imply a dualism and a conflict between two sides of our nature. The more, however, this dualism is emphasized, the more insecure the results claimed by the sense of value will come to appear. The heart, as Tennyson says, may stand up 'like a man in wrath' 'against the freezing reason's colder part '; ${ }^{1}$ but strength of assertion will not

${ }^{1}$ In Memoriam, cxxiv. 
suffice to banish the recurring doubt that, however cold and unacceptable we may find the conclusions of the reason, they may nevertheless be true-nay, must be so, unless the premisses of Naturalism can be invalidated. The reassertion of human values is, in point of fact, effective and convincing only when it is accompanied by the demonstration that the conclusions of Naturalism rest on a misinterpretation of the nature of the scientific theories on which they are based. And this may be shown, I think, by philosophical criticism to be the case, without abandoning the guidance of reason or indulging in any campaign against 'intellectualism'.

We have first, however, to see how the philosophical question actually shaped itself during the last sixty years; and examination will show that the way was paved for the more subjective, and essentially more sceptical, statement of the principle of value, by the specific form in which Kant cast his results, no less than by the immense prestige acquired by science during the period in question. I have referred to the abrupt separation made by Kant between the theoretical and the practical reason. That separation or dualism may be attributable in part to Kant's favourite method of 'isolating' his problems, and the subsequent difficulty of co-ordinating the results of his separate inquiries. But in the present case it must be admitted that Kant keeps steadily in view the complementary relation of the first two Critiques; the statement of the results of the analysis of scientific knowledge in the Pure Reason is constantly punctuated by forward references to the conclusions worked out in the Practical Reason. The nature of Kant's theory of knowledge is really explained by the relation of his undertaking to the scientific knowledge of his time. 'If you read the Critique of Pure Reason,' says M. Bergson, 'you see that Kant has criticized not reason in general, but a reason fashioned to the habits and exigencies of the 
Cartesian mechanism or the Newtonian physics.' 1 Modern philosophy was born along with modern science, or, to be more strictly correct, it followed close upon it, as a reflective analysis and generalization of its methods and results. The extent to which the physics of Galileo is transfused into the systems of the founders of modern philosophy has become a historical commonplace. It is seen in Descartes and Spinoza no less than in Hobbes and Gassendi. Completed by the genius of Newton, the world-scheme of mathematical physics has stood, almost down to our own day, as the ultimate ideal of knowledge which, if we could realize it in respect of the molecular constitution of bodies, would reveal to us, as Locke thought, their hidden 'essence'.

The categories of Kant are, in this respect, a philosophical generalization of the Newtonian astronomy; the reciprocal interaction of material particles in space is the kind of experience, the logical conditions of whose possibility they summarize. 'How is mathematics possible?' and 'How is pure physics possible?' - into these two questions Kant translates his inquiry in the Prolegomena. To this experience the title of knowledge is restricted; within this sphere alone is logical certainty attainable. Kant acknowledges, it is true-or rather, he insists - that the action of the moral will finds no place in this world-scheme; and as it is in the self responsive to duty, capable of moral goodness or badness, that he finds the real man and the only example of intrinsic value, he brands the world of knowledge as merely phenomenal, when contrasted with the real world of moral persons and actions. But, in the historical sequel, the honorific title of Knowledge, as compared with the Faith or Belief on which he bases the verities

${ }^{2}$ Le parallélisme psychophysique et la métaphysique positive. The passage is quoted by Mr. A. D. Lindsay in the introduction to his Philosophy of Bergson. 
of the ethical world, proved more potent than the disparaging adjective phenomenal, especially when the real world from which the phenomenal is distinguished was described by so mystically-sounding a term as noumenal.

A similar impression is produced by Kant's halting treatment of aesthetic experience and of the organism in the Critique of Judgment. While recognizing in both cases a range of experience which his categorses fail to express, he refuses to treat the aesthetic and the biological account of the phenomena as more than a subjective way of looking at facts which, were our analysis keen enough, might yet be reduced to instances of mechanical determination. In this way, the impression is fostered that scientific explanation must always be in terms of mathematical physics-that science and mathematical physics are in fact interchangeable terms, and that any phenomena which refuse to be reduced to mechanical terms may be treated as a subjective gloss upon the text of objective knowledge. And the ethical doctrine, despite its primacy for Kant himself, and in spite of the part it played in his idealistic successors, came in like manner to be regarded by many as an after-thought on the philosopher's part, intended to atone for the iconoclasm of the first Critique, or, at best, as an uncalledfor and baffling addition to an otherwise clear and consistent doctrine.

We may hold-and I do hold-that to read Kant's philosophy thus is wholly to misread its author's intention, and to neglect the plain indications of the solidarity of the three Critiques as integral parts of a coherent scheme. Nevertheless, the broad fact remains, if we leave out of account in the meantime the great idealistic movement which was the immediate sequel of the Kantian philosophy in Germany, that, for the average nineteenth-century thinker, it was the negative side of Kant's teaching-the 
critical limitation of knowledge to the world of sense-perception-that was of real significance; and the Kantian phenomenalism came to be identified with a somewhat facile agnosticism or relativism. Kant himself had treated physical science as the type and norm of true knowledge, and accordingly the prestige of purely physical explanations within the world of experience was hardly lessened by the formal acknowledgement at the end that the world we know is only the appearance to us of an unknown and unknowable reality. Such is the type of thought which meets us in Spencer and Huxley. Spencer did adopt a percentage of Kantian doctrine, as distilled by Sir William Hamilton; Huxley appeals as readily to Berkeley and Hume and physiological psychology as to Kant. Both thinkers are able, when challenged, to repudiate the charge of materialism, and they do so quite honestly. Nevertheless, their effective thinking is done entirely in physical terms, and the result is a sheer materialistic mechanism with consciousness as an epiphenomenon-an inactive and strangely superfluous accompaniment of the machinery. It is sufficient to refer to Spencer's reduction of the universe to a problem in the re-distribution of matter and motion, and to Huxley's theory of conscious automata, as an indication of the kind of doctrine which was thought in the seventies of last century to be imposed upon us alike by the criticism of knowledge and by the results of science.

In much closer relation to Kant, and more typical in its attitude, was Lange's widely influential History of Materialism, the first edition of which appeared in I865. Lange's work was an important factor in promoting the "return to Kant' which was so prominent a feature of the later decades of the nineteenth century. His own neo-Kantianism, which is intended to be a translation of Kant into the terms of modern scientific thought, is no doubt more 
correctly described by the late Professor Adamson as a reproduction of Hume in terms of physiological psychology; for Lange has left out of his statement all the profounder elements in the Kantian philosophy. But the historically important fact was the contemporary acceptance of this somewhat shallow relativism as the permanent outcome of Kant's teaching. For Lange's History, well-written and with a fine ethical undertone, was widely read, and formed the historical and philosophical staple of contemporary men of science when they entered the speculative field. Now Lange explicitly identifies reality (Wirklichkeit) with the mechanistic scheme as materialism presents it. But 'one thing is certain', he adds, 'namely, that man requires a completion of reality by an ideal world which he creates for himself, and in the creation of which the highest and noblest of his spiritual functions co-operate.' And he points to Schiller's philosophical poems as the best example of such imaginative creation, in which the spirit takes its flight 'in das Gedankenland der Schönheit', and finds there not only aesthetic satisfaction, but also ethical harmony and religious peace. The future of religion and of speculative metaphysics lies, according to him, in this free poetic creation of a spiritual home (Heimath der Geister) in which our highest ideals are realized. And inasmuch as, in the spirit of Kant, we recognize the 'real' world of science to be itself but a phenomenon, a product of our intellectual organization, Lange holds, as against dogmatic materialism, that we have a certain right to solace ourselves with such speculative creations. Experience, he says, is the product not of our organization alone, but of that organization in commerce with 'unknown factors' - with a foreign power which partly lays compulsion upon us, partly allows itself to be moulded to our ends. All the 'knowledge' of this power that we can attain to is the categorized world of senseperception, but it may be that the ideals of art and religion 
point us to its more intimate nature. At all events, they are the sources of all that man has ever reverenced as divine; and it is as 'free poesy', and not as theoretic truth, that this ' world of values' succeeds in lifting our spirits above the lets and hindrances of time. Vaihinger, writing some ten years later as a sympathetic expositor and disciple, was more emphatic than Lange himself in bidding us remember that the world of the speculative imagination is no more than ' $a$ subjective ideal, with no claim to represent reality '. ${ }^{1}$

So interpreted, it is obvious that the "flight to the ideal' becomes no better than an elaborate process of self-deception-a painful effort to shut our eyes to the features of what we know in our heart to be the real nature of existence. And if that is so, it is equally obvious that the impulse to shape a fairer and a nobler world must speedily wither at the root. The function can only be sustained by some degree of faith in the reality of the vision. As Martineau eloquently puts it at the outset of his Study of Religion:" Amid all the sickly talk about "ideals" which has become the commonplace of our age, it is well to remember that, so long as they are a mere selfpainting of the yearning spirit, they have no more solidity or steadiness than floating air-bubbles, gay in the sunshine and broken by the passing wind. . . . The very gate of entrance to [religion] is the discovery that your gleaming ideal is the everlasting Real, no transient brush of a fancied angel's wing, but the abiding presence and persuasion of the Soul of souls: short of this there is no object given you.' ${ }^{2}$ The wavering position of Lange and the more definitely negative position of Vaihinger prove sufficiently that, in spite of their would-be Kantian theory of knowledge, the mechanical system in space and time remains the bedrock of their world-theory.

${ }^{1}$ Hartmann, Dühring und Lange, p. 18.

${ }^{2}$ Study of Religion, vol. i, p. I3. 
A decade earlier than Lange's History, the crass and blatant materialism which spread over Germany after the collapse of Hegelian idealism had drawn from Lotze, in the preface to the Mikrokosmos ( 1856 ), his memorable protest against the 'presumptuous boldness' with which, in the name of science and a supposed service of truth for truth's sake, many gloried in renouncing and trampling on all that has been held most sacred by the soul of man. As he pointed out, his own early work in philosophy had been in support of an extension to organic life of a purely mechanical method of explanation in contrast to the old vitalistic theory. He was thus in no way inclined by his antecedents to contest the claims of mechanism to be the universal and only legitimate mode of scientific explanation. But (as he summarized his own position), while recognizing how absolutely universal is the extent, he recognized also how completely subordinate is the significance, of the function which mechanism has to fulfil in the structure of the world. He emphasizes this conviction in the distinction he draws, on Kantian lines, between the world of forms and the world of values. The former, the world regarded as a mere succession of facts, of changing shapes, cannot be conceived as self-subsistent. The function of mechanism is, in short, essentially instrumental; as Leibnitz said, Causae cfficientes pendent a finalibus. 'The scientific understanding has to be supplemented by the reason appreciative of value.' 1 For truth itself, he says again, we demand a value, and this value, this justification, it can attain only as an element in the total life of an intelligent being. If truth were merely the reflection in consciousness of an already existent world, this 'barren rehearsal' would have no self-sustaining value or significance, such as those who deify truth for truth's sake seem to suppose. Truth, there-

'Mikrokosmos, Book II, chap. v. 
fore, as Plato said, is subordinate to the general conception of the Good, and the world of forms must receive its final explanation from the world of values whose medium it is. This Lotze offers as his immovable conviction rather than as the result of a philosophical demonstration. He emphasizes indeed the impossibility of any such deductive certainty as Hegelian idealism seemed to claim to possess. Speaking of the alternatives of Naturalism and Idealism, he says, "I cannot for a moment doubt that the latter alternative is alone permissible; the whole sum of Nature can be nothing else than the condition for the realization of the Good. . . . But this decided conviction indicates only an ultimate and farthest goal that may give our thoughts their direction: it does not indicate knowledge that deserves the name of science, in the sense, namely, that it can be formulated in a demonstrable doctrine. To our human reason a chasm that cannot be filled, or at least that has never yet been filled, divides the world of values from the world of forms. . . W With the firmest conviction of the undivided unity of the two we combine the most distinctly conscious belief in the impossibility of this unity being known.' ${ }^{1}$

Lotze's statement remains typically Kantian in the ' chasm' it makes between the world of forms, as the sole object of knowledge, and the world of values, as resting on merely subjective conviction. The world of knowledge is also apparently identified by him, as by Kant, with the mechanistically conceived world of physical science. In some ways, indeed, Lotze's statement of the position impresses a reader as even more subjective and apologetic than Kant's-perhaps owing to the critical and balancing character of his mind and the reaction which can constantly be detected in him against what he deemed the over-

${ }^{2}$ Mikrokosmos, Conclusion of Book III. 
statements of speculative idealism. In spite of the firm assertion of the principle of value, there is wanting somehow the magisterial tone which seems to invest Kant's ethical pronouncements with an objectivity of their own. But Lotze's statement of the philosophical problem, as a conflict between supposed or apparent results of science and the cherished objects of religious faith, truthfully reflects the attitude of thought ful men during the latter half of the nineteenth century. This conflict provides philosophy during the period with its subject-matter, and in Lotze's view the problem does not admit of an intellectually coercive solution. The contribution of philosophy to an intellectual harmony, or perhaps it would be more accurate to say, to a modus vivendi, is to point out the limitations of the merely scientific point of view-the 'disinterested understanding' as he calls it in one place-and to vindicate 'the belief that, in its feeling for the value of things and their relations, our reason possesses as genuine a revelation as, in the principles of logical investigation, it has an indispensable instrument of experience'.'

Largely through Lotze's influence on Albrecht Ritschl, his colleague at Göttingen, the idea of value passed into theological thought. Formulating in the sharpest way the opposition between theoretic and religious knowledge, Ritschl sought to base theology exclusively on 'judgements of value', and thus place its doctrines on a foundation independent of controversies as to scientific matter of fact. There is much that is profoundly true in Ritschl's attempt to purge traditional doctrines of what he calls their 'metaphysical' accretions, and to restore to them (or to give to them) a purely religious significance; and it is matter of common knowledge that Ritschlianism, developed as it has been by a singularly able band of pupils and followers, has been perhaps the most important theo-

${ }^{2}$ Book II, chap. v (English translation, vol. i, p. 245). 
logical movement of the last forty years. But it is impossible to maintain, in the rigidity of its original formulation, the opposition between judgements of value and judgements of fact. Unless the objects of religious faith are real, theology is entirely in the air; and if they are real it is impossible to treat the world of religious belief and the world of fact, as science and philosophy handle it, as if they were two non-communicating spheres. Reality is one, and, after all, the human mind is also one, and not a bundle of unconnected and conflicting faculties. Our various modes of apprehending reality must have a relation to one another through their common basis both in the subject and in the object. Philosophy is just the attempt of the reason to realize the co-ordination of the different aspects of experience, and thereby to express, as far as may be, the nature of the total fact. But Ritschl's procedure amounts in effect to an invitation to do without philosophy altogether-to leave the apparent conclusions of science and the ethicoreligious interpretation of the world standing side by side, with no criticism of either and no attempt at mediation or co-ordination. Such a dualism is essentially a surrender to scepticism, and is therefore a seed of weakness in the Ritschlian theology. Man cannot find rest by balancing himself in this fashion first upon one leg and then upon another. But the dualistic position is entirely in keeping with the spirit of the period in which it took its rise. It was ebb-tide in philosophy, regarded as a synthetic doctrine. There was a widespread distrust of philosophical constructions, engendered by the excesses of speculative idealism, more particularly in the field of the 'Philosophy of Nature'. At the same time, the concentration of the best energies of the time on the special work of science and on historical research encouraged a 'positive' or anti-metaphysical habit of mind; and popular philosophy of the negative variety was already exploiting in a materialistic interest the conclusions 
to which the scientific data seemed to point. The salvage of religious belief from this encroaching tide is the interest both of Lotze and of Ritschl. But immensely subtle and suggestive as is their work, both are fatally hampered by the subjectivity of their theory of knowledge, which they accepted from Kant with adaptations of their own, and which results in the unsatisfactory blend of Idealism and Agnosticism that has just been considered.

Popularly, though inaccurately, described as 'the conflict between science and religion', the opposition of which Lotze speaks figured largely in the theological and antitheological literature of the century, and drew from Herbert Spencer a few years later ( 1862 ) the opening chapters of the First Principles in which, with the best of intentions but with a certain fatuity, he presented his doctrine of the Unknowable as offering 'the terms of a real and permanent peace' between the combatants. 'If Religion and Science are to be reconciled, the reconciliation must be this deepest, widest and most certain of all facts-that the Power which the Universe manifests to us is utterly inscrutable.' ' 'A permanent peace will be reached when Science becomes fully convinced that its explanations are proximate and relative, while Religion becomes fully convinced that the mystery it contemplates is ultimate and absolute.' ${ }^{2}$ As Mr. Balfour wittily puts it: " His method is a simple one. . . He divides the verities which have to be believed into those which relate to the Knowable and those which relate to the Unknowable. What is knowable he appropriates, without exception, for science, what is unknowable he abandons, without reserve, to religion. . . The one possesses all that can be known, the other all that seems worth knowing. With so equal a partition of the spoils both combatants should be content.' ${ }^{\prime}$ Spencer's doctrine of the

${ }^{1}$ First Principles, chap. ii, p. 46.

'Ibid., chap. v, p. 107.

'Foundations of Belief, ist ed., p. 285. 
relativity of knowledge and the unknowableness of reality was, of course, a direct descendant of the Kantian opposition between the phenomenon and the thing-in-itself; and the reconciliation bears a certain resemblance to the corresponding contrast in Kant between knowledge and belief. But in Spencer's case the object of belief is something to which we are to ' refrain from assigning any attributes whatever'.' We shall not be able to avoid ' representing it to ourselves in some form of thought'; and 'we shall not err in doing this', he quaintly says; 'so long as we treat every notion we thus frame as merely a symbol, utterly without resemblance to that for which it stands.' The words which I have italicized were withdrawn, it is fair to say, in I90o, their author having apparently by that time come to realize the reductio ad absurdum which they involve.

Mr. Balfour's own philosophical work is one of the most characteristic products of the conflict we have been considering. It offers as clear an example as could be desired of the teridency to seek an escape from the conclusions of Naturalism, either in a purely sceptical position or, at all events, by a line of argument which limits and disparages the function of reason in experience. In the Defence of Philosophic Doubt, published in I 879 at the very flood-tide of naturalistic confidence, Mr. Balfour turned his sceptical batteries upon the reputed foundation of the naturalistic creed in the certainties of sense-perception. His conclusion is, that the ordinary scientific beliefs about the material world, which we all share, are not based upon reason but thrust on us by the practical needs of life. No doubt the concatenation of the parts is brought about by the exercise of reason, but 'the system as a whole is incapable of rational defence '.2 It cannot, therefore, set itself up as a standard to which religious beliefs must conform. 'Religion is at

${ }^{2}$ First Principles, chap. v, p. 109.

'Defence of Philosophic Doubt, p. 315. 
any rate no worse off than science in the matter of proof,' and therefore we have as much right to believe the one as the other, if so inclined. The state of matters may, in fact, be described in his own words thus: 'I and an indefinite number of other persons, if we contemplate religion and science as unproved systems of belief standing side by side, feel a practical need for both. . . . But as no legitimate argument can be founded on the mere existence of this need or impulse, so no legitimate argument can be founded on any differences which psychological analysis may detect between different cases of its manifestation. We are in this matter, unfortunately, altogether outside the sphere of Reason.' ' In such a passage, and in others like it, we have obviously a formulation of the purest scepticism, for a parallel to which we have to go back to Hume-the Hume of the Treatise. Hume also, like Mr. Balfour, seeks to reduce belief to ' a kind of inward inclination or impulse '- ' a strong propensity' is his favourite phrase-and he consistently substitutes for logical grounds of belief the psychological causes which bring it about. A more dangerous defence of religious beliefs it would be difficult, I think, to imagine; it surrenders all claim to rational criticism of the dogmas offered for acceptance, and supplies, accordingly, no safeguard against the re-invasion of the grossest superstition.

There is much more that is constructive in the later volume on The Foundations of Belief. It contains, for example, the significant argument for Theism 'from the

'Defence of Philosophic Doubt, pp. 319-2o (italics mine). Cf. pp. 316-17: "What constitute the "claims on our belief" which I assert to be possessed alike by Science and Theology? ... Whatever they may be, they are not rational grounds of conviction. . . . It would be more proper to describe them as a kind of inward inclination or impulse, falling far short of -I should perhaps rather say, altogether differing in kind from-philosophic certitude, leaving the reason therefore unsatisfied, but amounting nevertheless to a practical cause of belief, from the effects of which we do not even desire to be released.' 
mere fact that we know, a fact which like every other has to be accounted for'. If the general system of scientific beliefs is to be accepted as rational-which is the contention of Naturalism and also the assumption of commonsense-it must be because "we bring to the study of the world the presupposition that it is the work of a rational Being, who made $i t$ intelligible, and at the same time made $u s$, in however feeble a fashion, able to understand it.' ${ }^{\prime}$ I have pointed out elsewhere ${ }^{2}$ the affinities of Mr. Balfour's procedure here with Kant's central argument in the first Critique from the possibility of experience, especially when that argument is amplified by Kant at the close, by reference to the regulative function of the Ideas of Pure Reason, so that, even in the theoretical sphere, as he points out, reason teaches us to regard reality as intelligible in all its parts, and therefore as if it were the product of a supreme Reason. And, like Kant, having postulated 'a rational God in the interests of science', Mr. Balfour goes on to postulate 'a moral God in the interests of morality '.' The argument from 'needs' to their satisfaction-presented in the Defence of Philosophic Doubt so sceptically that we find the terms 'need' and 'impulse' used at times as equivalent ${ }^{4}$ - is here deepened so as to be substantially identical with the principle of value. The author recognizes also the caution with which the argument requires to be applied. "Whether this correspondence be best described as that which obtains between a "need" and its "satisfaction ",' he says, 'may be open to question. But, at all events, let it be understood that if the relation described is, on the one side, something different from that between a premiss and its conclusion, so, on the other, it is intended

'Foundations of Belief, pp. 296, 30I.

${ }^{2}$ Man's Place in the Cosmos, and ed., pp. 159-213, 'Mr. Balfour and his Critics.'

'Foundations of Belief, p. 323.

e. $g$. in the passage already quoted on p. 60. 
to be equally remote from that between a desire and its fulfilment. . . For the correspondence postulated is not between the fleeting fancies of the individual and the immutable verities of an unseen world, but between these characteristics of our nature which we recognize as that in us which, though not necessarily the strongest, is the highest; which, though not always the most universal, is nevertheless the best.'

It is a pity that so much that is sound and valuable should be associated with an elaborate argument in disparagement of reason and an exaltation of authority which seems to introduce again that unhappy disruption of our nature which is philosophically so dangerous an expedient. It turns out on a closer scrutiny that Mr. Balfour uses 'reason' in the old English sense of reasoning, or the process of conscious logical ratiocination; and it does not require any argument to convince us that the vast majority of human beliefs-including certainly our ethical, social, and religious beliefs-have not been reached by such a process. They have been generated in the individual, as Mr. Balfour says, by 'custom, education, public opinion, the contagious convictions of countrymen, family, party, or Church'. But it is to court misapprehension when he proceeds to sum up these various forces under the term Authority, and to express his meaning (which every one surely would accept) in the form of an elaborate contrast between Authority and Reason as operative forces in human belief and action. This use of the term authority is, if I may say so, itself without authority in current English usage, and if we do take it in Mr. Balfour's sense to cover causes such as those enumerated above-custom, education, public opinion, and so forth-the radical opposition between authority and reason at once disappears. The contrast is really between the private, consciously acting reason of the individual and the historic rea-

${ }^{2}$ Foundations, pp. 247-8. 
son in which is summed up the experience of the race. The advance of speculative thought since Kant has largely consisted in surmounting the abstract and unhistoric individualism of preceding philosophy, which we find also in Kant himself, and bringing home to us the larger or corporate reason, active in history and embodied in the social structure. The term reason cannot, in short, be identified with the logical intellect without a grave departure even from ordinary usage. Mr. Balfour himself adopts the larger sense involuntarily from time to time in other passages of his book, as when he speaks of Reason as "the roof and crown of things ', ${ }^{1}$ or of Naturalism as deposing ' Reason from its ancient position as the Ground of all existence '. ${ }^{2}$ And if it is a deviation from ordinary usage so to restrict the term, the disparagement of reason also sounds strangely in the mouth of a thinker. 'I express myself with caution,' said Bishop Butler in a similar connexion, "lest I should be mistaken to vilify reason, which is indeed the only faculty we have wherewith to judge concerning anything, even revelation itself '." The august name of reason is, in a sense, the symbol of the unity of our nature as intelligences, and the appeal to the non-rational soon leads us into strange company and to strange conclusions.

This is well exemplified in another volume characteristic of the trend of thought towards the close of the century. Mr. Kidd's Social Evolution, published in r894, a year before Mr. Balfour's book, takes reason and rational in a similar narrow sense. Dealing with its ethical and social action, Mr. Kidd identifies reason with the principle of the baldest self-interest, and treats it, therefore, as essentially a divisive and disintegrative force, reaching finally the monstrous conclusion that reason is 'the most profoundly individualistic, anti-social, and anti-evolutionary of all human qualities'. Naturally, therefore, he is bound to have recourse to what
${ }^{2}$ p. 72.
${ }^{2}$ p. 75.
'Analogy, Part I, chap. iii. 
he calls 'ultra-rational sanctions' to explain the possibility' of social cohesion and social evolution. It is the chief function of religion, he says, to supply such sanctions. Religion, on the basis of these definitions, is essentially in antagonism to reason. 'A rational religion is a scientific impossibility,' ' the essential element in all religious beliefs' being 'the ultra-rational sanction which they provide for social conduct '. ${ }^{1}$ In reactionary circles the attack on reason, and the stress laid on religion as the only bond of cohesion in human society, were equally welcome. In France, especially, where an anti-religious scientific dogmatism had been peculiarly pretentious and aggressive, the ideas of Mr. Kidd and Mr. Balfour had a great reception from Brunetière and other literary leaders. Extravagant promises had been held out in the name of science-promises impossible of fulfilment-and Brunetière's phrase, 'the bankruptcy of science,' was primarily intended to signalize the failure of a materialistically interpreted science to fulfil its own programme as moral and social guide of humanity. But the controversial phrase gained wide currency and was given a more extended application. The bigotry of negation led by revulsion to a temper of mind which was ready to discredit reason as such, and to seek a refuge in the uncriticized simplicities of faith. As might have been expected from the terms in which the controversy was stated, the whole movement tended to be exploited in the interests of clericalism and reaction. Such is the danger to which the assailant of reason inevitably exposes himself.

I have dwelt in the latter part of this lecture on the tendency to slip into an anti-intellectualistic, and even irrationalistic, mode of statement in expressing the principle of value, and we have considered some historical instances of this tendency in the course of the sixty years' controversy. I have done so because I believe that this is to endanger

'Social Evolution, chap. v, p. Iog. 
the principle itself, which is true only when taken as inherent in our experience as a whole. A house divided against itself cannot stand, and if value is set in opposition to reason, it must inevitably appear as a subjective and arbitrary judgement. Hence the mere assertion of the principle is not enough; it must be articulated as far as possible into a coherent system of reality, and shown to represent the ultimate insight of a larger knowledge. The only ultimately satisfactory answer to Naturalism is a philosophical construction of reality which can stand on its own merits. Such a constructive theory should be able to show that Naturalism is essentially the substantiation of a-fragment which can exist only as an element in a larger whole. In other words, the reassertion of human values becomes effective and convincing only when it is accompanied by a demonstration that the naturalistic conclusions rest on a misinterpretation of the nature of the scientific theories on which they are based. That this is so I hope to illustrate in the next lecture from the advance of science itself. 


\section{LECTURE IV}

\section{THE LIBERATING INFLUENCE OF BIOLOGY}

THE advance of science itself, and the continued reflection of scientific men upon their own principles and methods, has been powerfully instrumental within the last quarter of a century in relieving us from the naturalistic incubus. This result has been brought about in two ways-in the first instance, by a truer view of the function of scientific conceptions and the meaning of scientific laws; in the second place, by the advance of scientific knowledge itself, more especially, so far as our present purpose is concerned, by the development of biology as a separate science. In the present lecture it is upon the second point that I wish to dwell, upon the new insights gained from biological science, and their influence in emancipating us from the bad dream. of Naturalism. The last half-century has been pre-eminently the age of biology. There has been, of course, a continued advance (in many ways marvellous and latterly even revolutionary) of physical and chemical science. But biology, since the immense impetus given to it by Darwin, has undoubtedly stood in the forefront of human interest. It has exercised a more important influence than any other branch of knowledge in shaping our general conception of nature and man. And it is not too much to say that we are only now-or let us say, within the last twenty yearsbeginning to enter, as philosophers, into the full results of the biologist's labours.

In this connexion the indissoluble relation of philosophy to the advance of scientific knowledge and the progress of social experience is still constantly misconceived. Philosophical theory is still treated in many quarters as an arbitrary 
speculation of the individual thinker, a flight of the imagination into a transcendent void, in which the control of facts. is entirely left behind. But there is an often-quoted metaphor of Hegel's-who is usually deemed the most flagrant example of this masterful transcendent way of thinkingwhich might have sufficed to dissipate such misconceptions. - The owl of Minerva does not start upon her flight till the evening twilight has begun to fall.' "It is only when the actual world has reached its full fruition that the ideal rises to confront the reality, and builds up, in the shape of an intellectual realm, that same world grasped in its substantial being.' 1 Philosophy is, and can be, nothing more than the critical interpretation of human experience; and in that experience the systems of knowledge represented by the different sciences have obviously an important part. Philosophy is, in reference to them, a criticism of the categories or principles on which they proceed.

This criticism, it is important to note, is not an abstract criticism undertaken by the philosopher ab extra, according to $a$ priori or self-invented canons of his own. To such a conception of the philosopher's attitude and pretensions is largely due the suspicion with which the average man of science regards the interference of the 'metaphysician'. And it need not be denied that philosophers in the past have often given ground for such jealousy. But philosophical criticism is simply the thinking out and setting in a clear light of the conceptions and methods which science actually employs. To be fruitful, such an analysis must be the joint outcome of the intimate acquaintance of the scientific specialist with his own range of facts and problems, and of the discipline in abstract thought and the comprehensive survey of experience which we mean by philosophy. The work would be best done by the man of science turned philosopher;

${ }^{1}$ Werke, vol. viii, pp. 20-I, at the close of the Preface to the Philosophie des Rechts. 
and although that type is too rare, it is happily not nonexistent. In any case, the best work of the kind is impossible until scientific workers have themselves begun to reflect upon the principles of their own procedure-upon the characteristic modes of behaviour which they investigate, and the nature of the conceptions by which they instinctively interpret them. Such reflection may easily result in conflicting theories; still oftener, from lack of acquaintance with the counters of thought and their past history and associations, it may fail to reach a just expression of what it really intends to convey. But, on its basis, the philosopher proper may then profitably take up the work and attempt to carry the matter to a conclusion, lending his aid to set the points at issue in their true light by comparison with other fields of experience, and using the skill derived from his own special training to suggest an accurate and well-considered statement.

It is some time before a science reaches this stage of reflection. In living contact with his subject-matter, the scientific worker learns instinctively to appreciate its characteristic qualities and modes of behaviour, and develops appropriate methods of handling it. But if he sets out to formulate either, he will in all likelihood employ, to express himself, the fossilized metaphysics of common sense or the ready-to-hand terms of some other science. In the case of biology, it was natural that the prestige of physics and the more recent advances of chemistry should lead, in the first instance, to the view that the processes which the biologist studies in the organism are only very complex examples of the mechanical and chemical processes which are observable in non-living bodies, and that the ideal of explanation in biology must therefore be a resolution of the biological fact into simple mechanical relations and movements of which, on this view, it is the combined result. Such a statement was supposed to be an analysis of the fact into its ultimate 
terms, and in that sense to be an explanation of it. The universal claim made for this mode of explanation is strikingly exemplified, as we have seen, in the Kantian philosophy. The world of science is identified by Kant with the sphere of applied mathematics, the Newtonian scheme of acting and reacting particles; and the world of science is conterminous with the realm of the knowable. But just because he limited the term knowledge in this way, Kant was obliged, in order to include the other aspects of experience, to eke out knowledge by subjective principles of reflective judgement and by ethical faith, bequeathing to philosophy an arbitrary and ultimately unjustifiable dualism between knowledge and belief. The great biological advance belongs to the century between us and Kant, and we should expect accordingly to find in the science and philosophy of to-day a more adequate interpretation of the characteristic attributes of life than is offered in the Kantian theory. On the whole, this expectation is not disappointed. The mechanistic tradition is still strong, among ' the old guard' of physiologists, but among the more thoughtful biologists of a younger generation, a steadily increasing number of voices is heard pleading for 'the autonomy of life'. The last series of Gifford Lectures delivered in this University by Professor Driesch, on the 'Science and Philosophy of the Organism', sufficiently attests the prominence of this question at the present time. There are many strands in M. Bergson's philosophy, and, as a metaphysical theory of the universe, it must be judged by ultimate philosophical considerations. But undoubtedly the most striking feature of his thought is the extent to which it is determined by the biological way of looking at things. The intimate appreciation of living experience forms the basis of the whole Weltanschauung which he offers us. 'His philosophy connects itself, therefore, directly with the biological revolt against the reduction of reality to the interplay of physical constants. 
There was a further reason why biology did not at first come to its own-why the specific features of life were for long not frankly recognized in biological theory. When the -great advance began, physiology had only recently emerged from a victorious campaign against Vitalism. What was then known as Vitalism consisted in the assertion of a ' vital force' or 'vital principle', conceived as supplementing the physical and chemical energies of the organism and directing them in the service of the living whole. If one may judge from the polemic against it, this vital force was conceived after the fashion of an occult quality or 'metaphysical 'entity, such as Comte denounced and of which Molière's virtus dormitiva is the classical caricature. It was invoked to explain those features of the life-processes which the physical and chemical forces in operation seemed insufficient to account for; and it was itself conceived as a force on the same level-an independent source of energy, interfering in a more or less arbitrary fashion with the otherwise mechanically determined course of intra-organic events. Evidently, recourse to such an entity for purposes of explanation is scientifically as illegitimate as an appeal to the miraculous interposition of the Deity by way of explaining some particular physical event. Both explanations amount to an encouragement of intellectual indolence, inasmuch as they / seem to absolve us from further research into the natural causation of the phenomenon in question. Whether the biological facts can be wholly resolved into physical and chemical facts or not, it is plainly the duty of the scientific investigator to press that acknowledged mode of explanation in all directions, to pursue it as his ideal even though it should prove a flying goal. ${ }^{1}$ In fact, as Dr. J. S. Haldane

${ }^{1}$ As Kant says, 'It is infinitely important for Reason not to let slip the mechanism of nature in its products, and in their explanation not to pass it by; because without it no insight into the nature of things can be attained. ... We should explain all products and occurrences in nature, even the most purposive, by mechanism as far as is in our power. 
puts it, "vital force was useless as a means of explaining phenomena or suggesting definite paths of investigation, and was even blocking further progress. The mechanistic theory, on the other hand, suggested at every point clear and intelligible working hypotheses for further investigation.' 1 Accordingly, during the greater part of last century the acknowledged working hypotheses of nearly all physiologists and biologists were of a mechanistic order. Biology, as a consequence, if not actually incorporated with physics, presented, at all events from the wider point of view of philosophy, the appearance of a vassal state. The frontiers of mechanism were thus thrust forward to the very confines of the physical or conscious, which, in turn, came in many quarters to be looked upon as the inert accompaniment or appendage of a series of strictly mechanical transformations.

But the concentrated biological research of the last fifty years, while it has immensely extended our knowledge of the mechanics and the chemistry of organic processes, has. strikingly failed to substantiate the mechanistic hypothesis from which most of the researchers started. Instead of coming nearer, the reduction of biological processes to terms of mechanism appears to recede, as knowledge deepens and becomes more intimate; and the recognition of this has led within the last twenty or thirty years to a significant revival of 'neo-vitalistic' theories among the younger generation of botanists and zoologists. Professing to reject the old idea of 'vital force' as an additional force or entity acting on the same plane as the physical and chemical forces,

But at the same time [he adds significantly], we are not to lose sight of the fact that those things which we cannot even state for investigation except under the concept of a purpose of Reason, must, in conformity with the essential constitution of our Reason, and notwithstanding those mechanical causes, be subordinated by us finally to causality in accordance with purposes.' Critique of Judgment, section 78 (Bernard's translation, pp. 326,333 ).

${ }^{1}$ Life and Mechanism, Two Lectures (1906), p. 5. 
these neo-vitalists yet insist, not only that there are features of organic process which are wholly inexplicable from the point of view of pure mechanism, but that no vital process whatever, however simple and, at first sight, purely physical it may seem, admits of adequate statement in merely physical terms. They claim, therefore, that biology must stand alongside of physics as an 'autonomous' science, which has a right to use its own terms - the only appropriate terms or categories-to describe the facts with which it deals. ${ }^{1}$

Outstanding phenomena constantly referred to as forcing us beyond the mechanical point of view are such as the restitution of lost or injured parts, seen on a small scale in the healing of any wound, but more strikingly exemplified in many of the lower animals. If a newt's hand is amputated, the stump of the limb grows a new hand to make good the mutilation and thus restore the vital functions of the creature to their normal condition. Similarly, the Tubularia, a kind of sea-anemone, re-grows its flower-like head. Moreover, as Driesch points out, ' you may cut the stem at whatever level you like; a certain length of stem will always restore the new head by the co-operation of its parts '.2 So again, the elaborate embryological experiments of Driesch and others have shown that disturbances of the normal development of the egg, and the removal at an early stage of parts normally destined to develop into certain parts of the adult organism, may take place, and that a typically complete embryo will still be developed. Similarly in organisms of a low type, if the creature is cut in two, the

' One of Driesch's books is entitled Biologic als selbständige Wissenschaft, and the same idea explains the title of Professor J. Arthur Thomson's two articles in the Hibbert Journal (October IgI I and January 1912), 'Is there One Science of Nature?' Cf. the same writer's Introduction to Science, p. 163; Evolution, p. 231; also Karl Pearson, Grammar of Science, chap. ix, 'Life', section 6.

${ }^{2}$ Science and Philosophy of the Organism, vol. i, p. 127. 
separated segments will, in some cases, complete themselves as independent animals. Thus we are met everywhere by the idea of the whole. Such phenomena are only peculiarly striking examples of the fundamental characteristic of every living thing. The organism is a self-conserving system, building itself up by appropriating from its environment suitable material, which it transforms into its own tissue; responding continuously to changes in its surroundings by adaptive processes, which it is observed to vary repeatedly, should the first effort prove unsuccessful in achieving its end; and, finally, regulating in the minutest and most delicate fashion the action of each of its parts in the interest of the whole.

It is perhaps the last-mentioned feature of organic processes-their regulation or co-ordination in the interest of the living whole - that has been most conclusively established by the progress of research. ' It is only quite recently', says Dr. Haldane, "that we have come to realize the astounding fineness with which the kidneys, respiratory centres, and other parts regulate the composition of the blood.' ${ }^{1}$ It is the same with the regulation of the production and loss of heat which maintains the temperature of the body approximately constant. To state it generally, processes of absorption and secretion which might easily seem at first sight to proceed entirely on a physical level-and which were, in fact, long treated by physiologists as mere mechanical processes of filtration and diffusion-reveal themselves on closer analysis as selective in character and controlled throughout in the interest of the individual organism as a whole. And the same is true of reflex action conceived as an immediate and definitely determined response to a sensory stimulus. This is the ideal and the basis of the mechanical explanation of life in the hands of Loeb and others. But the tropisms and the phenomena of 'taxis' on which Loeb lays so much ${ }^{1}$ Mechanism, Life and Personality, p. 49. 
stress have been shown by Jennings to be ' not simple and immediate processes of orientation at all' but the final result of many different single performances on the part of the animal. They are not the direct result of physicochemical attraction, but are reached, in the main, by the method of trial and error. ${ }^{1}$ Similarly in the vertebrates the spinal reflexes, often taken as types of the pure reflex, are shown to be 'determined by all that happened and is happening in other parts of the moving body'.' As Dr. Haldane points out, "if we examine a reflex such as that of assuming a normal position or removing an irritant, it soon appears that it is by no means the simple mechanical response which it may at first sight be taken to be. The physical response varies endlessly according to circumstances. It is the end attained, and not the physical response, which is simple and definite' $:$ We cannot therefore treat any reflex action as an isolated phenomenon; its independence is only relative, and instead of the behaviour of the organism being resolvable into a combination of such elementary mechanisms, these actions appear more truly from the biological point of view as themselves 'secondarily automatic' in character, that is to say, as arrangements fixed by habit and inheritance in the service of the living creature as a whole, and never completely withdrawn from central control.

The fact is, that in the organism we are face to face for the first time with the real individual ${ }^{4}$ whose nature is 'to

${ }^{1} \mathrm{C} f$. Loeb's essay on 'The Mechanistic Conception of Life'; Jennings, Behaviour of Lower Organisms, p. 252 ; Driesch, op. cit., vol. ii, p. 19.

'Driesch, vol. ii, p. 33 .

- Life and Mechanism, p. 4I.

- Such a statement is not affected by the fact that, even in the realm of life, what we regard as an individual may be said to depend on the context of our irterests. To the physiologist, expounding the minute structure of the body and the functions of its parts, the unit may be the cell; but to the ordinary man, and to the physiologist himself outside of his professional work, the natural unit is the living creature as a whole. The unity of a complex organism is supra-individual with reference to the society of co-operating cells of which it is composed. But that does 
maintain and reproduce in the face of varying environment its structure and activities as a whole': This may be said to be the fundamental assumption of biology. $\mathrm{Bi}$ ology deals, not with transformations of matter and energy, but with the relations of organisms and their environment. Of course, the physical laws hold good throughout; it is easy, for example, to measure the amount of energy gained or lost in the course of vital activities. But the commerce of the organism and its environment can only be understood in terms of teleology or purpose. The organism is a selfconserving system which acts as a whole, and none of the actions of its parts can be fully or naturally understood except as the determinate function of such a system. 'Life', I urged more than twenty years ago, 'is the presupposition of physiology, the fact on which its existence is based, a fact which it has simply to accept, as all the other sciences have to accept their own presuppositions. Its explanations move within the fact of life, and cannot be used to explain that fact itself, or in other words to explain it away. Yet that is in substance what a purely mechanical physiology tries to do.'2 It is only, I would add, because he so instinctively assumes this in practice that, when he begins to reflect, the physiologist is in danger of failing to notice his own assumption and of leaving it out of his theory. Terms like stimulus, response, behaviour, all imply the notion of selection, the power of adaptation to environmental change, by which the organism maintains and develops its own characteristic being... All this seems to be involved in the notion

not mean that the unity of the organism is less individual than that of its component cells. Its real individuality, translated into terms of feeling, is matter of direct experience to each of us in our own case, and we cannot doubt that this is an intenser and more perfect individuality than that of the minor individuals on which it is based, but which it seems almost to absorb.

${ }^{1}$ Life and Mechanism, p. 43.

'Man's Place in the Cosmos, and ed., pp. 76-8, in an essay on 'The "New" Psychology and Automatism'. 
of a real individual. Physics knows no self-maintaining individuals - only a continuous transmutation of energy. It is fundamentally misleading to swamp the organism in its environment-to treat the living being simply as a network of pathways through which the energy of external nature takes its course, soaks in and oozes out again. We are misled by physical phrases like currents of energy and paths of least resistance. Such phrases seem to imply that what takes place is precisely the same as the selection of a channel by a rill of water trickling down a hill-side. But this is not a true account even of the humblest organism. Nerve currents cannot be treated in this isolated fashion, as if they took place in vacuo or in an indifferent medium they take place in a living individual, and apart from the unity of that individual, they are mere abstractions. A nerve-current means, originally and normally, central stimulation and appropriate central reaction; and neither the appreciation of the stimulus nor the nature of the response can be understood apart from the organism as a self-maintaining whole. Purposiveness, in short, is the very notion on which physiology is built, and it is worked into the whole theory of development. ${ }^{1}$ Yet it is a notion entirely alien to the blind vis a tergo of mechanism as such. The more clearly, therefore, a physiologist realizes what pure mechanism means, and the more fully he grasps the import of the processes with which he himself habitually deals, the more ready will be his acknowledgement that they belong to a different order of facts. As it was put in the passage already quoted from Kant, the phenomena in question are such as 'we cannot even state for investigation except under the concept of

${ }^{1}$ Dr. Haldane very properly points out that, whatever stress the theory of evolution may lay on natural selection as a mechanically acting cause, natural selection could not act unless we assumed that each organism actively maintains and reproduces its particular structure and activities. Natural selection is thus a cause operating only within the presuppositions of life, within a world of living creatures. 
a purpose of Reason'.' 'A self-stoking, self-repairing, self-preservative, self-adjusting, self-increasing, self-reproducing machine ' ${ }^{2}$ is only by an abuse of language spoken of as a machine at all.

I do not wish to be understood as committing myself to any of the current statements of what is called 'NeoVitalism'. Most of the writers thus referred to are careful to disclaim the implications which brought discredit on the older Vitalism, and they seek to avoid its phraseology. I am not sure, however, that they always succeed. It is certain, at any rate, that they are more successful as critics of the mechanistic theory than in the precise statement of their own position. Even the most recent theories, such as Driesch's elaborate theory of Enteetries or Psychoids and Reinke's theory of Dominants, seem to lapse into statements which perilously resemble the older doctrine which they repudiate. Thus Professor Driesch begins by telling us that 'entelechy is not a kind of energy', 'it lacks all the characteristics of quantity', ' it is order of relation and nothing else'. ${ }^{3}$ But he constantly speaks of it as an agent. ${ }^{4}$ The 'psychoid or entelechy uses the conductive and specific faculties of the brain as a piano-player uses the piano' (ii. 97). Hence, although he refuses to speak of 'psychophysical' interaction (seeing that he refuses to attribute

${ }^{1}$ So again, in a passage perhaps more frequently quoted: 'Absolutely no human Reason ... can hope to understand the production of even a blade of grass by mere mechanicat causes. As regards the possibility" of such an object, the teleological connection of causes and effects is quite indispensable for the Judgment, even for studying it by the clue of experience? Critique of Judgment, section 77 ad finem (Bernard, p. 326).

${ }^{2}$ I take this array of terms from Professor J. Arthur Thomson, who also points out that, in the common comparison of the organism to a machine, we forget that the latter is no ordinary sample of the inorganic world. 'It has inside of it a human thought' (Hibbert Journal, vol. x, p. I2I).

Vol. ii, p. I69.

- Entelechy, in a stricter sense, he says, is 'the natural agent which forms the body'; the psychoid is 'the elemental agent which directs it ' (vol. ii, p. 82). And again (p. 238), entelechy is 'a well-established elemental agent'. 
psychical characteristics to the psychoid), he recognizes 'interactions between physico-chemical and non-physicochemical agents of nature' (ii. I I7). 'Entelechy is affected by and acts upon spatial causality, as if it came out of an ultra-spatial dimension; it does not act in space, it acts into space; it is not in space, it only has points of manifestation in space' (ii. 235). In order to reconcile this action with the physical theory of energy, he explains that its function must be purely regulative. Entelechy possesses, he says, the power to suspend reactions which would otherwise take place (thus converting kinetic into potential energy), and the power subsequently to release the energy thus stored, and permit 'the mechanical-energetical events to continue their course from the point where it was broken' (ii. 22I). Entelechy, however, cannot transform every kind of potential energy into the kinetic forms; for that would mean removing the obstacle which had hitherto impeded the transformation, and 'that would require energy'. But for suspending a reaction and subsequently relaxing that suspension, he tells us, "no transfer of energy is required, but simply a transformation of energy from actuality into a potential form and vice versa'. Entelechy is thus (as he puts it in a headline) 'burdened with as little as possible', but 'this faculty of a temporary suspension of inorganic becoming is the most essential ontological characteristic of entelechy' (ii. I80-5). He refers several times in illustration to Clerk Maxwell's well-known fiction, and concludes, 'the work of Clerk Maxwell's "demons" is here regarded as actually accomplished' (ii. 225).

Now the objection to this whole mode of statement is the same as to the older Vitalism. It treats life or entelechy essentially on the physical level, as an additional force acting $a b$ extra upon a set of physical and chemical forces. which, apart from this interference, are conceived as going by themselves. So Driesch speaks, as we have seen, of 'the 
mechanical-energetical events continuing their course', as soon as the momentary interference of entelechy is at an end; apart from this 'temporary suspension', he appears to regard the processes that take place in the organism as simply 'inorganic-happening'. It seems to me fundamentally wrong to insert life in this fashion into a system otherwise regarded as purely mechanical, and then to seek to apologize for the intrusion by reducing its action to a minimum'burdening entelechy with as little as possible'. Once embarked on such calculations, I confess I fail to see why, if expenditure of energy is involved in removing the obstacle which, in ordinary cases, prevents the transformation of potential into kinetic energy, no expenditure should be involved in the operations of suspension and subsequent release. From the physical point of view, suspension must surely mean the interposition of some obstacle, and release must mean its removal. This seems to me, accordingly, no true vindication of 'the autonomy of life'. The autonomy of life, or the independence of biology, means, as I interpret it, that physical and chemical categories are superseded throughout - that we must pass to another range of conceptions altogether, if we wish to describe accurately the behaviour of anything that lives. Strictly speaking, there is no inorganic happening in a living creature. We may, of course, by the ordinary method of scientific abstraction, isolate different aspects of what happens, and usefully study organic processes, at one time from a purely physical, at another time from a chemical, point of view. But such accounts do not represent anything independently real, as if we had a set of facts into which life enters and which it proceeds to manipulate. The organism as 'an autonomous active whole', every function in which is centrally or organically determined, is the only conception which suffices to describe the biological facts; and however mechanistic a physiologist may be when he is working at the details of specific move- 
ments and connexions, he will be found recurring instinctively and unavoidably to this fundamental conception as soon as he begins to speak of the physiological fact as a whole in its proper nature, and to discuss, for example, the fundamental phenomena of assimilation, growth, and reproduction. ${ }^{1}$

I have not the training, nor would this be the place, to pursue this discussion into further technical detail. My purpose is simply to emphasize the significance of the biological demand for more adequate categories. The biologist's claim of 'autonomy' is just the assertion of his right to take the facts as he finds them, instead of forcing them into the Procrustes bed of a preconceived theory. By ex-

'Driesch's italicized description of entelechy as not acting in space but 'into space', ' as if it came out of an ultra-spatial dimension', might be taken, perhaps, as no more than an assertion of the fact that the organism as such overcomes or rises above the purely spatial relations of physical science. Just so far as the organism is a real whole, and its parts members one of another, to that extent these parts cannot be treated as mutually external facts interacting. in space, and the causality of the whole cannot be treated as the combined result of these separate actions. Driesch describes the 'ultra-spatial' action of entelechy as constituting 'the very essence of vitalism, of non-materialism'. But he does not maintain himself at this level of thought; and to seek to explain the fundamental characteristic of living action by referring it to the causality of a separate agent is, in reality, a failure to rise above the mechanical point of view. And we do not escape from the ingrained materialism of ordinary thought by the easy (but, as history shows, completely ineffective) device of calling our agents and entities 'immaterial'.

Reinke's 'dominants', so far as I am acquainted with his theory, seem to resemble Driesch's entelechies or psychoids. He means by the term, he says, 'those secondary forces in the organism whose existence we are forced to recognize, but which we cannot further analyse ... that principle of control which sways whatever energies are available, just as men use tools or machines'. The term is used in the plural simply because the manifestations of control are manifold; and he tells us that the term has been devised 'to provide a short explanatory description of certain essential processes', not as implying 'a troop of ghosts with which I have peopled the cells and organs of animals and plants'. But in his treatment of the 'dominants' as 'forces', and in his designation of them as secondary forces (Kräfle zweiter Hand), whose function is to control and guide the 'primary' forces of which physics and chemistry give an account, his theory seems open to the same objections as that of Driesch. 
hibiting the insufficiency of the purely mechanical theory which was the inherited assumption of the science in the middle of last century, the progress of biological reflection has helped, to that extent, to dissipate the apprehensions caused by the apparent inclusion of living beings-man being no exception-within a completely determined system of physical necessity. For, undoubtedly, the first impression produced by the theory of evolution in its Darwinian form (with exclusive or almost exclusive stress on natural selection as its explaining cause) was that of a universal levelling-down, man linked by his genealogy with the lowest forms of animal life, from which, by slow and insensible gradations, his physical and mental faculties had been developed, the rudimentary forms of life itself being but complex specifications of inorganic molecules. The result seemed to be the victory of materialism all along the line. It is not astonishing, therefore, that Darwinism, as having apparently supplied the most fatal weapon against the higher view of man's place in the universe-as claiming, so to speak, to complete the materialistic proof-should have been at first an object of terror and obloquy to the average theological mind of the generation which witnessed its rise. And this general impression was not likely to be removed by the facile Berkeleian or Humian sensationalism with which Huxley sought to evade an explicitly materialistic conclusion, by Lange's hardly less unsatisfactory Kantianism, or by the agnosticism, derived impartially from Kant and Hume, to which the scientific thinkers of the day relegated all the final questions of philosophic thought.

One thing at least the sequel should teach us-the faithlessness and the foolishness of despairing as to the future of the instincts and beliefs which constitute man's higher nature. These are indeed imperishable, the supreme example of that power of self-maintenance and of adaptation to changing circumstance which, science teaches us, is the character- 
istic of all that lives. Changes in our conception of nature may be fatal to one formulation after another; accidents of expression may drop away in deference to historical criticism, nay, much that seemed of the very essence of religious faith may have to be left behind. But each time that the earthly body of a belief is laid in the dust, it receives a more glorious spiritual body, in which it continues to function as of old in the heart of man. Timid theologians who tremble for the ark of God at every advance of scientific knowledge do but repeat the sacrilege of Uzzah in the sacred legend, smitten by the anger of heaven for his officious interference. Faith, which is an active belief in the reality of the ideal, is the very breath by which humanity lives, and it will reconstitute itself afresh as long as the race endures.

And it is significant how little we can forecast the course of new ideas, the ultimate forms they will assume, and the nature of the influence they are eventually destined to exercise on our world-view. Thus the doctrine of evolution seemed at first, as we have seen, to thrust man ruthlessly back into the lower circles of nature and to make for an allengulfing materialism. But, in another perspective, the process of evolution as a whole, with man as its crowning product, may be held to reintroduce into nature, on a grander scale and in a more tangible form, the idea of end or aim which the theory of natural selection had done its best to banish from the details of her procedure. Although the end is achieved, according to the theory, by purely mechanical means, and is the end, therefore, only in the sense of being the last term, the successive steps in any process may always be regarded teleologically as means towards the final achievement; and so Darwin may be taken as replacing man in the position from which he was ousted by Copernicus. Man appears, according to the doctrine of evolution,-so interpreted, as the goal and crown of nature's long upward effort. The evolution of ever higher forms of life, and 
ultimately of intelligence, appears as the event to which the whole creation moves; and, accordingly, man is once more, as in pre-Copernican days, set in the heart of the world, somehow centrally involved in any attempt to explain it. The mere concentration of men's minds upon the biological history tended to discount the influence of the astronomical outlook in dwarfing man's importance. And, after all, the evolution of life may take place similarly on innumerable other planetary worlds where the conditions permit; the point is the central importance of the living and sentient as compared with its inorganic environment. The very term environment indicates a subsidiary function, and the usage is characteristic of the biological point of view.

So again, what presented itself to the earlier evolutionists as the naturalizing of man appears to a later generation rather as a humanizing of nature, in view of the continuity of the process by which the higher emerges from the lower. We all remember Professor Huxley's denunciation of 'the cosmic process', his poignant insistence on the sheer breach between ethical man and pre-human nature, insomuch that he represented 'the ethical process' on which society depends as essentially a reversal of the cosmic process at every step. 'In place of ruthless self-assertion, it demands -selfrestraint; in place of thrusting aside, or treading down all competitors, it requires that the individual shall not merely, respect, but shall help, his fellows.' As regards pre-human animal nature, Professor Huxley held, in fact, what he himself characterizes as 'the gladiatorial theory of existence'; and this is admittedly impossible to harmonize with any ethical ideal hitherto known among men. This gladiatorial theory is itself a reflection of the omnipresent struggle for existence which so exclusively dominates the picture of nature given us by Darwin and his immediate successors. To this vivid idea, indeed, suggested to Darwin by his reading of Malthus, and reflecting, as Professor Geddes and others 
have pointed out, the keen competitive conditions of an industrial age, we owe the whole theory of natural selection. But later biologists have greatly modified the original Darwinian conception. It seems certain that natural selection is only one cause among several that determine the course of evolution. And animate nature, as these writers remind us, presents other aspects than that of a relentless struggle for a scanty subsistence. It has its aspects of bountiful plenty and of peaceful happiness. But, above all, animal life is not expressible in terms of the economics of modern commercialism. Its foundations are laid, as Professor Arthur Thomson says, on the facts of sex and parenthood. In the attraction of mate for mate-and in the care of offspring, as well as in the further facts of association and co-operation in flocks and herds, we can see prefigured the altruistic virtues which form the staple of our human morality. ${ }^{1}$ The exclusive individualism of the early evolutionists was in some measure due to the economic doctrines and practice of their age. But it is to be noted that, even if we look only at the struggle for existence itself, that struggle takes place not only or chiefly between individuals, but in its intensest form between different societies; and in that struggle the qualities which make for social efficiency are those which are most important, and which are furthered therefore by the principle of natural selection. We may expect, accordingly, as Karl Pearson says, that 'Science will ultimately balance the individualistic and socialistic tendencies in evolution better than Haeckel and Spencer seem to have done '. ${ }^{2}$ Science has, in fact, already begun to do so, and it is an ironic reflection that Nietzsche's apotheosis of the gladiatorial theory and the purely individualistic ideal was given to the world as the last word of biological science, just as the patient

'Cf. Geddes and Thomson's Evolution, p. 175; Kropotkin's Mutual Aid a Factor of Evolution; Pearson's Grammar of Science, chap. ix, sections 15 and 16.

${ }^{2}$ Grammar of Science, ist ed., p. 435. 
pioneers of that science were correcting that one-sided statement, and even abandoning natural selection itself as the sole principle of explanation.

Biology, finally, with its fundamental conception of evolution, has emphasized the contrast between history, as the ground-character of the living being, and the cycles of merely physical change, conceived as a ceaseless weaving and unweaving, of which no memory or trace remains in the inner nature of the things which undergo it. In a sense, as Bergson suggestively points out, the world of physics is not in time at all; real duration begins with-life and that organic memory which shows itself in the formation of habits. Changes, for the living being, are expcriences by which it learns, by which its very nature is moulded. All adaptation depends on this capacity of learning, and the capacity is observable in living beings at a very low stage. Thus in the righting reactions of the star-fish, the initial movement of each single arm is determined in the first instance separately by external stimuli or immediate internal conditions. But as soon as the least result with regard to righting is reached, a unified impulse appears; the actions of the parts are co-ordinated, and single stimuli are disregarded. For a living being, therefore, the past lives on as a vital moment in the present. Its nature at any given moment resumes, as it were, its whole past history; and its action in response to any given stimulus is determined not only by the present stimulus but, to an indefinitely greater extent, by its own accumulated past. We instinctively feel the term 'experience' to be out of place where this plasticity, this capacity of learning, is conceived to be absent. On such experience depends the possibility of progress; and whether the idea of progress can be applied in an ultimate reference or not, it is certainly the only idea which brings order and unity into our human world. Here again, therefore, biology, with its stress on the concrete reality of time, appears in the true line of advance. 
There can, at least, be no doubt that the twentieth century opens with a very remarkable revival of general interest in philosophy; and, as I have tried to show, it is not the least hopeful sign of this movement that the impulse has come not so much from the professional philosophers as from men of science, in virtue of insights reached and problems raised in the progress of scientific thought. There is, doubtless, as always where a movement spreads to wider circles, much crude statement and wild theorizing by philosophically uninstructed writers. But there is a hopefulness even in the determination expressed in so many quarters to be done with academic tradition, and to discuss the universe from its foundations entirely without prejudice. There is a new spirit abroad in the philosophical world, a freshness of outlook, a contagious fervour, a sense of expectancy, which have long been absent from philosophical writing. The greater part of the nineteenth century was, philosophically, a period of reaction and criticism, an age great in science and in history, but suspicious of philosophy, distrustful of her syntheses, too occupied for the most part with its own concrete work to feel the need of them, and otherwise prone to take refuge in positivism or agnosticism. The philosophy of the century was in these circumstances mostly in a minor key, critical and historical rather than creative, reviewing its own past and demonstrating the necessity of its own existence, rather than directly essaying the construction of experience. But now it seems as if, with a century's accumulation of fresh material, philosophy were girding herself afresh for her synthetic task.

I have tried in this lecture to trace the liberating influence of biology in helping to bring about this changed attitude of mind. The revolutionary discoveries in physics that have marked the turn of the century have also, I think, by the sense of new horizons which they have given us, powerfully helped to mature a more philosophical view of the nature 
and function of physical concepts and laws. In view of the sudden transformation which has overtaken the very elements of the old physical scheme, there has been reborn the confidence that experience is richer than any of the formulae in which we may have sought to confine it.

Nay come up hither. From this wave-washed mound Unto the furthest flood-brim look with me; Then reach on with thy thought till it be drowned. Miles and miles distant though the grey line be, And though thy soul sail leagues and leagues beyond,Still, leagues beyond those leagues, there is more sea. ${ }^{1}$

'D. G. Rossetti, sonnet 37, 'The Choice.' 


\section{LECTURE V}

\section{THE LOWER AND THE HIGHER NATURALISM}

THE term Naturalism shares the ambiguity of the term nature, from which it is derived. A life 'according to nature' meant to the Stoics that pious citizenship of the universe-the life of human brotherhood and cosmic pietyin which they saw the realization of the highest human ideal; to the Cynics it meant casting off the restraints of law and custom, and even discarding the ordinary decencies of civilized humanity. 'Back to nature,' said the eighteenthcentury sentimentalist, opposing nature to civilization, and glorifying the time 'when wild in woods the noble savage ran'. 'Back to nature,' cries Nietzsche, in his frenzied attack on all accepted morality and religion. 'Morality and religion belong entirely to the psychology of error,' 'everything good is instinct.' The task of the philosophical regenerator of the race is 'to translate man back again into nature - to make legible again upon the palimpsest the terrible original text, homo natura'. On the whole, it may be said, although the term need carry with it no such opposition or exclusion, that the tendency of usage is to take nature as equivalent to non-human or infra-human nature-the universe of physical forces and of merely animal existence. Hence, with Nietzsche, to translate man back again into nature means to brand as a history of morbid degeneration the process of moralization by which the distinctively human being has been created. So in art Naturalism means the accentuation of la bête humainc. And in philosophy, similarly, Naturalism has come to mean the type of theory which so emphasizes the continuity between man and the non-human nature from which he springs as to minimize, if 
not entirely to deny, any difference between them. It denies, at any rate, any central significance to human life in the play of the cosmic forces. ${ }^{2}$ Consciousness is an incident or accident of the universe, which does not throw any special illumination upon its ultimate nature. It arises and passes away; the physical basis of things remains. Naturalism is, in short, a larger, and, in some respects, a looser term for what used to be called materialism.

This usage is general in the best authorities, and there is no reason to disturb it, seeing that it designates intelligibly one great trend of philosophical theory about the universe. But one can sympathize with the regretful protest of the late Professor Wallace against this degradation of an inherently honourable name. 'The faults of Naturalism', he says,' 'spring from a creditable motive. It is the desire to be honest, to say only what you can prove, to require thorough consistency and continuity in the whole realm of accepted truths. . . Naturalism was a reaction from the follies of supernaturalism.' Indeed, he continues, 'Naturalism was at the outset and in essence a negation not of the supernatural in general, but of a supernatural conceived as incoherent, arbitrary, and chaotic; a protest against a conception which separated God from the world as a potter from his clay, against the ignava ratio which took customary sequences as needing no explanation, and looked for special revelation from portents and wonders.' Hence, 'in its main contention', he concludes, 'Naturalism was sound; and that contention is, as expressed in the old phrase, "Non fit saltus in natura." . . . It is the faith of science-the human faiththat only on the hypothesis that "all's reason and all's law"

' So Renan, in his last phase, is reported to have said that he had attributed to man too central a part in the universe, and that the development of humanity might be of no more significance than a growth of moss or lichen.

${ }^{2}$ In an article on Mr. Balfour's Foundations of Belief in the Fortnightly Review, April 1895, partly reproduced in his posthumous Lectures and Essays. 
shall we ever understand-as we can hope to understand" this unintelligible world ".'

There can be no doubt that these are the considerations to which Naturalism owes its vitality. It represents the victorious claim of the awakened intelligence to explain all events and existences by what are called natural causes-to view them, that is to say, as steps or phases in one orderly process of change-instead of having recourse at any point of difficulty to the direct 'interference' of some metaphysical agent or to some theory of special creation. Theology has itself, in great measure, abandoned the conception of a God who gives evidence of his existence chiefly by spasmodic interferences with the normal course of events - who lives, as it has been said, in the 'gaps' of our scientific knowledge, and whose position, therefore, every conquest of science renders more precarious. Such a conception has no place in philosophy, whose very idea is law or system. The continuity of nature's processes, so strongly insisted on by Naturalism, may, therefore, be regarded by a sympathetic critic as simply the most impressive form in which the general idea of law and orderly change presents itself to an age predominantly influenced by the natural sciences. But continuity is as much the interest of an enlightened philosophy as it can be of any scientific worker. It is, indeed, the working maxim or presupposition of every attempt to systematize our knowledge. If, therefore, an idealistic philosophy takes exception to the naturalistic theory, it must be, not on account of its Naturalism in the sense just explained, but because ordinary Naturalism takes 'nature' in an unduly narrow sense, and is dominated, moreover, by an erroneous idea of explanation which leads to a denial of real differences or an attempt to explain them away.

This constitutes what I may call the lower Naturalism. A charity like Professor Wallace's may condone its excesses as a reaction against the old theological idea of man as 
thrust from a supernatural sphere into material surroundings, which are, as it were, accidental to his real being; but its procedure is none the less fallacious, and its conclusions unfounded. The separation between man and nature may be the expression initially, as has been suggested, of a dualistic-spiritualism or supernaturalism; but the naturalistic denial of this separateness or foreignness tends, by way of reaction, to merge man altogether in that infrahuman nature from which it declares him to be derived. Nature, however, is not the less nature because it exhibits a scale of qualitative differences. The principle of continuity is misinterpreted, if it is supposed to necessitate the reduction of all nature's facts to the dead level of a single type. The higher Naturalism, as I venture to call it, feels no temptation to this levelling down; it does not hesitate to recognize differences where it sees them, without feeling that it is thereby creating an absolute chasm between one stage of nature's processes and another-a chasm which can only be cleared by supernatural assistance expressly invoked. And I wish to point out that this greater freedom of attitude is largely owing to its truer view of what is meant by explanation, and where and in what sense explanation is possible.

The most fundamental differences in philosophical interpretation may be shown to depend on the view that is taken of the nature of explanation. Explanation, in its most general sense, means, for science, the statement of a fact in its simplest terms, so that it can be assimilated to other facts and included as a case of what we call a general law. In Professor Bain's words, 'mystery means isolation'. We are said to 'understand' a fact when we are able to regard it as a particular example of a mode of happening already known to us. Explanation also means, in scientific usage, a statement of the conditions of the occurrence of any fact. Such causal explanation, as it is often 
called, consists in the discovery of some antecedent set of circumstances on which the given phenomenon follows and on which it appears to depend. The typical attitude of the scientific investigator is, as Professor Lloyd Morgan puts it, ' 'this retrospective outlook towards antecedent conditions,' the attempt to give the history of things, and, if possible, to trace them back to their beginnings. Explanation in this sense is therefore essentially explanation of the later by the earlier, an interpretation, as Spencer puts it, of 'the more developed by the less developed'. But it is important to remember that such explanation professes to be in the end no more than a description, in as simple and general terms as possible, of the way in which things happen, or the characteristic ways in which reality behaves. These ultimate modes of behaviour have to be taken for granted, in the sense, for example, that the law of gravitation summarizes one whole range of phenomena, 'but no one knows why two ultimate particles influence each other's motion.' " But if the ultimate modes of behaviour have thus simply to be accepted and described, a serious danger may lurk in this method of explaining facts exclusively by reference to their antecedents. The method may be unimpeachable in a science like mechanics or molar physics, where the facts with which we are dealing are all of the same order-transformations of matter and motion. Here the present configuration of the facts may be treated without danger of misconception as the mathematical resultant of its antecedents. There is equivalence just because there is no real gain in the process; there is change, but no advance, nothing new. Everything

In his little volume, The Interpretation of Nature, p. 9.

' Karl Pearson, Grammar of Science, p. 145. Hence, Du Bois-Reymond, in his essays emphasizing the limits of our knowledge of nature (Die Grenzen des Naturerkennens and Die sicben Welträthsel), treated the nature of matter and force as the first of the world-riddles before which the human mind is condemned to stand with the confession 'Ignoramus et Ignorabimus'. 
remains on the same level. But in the biological sciences, where the phenomenon of growth is fundamental, and in the region of the historical generally-wherever, in short, there is a real evolution-the question at once arises whether the 'retrospective' method of explanation does not inadvertently omit from its account of causation the very feature which distinguishes this mode of change from the dead-level equivalences of physics. The method of interpreting the more developed by the less developed is logically tantamount to a reduction of the more to the less, and, therefore, to a denial of the very fact to be explained. Or if the fact, as a phenomenon, is beyond dispute, it is still robbed of its significance by a method which simply refunds the later stage into the earlier, and equates the outcome of the process with its starting-point. This fallacy is plainly involved in the method, when we pass from one order of facts to another, say, from inorganic nature to the facts of life, or from animal sentience to the conceptual reason and self-consciousness of man. Both life and self-consciousness appear to emerge from antecedent conditions in which these distinctive qualities cannot be detected. But to insist on treating them as no more than the inorganic or non-rational phenomena which form their antecedents is not a legitimate explanation, in the genuine scientific sense of reducing a fact to simpler terms and thereby bringing it into line with other facts. The simplification is effected in this case by a process of abstraction which leaves out the characteristic features of the concrete fact supposed to be explained. It is by a progressive abstraction of this kind, and not by any real process of causal explanation, that we arrive at such a formula of the world-process as Spencer's re-distribution of matter and motion, and imagine ourselves obliged to look on the moving particles of physical science as the ultimate reality out of which all other phenomena are woven by cunning complication. 
This fallacious method of explanation has been very strongly pressed, as we have seen, in the case of life. In the sixties and seventies of last century, controversy raged round the question of the origin of life from the non-living, and then and later the ideal of the majority of physiologists was the expression of organic processes in physico-chemical terms. The extreme unwillingness to recognize in vital phenomena a range of facts with distinctive characteristics of their own must be traced to the idea that such acknowledgement would constitute a breach in the continuity of nature-would be equivalent, in fact, to the admission of special metaphysical causation $a b$ extra, to account for the specific characteristics of the facts. And, to be sure, illadvised theologians found great comfort in the apparent ' gap', which, they urged, manifestly necessitated an act of 'special creation'. The appearance of this deusexmachina increased the suspicion of the Naturalists; and to this must be added the difficulty of stating what has been called the vitalistic hypothesis in terms which shall not seem to imply an extraneously-acting directive force. But with the growth of a calmer temper the irreducible difference between vital and merely physical or merely chemical facts has, as we saw in the preceding lecture, more and more impressed itself upon unprejudiced observers. Perhaps the most striking example of the recognition of this difference is to be found in the chapter on 'The Dynamic Element in Life', added by Spencer himself in 1898 to the revised edition of his Principles of Biology, and containing the frank acknowledgement that 'the processes which go on in living things are incomprehensible as results of any physical actions known to us. . . We are obliged to confess that Life in its essence cannot be conceived in physicochemical terms.'

This transition in nature from one order of facts to another had already been stated by Mill quite simply in 
a chapter of his Logic, ${ }^{1}$ without any fuss or mystery about it; and it is indeed a fact which stares us in the face and forms the basis of the hierarchy of the sciences. It has, however, an important philosophical bearing, and the idea of 'creative synthesis', as it has not inaptly been called, has played a considerable part in recent discussion. The biological term 'epigenesis' has also been generalized to express the same idea of the origin, through synthesis, of features of experience which are essentially new. ${ }^{2}$ Such results of synthesis occur not only at points which mark the transition from one science to another; they are exemplified in such simple experiences as melody and harmony resulting from the combination of musical notes. So Browning finely celebrates the musician's power as lying in this:

That out of three sounds he frames, not a fourth sound, but a star.

${ }^{1}$ Book III, chap. vi, 'On the Composition of Causes.' 'All organized bodies are composed of parts similar to those composing inorganic nature, and which have even themselves existed in an inorganic state; but the phenomena of life which result from the juxtaposition of these parts in a certain manner bear no analogy to any of the effects which would be produced by the action of the component substances considered as mere physical agents.' Hence each science possesses a relative independence in respect of the peculiar nature of the phenomena with which it deals: "The Laws of Life will never be deducible from the mere laws of the ingredients, but the prodigiously complex Facts of Life may all be deducible.from comparatively simple laws of life.'

${ }^{2}$ Epigenesis or creative synthesis in the sense indicated does not necessarily imply, so far as I can see, the pluralism and contingency with which Professor Ward identifies, or at least associates, it. (Cf. The Realm of Ends, pp. 98 and 270: "To the pluralist the so-called evolution of the world is really epigenesis, creative synthesis; it implies continual new beginnings, the result of the mutual conflict and co-operation of agents, all of whom, though in varying degrees, act spontaneously or freely.' 'Here all is history, the result of effort, trial and error; here we have adventure and ultimate achievement.') Pluralism, so understood, may, no doubt, be more easily worked into a theory of epigenesis than into the opposite theory of preformation, with which, indeed, it is flatly irreconcilable. But the idea of epigenesis itself, it seems to me, would be equally applicable to the process of experience, if that process were conceived as the progressive self-revelation of an absolute being. The use of the term does not, therefore, decide the issue which Pluralism raises. 
And if the appearance of life is the most impressive instance of a synthesis which refuses to be analysed into its apparent antecedents, yet men of science, fighting for the idea of the continuity of nature against the theological doctrine of special creation, were not altogether wrong in the stress they laid on the phenomenon of crystallization as similarly inexplicable-if that is the right word to employ in either case-by the unguided forces of gravity and cohesion. There are, of course, important differences between the two cases, and there is the further difference that matter is constantly passing from a non-crystalline to a crystalline structure, and the experimenter can easily bring about the transition by arranging appropriate conditions, whereas, in the case of life, no instance can be shown in nature of the production of the living from the non-living, and the problem has hitherto equally baffled the experimenter. In the early days of Darwinism, the more enthusiastic spirits believed that they were on the eve of obtaining, if they had not already obtained, evidence of such transition. But it was a case of the wish being father to the thought, and more careful analysis has always left things just where they were. The attempt to 'catch nature half-in and halfout', as Hutchison Stirling graphically put it, has invariably failed, and the question of abiogenesis has latterly fallen into the background. ${ }^{1}$ I cannot myself believe that it is of any philosophical importance. The philosophical question is the difference of nature between the two orders of fact, not the question of historical emergence-how or when the one arose from the other or came to be added to it. Even if we were able to show a debatable land between the organic and the inorganic, as we can between the animal and the vegetable kingdoms, and to point to objects which might be classed almost indifferently as the one or the

'Although it was revived by Professor (Sir Edward) Schäfer in his presidential address to the British Association in 1912. 
other, even then the existence of such intermediate or transitional forms would not obscure the fact that we do pass to a new plane or level of existence, qualitatively different and, through that difference, opening up a new range of possibilities to the creatures which it includes.

Philosophy is not interested, therefore, in speculations like those of Lord Kelvin as to the origin of life upon our globe from germs carried to it by meteorites from other parts of space. This slightly grotesque hypothesis would at best only throw the difficulty a little farther back; and, after all, if we are not to think in quite primitive terms of a creator, at some point in the history of this globe or of other globes, manufacturing the first cells, as it were with hands, what other view can we take, so long as we think in terms of time-sequence, than that somewhere and at some time, under a convergence of appropriate conditions, life supervened upon a hitherto inorganic nature? But the fact that science finds absolute origination an insoluble problem in every department of investigation should at least suggest to us as philosophers that there must be something wrong with this whole method of attacking the subject. To the great philosophers this aspect of timesuccession has seemed in the main irrelevant. In the wellworn phrase, philosophy contemplates the world sub quadam specie aeternitatis. There may be a sense in which to do this is to avert one's gaze from the concrete world and to embrace an abstraction in its stead. But in its present application the phrase means that what philosophy primarily seeks to exhibit is the character or essential structure of the. universe, and that that character can only be held to be given when we keep in view the whole range of its manifestations, and relate these manifestations to one another according to their intrinsic nature-which may prove to be also a relation according to a scale of value or worth. But the intrinsic nature and the value of any phase are not altered 
in the least by its appearance sooner or later in a particular time-series; and therefore the latter question is strictly indifferent to philosophy, which is interested in the phase simply as a revelation, so far forth, of the real nature of the world, and thus an element helping to determine the final answer which it seeks.

We need have no difficulty, therefore, in agreeing with Professor Lloyd Morgan ' when he repudiates as unphilosophical the idea of 'a supernatural hiatus between the inorganic and the organic', and combats the conception of Vital Force as 'something outside the recognized course of nature', introduced to bridge this particular chasm and account for the peculiarities of the new order of phenomena. But if Vitalism means simply that 'living matter has certain distinctive properties'; if we use the term vital in a descriptive rather than a causal sense to denote a peculiarity of behaviour ' which is found nowhere else in nature', and which we cannot assert is 'anywhere foreshadowed in the inorganic sphere', then no objection, he allows, can be taken to the term. But in principle, he urges, the term Vital Force is, in that case, on the same footing as gravitative force, chemical force, crystalline force and similar terms; for ' no one has yet been able to show how certain observed modes of attraction can be developed out of others. . . . A candid and impartial inquiry into the facts enables us to realize that under these or those assignable conditions new modes of attraction supervene-modes which with our present knowledge no one could have foretold, since in science it must not infrequently suffice to be wise after the event.' Hence, he concludes, we must generalize our position, and if we speak of ' forces ' in connexion with these different groups of phenomena, they must all alike be regarded, not as implying at any point what has been called

'In his articles on 'Biology and Metaphysics' and 'Vitalism' in The Monist, vol. ix (January and July 1899 ). 
' an alien influx into nature', but as 'differential modes of manifestation of the self-existent Cause'.

Professor Lloyd Morgan expresses his conclusions much in the same terms as Spencer (to whose new chapter in the Principles of Biology he refers), and one might easily criticize his conception of the relation of science and metaphysics as dealing respectively with 'the realities of experience' and 'the sphere of noumenal existence'. His phraseology is also occasionally grudging in its seeming unwillingness to recognize the relatively greater step from the non-living to the living than from any one phase of inorganic nature to another. But, in principle, I take his contention to be sound on the two points of immanence and continuity. The argument which he presents from the scientific side is, indeed, essentially the same as that presented from the metaphysical side by Professor Bosanquet in his recent volume of Gifford Lectures. In his chapter on 'The Bodily Basis of Mind', Professor Bosanquet does not hesitate to apply the same principle to the perhaps still more crucial case of the appearance of consciousness and the genesis of souls. 'We may smile', he says, ' at the simplicity of the materialist who could explain consciousness as an effect of material combination'; yet it is important 'to emphasize the idea of a being essentially connected with or even founded upon its environment (past as well as present), to which, nevertheless, or out of which, it brings a principle of unity. . . . Instead of a self-subsistent eternal angelic being, we should thus be led to conceive of the soul as-to adapt a phrase of Lotze-a perfection granted by the Absolute according to general laws, upon certain complex occasions and arrangements of externality. . . . And we must bear in mind that, in the end, this being granted by the Absolute upon a certain combination is all that any connexion, any form of causation or inherence can mean.' In such a view, he claims, 'there is nothing whatever materialistic or 
unspiritual,' since 'in apparent cosmic development, whether inorganic, organic, or logical, the rule is for the stream to rise higher than its source'.'

Let me take one more example of what I mean by the transition from one order of facts to another, or from one plane of experience to another-the passage from the merely animal life of semi-passive perception and association to the distinctively human level of the active conceptual reason. The having of general ideas', says Locke in a wellknown passage, "is that which puts a perfect distinction betwixt man and brutes, and is an excellency which the faculties of brutes do by no means attain to.' 2 This is just the kind of passage which the average evolutionist with a negative bias in his thinking is apt to set down as a piece of antiquated theological prejudice. If evolution has proved anything, has it not proved that there is no such qualitative distinction between human reason and the lower ranges of animal intelligence? The whole thing is a question of degree-of advance by insensible gradations, with nowhere any hint of a difference in kind. So, in familiar accents, one can hear the indignant protest. And yet how absolutely true to the facts is Locke's honest report. He is talking, in the same context, of the comparison of our ideas one with another, and this is what he says: 'How far brutes partake in this faculty is not easy to determine. I imagine they have it not in any great degree: for though they probably have several ideas distinct enough, yet it seems to me to be the prerogative of human understanding, when it has sufficiently distinguished any ideas, so as to perceive them to be perfectly different, ... to cast about and consider in what circumstances they are capable to be compared, and therefore, I think, beasts compare not their ideas further than some sensible circumstances annexed to the objects

\footnotetext{
${ }^{2}$ Individuality and Value, pp. 189-9I.

'Essay, II. II. 10.
} 
themselves. The other power of comparing, which may be observed in men, belonging to general ideas, and useful only to abstract reasonings, we may probably conjecture beasts have not.' 1 An animal, that is to say, perceives objects, and of course it is aware of differences between the objects it perceives: it distinguishes one object from another. But the whole process is semi-passive; the differences impress themselves upon the mind as upon some sensitive plate. Differences and resemblances between objects are sensed or felt as part of the total unanalysed perception of the objects. The feeling of the differences or resemblances is sufficient to determine the animal's action this way or that; but it does not drive him, as it may drive a man, 'to cast about', as Locke says, 'and consider in what circumstances' the objects differ from or resemble one another. By this deliberate active comparison we define to ourselves the precise points of agreement or differencewe isolate them from the general context of the objects as sensed or perceived-we frame, in fact, a concept, a general or abstract idea. In this power of abstraction or, as we now more commonly say, in the conceptual reason-in the grasping by the mind of an idea which does not exist as an object of sense at all-Locke rightly saw the differentia of human intelligence, and he was also right, in connecting with it the use of words as general signs.

Apply this to the idea of causal connexion which lies at the basis of our scientific knowledge. Hume explains this idea as a habit of expectation generated by the repeated sequence of two events in the past. Now that is exactly the length we may suppose the animal mind to go-automatic association of two events through their repeated conjunction in the past-and you can guide a whole life by the habits of expectation thus generated. And yet the animal does not possess the idea of cause in the strict sense

${ }^{1}$ II. II. 5. 
at all-the general idea of connectedness or the dependence of one event upon another. To realize that idea is to form the first conception of an independent world-an independent system of definitely connected facts. It contains in itself all the potentialities of science; and the birth of reason in the individual, if we may so speak, is just the moment when repeated conjunctions suggest to the mind this idea of the connectedness, the interdependence, of the two phenomena. To the mind that remains on the animal plane, frequent repetition produces a firm association between two facts, firm habits of expectation; but if the customary sequence should be interfered with, if expectation should be baulked, that will mean only a feeling of discomfort; and if such disappointments occur frequently, the automatically generated habit of expectation will as automatically tend to disappear. To the incipient human intelligence, on the contrary-to the mind that has once grasped the general idea of causal dependence-the nonoccurrence of an expected effect sets the mind at once actively to work, to find out the reason of the non-occurrence, to find out what counteracting cause has been present to defeat expectation in this particular case. Obviously these two minds move on quite different levels.

But here again there is no need to entangle ourselves in the vexed question as to where precisely association ends and reason begins-as to whether there may not be instances of conscious process in the lower animals which deserve the name of reason in the full sense. The animal mind and the human mind, as I have used the terms, are to be taken as types, ideal stages of mental development. Nor need one minimize in the least the continuity of the process by which the one seems to pass, almost at a touch, into the other. But it is a case of 'the little more and how much it is, and the little less and what worlds away'. To cross this ideal line means to reach the notion of objectivity and 
truth on which science is built; it means morality, art and religion, and all the possibilities of human history. Can anything be more futile, then, than to ignore the qualitative distinction between the one range of mind and the other? When the dog develops a system of astronomy or the cow pauses on the hill-top to admire the view, we shall gladly welcome them to the logician's company of ' rational animals'; but, till then, the wise man will be content to recognize a difference which is real.

Continuity of process and the emergence of real differences-these are, in short, the twin aspects of the cosmic history, and it is essential to clear thinking that the one be not allowed to obscure the other. And whereas, formerly, the magnitude of the differences led to static or typical conceptions of separate species and (as in our last instance of the human and animal mind) to the assertion of a sheer discontinuity between the one stage and the other, so more recently the evolutional study of intervening forms and the accumulation of minute differences has made us realize so vividly the extremely gradual steps by which nature engineers her advances that, as Professor Ward puts it, " we are inclined to imagine either that there is no problem at all, or that, if there is, the problem is solved '.${ }^{1}$ Or in the words of Hume, which he aptly impresses into his service, "the passage is so smooth and easy that it produces little alteration in the mind. The thought glides along the succession with equal facility, as if it considered only one object, and therefore confounds the succession with the identity.' Continuity may be inconsistent with 'breaks', if we define a 'break' as a 'chasm' or 'an alien influx into nature'. But if we take the facts as they stand, without importing a theory into the word, we may say with the late Professor Wallace that 'all development is by breaks

'Naturalism and Agnosticism, ist ed., vol. i, p. 260. 
and yet makes for continuity' '. But the word, so used, will mean simply the acknowledgement of what I have called the emergence of real differences in the course of the process - actual 'increments' or 'lifts' in the process, where quantity may be said to pass into quality, difference of degree into difference of kind. Such crises, as it has been well said, ${ }^{2}$ are "greater in their implications than in the actual moment'; they are points after which everything seems to 'move in a new dimension'. But it is neither necessary, nor is it possible, to fix such points as definite dates in an historical sequence. The very nature of time forbids the translation of philosophical analysis into literal history.

It is instructive to note that all the 'world-riddles' of Du Bois-Reymond's once famous book, ${ }^{3}$ or all at least after the first, concern the origin of the differences or increments which mark the successive steps of the evolutionary process. After the first incomprehensibility of the nature of matter and force ${ }^{4}$ comes the origin of movement, then the origin of life and what appears to be purposive adaptation, then the origin of sentience, and finally the origin of rational consciousness and will. Each transition is one of the eternal "limits" set to our knowledge of nature, in regard to which the confession of Science must be a perpetual 'Ignorabimus'. As he puts it in one of the instances, 'it is not merely the case that, in the present state of our knowledge, consciousness is inexplicable from its natural conditions, but in

${ }^{1}$ Prolegomena to Hegel's Logic, second edition, p. 476. 'The reader of the Divina Commedia', Professor Wallace finely says, 'may hardly need to be reminded that, at each of the grander changes of scene and grade in his pilgrimage, Dantc suddenly finds himself without obvious means transported into a new rcgion of experience. There are catastrophes in the process of development: not unprepared, but summing up, as in a flash of insight, the gradual and unperceived process of growth."

${ }^{2}$ Professor J. Y. Simpson's Spiritual Interpretation of Nature, p. 13I.

- Die sieben Welträthsel, published in 1880.

4 Already referred to on p. 92. 
the nature of things it never can be explicable from these conditions.' Inexplicable, certainly, we might reply, from these conditions, if they are substantiated as self-existent in their purely physical aspect. Each new fact in turn must be sheerly unintelligible if we take our stand at the stage below, and if, in the last resort, we treat 'the mechanics of the atom' as the ultimately self-existing fact, out of which everything else is somehow to be conjured and so explained. And, in spite of his criticism of the atoms as philosophical fictions, Du Bois-Reymond is still dominated by the conception of matter, defined by its purely physical qualities, as the independently real substructure of phenomena.

It was this, too, that lent the sting to Tyndall's celebrated statement, in his Belfast Address of 1874 , that he felt compelled by an intellectual necessity to discern in matter 'the promise and potency of all terrestrial Life'. When we look back upon the passage and read it in its context, with its quotations from Lucretius and Bruno-when we note the use of the vague term "nature', the reference to 'latent powers', and the insistence on the continuity of nature as the chief point of the contention-the position appears neither so dangerous nor so unphilosophical as it did to those who first heard it. It appeared to them, in the controversial language of the day, 'material atheism', because they understood by matter the matter of the physicist as a prior self-existing fact. And that is the danger and, one may still say, the falsity which lurks in Tyndall's way of putting the truth he intends. If we take matter in anything like its accepted meaning, then our attempted explanation breaks down at every successive stage in the evolutionary process; if, on the other hand, we endow matter with 'the promise and potency, of all that eventually crowns the process, the word loses all definite meaning. Contemporary critics did not fail to point out that Tyndall's matter, in virtue of the powers attributed to it, was really 
indistinguishable from spirit, or, as Coleridge said in a similar connexion, 'a something-nothing-everything which does all of which we know'.' It becomes, indeed, simply the notion of potentiality as such-perhaps the most slippery term in the whole vocabulary of philosophy. If it is the complete or final fact which we wish to explain, and if, as we have seen, explanation can only mean accurate description or analysis of the nature of the fact, it is clear that it can serve no useful purpose-it must, indeed, be fundamentally misleading-to say that characteristics which, according to the very meaning of the terms, are not exhibited by the atoms and molecules of the physicist, are potentially present in these particles as such. To insist in this way on regarding the later stages as existing preformed, so to speak, in the bare beginning is, as we have seen, to ignore the true nature of the evolution-process, as characterized by the emergence of real differences and the attainment of results which transcend the apparent startingpoint. It is only in so far as we connect the physical with the vital and the conscious, as stages of a single process, that we can speak, with even a show of intelligibility, of the physical as containing the potentiality of all that is to follow. The philosophical meaning of potentiality is, in short, simply the insight that, in the interpretation of any process, it is the process as a whole that has to be considered, if we wish to know the nature of the reality revealed in it. In other words, every evolutionary process must be read in the light of its last term. This is the true meaning of the profound Aristotelian doctrine of the Telos or End as the ultimate principle of explanation. As $I$ have put it on a previous occasion-'All explanation of the higher by the lower is philosophically a hysteron-proteron. The antecedents assigned are not the causes of the consequents, for by antecedents the naturalistic theories mean the antecedents

' Biographia Literaria, chap. vii. 
in abstraction from their consequents-the antecedents taken as they appear in themselves, or as we might suppose them to be if no such consequents had ever issued from them. So conceived, however, the antecedents (matter and energy, for example), have no real existence-they are mere entia rationis, abstract aspects of the one concrete fact which we call the universe. . . All ultimate or philosophical explanation must look to the end. . . . If we are in earnest with the doctrine that the universe is one, we have to read back the nature of the latest consequent into the remotest antecedent. Only then is the one, in any true sense, the cause of the other.' 1

It is worth observing that the same apparently inveterate tendency to obliterate the distinctions between different ranges of experience may be seen asserting itself afresh in the relation of biology to psychology and sociology. Just as the long-established ascendancy of physical science has hindered the recognition of the autonomy of the science of life, imposing upon the biologist a foreign ideal, as if physical conceptions alone were ultimately valid-their de facto inadequacy in dealing with vital phenomena being attributed not to the characteristics of the subject-matter but to the biologist's (so far) imperfect analysis-in a similar fashion the prestige of biology has led within recent years to the wholesale application of biological conceptions and theories to the facts of mind and society. I do not wish to deny-I would, on the contrary, emphasizethe stimulus which psychology and sociology, as well as general philosophy, have derived from contact with the great biological movement of the last half-century. The biological analogies and metaphors are, in general, far more instructive than the physical conceptions which they replaced, and the restatement has made many phases of mental development more intelligible. But here again

'Man's Place in the Cosmos, pp. II-12. 
autonomy must be respected. Consciousness brings into view a new range of facts and values; and to suppose that biological categories can be more than suggestive analogies in the new sphere is once again to obliterate the distinctive characteristics of the facts which it is sought to describe. Loose talk about natural selection and the social organism will not solve the problems either of mental or of social science. A new order of facts demands its own conceptions in terms of which it may be described and systematized. ${ }^{1}$

From the philosophical point of view, therefore, explanation is essentially an affair of categories. Correct explanation depends in any department on the employment of appropriate categories, and philosophy consists in an insight into the relation of the categories in question and the realm of facts which they describe, to other categories and other realms or aspects of reality. We must have some notion of their significance in an account of the nature of the universe as a whole. The function of philosophy is, in this connexion, comparable to that of a "Warden of the Marches' between the various sciences, resisting the pretensions of any particular science to be the exclusive exponent of reality and assigning to each its hierarchical rank in a complete scheme of knowledge. For if, as men of science tell us, scientific explanation is in the end description, the same is ultimately true of philosophy itself. Philosophy, or perhaps I should qualify the statement and say, sane philosophy, is not really the quest of some transcendent reason why the nature of things is as it is; it does not attempt, in Lotze's phrase, to tell us 'how being is made'. 'All that can be asked of philosophy', I ventured to say in my first volume, published more than thirty years ago, 'is, by the help of the most complete analysis, to present a reasonable synthesis of the world as

'Cf. Ostwald, Natural Philosophy, p. I40 (English translation); Geddes and Thomson, Evolution, p. 23I. 
we find it. The difference between a true and a false philosophy is that a false philosophy fixes its eye on a part only of the material submitted to it, and would explain the whole, therefore, by a principle which is adequate merely to one of its parts or stages; a true philosophy, on the other hand, is one which "sees life steadily and sees it whole"- - whose principle, therefore, embraces in its evolution every phase of the actual.'

'The Development from Kant to Hegel, p. 66. 


\section{LECTURE VI}

\section{MAN AS ORGANIC TO THE WORLD}

- IT is as between human intelligence and its antecedent conditions that the idea of a chasm or absolute break is most deeply rooted, both in philosophy and in ordinary thought. A variety of causes have contributed to create and perpetuate the impression. But if we consistently apply in this case the twin principles of continuity and immanence, and steadily refuse to characterize the nature of the world till we have all the available facts before us, some of the most persistent difficulties of modern thought will be found, I think, to disappear. The nature of the power at work in any process, I urged in the preceding lecture, is only revealed in the process as a whole. It is revealed progressively in the different stages, but it cannot be fully and truly known till the final stage is reached, and it must inevitably lead to error if we substantiate any of the stages as something complete in itself and existing by itself. Now man-human knowledge and experience generally - is, from this point of view, the last term in the series, and the world is not complete -without him. When I say the last term in the series, this does not involve any arrogant claim on man's part to 'set himself', in Locke's words, 'proudly at the top of all things'; in other mansions of the universe, as Locke quaintly puts it, " there may be other and different intelligent beings, of whose faculties he has as little knowledge or apprehension as a worm shut up in one drawer of a cabinet hath of the senses or understanding of a man.' ${ }^{1}$ Man him-

${ }^{1}$ Essay, II. 2. 3 It is probably an unconscious reminiscence of this passage, when Huxley says (in a more sceptical interest) that we may be set down in the midst of infinite varieties of existences which we are not competent so much as to conceive- with no more notion of what is 
self, as we know him, assuredly represents, as the poet says, the dawn and not the day. ' Yet, whatever heights beyond heights may open above us, intelligence is in principle one, and it is the emergence of intelligence, that is to say, of beings with powers of knowledge and appreciation and selfdetermination, which supplies the final term, the goal or consummation of the evolutionary process. It is not, in short, with man specifically, as the historical denizen of this planet, that we have to do, but with man as rational, in however humble a degree. And my contention is, as expressed in the title of this lecture, that man is organic to the world; or as $I$ have just put it, the world is not complete without him. The intelligent being is, as it were, the organ through which the universe beholds and enjoys itself.

This is, of course, a well-known position of speculative idealism, but $I$ wish to present it, in the first instance at any rate, rather from the side of the higher naturalism, and to emphasize the fact of man's rootedness in nature, so that the rational intelligence which characterizes him may appear as the culmination of a continuous process of immanent development. I desire to do so because it has always seemed to me that some of the central difficulties of modern thought arise from the unconscious habit of treating man as if he were himself no denizen of the world in which he draws his breath-as if he were, so to say, a stranger visitant, contemplating $a b$ extra an independent universe. Otherwise why, for example, should it seem so difficult-nay, impossible, as so many philosophers would persuade us-for man to know things as they are? why should it be impossible for him to know the real nature of anything, or, in the last resort, to know anything but his own states? The so-called epistemological problem which obsesses modern philosophy, from Descartes and Locke to Kant and Spencer and the

about us than the worm in a flower-pot on a London balcony has of the life of the great city' (Hume, p. 286).

'Tennyson, 'The Dawn'. 
most recent magazine discussions-this problem, with all the varieties of subjective idealism, agnosticism, phenomenalism, and sceptical relativism to which it has given rise, depends upon the presupposition of a finished world, as an independently existing fact, and an equally independent knower, equipped, from heaven knows where, with a peculiar apparatus of faculties. This subjective apparatus, brought to bear upon the foreign object, colours and distorts it by investing it with its own subjective peculiarities, and so the mechanism of knowledge inevitably defeats its own purpose. Do what we may, our faculties get between us and the things, and we never know anything as it really is. As Locke sighs, we know not the real essence of a pebble or a fly or of our own selves.

This persistent mystification depends largely, I urge, upon extruding man from the world he seeks to known If we keep steadily in view the fact that man is from beginning to end, even qua knower, a member and, as it were, an organ of the universe, knowledge will appear to us in a more natural light, and we shall not be tempted to open this miraculous chasm between the knower and the realities which he knows. When one thinks of the labour and ingenuity expended upon this problem during the last three hundred years, it is easy to understand the impatience of the Pragmatists with the whole discussion. It is, indeed, encouraging to note that both the most recent movements in Britain and America-Pragmatism and the so-called New Realism-seek, each in its own way, to rid philosophy of a self-made difficulty and to transfer discussion to more fruitful topics. "Things are what they are experienced as,' says Pragmatism bluntly ; ${ }^{\mathbf{1}}$ knowledge is a direct relation between the knower and the reality known, says Realism - it is 'sui generis and as such cannot be explained', for explanation, in the sense of resolving it into simpler elements, could only mean falsification of the fact. ${ }^{2}$

1 Dewey, Influence of Darwin on Philosophy, p. 227.

'Cf. Prichard, Kant's Theory of Knowledge, p. II5. 
I would merely add, as a reason for dwelling on this point, that, if the imputation of subjectivism and relativity attaches with any justice to the seemingly objective constructions of our knowledge, it will apply with even greater force to the world of values in which our inmost and most personal nature finds expression. If man's knowledge does not put him in touch with reality, how can his ideals be supposed to furnish a clue? They will be treated as exotics, too delicate or, according to the critic's mood, too sickly for the common soil and the common air of the world. Whence, in that case, the seed was wafted and by what agencies it was nursed to maturity, such critics do not too narrowly inquire.

A further consequence of this view of intelligence as spectator $a b$ extra is that the function of intelligence is conceived as purely cognitive, in the sense of simply reproducing or mirroring an independent, finished reality. Even speculative idealism, under the dominance of the eye-metaphor, sometimes falls into a similar mode of expression. 'I am the eye with which the universe beholds itself' seems an apt expression for a divine experience, conceived on purely theoretic lines somewhat in Aristotle's fashion. But if it were simply reproduction as in a still mirror, we might reasonably ask, with Lotze, what point or value such a 'barren rehearsal' could possess. To Aristotle, the contemplation of which he speaks is not a passionless duplication of existence, but an experience of intensest fruition; it is the supremely blessed life. The word cognition misleads us by its exclusive reference to the object as something external; we forget that cognition is an experience of the soul, and as such has necessarily its feeling-value. We forget that the existence of such living centres, capable of feeling the beauty and grandeur of the world and tasting its manifold qualities, is what is really significant in the universe. To a collocation of purely unconscious facts it would be impossible to attribute any value either collectively or individually. All values 
are, in this sense, conscious values. Hence it is that the sentient and, still more, the rational being appears as the goal to which nature is working, namely, the development of an organ by which she may become conscious of herself and enter into the joy of her own being. Or, as Browning more finely puts it in Paracelsus:

God tastes an infinite joy

In infinite ways. . . .

... The wroth sea's waves are edged

With foam, white as the bitten lip of hate,

When in the solitary waste, strange groups

Of young volcanos come up, cyclops-like,

Staring together with their eyes on flame;-

God tastes a pleasure in their uncouth pride! . . .

The shining dorrs are busy; beetles run

Along the furrows, ants make their ado; . . .

Afar the ocean sleeps; white fishing-gulls

Flit where the strand is purple with its tribe

Of nested limpets; savage creatures seek

Their loves in wood and plain-and God renews

His ancient rapture!

It is this living experience, steeped in feeling and instinct with action, which is the real fact in which cognition, as such, is but an element. And, in the case of man, such experience means the building up of a mind and character. There is no virtue in the mere repetition, in the subject, of an independent object: the function of cognition in experience is either to subserve our practical activity or to awaken insights of beauty, the sympathetic thrill of kindred being and. the pure joy of intellectual conquest and harmony. ${ }^{1}$.

${ }^{2}$ The idea of intelligence as purely cognitive seems to be consistent only with the epiphenomenal or automaton theory of consciousness. On that theory mind is simply the inactive and useless mirror of an independent happening. And, as a matter of fact, Shadworth Hodgson's expressions, in his exposition of the theory, are the best examples that could be cited of the view of consciousness which I am repudiating. 'Pain', he says consistently, 'must be held to be no warning to abstain from the thing which has caused pain; pleasure no motive to seek the thing which has caused pleasure; pain no check, pleasure no spur, to 
The more we allow our thoughts to play freely on the idea, the more extraordinary appears the substantiation of the knower into a being outside the world he desires to know, and the treatment of the two as separate and independent facts which have a merely contingent relation to one another. Yet this is just the dualism of the res cogitans and the res. extensa with which modern philosophy starts in Descartes, and from which, in many quarters, it has not even yet emancipated itself. The two facts, as I have said, are conceived as having no organic relation to one another; the one is in no way the complement of the other, in such fashion that the being of things naturally passes over into consciousness and finds expression there, while (from the other side) the conscious being as naturally reads the face of a world which he feels to be continuous with his own being. The process of knowledge accomplishes itself, as a matter of fact, with perfect simplicity and naturalness; but philosophers have dug a chasm which cannot be bridged between the knowledge of the knower, conceived as a state of his own being, and the real thing which he knows, or rather fancies he knows. For if there is no essential relation between the two facts, such as would constitute them no longer two unconnected facts, but two elements in one single fact-if they are taken as really brought, so to speak, into accidental contact with one another-what guarantee is there that my knowledge represents things as they really are? Is that possibility not rather excluded $a b$ initio? For I can know things only as they appear to me through the medium of my bodily and mental organization; my knowledge, therefore, must inevitably be merely phenomenal, merely relative. On one side of the chasm we thus get the thing-in-itself, the thing as it is supposed to exist apart from being known, action.' Consciousness when it arises, he says, is ' not a new existence but the perception of the pre-existing world', 'nothing but a mirror or reduplication of the pre-existing and simultaneously existing world'. (Theory of Practice, vol. i, pp. 338, 339, 416.) 
which is eventually described, with perfect consistency, as the unknown and unknowable; and on the other side of the chasm we have a subjective modification, which is as a veil between us and the object rather than a revelation of its real nature. Because we began by denying any real relatedness between nature and mind, we end with the doctrine of the relativity of knowledge. Relatedness means continuity of process and truth of result-knowledge and reality as complementary elements of one system. Relativity, in the current sense of the term, means a finished world of fact complete in itself, but subsequently brought into contact with (what would almost seem to be) some extra-mundane creature in whom it produces certain effects. But these effects, being conditioned mainly by the creature's curious constitution, must be held to reveal rather the nature of the creature than the nature of the world which started the process of which they are the outcome.

The vitality of the doctrine of the relativity of knowledge -which is as much as to say the truth it contains-is entirely derived from its polemic against a wrongly-stated Realism, and against the copy-theory of truth, which our present-day pragmatists have made the object of their attack. The copy-theory, on the basis of the traditional philosophical dualism, defends what it calls the 'correspondence' of knowledge with reality. In that correspondence it finds its definition of truth. It is easy, of course, to put a sense upon the phrase which would remove any objection to such a definition; but correspondence, for the copy-theory, means such a relation as obtains between a picture and the object which it represents. In some such way the independent world of things, with their qualities and relations, is supposed to be reproduced in the knowing mind. We witness in Locke and Berkeley the break-down of this theory. Locke still clings to the theory in the case of the primary qualities: their ' patterns' do really exist in the things quite apart from 
our knowledge of them. But he abandons it in the case of the secondary qualities; the latter exhibit only such correspondence or conformity as exists between a cause and its effect. They are true in so far as they are the effects which things, in virtue of modifications of their primary qualities, are fitted to produce in us. They are the effects which God has arranged that things should produce, when acting on our sensibility. ${ }^{1}$ Berkeley's philosophy is a criticism of this compromise. The primary qualities are as much ideas of sense, he argues, as the secondary: where the secondary are, there the primary are also, namely, in the mind. The notion of an idea being 'like' some original in a non-mental world is transparently absurd, inasmuch as the comparison required to ascertain such likeness is inherently impossible; an idea can only be like an idea. Our whole sense-experience, therefore, is treated by Berkeley, as Locke treated the secondary qualities, namely, as a series of effects produced in the individual mind-produced, however, not as Locke assumed by an independent world of material substances, but by the immediate causation of the divine will. There is therefore no relation between knowledge and an external or trans-subjective reality which it has in some fashion to copy or represent. Knowledge is entirely an internal experience, and our sense-ideas and their relations of concomitance and sequence, being taken as the immediate inspiration of the Almighty, are themselves the only originals we require. Berkeley's world, apart from his theistic postulate, is, in fact, in William James's phrase, 'a world of pure experience', in which one part points cognitively to other parts, but which does not point as a whole to any extra-experiential world on which it rests or which it somehow renders to us. Conclusive as a criticism of the ordinary correspondencetheory, Berkeleianism is vitiated by the fact that it takes as its starting-point and basis the fundamental tenet of repre-

${ }^{1}$ Essay, II. 30. 2. 
sentationism, the presupposition that the primary or direct object of knowledge is a state of our own mind. And if this is the very reverse of the truth, it follows that what is true in Berkeley's way of putting things must be re-stated in a form which will not conflict with the realism of our common-sense beliefs. Berkeley is always elaborately anxious to persuade us that he is in agreement with 'the vulgar', but neither he nor any of his interpreters or successors has succeeded in convincing the world that this is really the case.

The Kantian theory is in some respects a return to the position of Locke. There are, of course, too many strands in Kant's doctrine to admit of its being presented as a consistent whole; but if we take it as it originally shaped itself in his own mind, we find a strong reassertion of the reference in knowledge to real things. This is at once an initial assumption and, in the face of misunderstanding and challenge, an explicit polemic against subjective idealism of the Berkeleian stamp. Kant resembles Locke also in starting with the acceptance of the representative theory of knowl"edge, the view, that is to say, that we are primarily limited to a knowledge of our own states. In his own words, we know ' only the mode in which our senses are affected by an unknown something '. As Hutchison Stirling puts it, ${ }^{2}$ the scratch only knows itself; it knows nothing of the thorn. But whereas Locke applied this causal method of interpretation only to the secondary qualities, the primary qualities are also treated by Kant as subjective for a different reason, seeing that he regards space, and consequently the geometrical or space-filling qualities of bodies, as a contribution of the mind in the act of knowing. But if both primary and

${ }^{1}$ Prolegomena, section 32. 'It is incomprehensible', he explains elsewhere (Prolegomena, section 9), 'how the perception of a present object should give me a knowledge of that object as it is in itself, seeing that its properties cannot migrate or wander over (hinüberwandern) into my presentative faculty.'

${ }^{2}$ Textbook to Kant, p. 353 . 
secondary qualities are thus subjective constructions, the real object which we set out to know remains on the farther side of knowledge as an unattainable Beyond-the abstraction of an unknowable thing-in-itself. This is the aspect of the Kantian theory of knowledge which made his doctrine one of the fountain-heads of modern agnosticism. In consequence of our ignorance of this real background, our knowledge is throughout a knowledge only of phenomena. The world of experience, whether of ordinary life or of scientific theory, is, for Kant, either a quasi-Berkeleian world of sense-ideas, connected together by the rational bonds of the categories instead of by the associational forces of custom; or it is the distorted vision of a reality, the fact of whose existence is an immediate certainty present in all our experience, but whose nature that experience is essentially impotent to reveal. Reality on this view is the ultimate subject of predication, but all our predicates only draw more systematically round us the veil of our own subjectivity.

Popular philosophy may be said to oscillate between an agnostic relativism based on such considerations, and a semiLockian view apparently sanctioned by the teaching of physical science and physiological psychology. We come back in such thinking to the old distinction between the primary qualities, as constituting the real nature of the objective fact, and the secondary, as subjective effects dependent upon the specific constitution of our organs of sense and nervous structure generally. We return, in short, to the conception of the physical scheme of moving particles or ethereal vibrations of varying amplitudes and speeds as the self-subsisting world, and all the rest as passing appearances to finite subjects. But this is practically to adopt the fundamental presupposition of materialism.

The crux of the philosophical question thus becomes the objectivity of the secondary qualities-whether, or in what 
sense, they are to be taken as objective determinations of reality. In one sense, of course, every one would admit their objectivity, in so far as they have in each case their physical counterpart, in the shape of some specific arrangement of molecules or some specific form of motion. But, according to the popular scientific view which we are considering, that molecular mechanism gives us the truth of nature. It is nature as an objective system; whereas our translation of the mechanism into terms of sensation is a subjective process. The results of that process may be of much interest to $u s$, because of the feeling-tone of the secondary qualities and their intimate connexion with the higher emotional life; but they are not, as such-as colour, for example, or as sound-predicable of nature in the same way in which the physical properties are. There is a fine chapter in Lotze's Mikrokosmos, ${ }^{1}$ in which he enters an eloquent protest against the stereotyped error of supposing that we come nearer the truth of reality when we abstract in this way from the conditions under which it is revealed to us-when we seek that truth not in the appearance of the world as it offers itself to the knowing mind, but in the stage-mechanism which effectuates this result. "Instead of setting up the external as the goal to which all the efforts of our sensation are to be directed, why should we not rather look upon the sensuous splendour of light and sound as the end which all these dispositions of the external world, whose obscurity we deplore, are designed to realize? What pleases us in a drama that we see developed before us on the stage is the poetical Idea and its inherent beauty; no one would expect to enhance this enjoyment or discern a profounder truth if he could indulge in an examination of the machinery that effects the changes of scenery and illumination. . . The course of the universe is such a drama; its essential truth is the meaning set forth so as to be intelligible to the spirit. The other in

${ }^{2}$ Book III, chap. iv, 'Life in Matter'. 
which, deceived by prejudice, we seek the true being of things, is nothing but the apparatus on which depends that which alone possesses value, the reality of this beauteous appearance. . . . Let us therefore cease to lament as if the reality of things escaped our apprehension; on the contrary, their reality consists in that as which they appear to us; and all that they are before they are made manifest to us is the mediating preparation for this final realization of their very being. The beauty of colours and tones, warmth and fragrance, are what Nature in itself strives to produce and express, but cannot do so by itself ; for this it needs as its last and noblest instrument the sentient mind, which alone can put into words its mute striving and, in the glory of sentient intuition, set forth in luminous actuality what all the motions and gestures of the external world were vainly endeavouring to express.'

Common sense clearly takes this view, and rejects the cheap profundity of popular science. Colours and sounds are for it not merely sensations or internal states; they are unmistakable predicates of the real. And a better psychological analysis bears out this presupposition. When the psychologist introspectively analyses what he calls the sensation of red, what he is really analysing is the process of perceiving a red object. Red, as a conscious fact, is from beginning to end a quality of objects. Just consider for a moment what the world would be if it were stripped of the secondary qualities; remove the eye and the other senses and what remains? As Stirling vividly puts it, taking as his instance the astronomical spectacle of the heavens: 'All that is going on, all these globes are whirling in a darkness blacker than the mouth of wolf, deeper than the deepest pit that ever man has sunk-all that is going on, all that is taking place in a darkness absolute; and more ... in a silence absolute, in a silence that never a whisper . . . never the most momentary echo breaks. . . . It is in a cave, 
in a den, blacker than the blackest night, soundless and more silent than the void of voids, that all those intermingling motions of the globes go on-but for us, that is; but for an eye and an ear and a soul behind them.' ${ }^{1}$ It is enough to make this simple reflection to recognize the helpless unreality of the abstraction. As Professor Bosanquet says, 'If the world apart from knowledge has no secondary qualities, it has hardly anything of what we care for. It is not recognizable as our world at all.' ? Moreover, if we are to reject the secondary qualities on account of their dependence on organic conditions, are the primary not in the end in the same case?

I find what I take to be the philosophical truth of the situation put with the simplicity and force of ripe metaphysical insight in the seventh Meditation of the late Professor Laurie's Synthetica. The fundamental point is that which I began by insisting on, that man the knower is within the real system which he knows, and that as regards. his knowledge of nature 'his body is within the naturesystem and continuous with it'. It is good for sanity of thinking to hold fast by the bodily aspect of man's existence; man's cognitive function is exercised through his organism. And, once more, do not let us be misled into treating the organism in turn, as we saw some theories treated the mind and its faculties, as a principle of isolation and subjectivity, cutting us off from the real. Do not let us be misled, I mean, into ascribing the specific qualities of the object as known to peculiarities of our sense-organs rather than to anything inherent in the object itself. Man's organism is the very means by which he is put in relation with reality. Through it the content of the real world is conveyed to him, and through this communication he himself becomes a real subject. For it cannot be too carefully remembered that the

'Philosophy and Theology (Gifford Lectures), p. 78.

${ }^{2}$ Logic, vol. ii, p. 308 (second edition). 
subject is himself a pure abstraction, apart from the real system with which he is in relation and which gives him his mental filling. As Laurie puts it, 'I do not like to say subject is object and object is subject, lest I should be misunderstood; but in truth, the subject, in so far as it is a Real and not a mere entitative potency, is a Real by virtue of the object as reflected into it.' Hence the fact that consciousness of an external object, say, of a cloud, is the final result of a complicated set of processes, partly in external nature and partly within the body of the percipient, does not vitiate the truth of the result. 'On the contrary the process exists for the very purpose of presenting that cloud as I see it, to the subject as conscious.' And the so-called secondary qualities of objects are just as real as space and time are. "When physics has said its last word about that cloud as a dynamical system of molecules and vibrations, that too I shall be aware of only as "related" to conscious subject; and it will be as much "relative" as the cloud in all its summer beauty as seen by the eye of child or poet:that is to say, not "relative" at all. . . For the real is truly to be found in the final presentation to subject; it is in that crisis that the thing gathers up all its causal conditions and prior processes (etheric, dynamic, or what not) and offers itself to us in all the richness of its phenomenal individuality. It is at this point that the bony skeleton of abstract mathematico-physical explanation is clothed with flesh and blood and lives; it is this that touches the emotions of the human breast, and gives birth in poetry and the other arts to the highest utterances of genius regarding our complex experiences.' 1 Thus consciousness, as he puts it almost in Lotze's words, 'provides the last explanatory term of the presentation, Save in a conscious subject the object cannot fulfil itself. . . The world without conscious subject is a world waiting for its meaning-an uncompleted circle wait-

'Synthetica, vol. i, pp. 83-5. 
ing to be closed. . . . Thus it is that the specific characters of our consciousness are the specific characters of the "other" or the object. The former do not merely correspond to the latter: they are the latter as fulfilled in a world which is a "system", and in which, consequently, sentient mind and nature are in organic community."

We get here a Natural Realism, but not of the old type; for this Realism is also a Monism. The older Natural Realism, while it asserts the direct presence of reality to the percipient subject, appears still to hold the two-substance dualism from which the whole mischief flows. Consequently it seems to find a difficulty in reconciling the assertion of a direct and true knowledge of reality with the undoubted fact of process or mediation. Conceiving mind, no less than matter, as a substance (though a substance of essentially opposite nature, removed from matter, as the saying goes, by the whole diameter of being) the Natural Realists seem inclined to deny mediation altogether, and, as Hartmann somewhat crassly expresses it, to put mind with its nose up against the material object. Hence such problems as Hamilton raises, in criticizing Reid, as to what external object it is that we immediately perceive, and his final conclusion that the immediate object of knowledge is "really an affection of the bodily organism'. ${ }^{2}$ 'We actually perceive at the external point of sensation and we perceive the material reality,' but 'we perceive through no sense aught external but what is in immediate relation and in immediate contact with its organ '. " Hence, as he puts it more elaborately in his edition of Reid, 'the mind perceives nothing external to itself except the affections of the organism as animated, the reciprocal relations of these affections and the correlative involved in the consciousness of its locomotive energy being resisted'. 'The primary qualities are perceived as in our organism', and such per'Synthetica, vol. i, pp. 9I, 107. ' Lectures on Metaphysics, vol. ii, p. 137. 'Ibid., pp. 129-30. 
ception 'does not, originally and in itself, reveal to us the existence, and qualitative existence, of aught beyond the organism'; while 'colour in itself, as apprehended or immediately known by us, is a mere affection of the sentient organism, and therefore, like the other secondary qualities, an object, not of perception, but of sensation, proper'. ${ }^{1}$ Such a theory is not the Natural Realism of common sense at all, and would never have been devised but for the materialistic substantiation of mind as a so-called immaterial substance, which must somewhere and somehow come in contact with any object if it is to perceive it. It is part of Hamilton's theory that the mind is present in this way at all parts of the organism and not merely in the brain, so that, for example, 'the mind feels at the finger-points as consciousness assures us'. ${ }^{2}$ Now it is certainly on the physical continuity of my organism with the whole material system that my entire knowledge of that system depends; but for knowledge so mediated there is neither near nor far. What I locate at the end of my fingers is exactly on the same footing as the remotest star projected on the bosom of the night. They are both mediated by a process; but the mind is present to both, and they are both perceived directly and as they are. Body is the medium of mind in a far more intimate sense than is contemplated in such a theory of their connexion as Hamilton's language would imply. Materialistic as it may sound, it would be far more correct to say that the body perceives, than to figure physiological movements and contacts transmitted or passed on, as it were, to a second entity called mind. ${ }^{3}$

${ }^{2}$ Hamilton's Reid, vol. ii, pp. 88I, 885.

2 Lectures on Metaphysics, vol. ii, p. I28.

'Locke, it is perhaps worth remembering, left it an open question 'whether Omnipotency has not given to some systems of matter, fitly disposed, a power to perceive and think, or else joined and fixed to matter, so disposed, a thinking immaterial substance'; and he was of opinion that all the great ends of morality and religion are well enough secured, without philosophical proofs of the soul's immateriality' (Essay, IV. 3. 6). 
Perhaps it would sound materialistic only because, under the unconscious influence of the long dualistic tradition, we continue to think of the body in merely physical terms. Aristotle, it will be remembered, compared the distinction between body and soul to that between matter and form, and defined soul as the realization of the potentialities of the organized body - the completed idea, so to speak, of that which it has it in it to be. Hamilton's abandonment of the notion of a special seat of the soul-his conception of it as present at every part of the bodily organism-might, in itself, be taken as a step in the direction of a truer theory; but as actually stated, in terms of the old metaphysical dualism, it is a grotesque combination of the points of view of physiology and of common sense-a combination which fails in justice to the truth of either.

To return to the question of the secondary qualities, it. is obvious how a genuinely realistic theory such as I have sketched and illustrated, incorporates into itself all that is true in the doctrine of the relativity of knowledge. The range as well as the quality of our knowledge of the external world-its delicacy and precision-depend undoubtedly on the structure of the sense-organs and the nervous system generally. The universe must therefore appear differently to different creatures according to the difference of their equipment in these respects. The development of the special senses out of a general sensibility to contact is an evolutionary commonplace. One creature exhibits a vague organic sensitiveness to the difference between light and darkness. By another, with a rudimentary organ of vision, the difference between the two is clearly perceived; and, as the organ is perfected, there is added, with ever-increasing precision and delicacy, the perception of the different colours and the discrimination of their finest shades. Similarly the sense of hearing advances from ' $a$ sensitiveness to concussions affecting the whole environment' to accurate 
localization and the refinements of musical appreciation. Each creature, therefore, has its own world, in the sense that it sees only what it has the power of seeing; but what it apprehends, up to the limit of its capacity, is a true account of the environment, so far as it goes. And the progressive development of more delicate organs of apprehension just means the discovery of fresh aspects of the world, qualities and distinctions of its real being, too subtle to be appreciated by the ruder instruments previously at our disposal. There is no explanation possible of the evolution of the sense-organs and of the sentient organism. generally, unless we assume the reality of the new features of the world to which that evolution introduces us. The organism is developed and its powers perfected as an instrument of nature's purpose of self-revelation. ${ }^{1}$

And what is thus asserted of the secondary qualities will hold also of what Professor Bosanquet in one place calls the 'tertiary' qualities, the aspects of beauty and sublimity which we recognize in nature, and the finer spirit of sense revealed by the insight of the poet and the artist. These things also are not subjective imaginings; they give us a deeper truth than ordinary vision, just as the more developed eye or ear carries us farther into nature's refinements and beauties. The truth of the poetic imagination is perhaps the profoundest doctrine of a true philosophy. "I am certain of nothing', said Keats, " but of the holiness of the heart's affections and the truth of Imagination.' It

${ }^{2}$ Instead of speaking of primary and secondary qualities, Laurie suggests a distinction between the quantitative or common sensibles, as Aristotle called them, and the qualitative or proper sensibles, and he points out, suggestively, as it seems to me, that 'through these qualitative affections we ascertain certain peculiar characters of the quantitative external which, but for the subjective qualitative feeling, would never have been the object of physical investigation at all'. Science, when thus set upon the track, can show us the quantitative equivalent of a colour or a sound; but it is as if 'the more subtle characters of the object cannot be conveyed quantitatively in sensation but only qualitatively'. Cf. Synthetica, vol. i, pp. II4-16. 
is with the second of these far-reaching certainties that we are here concerned. The poet, it has been often said, is a revealer; he teaches us to see, and what he shows us is really in the facts. It is not put into them, but elicited from them by his intenser sympathy. Did Wordsworth spread the fictitious glamour of an individual fancy over the hills and vales of his beloved Lakeland, or was he not rather the voice by which they uttered their inmost spirit to the world? Remember his own noble claim for poetry as 'the breath and finer spirit of all knowledge, the impassioned expression which is in the countenance of all science'. 'Of genius in the fine arts,' he says, 'the only infallible sign is the widening of the sphere of human sensibility, for the delight, honour and benefit of human nature. Genius is the introduction of a new element into the intellectual universe. . . it is an advance or a conquest made by the soul of the poet.' But, again, the new element is not imported; the advance is an advance in the interpretation of the real world, a new insight which brings us nearer to the truth of things. Hence, when Coleridge says in a well-known passage,

$O$ Lady, we receive but what we give, And in our life alone doth Nature live,

the statement is exactly the reverse of the truth, if it be taken to mean that the beauty of nature is reflected upon it from the subjective spirit of the observer, and does not express what Wordsworth calls 'the spirit of the place'.'

'Certainly when we give way to 'the pathetic fallacy', investing nature with our transient moods of joy or grief, we fall into this subjectivism and falsify the facts. To take a glaring example:

Call it not vain: they do not err,

Who say, that when the Poet dies,

Mute nature mourns her worshipper,

And celebrates his obsequies:

Who say, tall cliff and cavern lone

For the departed Bard make moan. 
Coleridge's lines are only true if they are understood, as they may be understood, to mean that unless we bring the seeing eye, we shall not see the vision. All idealism teaches, the correlativity of subject and object; they develop pari passu, keeping step together, inasmuch as the objective world seems to grow in richness as we develop faculties to apprehend it. But all sane idealism teaches that, in such advance, the subject is not creating new worlds of knowledge and appreciation for himself, but learning to see more of the one world, ' which is the world of all of us'.

Philosophy does not require us, then, to treat the beauty and sublimity of natural objects as subjective emotions in the bystander: we are entitled, on the principles $I$ have been advocating, to treat them as qualities of the object just as much as the vaunted primary qualities.

There was an awful rainbow once in heaven;

We know her woof and texture; she is given

In the dull catalogue of common things.

Keats attributes this result to 'cold philosophy', at whose mere touch all charms fly. The poet's complaint is that a knowledge of physical optics-the laws of refraction and so forth-reduces the rainbow to an illusion, by showing us the mechanism on which the beautiful phenomenon depends. Keats, in fact, momentarily accepts the popular scientific view that this physical mechanism is the reality of the rainbow; and as a poet he mourns his lost illusion. But that is the abstraction against which our whole argument has been a protest. The reality of the rainbow in

But Scott knows that they do err, and that he is merely playing with fancies, for he acknowledges it himself in the next stanza:

Not that, in sooth, o'er mortal urn

Those things inanimate can mourn.

How different from this the transfiguring touch of the Wordsworthian imagination, even when it seems to involve a similar transference of emotion :

The moon doth with delight

Look round her when the heavens are bare. 
cludes that very shimmer of lovely colour and the wonderful aesthetic suggestion which made the primitive poet call it God's bow in the clouds, and which still makes our hearts ' leap up' when we behold it in the sky. Things are as they reveal themselves in their fullness to the knowing mind. As a French thinker expresses it, "if we wish to form a true idea of the total fact, of the real, we must not eliminate from it precisely what completes reality, what makes it exist for itself '. ${ }^{1}$

'A. Fouillée, Evolutionnisme des Idées-forces, p. 279. 


\section{LECTURE VII}

\section{ETHICAL MAN. THE RELIGION OF HUMANITY}

THE last lecture elaborated the contention that man is to be taken as organic to the world, and his experience, therefore, in all its reaches, as a process by which the true nature of reality communicates itself to him. The terror of the subjective, as M. Fouillée happily puts it, is an obsession introduced into philosophy by Kant. If it was not exactly ' introduced ' by Kant, it was certainly intensified by his method of statement. I attempted to show the inherent absurdity of the position that, because knowledge is the result of a process, the truth of its report is thereby invalidated. Because, in order to be known, things must appear to the knowing subject, it surely does not follow, as Kant seems naively to assume, that they appear as they are not. Yet it is due to this presupposition that the relation between the thing-in-itself and the phenomenon becomes the negative one of contrast or difference, and forms the fundamental opposition on which the Kantian system is based. ${ }^{1}$ On the view I have advocated, the relation between reality and appearance is not this negative relation of contrast or difference; the thing really does appear, or, in other words, reveal its nature. The thing as it is and the thing as it appears are, in principle, the same fact differently named, because looked at in different aspects. They may be intelligibly contrasted in so far as our knowledge is partial and does not therefore exhaust the nature of the object in question,

${ }^{1}$ As Hegel wittily puts it, Kant holds that what we think is false, because it is we who think it (Encyclopädie, section 60, Wallace's translation, p. IIg). 
but not in the Kantian and agnostic sense that, even as regards the part we know, the thing would look quite different if, per impossibile, we could see it as it really is. The whole conception of reality as meaning existence apart from being known, and the accompanying theory of truth as lying in the correspondence of knowledge with what is by definition unknowable-this whole conception, with the agnosticism inherent in its very statement, is swept away by the view which I have been urging. That view abolishes the thing-in-itself in the Kantian sense; or, if the term is retained, it teaches that the reality of the thing is not the thing apart from knowledge, but the thing conceived-as completely known, the thing as it would appear in its complete setting to a perfect intelligence. Mind is thus no more condemned, as it were, to circle round the circumference of the real world, put off with outside shows, and unable to penetrate to its essential core. Mind is set in the heart of the world; it is itself the centre in which the essential nature of the whole reveals itself.

So far we have treated the question of man's organic relation to the world with almost exclusive reference to his cognitive experience of the external world. That is the connexion in which the question arises in modern philosophy, and it had to be first disposed of, for the reason stated at the beginning of the last lecture. If man's knowledge, I said, does not put him in touch with reality, how can his ideals be supposed to furnish a clue? In the concluding pages of the lecture we applied the principle of organic relation to the aesthetic aspects of our experience. But it is, as we have seen throughout, between man's nature as an ethical being and what is taken to be the completely non-moral nature of the world from which he springs, that the cleavage, the apparent break of continuity, has usually been most keenly felt. I have already referred to Huxley's passionate indictment of 'cosmic nature' as not only 'no 
school of virtue but the headquarters of the enemy of ethical nature'. Man is thus, in his moral nature, so far from being organic to the universe that, in such a view, his noblest qualities are a reversal of all its ways. Man is at odds with the cosmos: it is open war between them. 'Let us understand, once for all, that the ethical progress of society depends not on imitating the cosmic process, still less in running away from it, but in combating it.' With this characteristic call to arms the deeply-felt address concludes. ${ }^{1}$

A similar sense of dualism, and even of conflict, between ethical man and cosmic nature underlies the Religion of Humanity as formulated by Comte. In this respect the Religion of Humanity is one of the most characteristic products of the nineteenth century. It is an ethical and religious idealism of a lofty type; but it is an idealism manqué-an idealism truncated and imperfect-because infected by the agnostic relativism which we have seen to be characteristic of the period. There are many parallels between Comte and Kant, both in the positive and the negative aspects of their work, although Comte knew his German predecessor only at second-hand and reached his own conclusions independently. To both the moral is the foundation of intrinsic value, and both make the moral development of mankind the central point of reference in their systems. And, again, the doctrine of the phenomenality or relativity of knowledge drives a wedge deep into the philosophy of both. If Kant in some degree extricates himself from his dualism, or at least shows others a way out, Comte's religious philosophy remains to the end, what he explicitly designates it, a 'subjective synthesis'-a synthesis of humanity, that is to say, which leaves the rest of the universe out of account. An attempt to disentangle the true and the false in Comte's statement of the

${ }^{1}$ Romanes Lecture on Evolution and Ethics, 1893. 
philosophical and religious position will prove, I think, as instructive a method as we could adopt of carrying our own argument to its conclusion and illuminating the nature of the position to which the preceding lectures have been leading up. There is, besides, so much that is true and valuable in Comte's ideas that $I$ am not unwilling to dwell for a little on a system of thought which has perhaps been treated by constructive thinkers in this country too exclusively in its negative aspects.

The negative element in Comte's philosophy connects itself with his famous 'law of the three stages.' of human thought. Man begins by explaining events as the results of volitions like his own; this is the theological stage of thought, leading from Fetishism through Polytheism to Monotheism. When the insight into the uniformity of nature's processes makes the resort to interfering wills unmeaning, theology is supplanted by metaphysics, which finds the causal explanation of events in essences or powers, conceived as real entities behind and separate from the phenomena which they dominate. Such an essence, power, or faculty, is so manifestly just the duplicate of the phenomenon which it is invoked to explain, that it might be difficult to understand how such pure abstractions came to be substantiated, if we did not remember that the metaphysical stage was preceded by the theological. The essence is the ghost or residuum of the spirit which was formerly believed to control the fact. As Mill puts it, 'the realization of abstractions was not the embodiment of a word, but the gradual disembodiment of a fetish '. The metaphysical stage is thus essentially transitional and yields place in the fullness of time to the third, the positive or purely scientific stage. Here thought gives up the search after transcendent causes, and limits itself to investigating the laws of phenomena, that is to say, the

${ }^{2}$ Auguste Comte and Positivism, p. 18. 
relations of resemblance, co-existence and sequence which obtain between different natural facts. Such a knowledge enables us to foresee the course of phenomena: voir pour prévoir is the motto of science. Foresight means the possibility of controlling the course of phenomena or, at least, of adapting our conduct to what we cannot change. And, as Comte strongly holds, science realizes its true function in the service of human life. With the spread of the positive or truly scientific spirit, theological and metaphysical debates will die a natural death, without the need of any explicit demonstration of the unreality of the conceptions on which they are based.

It is a fundamental tenet, therefore, of the Positivist philosophy that our knowledge is only of phenomena and their laws. Comte also uses the term relative to describe the nature of his position, referring with approbation to Kant's distinction of the subjective and objective elements in knowledge. Although we can eliminate the subjective peculiarities which belong to us as individuals, we cannot rise above the subjectivity which is common to our species as a whole; and, accordingly, 'our conceptions can never attain to a pure objectivity. It is therefore as impossible as it is useless to determine exactly the respective contributions of the internal and the external in the production of knowledge.' 1

The criticism which I would offer of this position is, in sum, that it conveys a false idea of what metaphysics consists in, and that it depends itself upon the false idea which it repudiates. Comte adopts the view of the ordinary empiricist that the metaphysician or the transcendental philosopher is ceaselessly employed in the quest or elaboration of transcendent noumena, which are really duplicates of the facts to be explained. There have been, doubtless, historical examples of such a procedure-to be treated as

${ }^{2}$ Positive Polity, vol. ii, p. 30 (English translation). 
beacons of warning-but it is ludicrous to attribute it to the greater philosophers. Metaphysics is simply the attempt to think things out - to exhibit the relation of the facts to one another and thereby to reduce them finally to a coherent system. To do this is to disclose the informing principle of the whole. Certainly, whatever may be true of the past, idealistic philosophy since Kant has been mainly engaged in exploding the notion on which Comte proceeds, that the phenomenon and the noumenon are two separate facts, or that the reality is something apart and different from its appearances. I have said that Comte proceeds on this notion because, although he dismisses as false the explanations which he takes to be proffered by the metaphysician, and himself abandons the metaphysical quest, it is apparently because of the impotence of our faculties that he does so, and not on account of the falsity inherent in such a statement of the philosophical problem. He speaks of the 'insolubility' of the question much in the style of Kant, and his characterization of our knowledge as 'only of phenomena' seems to rest on similar grounds. Otherwise why the regretful 'only'? 'For the assertion that we know only phenomena,' says Caird,' 'has no meaning except in reference to the doctrine that there are, or can by us be conceived to be, things in themselves, i. e. things unrelated to thought; and that while we know them to exist, we cannot know what they are. Now this dogma is simply the scholastic realism, or what Comte calls metaphysics, in its most abstract and irrational form. It is a residuum of bad metaphysics, which by a natural nemesis seems almost invariably to haunt the minds of those writers who think they have renounced metaphysics altogether.' The misconceptions involved in the imputation of relativity have been sufficiently dealt with in the preceding lecture. Obviously the quaint idea of 'apportioning exactly the 
respective contributions of the internal and the external in the production of knowledge' derives any plausibility it possesses from the conception of the knowing subject as entirely outside the world he seeks to know. To this original denial of an organic relation between man and the rest of the cosmos are traceable, we shall find, the characteristic features of Comte's social and religious doctrines. But let us first consider the truths which these doctrines contain.

Comte is strongly impressed by the central function of religion in human experience. Religion, he says, ${ }^{1}$ embraces the whole of our existence, and the history of religion resumes the entire history of human development. In religion man attains harmony of life through recognition of his dependence on a Power which sustains and encompasses his life-a Being whom he can worship and love, as the source and embodiment of all that is adorable, and as the sustaining providence to which he owes every good that he enjoys. We must love the Power to which we submit; otherwise there is nothing religious in our submission, nothing but resignation to a fatality. Further, Comte rightly holds that only in the moral affections are there revealed to us qualities to which we can bow in worship and in love. The external world, regarded by itself and in its merely mechanical aspects, possesses, as we have seen, no intrinsic value. Taken in abstraction, as Comte takes it, it is, indeed, just what he calls it, a fatality with which we have to make our account, but in nowise a Power moving us either to gratitude or to worship. Size counts for nothing in such an estimate. It is the insight of religion and of the deepest philosophy that size has nothing to do with true greatness. Pascal's 'thinking reed' is greater in death than the universe which overwhelms him. Comte's Religion of Humanity has the same thought at its root. As

${ }^{1}$ Positive Polity, vol. ii, p. II 
Mr. Frederic Harrison finely illustrates it: 'The man who reviles Humanity on the ground of its small place in the scale of the Universe is the kind of man who sneers at patriotism and sees nothing great in England, on the ground that our island holds so small a place in the map of the world. On the atlas England is but a dot. Morally and spiritually, our Fatherland is our glory, our cradle and our grave.' 1

Comte has no difficulty in showing that the individual man, alike in his intelligence, his activities and his affections, is the creature and the organ of the race to which he belongs. The language he speaks, the intellectual tools he uses, the moral qualities of self-restraint, co-operation and mutual affection, all come to him as a heritage from the past. Quite as much as the material appliances of civilization which soften and humanize his lot, raising him above the grim struggle with external nature, they represent the collective labours of unrecorded generations since the dim dawn of human history... Thus the very tissue of his life is woven for him by the collective activities of the race, which Comte conceives as one great Organism or living Being, whose existence is continuous throughout time, and which contains, at least in a mystical sense, its dead as well as its living and its still unborn members in one great fellowship. ${ }^{2}$ In other organisms, Comte proceeds, the parts have no existence when severed from the whole, but this greatest of all organisms is made up of lives which can really be separated. Humanity would cease, he says, to be superior to other beings were it possible for her

${ }^{1}$ Creed of a Layman, p. 76 .

2 'This mighty Being whose life endures through all time, and who is formed of the dead far more than of the living' (General View of Positivism, p. 235, Bridges' translation). The present is but a span or a section between the past and the future. It ' can only be properly conceived by the aid of the two extremes which it unites and separates' (Positive Polity, vol. ii, p. 296). 
elements to become inseparable. Independence is necessary as well as harmony or co-operation; but the difficulty of reconciling them is so great as to account at once for the slowness with which this highest of all organisms has been developed. ${ }^{1}$ We must not, however, in speaking thus of independence, lapse from the organic point of view; for Comte immediately reminds us that 'man as an individual cannot properly be said to exist except in the exaggerated abstractions of modern metaphysicians. Existence in the true sense can be predicated only of Humanity; although the complexity of her nature prevented men from forming a systematic conception of it until the necessary stages of scientific initiation had been passed.'

Humanity, therefore, becomes for the individual the object of religious adoration, the Great Being towards which every aspect of his life is directed. "Our thoughts will be devoted to the knowledge of Humanity, our affections to her love, our actions to her service.'Humanity is the Providence which mediates between its members and the system of external necessity which forms our environment, turning its very fatality into a means of moral development and selfperfection. To Humanity, therefore, is due the gratitude for all the benefits for which, in the past, men have mistakenly poured out their thanks to an abstraction of their own invention. Unlike the Supreme Being of the old religions, Humanity is an object of worship whose existence is patent and indubitable, whose nature and the laws of whose existence we know-a Being, moreover, whom we can actively serve and really benefit. The beneficial and moralizing influence of the old theology in its day and generation Comte willingly acknowledges, especially mentioning the Christian doctrine of the Incarnation and the worship of the Virgin. But its function was, in his view, merely

${ }^{1}$ General View, p. 246. 
transitional and preparatory-' to direct provisionally the evolution of our best feelings under the regency of God during the long minority of Humanity.' ' 'Monotheism in Western Europe is now as obsolete and as injurious as Polytheism was fifteen centuries ago. . . . The sole effect of its doctrine is to degrade the affections by unlimited desires, and to weaken the character by servile terrors.' Humanity is not omnipotent, and therefore we do not expect from it the impossible. 'We know well that the great Organism, superior though it be to all beings known to us, is yet under the dominion of inscrutable laws, and is in no respect either absolutely perfect or absolutely secure from danger.' But just on that account religion does not exhaust itself in adoration; it finds its actual expression in the active service of Humanity. Immutable omnipotence had no need of human services, but Humanity, 'the most vital of all living beings known to us, lives and grows only through the unceasing efforts of its members.' Humanity is so far from being perfect that 'we study her natural defects with care, in order to remedy them as far as possible. Thus the love we bear her calls for no degrading expressions of adulation, but it inspires us with unremitting zeal for moral improvement.' To the Positivist, therefore, 'life becomes a continuous act of worship, performed under the inspiration of universal Love. All our thoughts, feelings and actions flow spontaneously towards a common centre in Humanity, one Supreme Being - a Being who is real, accessible and sympathetic, because she is of the same nature as her worshippers.' The history of the long travail of Humanity, 'her constant struggle against painful fatalities which have at last become

${ }^{2}$ Quoted by Caird, op. cit., p. 32. Cf. Swinburne's Hertha:

I that saw where ye trod

The dim paths of the night,

Set the shadow called God

In your skies to give light ;

But the morning of manhood is risen, and the shadowless soul is in sight. 
a source of happiness and greatness, the history of the advance of man from brutal appetite to pure unselfish sympathy, is an endless theme for the poetry of the future.' Positivism offers us 'a religion clothed in all the beauty of Art and yet never inconsistent with Science'.'

Such are Comte's claims for the new faith of which in his later years he constituted himself the high-priest. One valuable truth in the philosophical groundwork - a truth not peculiar to Comte, though he had an important influence in impressing it on modern thought-is the repudiation of the abstract individualism of the eighteenth century, and the insistence on the concrete reality of humanity as a universal life in which individual men are sharers. Individual man is an abstraction of the metaphysicians, Comte tells us; he cannot properly be said to exist, if severed from the community of this larger life. Now we are all of us Nominalists in our ordinary moods, and too apt to ridicule such a statement as a piece of fantastic mysticism. Accordingly, it is a common criticism of Comte that he sets up an abstraction for us to worship. But it is perhaps not too much to say that, by such a line of criticism, we cut ourselves off from religion altogether, and, with religion, from sound philosophy. The mystical union of the worshipper with his God is a cardinal article of religious faith. If humanity, as a universal, is to be dismissed as an abstraction, may not God, the supreme universal, succumb to a similar criticism?

Before taking up this Philistine attitude, let us apply the same test to the narrower case of patriotism, ${ }^{2}$ whose more vivid associations may perhaps help us to appreciate the

1 The passages quoted are all taken from the concluding chapter of the General View of Positivism.

${ }^{2}$ This paragraph was written two years before the war, and I have thought it best to let it stand exactly as it was spoken. 
reality of the larger and more passionless unity. Take Shakespeare's famous apostrophe to England:

This happy breed of men, this little world,

This precious stone set in the silver sea . . .

This blessed plot, this earth, this realm, this England. Or Browning's 'Home-Thoughts, from the Sea': Nobly, nobly Cape Saint Vincent to the north-west died away;

Sunset ran, one glorious blood-red, reeking into Cadiz Bay; Bluish 'mid the burning water, full in face Trafalgar lay; In the dimmest north-east distance dawned Gibraltar grand and gray;

"Here and here did England help me: how can I help England?"-say,

Whoso turns as I, this evening, turn to God to praise and pray,

While Jove's planet rises yonder, silent over Africa.

Or these lines of a younger poet:

Never the lotus closes, never the wild-fowl wake,

But a soul goes out on the East Wind that died for England's sake.

Is England, then, an abstraction? Was Italy an abstraction to the Italian patriots who fought for her freedom and unity in the middle of last century? 'Jtaly', Mazzini said, 'is itself a religion.' Was Israel an abstraction to the pious Jew? Nay, we know that he thought and spoke of Israel in the very terms which Comte applies to Humanity, as the great Being to whom the promises of Jehovah are made and in whom his purposes are fulfilled. He himself will be gathered to his fathers, but Israel, ' the servant of the Lord,' enjoys an age-long life. Ancient Israel is, in this respect, only the best-known example-touched to the finest issuesof a familiar historical fact. The individual, it has been said, is a late product of evolution. At an earlier stage he is largely merged in the tribal life; he does not round himself to a separate whole, with the modern sense of individual detachment and personal destiny. $\mathrm{He}$ acts as the organ of 
a larger life in which he is content to be, and apart from which he makes no personal claims. The growth of individual self-consciousness undoubtedly marks_an advance, As Comte rightly points out, it is a mark of the perfection of the greatest of all organisms that the parts of which it consists are living beings which have an existence for themselves. But however far such development may go, it can never mean that the individuals detach themselves altogether from the nation or the race, and cease to be channels of the corporate life which makes them men. They cannot place themselves outside the 'little world' of man and continue to exist, any more than they can take up an independent station outside the universe of which they are the product and the organ.

May we not also explain by the analogy of patriotism Comte's idealization of Humanity? How can we worship (it is often said), or even reverence and love, a Being with such a history-a Being, great masses of whose members offer, even now, such a spectacle of pettiness and folly, of grossness, baseness and all manner of wickedness? Alas, is it not the same when we turn our thoughts from the patriot's 'England ' to our countrymen in the flesh? How much that is vulgar and mean and vicious crowds with pain and shame upon the mind! Yet, though we may be chastened and humbled-and inspired, as Comte also says, with zeal to make these things better-the features of our ideal are not blurred. Ideal England still stands before us as supremely real, the just object of our unstinted devotion, sacred to us as a heritage from all the brave and good who have laboured in her service, a fabric strong enough to bear, and, as it were, to redeem or transmute, the weakness and the evil which mingle with all human things. In a spiritual organism the evil is thrown off and perishes; the good only remains and is incorporated, to become the substance of the future. So, with Comte, it is Humanity in its ideal aspect that 
is offered for our worship-Humanity purged of its own dross, militant, indeed, not perfect, but triumphant over the baser elements in its constitution, transforming obstacles into stepping-stones of progress and replacing the life of selfish struggle by one of universal sympathy and mutual help. And it is plain, as Seeley says, that 'the worship of Humanity belongs to the very essence of Christianity itself. and only becomes heretical in the modern system by being separated from the worship of Deity'.' As Blake puts it, with a kind of divine simplicity, in his Songs of Innocence:

For Mercy, Pity, Peace and Love Is God our Father dear, And Mercy, Pity, Peace and Love Is Man His child and care.

For Mercy has a human heart, Pity a human face, And Love the human form divine, And Peace the human dress.

The Religion of Humanity does, indeed, emphasize elements which are essential in the Christian view of God and the world, but which have often been neutralized, especially in theological systems, by the predominance of the old monarchical idea of God, conceived, in William 'James's happy phrase, as 'a sort of Louis XIV of the heavens'. But, presented as Comte presents it, as a substitute for the worship of God, the worship of a finite Being, however great, offers insuperable philosophical difficulties. Most people will think, with Höffding, 'that the religious problem proper only begins where Comte's religion ends, viz. with the question as to how the development of the world is related to that of the human race and the human ideal.' $^{2}$ It is time to return, therefore, to consider the 'subjectivity' of the Positivist synthesis.

'Natural Religion, p. 75 (second edition).

'History of Modern Philosophy, ii. 359 (English translation). 
To judge from his own language, Comte appears to consider the subjective and relative character of his synthesis a merit rather than a defect. But to fail of the objective and the absolute, while it may doubtless be inevitable, must certainly, just to the extent of the failure, be prof nounced a defect. Comte's attitude, therefore, can only be held as meaning that, since, in his view, objective knowledge is unattainable, it is better to rest satisfied with a result which honestly proclaims itself subjective than to pretend to a final synthesis which is beyond our powers. The peculiarity of Comte's scheme, however, is that it entirely depends on treating. Humanity as a self-contained and self-creative being - $\mathrm{a}$ kind of finite Absolute-which evolves all its properties, and engineers all its advance, out of the resources of its own nature. Hence it comes that at the end he crowns it as God in a godless world. Comte, of course, does not fail to recognize that Humanity is not literally self-contained, but develops in a 'medium' or environment furnished by the external or physical world. Indeed he lays stress on the fact that his synthesis 'rests at every point upon the unchangeable order of the world', as revealed by science; ${ }^{1}$ he calls this the objective basis of his synthesis. It is the function of intellect to discover the laws of this universal order, teaching us how to modify the course of phenomena when that is possible, or, when that is not the case, to adapt ourselves to an inevitable necessity. And the social education of the race depends also, as he shows, ${ }^{2}$ upon the ever-present consciousness of this external power and the coercions of its unchanging laws. But, in spite of the dependence thus acknowledged, he still proceeds, in building up his theory, as if there were no organic relation between man and the world which gives him birth. 'External fatality' is the phrase he most commonly uses of the non-human world: it appears in the light of a hostile power

${ }^{1}$ General View, p. 19.

Ibid., p. 253. 
with which humanity is in conflict, rather than as antegral element in the single universe which we have to explain. In spite of his instructive classification of the sciences and his polemic against the 'materialism', as he calls it, which seeks to reduce the higher to the lower, Comte's deification of Humanity really depends on the same practical severance of man from nature and the acceptance of the latter as a self-contained system of physical necessity. The difference is that, whereas materialism treats man as an evanescent product of cosmic nature, the idealist in Comte celebrates in Humanity the only object of religious reverence and love, and nature tends with him to take a secondary place. It is a necessary condition of the existence and evolution of humanity, but it is ultimately an $x$, a thing-in-itself, of whose real nature we know nothing. We cannot penetrate, he says, "the unattainable mystery of the essential cause that produces phenomena '; ${ }^{1}$ and having once accepted the false distinction between phenomena and essential causes, Comte feels himself precluded from any attempt to construe nature and man as elements in one system of reality. It is ' metaphysical', in his view, to relate nature and man in that way to a common principle, although it is apparently not metaphysical, but commendably positive and scientific, to unify the dispersive multiplicity of human phenomena in the conception of a single Life.

But it is impossible to rest in a merely subjective synthesis. In reality Comte, in the natural progress of his thought, is led to bring the world of nature more and more within the scope of his system, and so to remove the dualism which makes the elevation of the human equivalent to the banishment of the divine. Professor Edward Caird has pointed out very clearly the crossing of two opposite lines of thought in Comte's philosophy. It was largely in a justifiable reaction against a shallow, sentimental optimism and an

Ibid., p. 34. 
external teleology that Comte originally represented Nature as a hostile, or at least indifferent power, from which every gift has to be wrung by man's own labour and fertility of device. Man has had to constitute himself his own Providence. But, on the other hand, all through the Politique positive Comte is found insisting "that the influence of an external limiting fatality, which forces upon man the surrender of his natural self-will was the necessary condition of the development of all his higher powers of intelligence and heart'. I It is not only the intellectual powers that are first called into action by the practical necessities of the struggle with nature; the same struggle imposes on him the discipline of labour, and teaches him the need of co-operation with his fellows. It thus becomes the fostering nurse of the altruistic affections which otherwise would never make way against man's native egoism. 'But assisted by the supreme fatality [these are Comte's own words] universal love is able habitually to secure that personality ${ }^{2}$ should be subordinated to sociality.' From this point of view, Caird justly comments, the external fatality ' can no longer be called unfriendly, or even indifferent to man; or, rather, its immediate appearance as his enemy is the condition of its being, in a higher sense, his friend'.

Comte's thought here is the same as Kant's in the little treatise, Idee zu einer allgemeinen Geschichte, which, as I mentioned before, led some of the German pessimists to claim him as an adherent of their doctrine. But the pessimism is only on the surface, for Kant teaches that nature, if a niggardly stepmother as regards man's immediate happiness, is the power that converts him into a moral being and drives him on to all his higher attainments. ${ }^{3}$ Comte's statements in the same sense are numerous and emphatic:

${ }^{2}$ E. Caird, Social Philosophy of Comte, p. 149.

'Comte uses this phrase to designate the selfish, as opposed to the social, impulses.

This was the only one of Kant's writings which Comte knew at first- 
"We have to consider the exceeding imperfection of our nature. Self-love is deeply implanted within it, and when left to itself is far stronger than social sympathy. The social instincts would never gain the mastery, were they not sustained and called into exercise by the economy of the external world. . . . Thus it is that a systematic study of the laws of nature is needed on far higher grounds than those of satisfying our theoretical faculties. .. It is needed because it solves at once the most difficult problem of the moral synthesis. . . O Our synthesis rests at every point upon the unchangeable order of the world. . . . To form a more precise notion of its influence, let us imagine that for a moment it were really to cease. The result would be that our intellectual faculties, after wasting themselves in wild extravagances, would sink rapidly into incurable sloth; our nobler feelings would be unable to prevent the ascendancy of the lower instincts; and our active powers would abandon themselves to purposeless agitation. ... In some departments this order has the character of fate ; that is, it admits of no modification. But even here, in spite of the superficial objections to it which have arisen from intellectual pride, it is necessary for the proper regulation of human life. Suppose, for instance, that man were exempt from the necessity of living on the earth, and were free to pass at will from one planet to another, the very notion of society would be rendered impossible by the license which each individual would have to give way to whatever unsettling and distracting impulses his nature might incline him. Our propensities are so heterogeneous and so deficient in elevation that there would be no fixity or consistency in our conduct, but for these insurmountable conditions. . . . Supposing us in possession of that absolute independence to which metaphysical pride aspires, it is certain that so far from improving our condition, it would be a bar to all development, whether social or individual." 1

hand. It was translated for him by a friend in 1824 . He greatly admired it, and said that, if he had known it six or seven years earlier, it would have saved him the trouble of writing his treatises of 1820 and 1822 .

'General View, pp. 16-20. Cf. Positive Polity, vol. ii, pp. 25-8 ('General Theory of Religion'). 
It would really be difficult to put the organic relation of nature to man more strongly; the external fatality has become a beneficent necessity. And in his later elaboration of the Religion of Humanity he goes so far in retracting the dualism of nature and man as to add Space and the Earth to Humanity as objects of worship. "The Cultus of Space and of the Earth, completing that of Humanity, makes us see in all that surrounds us the free auxiliaries of Humanity.' The world-space as the Great Medium, the Earth as the Great Fetish, and Humanity as the Great Being to which they are subsidiary, form the fantastic Trinity with which the new religion concludes. Space is the medium in which the earth has shaped itself; the earth or the great fetish has abstained from exerting its colossal and elementary forces, and has sacrificed itself in its longing that the 'Great Being', in which the highest perfection appears in the most concentrated form, may develop.

But, with Comte's presuppositions, this can be no more than a conscious appeal to poetry to cover with its flowers the cold reality of the situation. Comte says, indeed, that, just because Positivism has so completely emancipated itself from the old theological and metaphysical ways of looking at the world, it may safely adopt in imagination, that is to say, in art and religion, this primitive fetishistic view of nature "without any danger of confusion between the two distinct methods of thinking, which it consecrates, the one to reality and the other to ideality' ${ }^{1}$ He ends thus, like Lange, with a flight from reality into the shadow-land of poetic fancy. But, in Comte's case, the imaginative effort is still more consciously make-believe; it hardly makes any claim on our serious belief. It is significant only as a final admission of the impossibility of resting, either philosophically or religiously, in a merely subjective synthesis. As Caird says, commenting on the passage last quoted, 'a

${ }^{1}$ Synthèse subjective, p. 40. 
worship of fictions, confessed as such, is impossible. Art, indeed, is kindred with Religion, but that means only that Art is untrue to the immediate appearances of things, in order that it may suggest the deeper reality that underlies them.' And, after all, the Great Medium and the Great Fetish have little about them of the genuine intuitions of Art. If Comte had followed out his own correlation of nature and man to a serious conclusion, he would have found the true 'medium' of Humanity's life in God, 'that Power which alone is great '.

But to accept this view would have meant the disappearance of Positivism as a distinctive doctrine, for it would have involved a revision of the mistaken phenomenalism on which it is based. Such revision and reconstruction was not to be looked for from the founder and highpriest of the new religion. The progress we find is in the opposite direction. The subjective and relative character of the synthesis is emphasized by the strict subordination of knowledge to the moral ends of Humanity, or, in Comte's own phrase, the subordination of the intellect to the heart. 'L'esprit doit être le ministre du cœur.' This is as essential a feature of Positivism, says Dr. Bridges, ${ }^{2}$ as the subordination of egoism to altruism; and it means for Comte, that the intellect should devote itself exclusively to the problems which the heart suggests, the ultimate object being to find proper satisfaction for our various wants. ... The universe is to be studied not for its own sake but for the sake of man or rather of Humanity.' 3 ' 'It is idle, and indeed injurious,' we read again, 'to carry the study of the natural order beyond the point needed for the work of the artificial order constructed by man.' This short-sighted limitation of

'Tennyson, 'God and the Universe'.

'Unity of Comte's Life and Doctrine, p. 32 (popular edition, 1910).

- General View, pp. 14, 26.

- Positive Polity, vol. ii, p. 39. 
scientific inquiry to what can be shown to be of social utility became a fixed article of Comte's creed, and forms one of the most dangerous articles of the new religion. Even in his earlier work, the Philosophie positive, ${ }^{1}$ he had condemned sidereal astronomy as a grave scientific aberration, on the ground that the phenomena of the stellar universe appear to exert no appreciable influence on events within our solar system. Ten years later, in the first volume of the Positive Polity, he was no longer content thus to limit astronomy to a knowledge of the solar system. It should restrict itself to a knowledge of the earth, and consider the other celestial bodies only in their relation to the human planet. No doubt the ancients were deceived in believing the earth to be the centre of the world; but it is the centre of our world, and accordingly the subjective synthesis 'concentrates the celestial studies round the earth'. By the time he had reached the fourth volume of the Positive Polity, he was of opinion that, strictly speaking, the study of the sun and moon would suffice, although we might add to them, if so inclined, the planets of the ancients, but not the 'little telescopic planets' due to modern discovery. ${ }^{2}$ This is only an example of the lengths which he was prepared to go. No science, he thought, should be carried further as an abstract study than is necessary to lay the foundation for the science next above it in the hierarchy of the sciences, and so ultimately for the moral and social science in which they culminate. Any further extension of the mathematical and physical sciences should be merely 'episodic'-limited, that is to say, to what may from time to time be demanded by the requirements of industry and the arts-and should be left to the industrial classes. It was, in fact, to be one of the main functions of the spiritual power, or the priesthood of the new religion, to restrain the intellectual activity of the

${ }^{1}$ In the sixth volume.

'Cf. Lévy Bruhl, Philosophy of Auguste Comte, pp. I50-2. 
community from wandering at large in the fields of useless knowledge. Comte says somewhere that the Religion of Humanity will keep as jealous a watch as mediaeval Catholicism over the rovings of the intellect.

This is not the place to enlarge on the short-sightedness of this incredibly narrow utilitarian view of knowledgecondemned, even from the utilitarian point of view itself, by the impossibility of foreseeing what researches are destined to lead to valuable applications and what are not. How often have the abstrusest and apparently most purely speculative investigations, or, again, researches into phenomena of apparently the most trivial kind, resulted in transforming our practical activities or revolutionizing our intellectual outlook on the world! Bacon, who also subordinated knowledge to practice, knew that it is 'light' not 'fruit' which we must seek in the first instance. And while no man of science will undervalue the benefits which his discoveries may confer on his fellows, it is knowledge on its own account which he first instinctively seeks; the rest, he feels, will be added, if his knowledge is true. Comte's proposal to select certain provinces as worth knowing and to leave others out of account, and to determine, moreover, with what degree of thoroughness the selected provinces are to be investigated, is so subversive of the primary faith both of science and philosophy that it comes near reducing the idea of truth to one of subjective convenience. These things are cited merely to show how the idea of stopping short with a subjective synthesis, of taking man as a world by himself, involves an arbitrariness of treatment which subtly affects Comte's whole method of procedure, and eventually makes him a traitor to the scientific spirit of which he had constituted himself the champion. Thought, in whatever sphere, cannot stop short of the idea of an order or system of the universe as a whole. 


\section{LECTURE VIII \\ POSITIVISM AND AGNOSTICISM}

We traced in the preceding lecture the conflict of ideas running through Comte's speculations. What is characteristic in his philosophico-religious theory, what gives him his distinctive place in the history of thought, is the sharp initial dualism between man and nature. This leads, in his theory of knowledge, to a pure phenomenalism or subjectivism, buttressed by a polemic against metaphysics which depends upon the same 'residuum of bad metaphysics' that led Kant to his doctrine of the unknowable thing-in-itself. In his ethical and religious theory, it leads him to treat nature entirely as a mechanical system, an indifferent, if not a hostile power, which he therefore fitly describes as an external fatality. For although man converts this fatality to his own uses, and makes its existence the instrument of his own advance in knowledge and goodness, this is represented as entirely man's own doing, making the best of an existing situation. Nature and man are not part of one scheme of things; nature is just, as it were, a brute fact with which man finds himself confronted. Hence man appears in the universe like a moral Melchizedek without ancestry, owing everything to himself, his own Providence, bringing into the universe for the first time the qualities which merit the attribute divine. And accordingly, the deification of man is equivalent to the dethronement of God. As Comte puts it in a notable, if somewhat blustering paradox, the heavens declare the glory, not of God, but of Kepler and Newton.

Now, if we look simply at the historical process, as traceable in the evolution, say, of the solar system and of our own planet, it is undoubtedly the case that in the time- 
sequence the authentic lineaments of the divine are recognizable for the first time in ethical man. And if we ignore the biological preparation and prefigurement-if we cut the world in two with a hatchet, as the saying is, leaving ethical man on the one hand and an external fatality on the otherthen man does seem the only source and seat of the qualities which have a rightful claim upon our worship. But, when we try to think seriously, can we really suppose that before the planets cooled sufficiently to admit of organic life, the universe (and by universe I mean here the All of existence) consisted literally of nothing else but space and its inorganic contents, or that before the appearance of palaeolithic man the good and the beautiful had no place in the nature of things. Surely these qualities are in their very nature eternal; they are not actually created by man, shaped by him out of nothing, and added henceforth to the sum of existence. It is to take the time-process too seriously-it is to take it falsely-to regard its separate parts as equally and independently real. Time, as Plato said in a fine figure, is the moving image of eternity. We are creatures of time, and in a sense it may be said with truth that we cannot comprehend the timeless; our thinking must to the end be done, whether we will it or not, in terms of time. But we can at least see that time is a continuous process, and that the nature of reality can only be revealed in the process as a wyhole. We must look to the end, as Aristotle said; or as Hegel put it, the truth is the Whole, the End plus the process of its becoming,

It has been the fundamental contention of these lectures that the isolation or substantiation of the earlier stages of a time-process is a radical error in philosophy. Continuity of process, I have urged, is not inconsistent with the emergence of qualitative differences; we pass from one plane of experience to another. But the whole process wears the appearance of a progressive revelation, not of a sheer addi- 
tion to the life of the universe. It is impossible to get away from the conception of a natura rerum, whether we call it Nature, the Absolute, or God. And it seems impossible to apply in such a quarter the idea of actual progress or growth from less to more. I cannot believe that the feeling of this impossibility is no more than a metaphysical obsession inherited, as M. Bergson appears to imply, from the philosophical mistakes of the past. 'Creative evolution' is, I think, an eminently fruitful idea, if applied on the phenomenal level to emphasize the living reality of the process, the idea of the future as something to be won by our own effort, the outcome of which is unforeseeable on the basis of any analysis of the past or the present. As against the ordinary idea of a predestinated course of things, and especially against the idea of a future fatally determined by the past, M. Bergson seems to me to argue with convincing force; and this gives his pages such an extraordinary freshnessthe freshness and the forward impulse of life itself. But the novelty is due, surely, to the inexhaustible nature of the fountain from which we draw, not to any inconceivable birth of something out of nothing. It all strikes one as a process of 'communication '- to use a phrase of Green'sor, as I said already, of progressive revelation. The novelty is like that of entering a new room in the Interpreter's House, not of building out the universe into 'the intense inane.' It is novelty as it appears to us, in the time-process, but how can it be qualitatively new in ordine ad universum? How can anything come into being unless it is founded in the nature of things, that is, unless it eternally is?

So that while in one sense it is true that we think to the end in terms of time, it is equally true that we cannot think any continuous process in time, we cannot think life or development (and, as Bergson says, it is only in the living being that we encounter time as a concrete reality) without being lifted in a sense above time and bringing in the 
eternal. If we were really absolutely subject to time, incapable of transcending it, we should be imprisoned each of us as a single point of particularity in its own moment of time. We should be absolutely unchanging because we should be reduced to the abstraction of a bare point of existence. To think of time as a process is therefore, ipso facto, to think of a reality which transcends time, and whose nature is revealed in the process. The truth, once more, is the Whole. We cannot, as philosophers, rest in any principle of explanation short of that which we name the Absolute or God. All experience might not unfitly be described, from the human side, as the quest of Godthe progressive attempt, through living and knowing, to reach a true conception of the Power-whose nature is revealed in all that is. Man, accordingly, does not step outside of this universal life when he develops the qualities of a moral being; the specifically human experiences cannot be taken as an excrescence on the universe or as a self-contained and underived world by themselves. Man is the child of nature, and it is on the basis of natural impulses and in commerce with the system of external things, that his ethical being is built up. The characteristics of the ethical-life must be taken,-therefore, as contributing to determine the nature of the system in which we live. Nay, according to the interpretation we have put upon the principle of value and upon the evolutionary distinction between lower and higher ranges of experience, the ethical predicates must carry us nearer to a true definition of the ultimate Life in which we live than the categories which suffice to describe, for example, the environmental conditions of our existence. 'This fair universe', says Carlyle, in the famous chapter in Sartor Resartus on Natural Supernaturalism, 'is in verydeed the star-domed city of God; through every star. through every grass-blade, and most through every living soul, the glory of a present God still beams.' 'Man,' he 
quotes elsewhere from Chrysostom, 'Man is the true Shekinah'-the visible presence, that is to say, of the divine. We are far too apt to limit and mechanize the great doctrine of the Incarnation which forms the centre of the Christian faith. Whatever else it may mean, it means at least this- that in the conditions of the highest human life we have access, as nowhere else, to the inmost nature of the divine. 'God manifest in the flesh' is a more profound philosophical truth than the loftiest flight of speculation that outsoars all predicates and, for the greater glory of God, declares Him unknowable.

And this, we saw, was the central truth of the Religion of Humanity to which it owes what vitality it possesses. It was one of Comte's boasts that the new God of his religion, as contrasted with the abstract deities of theology or metaphysics, was positive, verifiable like a scientific fact, an object which one could, as it were, directly see and touch. But it is only so far as he presses the organic point of view, so as to unite the Future with the Present and the Past in one mystical body, that ideal humanity assumes for the Comtist the features and proportions of deity. But humanity in the idea-humanity with the light of the ideal upon its upward path and the same light projected on the infinite possibilities of the future - is not a fact of the historical order. It is an idea every whit as mystical as that of God. For just in so far as we do not identify humanity with its own past and present, but endow it with the potency of an ampler and nobler future, just so far do we take man and his history as the expression of a principle of perfection, whose presence at every stage constitutes the possibility of advance beyond that stage. Humanity is, in short, the organ and expression of the divine, just as the individual, in Comte's way of putting it, is the organ and expression of his race. Mankind has no more an entitative independence of God, the larger Providence, than the individual possesses such independence of the proximate and 
lesser Providence which the pious Positivist recognizes in Humanity.

Comte complains, with some show of justice, that the God of traditional theism, and still more Nature, which he says metaphysics substitutes for God, is an abstract and empty term. A critic might say that it is just the bare idea of potentiality or faculty, into which we refund the actual characteristics of the actual world. And in a sense this is true, just as it is true that the essence, if separated from its manifestation, becomes at once the blank abstraction of the unknowable. But to complain of this is to betray one's own bondage to a false and exploded metaphysics. Certainly, apart from our actual experience, God or the Absolute is a subject waiting for predicates, an empty form waiting to be filled. But we need be at no loss for predicates: in the words of the Apostle, 'the invisible things of him from the creation of the world are clearly seen, bcing understood by the things that are made, even his eternal power and Godhead'. Where, indeed, should we gain a knowledge of God except from his manifestation? In precisely the same way, our knowledge of the character of a fellow-man is gained from his words and deeds. But, as Carlyle phrases it, 'Nature, which is the time-vesture of God and reveals Him to the wise, hides Him from the foolish '. And among the foolish are enrolled not a few philosophical writers who clamour for a knowledge of God, not as He reveals himself in nature and in human experience, but as something to be known, it would seem, directly, apart from his manifestation altogether. And when this craving for the impossible is not satisfied, they either deny his existence or proclaim his nature to be unknowable. This false ideal of knowledge has crossed our path several times, and now that it meets us in this supreme instance, it may be well to examine it more closely so as finally to lay the spectre.

Locke and Kant, as we have already seen in the sixth. 
lecture, ${ }^{1}$ are the typical modern examples of the working of this false ideal, and the chief sources to which its prevalence in popular philosophy may be traced. In Locke it connects itself with the distinction between the qualities and the substance, in Kant with the distinction (fundamentally similar) between phenomenon and noumenon, the appearance and the thing-in-itself. Substance and quality are correlative terms by which we interpret what is given or presented in perception. The distinction corresponds to that between subject and predicate or substantive and adjective, and neither member of the pair has any separate existence. Qualities do not fly loose as abstract entities, and substance does not exist as an undetermined somewhat -a mere 'that'-to which they are afterwards attached. The idea of substance is the idea of the qualities as unified and systematized, and indicating, through this unity or system, the presence of a concrete individual. The two ideas, therefore, are in the strictest sense inseparable - the two aspects of every reality -its existence and its nature. Nothing exists except as qualitatively determined; and its existence as such and such an individual is, in fact, determined or constituted by the systematic unity of the qualities. But the scholastic tradition of the substance as a substratum -something in which the qualities inhere-suggests the notion that substance and qualities are two separate facts, the substance or 'support of accidents' being something behind the qualities, over and above them, a bit of realitystuff, so to speak, an atom or core of mere existence, on which the qualitative determinations are hung. And the next step is to conclude, as Locke does, that this substance is a mystery which must remain for ever impenetrable by human faculties; for it is clear that the most exhaustive knowledge of the qualities cannot advance us one step towards a knowledge of what is, by definition, beyond or

${ }^{1}$ Cf. supra, pp. 116-19. 
behind all qualities. As Locke puts it, 'By the complex idea of extended, figured, coloured, and all other sensible qualities, which is all that we know of it, we are as far from the idea of the substance of body, as if we knew nothing at all'. ' Our ignorance in this respect is universal. The substance of spirit and the substance of body, he says in the same chapter, are equally unknown to us. "We do not know the real essence of a pebble or a fly or of our own selves.'

In Kant the contrast is between the thing-in-itself and the thing as it appears, between the noumenon and the phenomenon, and is more expressly connected with the idea of knowledge as a subjective affection. But his manner of arguing is often almost a verbal repetition of Locke's. ' Supposing us to carry our empirical perception even to the very highest degree of clearness,' he tells us, for example, 'we should not thereby advance a step nearer to a knowledge of the constitution of objects as things-in-themselves.' ${ }^{2}$ Or, again, 'All in our cognition that belongs to perception contains nothing more than mere relations. . . Now by means of mere relations a thing cannot be known in itself, and it may therefore be fairly concluded that the presentations of the external sense can contain only the relation of an object to the subject but not the internal nature of the object as a thing-in-itself.' ${ }^{3}$ And he complains of the nature of our intelligence as 'an instrument of research unfitted to discover anything more than always fresh phenomena':

To this strange duplication of appearance and essence, and the substantiation of the one over against the other as

Essay, II. 23. I6.

General Remarks on Transcendental Aesthetic, Werke, vol. iii, p. 73 (Hartenstein).

' 'Das Innere, was dem Objekte an sich zukommt' (ibid., p. 76).

- Remark on the Amphiboly of the Conceptions of Reflection (ibid., p. 235). 
a distinct and different fact, philosophers are indebted, as Berkeley says with delicate irony, 'for being ignorant of what everybody else knows perfectly well.' 'How often must I tell you', says Hylas in the Dialogues, 'that I know not the real nature of any one thing in the universe? I may indeed upon occasion make use of pen, ink, and paper. But what any one of them is in its own true nature, I declare positively I know not.' Philosophers are distinguished, then, from the vulgar, says Philonous, only because ' they know that they know nothing'. 'That', replies Hylas, 'is the very top and perfection of human knowledge.' ' Must we not agree with Berkeley that the whole line of thought is an elaborate and perfectly gratuitous mystification? Yet what Berkeley put forward in irony was propounded at a later date in sober earnest by Sir William Hamilton. 'Our Science', he says, 'is at best the reflection of a reality we cannot know; we strive to penetrate to existence in itself, and what we have laboured intensely to attain, we at last fondly believe that we have accomplished. But, like Ixion, we embrace a cloud for a divinity.' .Man's 'science' is actually 'nescience', and the consummation of knowledge is a 'learned ignorance'. 2 Or, as he explains it in his Lectures: "Matter or body is to us the name either of something known or of something unknown. In so far as matter is a name for something known, it means that which appears to us under the forms of extension, solidity, divisibility, figure, motion, roughness, smoothness, colour, heat, cold, etc. . . . But as these phenomena appear only in conjunction, we are compelled by the constitution of our nature to think them as conjoined in and by something; and as they are phenomena, we cannot think them the phenomena of nothing, but must regard them as the properties of something that is

${ }^{1}$ Three Dialogues between Hylas and Philonous, Third Dialogue, at the beginning.

"Discussions, p. 36 . 
extended, solid, figured, etc. But this something, absolutely and in itself $-\mathrm{i}$. e. considered apart from its phenomena-is to us a zero. It is only in its qualities, only in its effects, in its relative or phenomenal existence, that it is cognizable or conceivable; and it is only by a law of thought which compels us to think something absolute and unknown as the basis and condition of the relative and known, that this something obtains a kind of incomprehensible reality to us.' 1 Our ignorance, he is careful to explain, has nothing to do with the modest range of our senses or faculties. "We may suppose existence to have a thousand modes, but were the number of our faculties co-extensive with the modes of being - had we for each of these thousand modes a separate organ competent to make it known to us-still would our whole knowledge be, as it is at present, only of the relative. Of existence, absolutely and in itself, we should then be as ignorant as we are now.' 2 It is hardly fair to father such fatuities upon ' a law of thought' or 'the constitution of our nature'. It is no doubt in accordance with a law of thought that we refund the multiplicity of the qualities into the unity of the substance; but living thought, as it functions thus in actual experience, has no suspicion of the terrible impasse it is preparing for itself. It takes itself to be making a useful and intelligible distinction within experience, where substance and qualities are complementary and inseparable, as well as mutually explanatory, aspects of the same fact, with no hint of anything 'considered apart from its phenomena'. The qualities are the modes in which the substance exists and reveals itself; to know a thing through its qualities or phenomena-its modes of action-is to know the real thing in the only way in which God or man can know anything. It is only the bungling reflection of the philosopher that ignores the essential relativity of the two conceptions and substantiates the two aspects as two separate facts-the

${ }^{1}$ Lectures on Metaphysics, vol. i, p. 137.

I Ibid., p. 153. 
qualities or phenomena as known or knowable, and the thing-in-itself, by definition, unknown and unknowable. And although expressly defined as unknowable, it is still, it would seem, a slur upon our knowledge that we do not know this thing-in-itself; for that is the reason why our knowledge is labelled by these thinkers as 'merely relative', 'only of phenomena', or, in Hamilton's phrase, a species of 'nescience'. But if, as I have argued, this inaccessible reality - the thing 'considered apart from its phenomena '-is really a phantom created by a misguided logic, these imputations fall to the ground; and however limited and imperfect our knowledge may be, it is still, so far as it goes, a knowledge of reality. Certainly, as Kant says, the progress of knowledge will never discover more than 'fresh phenomena'; but phenomena are not one set of facts and noumena another. The phenomenon is the noumenon so far as it has manifested itself, so far as we have grasped it in knowledge. In a strict sense, it is not really correct to say that we know phenomena: that is like saying twice over that we know. It is the noumena or real things that we know, and phenomena are what we know about them.

There can indeed be no greater absurdity than the perverse reasoning which, as Hutchison Stirling puts it, adduces our knowledge of a thing as the proof and guarantee of our. ignorance of it. ${ }^{1}$ And yet on this notion is founded the usual .agnostic travesty of metaphysics. Metaphysical philosophy is supposed by the ordinary agnostic critic to be engaged in the hopeless quest of this mythical noumenon. No wonder he regards it as an occupation scarcely compatible with sanity. As it was put with brutal frankness quite recently by Sir E. Ray Lankester, a doughty survivor from the wars of last century, 'One may regard the utmost possibilities of the results of human knowledge as the contents of a bracket,

${ }^{2} A s$ regards Protoplasm, p. $7 \mathrm{I}$ (second edition). 
and place outside that bracket the factor $x$ to represent those unknown and unknowable possibilities which the imagination of man is never wearied of suggesting. This factor $x$ is the plaything of the metaphysician '.' It is this same factor $x$ which Herbert Spencer proposed to hand over to religion as an object of worship. For Spencer's doctrine of the Unknowable rests entirely on the considerations that have already met us in Locke, Kant, and Hamilton. He formulates them in the law of the Relativity of Knowledge. ' Thought can never express more than relations,' so that 'from the very nature of our intelligence' 'the reality underlying appearances is totally and for ever inconceivable by us'. 'The man of science', he tells us, 'realizes with a special vividness the utter incomprehensibleness of the simplest fact considered in itself. He, more than any other, truly knows that in its ultimate essence nothing can be known '.2 When this transcendent mystery, which meets us in every particular fact, is generalized, it becomes the Incomprehensible Power on the acknowledgement of which religion is founded. 'Religion', he admits, ' has ever been more or less irreligious' in so far as 'it has all along professed to have some knowledge of that which transcends knowledge'. It 'has from the first struggled to unite more or less science with its nescience', but as it resigns itself entirely to nescience it will reach its legitimate goal. "Through all its successive phases, the disappearance of those positive dogmas by which the mystery was made unmysterious, has formed the essential change delineated in religious history. And so religion has ever been approximating towards that complete recognition of this mystery which is its goal.' When that goal is reached we shall have achieved that "permanent peace' between science and religion referred to in an earlier lecture. We shall 'refrain from assigning any

\footnotetext{
'Preface to Hugh S. R. Elliot's Modern Science and the Illusions of Professor Bergson.

${ }^{2}$ First Principles, p. 67.
} 
attributes whatever' to the object of our worship. We shall recognize it, in fine, as 'alike our highest wisdom and our highest duty to regard that through which all things exist as the Unknowable ' 1

Volumes, doubtless, might be written, as Spencer truly remarked, on the impiety of the pious; their familiarity with the secret counsels of the Most High makes Agnosticism seem by comparison a reverent and a reasonable attitude. And so it would be, if Agnosticism meant no more than the Biblical challenge: 'Canst thou find out the Almighty unto perfection? It is as high as heaven: what canst thou do? deeper than hell, what canst thou know?' If to comprehend means to grasp, as it were, in the hand, to understand thoroughly, to see all round an object, then unquestionably the Infinite must for ever remain incomprehensible by the finite. So far as Agnosticism simply emphasizes the unfathomableness of the universe by any human sounding-line, and opposes the little that we know to the vast unknown, it is a praiseworthy lesson in humility. This is really what most of the 'cloud of witnesses', cited by Hamilton and Spencer, intend by their testimony-not a blank and total nescience, but the narrow limits of our insight as measured against the immensity of our ignorance. It is this feeling of the vast unexplored possibilities of the universe that mingles subtly with the conception of the Unknowable, and half redeems the notion in spite of itself. Curiously, neither Hamilton nor Spencer seems to realize the fundamental difference between the two conceptions, that of the inherently unknowable, and that of the unknownthe not yet known, and doubtless never by us to be fully known, but still the ever to be better known. Hamilton sums up at one point by saying that 'the grand result of human wisdom is thus only a consciousness that what we know is as nothing to what we know not', a proposition

${ }^{1}$ Ibid., pp. 100-13. 
which no reasonable man would wish for a moment to deny. Spencer's phrases are likewise often vague enough to cover either meaning. Thus, when he lays it down that "all things are manifestations of a Power that transcends our knowledge', what transcends our knowledge may mean, and of course in Spencer's theory it ought to mean, what is absolutely inaccessible to our knowledge. But it may be taken quite as naturally to mean that which overpasses our knowledge, that which is inexhaustible by the finite creature; in short, in the apt phrase of the Apostle "the depth of the riches of the wisdom and knowledge of God'. 'Inaccessible ' carries us back to the barren abstraction of the substance hidden behind its qualities. 'Inexhaustible' implies no such unmeaning dualism; it suggests a self-revealing Power, whose manifestation is limited only by the capacity of the recipient.

The radical inconsistency of a pure Agnosticism has often been pointed out. Spencer's very phraseology betrays him. To describe as unknowable 'the Power manifested to us through all existence' is a plain contradictio in adjecto, and yet that is his constant usage. He even tells us that "the Power manifested throughout the Universe, distinguished as material, is the same Power which in ourselves wells up under the form of consciousness', though he seeks to preserve a semblance of consistency by reminding us that ' a conception given in phenomenal manifestations of this ultimate energy can in nowise show us what it is '. $\mathrm{He}$ speaks in the First Principles ${ }^{2}$ of 'the good and bad consequences which conduct brings round through the established order of the Unknowable', and comments on the inability of most men to realize this immanent moral order, which he describes in the same connexion as one of the "actions of the Unseen Reality'. And in the fine passage at the close of the chapters on the Unknowable, ${ }^{3}$ in which he vindicates the

\footnotetext{
'In the essay, 'Religion, a Retrospect and Prospect,' Nineteenth Century, vol. Xv, p. II.

p. II7.

Ibid., p. 123.
} 
right of every thinker to utter what he deems the highest truth without hesitating lest it should be too much in advance of the time, he reminds his possible critics that the thinker himself 'with all his capacities and aspirations and beliefs is not an accident but a product of the time . . . and that his thoughts are as children born to him which he may not carelessly let die. He, like every other man, may properly consider himself as one of the myriad agencies through whom works the Unknown Cause; and when the Unknown Cause produces in him a certain belief, he is thereby authorized to profess and act out that belief. For, to render in their highest sense the words of the poet-

Nature is made better by no mean, But nature makes that mean: so o'er that art Which you say adds to nature, is an art That nature makes.'

We have thus a Power which manifests itself in the intelligible order of the material system, which wells up in consciousness in ourselves, which inspires man 'with all his capacities and aspirations and beliefs', progressively guiding him to truth, and disciplining him also to goodness by an 'established order' of ' good and bad consequences'. Consequently when Spencer began to talk, in all the dignity of capitals, of the one absolute certainty that we are 'ever in presence of an Infinite and Eternal Energy from which all things proceed '-when he confided to the public that as originally written the expression ran, "an Infinite and Eternal Energy by which all things are created and sustained', and that the last clause had been struck out in proof, not because it expressed more than he meant, but only because the ideas associated with the words might prove misleading-it was not surprising that sympathetically minded theologians began to claim him as a Theist malgré lui. 'I held at the outset', he says himself, ' and continue to hold that this Inscrutable Existence . . . stands towards 
our general conception of things in substantially the same relation as does the Creative Power asserted by Theology.' 'Everywhere I have spoken of the Unknowable as the Ultimate Reality-the sole existence: all things present to consciousness being but shows of it.' To 'the Infinite and Eternal Energy, manifested alike within us and without us', 'we must ascribe not only the manifestations themsclves but the law of their order'.' Obviously such statements must be taken as proving, if it needed proof, that it was the positive elements, acknowledged or unacknowledged, in the conception of the Unknowable, that invested it in Spencer's eyes with a genuine religious halo and mąe such a Being appear to him the suitable residuary legatee of the religious sentiments of mankind. But as formulated on the basis of his perverse theory of knowledge, the Unknowable remains a purely negative conception. Its existence, we are told, is 'of all things the most certain', but its nature he still obstinately declares to be 'not simply unknown but proved by analysis of the forms of our intelligence to be unknowable'. And in summing up his position, he describes the perfected religious consciousness as 'the consciousness of an Omnipotent Power to which no attributes can be ascribed' ${ }^{2}$ Could intellectual perversity go further, or is it possible to conceive a more gratuitous selfstultification?

Some of the last quotations are drawn from Spencer's papers in the interesting duel with Mr. Frederic Harrison which enlivened the pages of the Nineteenth Century during the months of 1884 . The duel eventually became triangular through the intervention of Sir James Fitzjames Stephen, who discharged the blunderbuss of a worldly commonsense at both combatants impartially. Mr. Harrison, who

'Nineteenth Century, vol. xvi, pp. 6, 24, 25.

'Nineteenth Century, vol. xvi, p. 838 ("Last Words on Agnosticism and the Religion of Humanity'). The italics in the last two quotations are mine. 
came forward as the chief representative of English Positivism, derided the idea of the Unknowable as the foundation of a religious creed. 'Wonder has its place in religion,' he said, 'and so has mystery; but it is a subordinate place. The roots and fibres of religion are to be found in love, awe, sympathy, gratitude, consciousness of inferiority and of dependence, community of will, acceptance of control, manifestation of purpose, reverence for majesty, goodness, creative energy and life. Where these are not, religion is not.' 'Helpless, objectless, apathetic wonder at an inscrutable infinity may be attractive to a metaphysical divine; but it does not sound like a working force in the world.' 'The precise and yet inexhaustible language of mathematics', as he wittily put it, 'enables us to express, in a common algebraic formula, the exact combination of the unknown raised to its highest power of infinity. That formula is $x^{\mathrm{n}}$. . . Where two or three are gathered together to worship the Unknowable, there the algebraic formula may suffice to give form to their emotions : they may be heard to profess their unwearying belief in $x^{\mathrm{n}}$, even if no weak brother with ritualist tendencies be heard to cry: O $x^{\mathrm{n}}$ love us, help us, make us one with thee.'

Mr. Harrison's ulterior purpose, as a good Comtist, was to point out the superior claims of the Religion of Humanity to be the religion of the future. But, as may be imagined, Spencer was at no loss for rejoinders very damaging to the mixed and ambiguous character of Mr. Harrison's deity, while Sir James Stephen cynically declared that 'Humanity with a capital $\mathrm{H}$ ' was neither better nor worse fitted to be a god than the Unknowable with a capital $U$, each being, a barren abstraction to which any one can attach any meaning he likes'.2 A bystander, more sympathetic than Sir James Stephen, and with a better understanding of

1 'The Ghost of Religion' (Nineteenth Century, vol. xv, pp. 494-506).

${ }^{2}$ Ibid., p. 9 Io. 
religious feelings and motives, might have pointed out that the two disputants shared the truth between them, Mr. Harrison being right in his account (in the passage quoted) of the constitutive factors of religion and the qualities which call forth our gratitude, our reverence, and our love, Spencer being right, on the other hand, in insisting that worship cannot be accorded to anything less than the Perfect and the Infinite, and that Humanity, therefore, as a finite object developing in time, can never fill the place of God. 'If " veneration and gratitude" are due at all,' Spencer says-taking two of the emotions which Mr. Harrison had mentioned as essential constituents of religion' they are due to that Ultimate Cause from which Humanity, individually and as a whole, in common with all other things has proceeded. . . . If we take the highest product of evolution, civilized human society, and ask to what agency all its marvels must be credited, the inevitable answer is-To that Unknown Cause of which the entire Cosmos is a manifestation. A spectator who, seeing a bubble floating on a great river, had his attention so absorbed by the bubble that he ignored the river . . . would fitly typify a disciple of M. Comte, who, centring all his higher sentiments on Humanity, holds it absurd to let either thought or feeling be occupied with that great stream of Creative Power, unlimited in Space or in Time, of which Humanity is a transitory product. Even if, instead of being the dull leaden-hued thing it is, the bubble Humanity had reached that stage of iridescence of which, happily, a high sample of man or woman sometimes shows us a beginning, it would still owe whatever there was in it of beauty to that Infinite and Eternal Energy out of which Humanity has quite recently emerged.'

If this passage of Spencer's may be taken as conclusive against the Positivist attempt to treat Humanity as a selfcontained fact, an Absolute on its own account-and I think 
it is conclusive-surely it is equally conclusive (although Spencer himself will not see it so) against his own cherished doctrine of the unknowability of the ultimate Cause. For the whole process of human evolution is here unequivocally treated as the active self-manifestation of the principle of the Whole. And so the worship of Humanity and the worship of the Unknowable, each untenable in itself, are seen both to owe their vitality, as we might have surmised, to the partial and complementary truths which they respectively enshrine. And these truths are only kept apart by a distorted conception of the relation of reality to its appearances. 


\section{LECTURE IX}

\section{IDEALISM AND PAN-PSYCHISM}

ThE greater part of the last lecture was devoted to an analysis of the fallacy which seems to me to underlie philosophical agnosticism, and, in particular, to Spencer's wellknown application to religion of the sheer disjunction between reality and its appearances. The result of this disjunction is necessarily to leave the one member of it a blank abstraction, to which, as Spencer truly says, 'no attributes can be ascribed;' for if the qualitative nature of the manifestation throws no light on that which is manifested, the latter remains simply the bare fact of an existent somewhat. It is, in short, the old notion of substance as a support of accidents or as the bare point of existence to which the qualities are somehow attached. This comes out so plainly in Spencer's presentation of the agnostic position that it will be worth our while, before passing from the subject, to advert to another line of reflection by which he supports his conclusion. It is significant that he so frequently tells us that, while we can neither know nor conceive the nature of the Power manifested through phenomena, the existence of that Power is of all things the most certain. Thus in the chapter on 'The Relativity of all Knowledge', where he expressly defends (against theorists who bid us 'rest wholly in the consciousness of phenomena') the existence of a positive consciousness of the Absolute or Unconditioned, he insists that 'in the very denial of our power to learn what the Absolute is, there lies hidden the assumption that it is. . . . It is rigorously impossible to conceive that our knowledge is a knowledge of Appearances

\footnotetext{
${ }^{1}$ First Principles, Part I, chap. iv.
} 
only, without at the same time conceiving a Reality of which they are appearances; for appearance without reality is unthinkable. . . Clearly, then, the very demonstration that a definite consciousness of the Absolute is impossible to us, unavoidably presupposes an indefinite consciousness of it. . . The sense of a something which is conditioned in every thought cannot be got rid of.' $\mathrm{He}$ describes it as ' an indefinite notion of general existence, . . . an indefinite consciousness of something constant under all modes-of being apart from its appearances'. It is, accordingly, this notion of 'being' or of 'something' which Spencer has in view when he talks in another chapter of 'the utter incomprehensibleness of the simplest fact, considered in itself', and tells us that 'in its ultimate essence nothing can be known'. The ultimate essence is just the being of the thing, the 'that' of it as opposed to the 'what '-its existence as distinguished from its nature. The statement is, indeed, so paraphrased by a disciple: all things, he tells us, are ' in their essence unknowable, that is, in their reality as resting in what is. . . Precisely that relation to the oneness of Being by which alone they are at all is neither known nor knowable.' ${ }^{1}$

Now there is a sense in which Being may be described as an ultimate and abysmal mystery. It is the sense which fascinated Parmenides and Spinoza and many of the mystic theologians. Von Hartmann speaks ${ }^{2}$ of the ability to appreciate the problem of mere Being, or, as he calls it, of groundless subsistence, as the true touchstone of metaphysical talent. 'If nothing at all existed,' he says, 'no world, no process, no substance, and also, of course, no one to indulge in philosophic wonder, there would be nothing wonderful in that-it would be eminently natural and

${ }^{1} \mathrm{~J}$. Allanson Picton, Religion of the Universe, pp. 55-7. The book is inscribed To the Memory of Herbert Spencer, the first true reconciler of Religion and Science'.

${ }^{2}$ Philosophy of the Unconscious, vol. iii, p. 196 (English translation). 
there would be no problem to solve.' But, that anything at all exists, or how the somewhat on which everything else depends comes to exist-this is so unfathomably mysterious, that when the question is once realized it eclipses all possible wonder at the detailed nature of the universe which thus exists. But if this be, as Hartmann calls it, the problem of problems before which we become rigid as before a Gorgon's head, it is obvious that it is, as he says, inherently insoluble-whether the metaphysician be human or divine. It is fruitless, if not absurd, to inquire, in Lotze's quaint phrase, 'how being is made,' how there comes to be anything at all. Even a divine metaphysician must start from the fact of his own existence; and we, as philosophers, have not to create the universe or to explain why there should be a universe at all, but to find out what kind of a universe it is. It becomes quite misleading, therefore, to speak as if we were cut off from a knowledge of the essence of things, because we have to take their existence for granted. From this point of view, there is nothing mysterious or unfathomable at all about being: there is nothing more to know about it than just 'being', or, as Spencer dilutes the term, 'the sense of a something' or 'an indefinite notion of general existence'. It is the beginning of knowledge, not its ultimate and transcendent goal. The task of knowledge, philosophical as well as scientific, is to make this indefinite consciousness definite, to discover what kind of a something it is that we have to deal with. But the agnostic way of putting it converts the mere 'that'-the fact of the thing's existence-into a profounder kind of 'what', and declares this to be unknowable. For such a procedure there is no justification either in the case of an individual thing or in the case of the Absolute. Of the Absolute it has been finely said, 'its predicates are the worlds'.' We learn its nature through

'Laurie, Synthetica, vol. ii, p. 88. 
the facts of the universe, especially so far as any system or scale of values is discernible in them. This is the immanent God on our knowledge of whom it has been the purpose of this first course of lectures to insist.

The nature of ultimate Reality is to be read, therefore, in its manifestation, and may be read there truly. We may be sure the revelation is not exhaustive, for all revelation must be ad modum recipientis; it must be proportionate to the capacity of the receiving mind. Every advance in knowledge, or in goodness, or in the intuitions of beauty and grandeur offered us in nature or in art, is a further revelation of the heights and depths of the divine nature. From this point of view the very notion of development is progressive initiation. 'I have yet many things to say unto you, but ye cannot bear them now.' And if this is true within the historical development of mankind in the past, it is reasonable to suppose that the record is not closed at the present stage of attainment. Every creature, says Nietzsche, has paved the way for something higher; man is but a transition figure, ' a rope,' as he calls it, between the beast and the superman of the future. In a nobler sense than he himself applies it, we may accept the idea of the more godlike man that is to bejust as we may give rein to our imagination and suppose such larger intelligences existing now in worlds beyond our ken. But all such acknowledgements alter nothing as to the attitude of the knower and the mode in which his knowledge is obtained. The most exalted intelligence must read, as we do, in the volume of God's works, to learn His nature: his knowledge, like ours, is through the manifestation. Though it may be truer in the sense of being ampler and more adequate, and so correcting errors and solving difficulties incident to our more limited range of vision, this is but a difference of degree, not a qualitative distinction between absolute and relative, as if the one knowledge were true and the other vitiated by some inherent defect. Our 
knowledge is as true for us as the ampler knowledge for the higher being. Each is true as being an interpretation of the facts accessible at that particular stage. With new data comes new insight; but the new insight carries forward and incorporates the old-it does not abolish it.

That being so, it has been the contention of these lectures that everything depends upon our keeping in view the whole range of accessible facts, if we are to form a true idea of the nature of the system as a whole, and consequently of the nature of the Being whom it reveals. We began by accepting Hume's challenge: 'Whence can any cause be known but from the known effects? Whence can any hypothesis be established but from the apparent phenomena?' But we demurred to his own limitation of the argument to 'a contemplation of the works of nature', i. e., to the structure and arrangements of the external world. Hume himself speaks of 'living existences' as 'the only beings worth regarding' when it comes to a final judgement on the nature of the universe." The ultimate Power 'wells up' as Spencer phrases it, in man, the knower, no less than in the objects he contemplates, and not only in man as knower, but in all the aspects of human life. It seemed to us, accordingly, that, instead of being excluded from consideration, the characteristics of human consciousness and human development must be the most significant of all facts for the solution of our question. We saw how Kant gave this central significance to man's ethical experience. But all through our discussion we have had to struggle against the tendency to treat the world of nature as a fact complete in itself, a system finished without man. This tendency appeared in very different forms, sometimes reducing consciousness to an inactive accompaniment of material processes going on by themselves, at other times, as in the Positivist theory, making man his own creator, so far as the distinctively human virtues and

${ }^{2}$ Dialogues, Part XI. 
excellences are concerned. I have insisted, on the contrary, that to do this is to convert abstractions into realities by separating what is given together and cannot be conceived apart. Man is organic to nature, and nature is organic to man. It is a false abstraction to try to take the world apart from the central fact in which it so obviously finds expression. So taken, it is like a broken arch or, in Laurie's figure, a circle unclosed; there is no system, no whole of being, no real fact at all, till the external gathers itself up, as it were, into internality, and existence sums itself in the conscious soul. And this way of talking in terms of a time-process, common and natural as it is, should not mislead us into thinking that the external ever existed as a mere external, before it internalized itself-as if the body of the universe existed, so to speak, like an empty case waiting for a soul. The metaphorical language in which Lotze, not to mention Hegel and others, speaks of nature as striving towards selfexpression and rising, as it were, stage by stage towards its self-completion in mind, is clearly not intended as the record of an historical progress. Such expressions are an analysis of ideal stages or ' moments', as idealistic writers are fond of calling them, aspects of one total fact, which can only be known truly as a whole or system. Hence I was at pains to insist that questions of the apparent historical genesis of the higher or more complex from the lower or simpler have no philosophical importance or relevance, seeing that, philosophically considered, the lower or simpler phases are not independent facts existing as a prius, but abstract aspects of a single fact, which is fully expressible only in terms of selfconscious experience.

So far our argument may claim to have been continuous and to have reached a definite, if still very general, conclusion. I will not attempt to carry the argument further within the limits of the present course. I will try instead to 
render the nature of our conclusion more precise by differentiating it from theories which it may seem to resemble, and by the refutation of which it is frequently supposed to be overthrown. It is specially important at the present time to disentangle the position from its supposed dependence on the questionable or more than questionable arguments by which those other theories are supported; and in what follows we shall have in view, in the first place, the strong trend of speculation in certain quarters at the present day in the direction of Pan-psychism, and, in the second place, the active contemporary propaganda in support of Realism.

Our doctrine, as we have built it up, may be focused in the saying that man (or mind) is organic to nature. The very phrase, it may be pointed out, implies the complementary truth of nature as organic to man, nature as the essential condition of finite mind. Internality is impossible without externality; a subject or a self would be an empty form, if it had not a world to draw on for its filling. Just as every living centre has its environment, which furnishes it with the material which it transmutes and builds into the fabric of its own life-so that it is only through its environment that it lives at all-so, still more obviously, the self of knowledge and action could have nothing either to know or to do, apart from the natural and social world of which it is at once the consciousness and the active organ. The world of nature and the world of social relations founded upon it constitute, as it were, the condition of individuation. And in emphatically repudiating the mechanistic scheme of physical science as a self-existent, underlying reality, of which everything else is the inexplicable outcome, a spiritual philosophy which is sure of itself feels no temptation to deny or to minimize the mechanical aspects of the cosmos on which its higher life reposes. On the contrary, nature, as a realm of inviolable law, appears, so far as we can see, to be 
the necessary condition of the life of intelligence and reasonable action. Nevertheless, a revulsion from the conclusions of the lower Naturalism has led a number of idealistic thinkers at the present day to seek to turn the tables upon Naturalism by resolving the universe without remainder into an assemblage of subjective centres of existence, and thus abolishing altogether the conception of nature in the ordinary sense of the term. On the ordinary view, nature provides the theatre, the scenery, and properties for the spiritual drama. The system of nature seems, as I have suggested, to furnish at once the conditions of individuation and the means of communication between individuals. But, on this monadistic theory, the organic vesture of the spirit and its environmental conditions are both resolved into innumerable quasi-spiritual centres; and the objective world becomes simply the appearance of these souls or monads to one another. The classical type of this theory is the Monadology of Leibnitz, and its recent advocates have not greatly departed from or improved upon his exposition.

The thought-motives of the theory are fairly obvious. It seems to furnish the most crushing reply conceivable to materialism by spiritualizing the universe to its tiniest particle. The principle of continuity also seems to lend it powerful support; and this is, in fact, the principle on which the theory is mainly based by Leibnitz and most of his followers. Our own existence, as we immediately experience it, gives us our pied-à-terre, the living instance from which we start. We habitually assume that the lower animals exist as similar centres of feeling and striving; they are conscious, although not possessing the self-consciousness that comes with the conceptual reason. As we descend in the animal scale to the lowest organic forms, we still imagine some degree of this consciousness to remain-some faint analogue of our own self-centred life, though we may hesitate to speak of it even as consciousness and may invoke the convenient 
term subconsciousness to describe it-a vague, diffused, undifferentiated feeling, conceived as the impulsive basis of action, seeing that feeling and activity are for psychology two inseparable aspects of a single fact. And when we once surrender ourselves to the principle of continuity, why should we stop at the confines of the animal kingdom, or why should we limit such considerations to the case of the organism as a whole? Modern psychology is on the track of many obscure phenomena which suggest the idea of subordinate centres of experience and memory besides the central and normal consciousness based upon the cortical centres in the brain. Speculative biologists have extended this idea, and would treat each living cell as in some degree conscious or quasi-conscious, explaining thereby its selective action and general behaviour. And again, why stop at the living cell? The affinities, as they are called, of chemical atoms and molecules seem to exhibit the same characteristics of action from within-some analogue of selection or choice. And the matter of the physicist only seems to us dead and inert because we ordinarily view it in the mass. But science resolves the passive lump of extended matter into a mazy dance of invisible particles, if not into sheerly ideal centres of force. Hence the atom, or whatever lies behind the atom, as the ultimate term of physical science, is itself conceived by the Monadist as psychical in essence, a feeling and responsive centre after the analogy of our own existence, in however remote a degree. And thus we arrive at the view expressed by Leibnitz in a well-known passage: ' Each portion of matter is not only infinitely divisible, but is also actually subdivided without end. . . . Whence it appears that in the smallest particle of matter there is a world of creatures, living beings, animals, entelechies, souls. Each portion of matter may be conceived as like a garden full of plants or like a pond full of fishes. But each branch of every plant, each member of every animal, each drop of its liquid 
parts is also some such garden or pond. . . . Thus there is nothing fallow, nothing sterile, nothing dead in the universe, no chaos, no confusion save in appearance, somewhat as it might appear to be in a pond at a distance, in which one would see a confused movement and, as it were, a swarming of fish in the pond, without separately distinguishing the fish themselves.' 1

Sometimes in contemporary writers the theory of an atomic soul appears as a blundering attempt to throw the glamour of Idealism over a purely materialistic position. So it is, for example, in Haeckel, who seems to think he has solved the 'Riddle of the Universe' by allowing each atom ' a rudimentary form of sensation and will, or, as it is better expressed, of feeling (aesthesis) and inclination (tropesis)'.2 But things are not changed by giving them Greek names, nor is the philosophical position altered by infusing, as it were, into each occurrence a drop of consciousness. Idealism means essentially the interpretation of the world according to a scale of value, or, in Plato's phrase, by the Idea of the Good or the Best. The addition of consciousness to everything as its inner side, a running accompaniment, which makes no difference-this favourite idea of popular scientific Monism is a complete philosophical cul-de-sac. The philosophical interest of consciousness lies in the ideal values of which it is, so to say, the bearer, not in its mere existence as a more refined kind of fact. One has heard of people who treated the ether as a half-way house between matter and thought, and this way of treating consciousness shows much the same habit of mind.

In other quarters, Pan-psychism is adopted as a way of escape from difficulties in the theory of knowledge. Thus Clifford escapes from Subjective Idealism by a distinction between the object, which he takes to be a subjective modifi-

1 Monadology, sections 65-9.

${ }^{2}$ Riddle of the Universe, chap. xii. 
cation in the knowing mind, and the eject or extra-mental reality which these conscious states symbolize. The typical ejects which we all recognize are the minds or consciousnesses of our fellow-men; and on that analogy Clifford concludes that ejects (or things-in-themselves, as he also calls them) are always psychical in character. He does not, indeed, place a mind or unitary consciousness behind every material particle; but, since mind may be regarded as a complex, of which simple feelings are the elements, he supposes these elements to exist independently, and by subsequent combination to give rise to the faint beginnings of sentience in a low organism, and eventually, in more complex combinations, to the phenomena of human consciousness. 'A moving molecule of inorganic matter does not possess mind or consciousness; but it possesses a small piece of mindstuff. When molecules are so combined together as to form the film on the under side of a jelly-fish, the elements of mind-stuff which go along with them are so combined as to form the faint beginnings of Sentience. When the molecules are so combined as to form the brain and nervous system of a vertebrate, the corresponding elements of mind-stuff are so combined as to form some kind of consciousness. ... When matter takes the complex form of a human brain, the corresponding mind-stuff takes the form of a human consciousness, having intelligence and volition.' 'Mind-stuff is then the reality which we perceive as matter.' 1

The idea of small pieces of unconscious mind-stuff combining independently into minds is, I take it, a 'psychological monster' of the most impossible type. But that peculiar feature of Clifford's theory has no special relevance in the present connexion. The theory is quoted simply as an example of the difficulty which is widely felt in taking material things, as we perceive them, to be realities existing

'Lectures and Essays, vol. ii, p. 85: Essay ' On the Nature of Thingsin-themselves'. 
in their own right. This is a genuine difficulty. It is the nerve of Berkeley's criticism of Locke's 'stupid thoughtless somewhat'; and unless we are satisfied, like Berkeley, to treat the material world as a system of signs, which have no existence save as intermittent experiences in the minds of individual knowers and as a continuous divine purpose of acting according to certain rules, the alternative seems to be that of the Pan-psychists, namely, to place behind each material appearance a mental counterpart or monadic soul. But this philosophical animism is in the end, I propose to argue, too primitively simple an expedient, and it is a theory difficult to reconcile with our common-sense attitude towards natural things.

But perhaps the most important motive underlying Monadism still remains to be mentioned. By its most recent advocates, Monadism appears to be regarded as a way of escape from the complete determinism with which the mechanistic scheme seems to threaten human life. Inasmuch as it treats feeling and striving-that is to say, the fundamental characteristics of conscious life-as the primary fact in the universe, it makes the idea of law derivative from that of activity. This is the form in which the theory meets us in Professor Ward's recent Gifford Lectures on Pluralism and Theism. Professor Ward presents it, in the first instance, as developed by those whom he calls Pluralists, some of whom might. also be described as Pragmatists; but, so far as I am able to judge, he accepts the main position as his own. On this view, then, we do not start with an established order, a reign of law, or system of conditions within which purposive action (and all action) takes place. Pluralism, we are told, ${ }^{1}$ 'attempts to get behind all this'; it 'undertakes to explain how this orderliness has itself been developed'. The fixed laws and stable arrangements of the world have been gradually evolved,

${ }^{1}$ Cf. The Realm of Ends, or Pluralism and Theism, pp. 67-9. 
it is contended, as a result of the behaviour to one another of the active individuals which ultimately compose the universe. They represent the result, that is to say, of the action and reaction of these psychical individua in their struggle for the best modus vivendi. ${ }^{1}$ Professor Ward applies here the idea, so prominent in his own 'Psychology', of habits and automatisms as essentially secondary formations-deposits, so to speak, of actions originally due to subjective selection. This idea is, of course, both true and fruitful, as commonly applied in psychology and biology. But extending the conception beyond the usual psychological and biological limits, Professor Ward seems to accept, or at least seriously to entertain, the statement which he quotes from C. S. Peirce that 'matter is effete mind, inveterate habits becoming physical laws'. He speaks repeatedly of nature in this sense as 'plastic', and adapts the old scholastic distinction of natura naturata and natura naturans to express his meaning. 'What is done, natura naturata-the decisions made, the habits formed, the customs fixed-constitutes at any stage the routine, the general trend of things, within which future possibilities lie. What is still to do, natura naturans, implies further spontaneity and growth-new decisions to be taken, fresh experiments to be made, with their usual sequel of trial and error and possible eventual success.'

But in the attempt to derive all laws from previous actions, this ultra-pragmatism appears to overleap itself; for surely the very consolidation of actions into habits depends upon the pre-existence of a stable system of conditions. What meaning can we attach to actions in abstracto, apart from any environment? The laudable desire to save spontaneity and freedom seems, by denying necessity altogether, to fall into the other extreme of pure chance. It would obviously be unfair to make Professor

${ }^{1}$ The Realm of Ends, or Pluralism and Theism, p. 80. 
Ward responsible for everything that Mr. Peirce may say, but some of the passages in the article from which the above quotation was taken, ${ }^{1}$ and in particular its conclusion, are too remarkable to be passed over without notice. 'Law', says Mr. Peirce, 'is par excellence the thing that wants a reason'; and so he sets about 'accounting for the laws of nature and for uniformity in general', i. e. for the fact of law or order at all. The only possible way of accounting for them, he proceeds, is 'to suppose them results of evolution'; and he adds that 'this supposes them not to be absolute, not to be obeyed precisely. It makes an element of indeterminacy, spontaneity or absolute chance in nature.' And the article concludes with this startling picture of the way in which we may conceive the generation of law and order, the growth of cosmos out of chaos: 'In the beginning, infinitely remote,' we may suppose, 'there was a chaos of unpersonalised feeling which, being without connection or regularity, would properly be without existence. $^{2}$ This feeling, sporting here and there in pure arbitrariness, would have started the germ of a generalising tendency. Its other sportings would be evanescent, but this would have a growing virtue. Thus the tendency to habit would be started; and from this, with the other principles of evolution, all the regularities of the universe would be evolved. At any time, however, an element of pure chance survives, and will remain until the world becomes an absolutely perfect, rational and symmetrical system, in which mind is at last crystallised in the infinitely distant future.'

I will not trust myself to characterize this extraordinary attempt to evolve out of pure chaos the very conditions of

1 ' The Architectonic of Theories' in the Monist, January 189r, vol. i, p. I6r et seq.

${ }^{2}$ What this means I confess I do not understand; presumably it depends on some idiosyncrasy in Mr. Peirce's terminology. 
evolution itself. I should not have thought it worth mentioning, indeed, but for Professor Ward's approving quotation from the article. Professor Ward himself, it is fair to say, while he notes that certain pluralists, ill-advised, as he deems them, have not hesitated to draw this conclusion of absolute contingency, and have even proposed the term 'Tychism' to describe their doctrine, denies the start with chaos, and introduces a distinction between what he calls the contingency of chance and the contingency of freedom. ${ }^{1}$ But so long as he maintains the foregoing account of the origin of physical law, it is difficult to see how he can logically escape the consequences which he repudiates. And one cannot forget that Professor Ward, both in his earlier course of Gifford Lectures and in this one, has lent his countenance to the idea of contingency, by representing the uniformity of natural law as comparable to that of a statistical average, which gives results that are constant for large aggregates but cover an indefinite amount of variation in individual cases. Statistical results, as he puts it in his recent volume ${ }^{2}$, frequently hide the diversity and spontaneity of animated beings when they and their actions are taken en masse. This diversity and spontaneity' (he adds) 'are held to be fundamental: and the orderliness and regularity we now observe, to be the result of conduct, not its presupposition.' But, at the atomic level contemplated, it is difficult to see what scope there is for spontaneity, unless it is taken to mean a power of reacting differently in identical circumstances; for a different mode of reaction to a different stimulus is just what is implied in the idea of law which it is sought to repudiate or get behind. Professor Bosanquet, who traverses this whole line of argument, points out that relevancy, rather than uniformity, is the proper designation of the scientific postu-

'Realm of Ends, p. 454. Cf. Naturalism and Agnosticism, vol. ii, p. 281.

${ }^{2}$ Realm of Ends, p. 433 . 
late of law, i. e. appropriate reaction, remaining the same doubtless when the circumstances are the same, but varying with every change of circumstance-the principle, in short, that 'for every difference there must be a reason'. So that fineness of adjustment, precision and relevancy of determinate response, should mean at once the perfection of the living intelligence and the completest realization of law. To take spontaneity in any other sense 'sets us wrong $a b$ initio in our attitude to the characteristics of consciousness, teaching us to connect it with eccentricity and caprice instead of with system and rationality'.' The argument from statistics seems intended to prove that the uniformity on the whole which appears in physical movements is a mere average, each individual movement being due to the 'spontaneity' of the individual particle and varying possibly in one direction or the other, and in greater or less degree, from the mean which the law formulates. But what is gained for the cause of spiritual freedom by endowing particles with a spontaneity of this kind, it is not easy to see. Action cannot be intelligibly considered apart from the ideas of stimulus and response, and when it is so considered, spontaneity can only mean unhampered response according to the joint nature of the interacting factors. The idea of spontaneity in the abstract, apart from such a reference, must reduce itself to sheer wilfulness, and lead us back to Peirce's conception of ' feeling sporting here and there in pure arbitrariness'. A system of unvarying natural order is demanded, it may be pointed out, in the service of the higher conscious life itself as the condition of reasonable action. It is instructive, for example, to observe Hume complaining of the pains and hardships which come to individuals from 'the conducting of the world by general laws' and admitting in the same breath that 'if everything were conducted by particular volitions, the course of

${ }^{1}$ Principle of Individuality and Value, p. 94. 
nature would be perpetually broken, and no man could employ his reason in the conduct of life '. ${ }^{1}$

Much the same criticism applies to the general theory of Monadism, if carried to its logical conclusion. What are we to make of those monads towards the lower limit, those bare or naked monads, as Leibnitz called them, which are simply a mens momentanea, without memory or the power of profiting by experience, and which therefore can only react immediately and to what is immediately given? If, in Professor Ward's words, they are 'beings which have only external relations to one another, or rather for which as the limit of our regress, the distinction of internal and external ceases to hold', how does their behaviour to one another differ from a case of mechanical interaction as ordinarily understood? And if the two are indistinguishable, what is the use of the monadistic construction? Might we not as well have accepted the realm of physical law to begin with, as the substructure of the spiritual, and, so far as we can see, the necessary presupposition of individual experience? On the hypothesis of Pan-psychism, it has been said," "what becomes of the material incidents of life-of our food, our clothes, our country, our bodies? Is it not obvious that our relation to these things is essential to finite being, and that if they are in addition subjective psychical centres their subjective psychical quality is one which, so far as realized, would destroy their function and character for us?' In other words, it is as things, as externalities, that they function in our life, not as other selves; if we had to treat them as other selves, their characteristic being would disappear. We conclude, therefore, that absolutely nothing is gained, and much confusion is introduced, by resolving external nature into an aggregate of tiny minds or, still worse, of ' small pieces of mind-stuff'.

${ }^{1}$ Dialogues, Part II.

'Bosanquet, Individuality and Value, p. 363. Cf. p. 194. 
It is sufficient for the purposes of Idealism that nature as a whole should be recognized as complementary to mind, and possessing therefore no absolute existence of its own apart from its spiritual completion; just as mind in turn would be intellectually and ethically void without a world to furnish it with the materials of knowledge and of duty. Both are necessary elements of a single system. ${ }^{1}$

${ }^{2}$ See Supplementary Note A to Second Edition, p. 419. 


\section{LECTURE X}

\section{IDEALISM AND MENTALISM}

A FURTHER point requires elucidation. The conclusion we have reached-the doctrine of the self-conscious life as organic to the world or of the world as finding completion and expression in that life, so that the universe, as a complete or self-existent fact, is statable only in terms of mindthis is the doctrine historically known as Idealism, sometimes described in recent discussion as objective, transcendental or absolute Idealism, according to its historical origin and colouring or the special emphasis of the controversy. But Idealism also means historically the doctrine that the being of things is dependent on their being known - the familiar Berkeleian doctrine that esse is percipi, or, as some later transcendentalists have modified it, that esse is intelligi-which yields directly Berkeley's further position that the existence of unthinking things is a contradiction in terms, and therefore, as he puts it, 'nothing properly but Persons, i.e. conscious things, do exist. All other things are not so much existences as manners of the existence of persons'. ${ }^{1}$ This position, in the typical form given to it by Berkeley, is more specifically known as Subjective Idealism, but the fundamental argument on which it is based-the dependence of being on being known-re-

${ }^{1}$ In the Commonplace Book, Works, Vol. I, p. 59 (Fraser's edition of Igor). Cf. Mr. Bradley's statements (Appearance and Reality, p. 144): 'We perceive, on reflection, that to be real. or even barely to exist, must be to fall within sentience. Sentient experience, in short. is reality, and what is not this is not real. . . Feeling, thought, and volition . . . are all the material for existence.' Professor Taylor uses similar language in his Elements of Metaphysics, p. 347: 'We are already agreed that reality is exclusively composed of psychical fact.' But see Supplementary Note B., p. 420. 
mains the same in those transcendental theories which endeavour to avoid the private or individualistic character of Berkeley's doctrine by bringing in an All-Knower to maintain in existence the world of objects which we recognize in common, and which we usually think of as existing quite irrespective of whether they are known or not known. For this characteristic position the term Mentalism, which we appear to owe to the late Professor Sidgwick, ${ }^{1}$ would seem to be a more appropriate name than the overdriven and many-coloured term Idealism, and I propose to use it consistently in that sense throughout the present lecture. Mentalism, in its older form, was the object of Thomas Reid's attack in this very University of Aberdeen a century and a half ago; and it is matter of common knowledge that the opening years of the twentieth century have been marked, on both sides of the Atlantic, by a strong attack on the fundamental tenet of Mentalism on the part of thinkers who call themselves Realists or Neo-Realists. Into the whole of this controversy it would be impossible, as well as hardly relevant, to enter here. But I feel it to be important, if misconception is to be avoided, to free the position I am defending from any supposed dependence on the Mentalistic doctrines which have often been used to support it, but which I agree with the Realists in considering untenable.

First, then, we must admit that the argument so persuasively stated by Berkeley is essentially circular. We cannot conceive the existence of material things apart from

'In his posthumous lectures on Philosophy, its Scope and Relations, Sidgwick extends the scope of the term so as to include not only Sensationalists and Idealists (whom he calls Pure Mentalists), but also Phenomenalists or Relativists, who do not deny the existence of matter independently of mind, but hold that we can have no knowledge of it as so existing. See pp. 61-2. The term is not to be found in Baldwin's Dictionary of Philosophy, but I note that Professor Bosanquet has recently employed it in his Adamson Lecture on The Distinction between Mind and its Objects (1913). 
a mind which perceives or knows them, because, as Berkeley himself puts it, we are trying to "conceive them existing unconceived or unthought of ', which is a plain contradiction. The mind in the attempt inevitably introduces itself, but, 'taking no notice of itself', fails to observe that it has vitiated the experiment. This is what an American Realist, in a phrase worthy of Kant, in its full-flavoured technicality, has dubbed 'the ego-centric predicament'. The Ego is the centre of its own world, the presupposition of all its knowledge; it is impossible, in the nature of the case, to extrude it. But that of itself decides nothing as to the existence of things before or after they were known, and apart from the effort to conceive them. Berkeley proves that they cannot exist in the knowledge relation without implying a mind or ego, and also that we cannot say anything about them except as known, so that out of that relation they are to us, in a Kantian phrase, as good as nothing at all. But this method of approach cannot possibly prove that they do not exist out of that relation; it cannot prove Berkeley's thesis that being-in-that-relation constitutes their existence. On the contrary, we should all say, prima facie, that being known makes no difference to the existence of anything real.

The Mentalist will no doubt admit, as Berkeley himself does, that things known have an obvious independence of the individual subject; but he will still insist that their being consists in their presence to a universal consciousness, an All-Knower, who, by knowing them, maintains them, so to speak, in existence. This is, more particularly, the transcendental variety of Mentalism. But if knowledge has the same meaning in the two cases, the existence of a thing can no more depend on God's knowing it than on my knowing it. And hence it will be noticed that most versions of this theory, in speaking of the universal Knower, introduce phrases like a creative consciousness, a perceptive understanding which originates the matter as well as the form of its objects, 
and so forth. But in so doing they entirely alter the conditions. No doubt the phrases used are exceedingly obscure, and not always consistently applied; but the general implication is that the creative subject conveys into the object something of his own being. Sometimes the process is described as a self-externalization or outering of itself on the part of the subject. But however it may be described, it is this act which, as it were, supplies the object to be known: it is not the knowing, as such, that constitutes or makes the object. The change in phraseology is, in short, a tacit acknowledgement of the principle that in every case knowledge presupposes a reality, which it knows but does not make. ${ }^{1}$

But the point for us is that this transcendental idealism is just Berkeleian idealism in excelsis, Berkeleianism universalized and applied on the cosmic scale; and the reasoning is, therefore, of the same circular character. This may be very clearly seen in Ferrier's philosophy, which is perhaps the clearest statement of this form of idealism. Ferrier expressly recognizes Berkeley as 'the first to swell the current of that mighty stream of tendency towards which all modern meditation flows, the great gulf stream of Absolute Idealism '; and in his own theory he claims to present Berkeley's principle purged of Berkeley's sensationalism. Accordingly the central propositions of his Institutes all turn on 'the inseparability of the objective and the subjective', that is, on the necessary presence of the subject in every act of

'Berkeley also has recourse to God, in a more naive way, to account for the persistence of objects in the intervals of finite percipience and, in general, for the permanence and order of the material world. But it will be remembered that he gives no account of the mode in which sensible objects are present to the divine consciousness; this apparently occurred to him as a difficulty after his chief works were written, for he touches upon it in Siris. In general, he treats our sense-experience simply as an effect of the divine will, and this may perhaps be taken as another way of acknowledging that more than knowledge is implied in the constitution of any reality. 
knowledge. 'Object plus subject is the absolute in cognition,' the unit in knowledge; 'matter mecum,' he otherwise expresses it, 'thoughts or mental states together with the self or subject.' 1 Matter per se (and the same applies to an Ego per se) thus "lapses into a contradiction; it becomes a mere absurdity'; 'it is not simply the inconceivable by us, but the absolutely inconceivable in itself.' And the conclusion thus based upon the analysis of knowledge in the first part of the work (the Epistemology) is translated in the third part into an Ontology or theory of Being: 'Absolute existence is the synthesis of the subject and the object . . . the concentration of the Ego and non-ego; in other words, the only true and real and independent existences are mindstogether-with-that-which-they-apprehend.' And the one absolute existence which is strictly necessary is 'a supreme and infinite and everlasting Mind in synthesis with all things'.2 The whole volume, with its elaborate series of propositions and demonstrations, is too patently only a statement and re-statement of the ego-centric predicament. Moreover, the result of this line of argument, even if we were to take it as legitimately reached, scems more valuable than it is; for the Ego gained, whether human or divine, is no more than the bare form of consciousness. In our analysis we have allowed ourselves to become the victims of the eyemetaphor, the spectator-theory of consciousness. Instead of treating the subject as the organic unity of the psychical content, this theory lifts it out of the living process altogether, and sets it like a static eye in position over against its states or ideas, to which it is related, accordingly, as a kind of abstract and unchanging unit or point of reference. The Ego, we are told, is not the ideas and states, it has them. But an Ego or subject thus conceived stands in a merely

\footnotetext{
${ }^{1}$ Institutes of Metaphysics, p. $\mathrm{I} 37$ (section I, proposition 4, observation 13 ).

${ }^{2}$ Ibid., pp. 511, 522 (section 3, propositions io and II).
} 
external relation to its content; it is the abstraction of a formal unity or, to vary the metaphor, it is like an empty vessel into which the content is packed. If the proof of an everlasting mind in synthesis with all things means no more than the necessity of such an abstract point of reference, its existence seems hardly worth contending for. And yet I do not think that this kind of epistemological demonstration can yield us more.

We reach, I am afraid, a very similar result in Green. Green's theory moves in a Kantian atmosphere. His Spiritual Principle is directly derived from Kant's doctrine of the synthetic unity of apperception present in every act of knowing. Green, perhaps with Ferrier in his mind, acknowledges that it is unwarrantable 'to assume, because all reality requires thought to conceive it, that therefore thought is the condition of its existence'. But although we cannot take up this general position, we may, he thinks, arrive at the same result by observing that what we call the real world consists of things in relation to one another, or, as Green tends on the whole to say, consists of relations. ${ }^{1}$ Knowledge of relation implies 'a combining agency' or ' unifying principle' which, while maintaining the distinction of the terms, produces 'a real unity of the manifold' by setting them in relation to one another, viewing them, for example, as successive or co-existent, as similar, or as related in the way of cause and effect-related, in short, in some one of the many ways which constitute facts members of a common world. And as we are obliged to believe that relations are somehow real apart from our individual knowledge of them, "we must recognize as the condition of this reality the action of some unifying principle analogous to that of our understanding "; for "relations can only exist for

${ }^{1} \mathrm{He}$ identifies 'the conception of nature' with that 'of a single allinclusive system of relations', and formulates his inquiry, 'What is implied in there being such a single all-inclusive system of relations?' (Prolegomena to Ethics, p. 30). 
a thinking consciousness': The synthetic unity is thus taken to be "the basis not merely of our knowledge of uniform relations between phenomena but of there being those uniform relations. The source of the relations and the source of our knowledge of them is one and the same,' 'the consciousness [namely] which constitutes reality and makes the world one,' 'the all-uniting consciousness'. Relations 'only exist for or through the action of [this] unifying and self-distinguishing spiritual subject '. Consciousness, he says again, is 'the medium and sustainer' of relations. The eternal consciousness is 'the spirit for which the relations of the universe exist '. ${ }^{2}$

Now, as William James in his character of ' radical empiricist', so often pointed out, this argument really starts from the assumption of atomistic and unrelated sensations, such as we find it, for example, in Locke and Hume. According to this defunct psychology (which was, it must be remembered, the presupposition and the raison d'être of the Kantian scheme), what is given to us in sensation is mere multiplicity or disjunction. All unity and relatedness thus comes to be explained, by Hume, as a fiction of the imagination, and, by Kant, as superinduced upon the matter of sense by the synthetic activity of thought. Thought, in Green's phrase, is 'the combining agency' which, acting as it were $a b$ extra on the sensational flux, transforms it into a world of permanently related objects. But, as James quite unanswerably urges, if relations between objects are in any way real, they must be represented in feeling just as much as the objects which are said to be related. "We ought to say a feeling of "and", a feeling of "if ", a feeling of "but", and a feeling of "by", quite as readily as we say a feeling of blue or a feeling of cold.' And it

${ }^{2}$ Prolegomena to Ethics, pp. 32, 53.

2 These quotations are all from the first and second chapters of the Prolegomena to Ethics. See in particular pp. $35,43,52-3,68,78$. 
may be taken as admitted in recent discussion that thought, in operating upon sense and transforming it, as it undoubtedly does, does not infuse into sense anything which was not already there in sensuous form. ${ }^{1}$ The unity of experience, so far as it is unified and connected, is just as real and primitive a fact as its variety, and we do not require the apparatus of a special principle to constitute and sustain rclations any more than to sustain existence in general. Green's argument, therefore, reduces itself to that of Ferrier for 'an everlasting mind in synthesis with all things'.

Green's eternal consciousness, moreover, is described exactly as if it were an enlarged human mind, built upon the same pattern of relational thought, but having spread out before it a complete intellectual scheme of the cosmic relations, which is partially and intermittently present to finite minds-' communicated' to them, as he frequently says, by this eternal spiritual principle. But we want more than a conceptual scheme of this sort to give us the kind of reality and independence which all theories are forced to attribute to the world of sense-perception. To think of the world as a permanent presentation, self-presented to an eternal percipient, does not meet the case, unless we confer upon the presentation just that degree of distinct and independent being which makes it a real object contemplated by the eternal percipient, and therefore capable of being similarly contemplated by other minds. Green's own account is extremely vague as to the sense in which he understands the spiritual principle to 'sustain' and 'constitute' nature. He talks of it most frequently as 'present to' the facts, and by its presence relating them to one another. He talks at other times-pretty frequently - of the 'action' or the 'activity' of the principle in 'constituting' or ' making' nature; but the agency appears on examination to be simply the combining and relating

${ }^{1}$ Psychology, vol. i, p. 245. Cf. Essays in Radical Empiricism, pp. 42-4 
activity in knowledge- 'the unifying action of spirit'from which he started. ${ }^{2}$

In fact, the more closely we examine Green's statements, the more unsatisfactory appears the result reached by his argument. He talks of it habitually as a spiritual principle, and describes it more fully as ' a single active self-conscious principle ', 2 or, as he puts it in the closing sentence of his long Introduction to Hume: 'The recognition of a system of nature logically carries with it that of a selfconscious subject-the designation of which as "mind", as " human", as " personal ", is of secondary importance, but which is eternal, self-determined, and thinks.' But the nature of the transcendental argument is enough to remind us that, as it is with reference to the system of nature that the principle has been deduced, it is nothing out of that reference, and it is what in that reference it does. Now what it does in relation to the manifold world is simply to unify it. Hence the designation of the principle almost ad nauseam in English Hegelian writers as 'a principle of unity'. The unity of apperception, Kant teaches in his Deduction, is precisely equivalent to the idea of nature as a unity, or at least the one idea is the obverse of the other. So Green tells us: "That the unifying principle should distinguish itself from the manifold which it unifies is, indeed, the condition of the unification; but it must not be supposed that the manifold has a nature of its own apart from the unifying principle, or this principle another nature of

'p. 43. On p. 34 it is described as ' an agent which distinguishes itself from the feelings, uniting them in their severalty, making them equally present in their succession'. Cf. p. 53: 'the consciousness which constitutes reality and makes the world one'. In a different context ( $p .78)$ he speaks of our partial knowledge of the universe as rendered possible through 'the continued action of the eternal consciousness in and upon the sentient life'. But the reference here is to the ideal of completed knowledge as operative in a growing experience; and the expression, therefore, does not bear on the question we are specially considering.

'p. 40. 
its own apart from what it does in relation to the manifold world. . . . There is no separate particularity, in the agent, on the one side, and the determined world as a whole, on the other. . . . The world has no character but that given it by this action, the agent no character but that which it gives itself in this action.' ${ }^{\prime}$ Consequently, as he says in another place, 'the concrete whole may be described indifferently as an eternal intelligence realised in the related facts of the world or as a system of related facts rendered possible by such an intelligence '. ${ }^{2}$ 'All things in the world are determined by it, in the sense that they are determined by each other in a manner that would be impossible but for its equal self-distinguishing presence to them all.' ${ }^{3}$ As such an impartial presence, the eternal consciousness becomes, in a phrase of Mr. Balfour's, just 'the bare geometrical point through which must pass all the threads which make up the web of nature '; ${ }^{4}$ or, as we may say, it is the ideal focus into which the system of relations is reflected, the empty form of the Ego or consciousness in general, the dot upon the $\mathrm{i}$, which the theory of knowledge exacts. ${ }^{5}$

This is the same result as we reached before in Ferrier's case, and it seems to confirm our view of the fallacious character of any direct argument from the conditions of knowledge to the theorem of an All-Thinker and of the universe as the system of his thought. It confirms also the nugatory nature of any conclusion that could possibly be reached by such a method, even if valid. The formal Ego, which is all that the mentalistic argument yields, is of no real account. What difference does it make whether we

'p. 38.
pp. $80-\mathrm{I}$. p. 89 ( 1884 ).

"So Caird speaks of the consciousness of God (which, he is insisting, is involved in the consciousness of self) as 'the consciousness of the universal unity or centre which all knowledge implies' (Critical Philosophy of Kant, vol. i, p. 215). 
regard nature as existing per se, or insist that all her processes are registered in a mind, if that mind is nothing but such a register or impartial reflection of the facts? I do not think, therefore, that any such short cut to the desired goal is likely to take us there. Ultimately, I believe it is true, as I have argued all along, that we cannot take nature as existing per se ; it has to be taken as an element in a whole which cannot be expressed except in terms of conscious values. All values depend on feeling, on some form of consciousness or living experience. Familiar with values in our own experience, we feel it impossible to conceive anything devoid of value (such as an unconscious material system would be) as ultimately real or self-subsistent, in other words, as a whole, a res completa. It is this moral impossibility, I think, as much as the speculative contradiction of a world existing absolutely unknown, that is the drivingpower of the idealistic argument. In both its aspects the argument may be impeached as circular in its proof. It is not so much an argument perhaps as an absolute conviction, but it is, I think, a conviction whose reasonableness is sustained by the unreasonableness of the opposite hypothesis.

Spirit, we believe, therefore, is the terminus ad quem of nature. As it has been finely expressed by an Eastern thinker, 'all external things were formed that the soul might know itself and be free'.' Unconscious nature thus assumes the character of a means or intermediary towards an end, in so far as conscious centres of existence alone possess that degree of separateness and independence which would justify the term creation in their regard. Such terms as creation, means and end demand, as we shall find, a rigid scrutiny, which may leave little of their ordinary meaning attaching to them when they are used to describe the ultimate conditions of the universe. But with that reserve they still remain useful and intelligible modes of

'Kapila (quoted in Professor A. G. Hogg's Karma and Redemption). 
indicating a real distinction within the world of facts as known. The instrumental or mediating function of the material world was the larger idealistic truth which underlay the mentalistic form of Berkeley's argument. And that may, I think, be held along with a frankly realistic attitude towards external nature.

Hume epigrammatically described Berkeley's arguments as admitting of no answer but producing no conviction. The apparent unanswerability was due, however, to the presuppositions common to both thinkers; and modern analysis successfully exposes the failure to distinguish in the ambiguous word 'idea' between the act of knowing and the object known, on which ambiguity Berkeley's identification of the object and the sensation really rests. ${ }^{1}$ In all knowledge there is the reference to an object beyond the process itself; and this realistic implication is so imbedded in language that subjective idealism achieves its apparent success only by tacitly presupposing the real object which it attempts to deny. The distinction between the act or the subjective process and the object applies as much to the knowledge of our own states, when these are introspectively observed, as to the knowledge of anything else; and there is no justification, therefore, for the traditional theory, on which Mentalism bases, that we know only our own states directly and all other things representatively through them. Knowledge, as the modern realists sometimes say, is 'a unique relation', which cannot be explained by analysing it into anything simpler, or by the use of physical and quasi-physical metaphors. The knower is everywhere in direct relation with his object, and we know all kinds of objects on the same terms. There is no more difficulty in knowing

2 'In truth the object and the sensation are the same thing, and cannot therefore be abstracted from each other' (Principles of Human Knowl$e d g e$, section 5). This noteworthy but too dangerous phraseology was withdrawn in the second edition. 
a material thing than there is in knowing the memoryimage of it or any other purely subjective phenomenon. The unconvincingness of the mentalistic argument is due, therefore, to its real unsoundness-a very simple and sufficient explanation, which naturally did not occur to Hume.

And when we are forced to abandon the attempt to identify perceived objects with the transient experiences of finite minds-as Berkeley of course is almost at once compelled to do-it is no legitimate way out of the difficulty to fly off, as he does, to an ultimate generality, and refer them simpliciter to the will of an Infinite Spirit, or to treat them, with Green, as thought-relations permanently present to such a cosmic Mind. That is to reverse the true order of going, and is really an attempt to evade the full consequences of our failure. For an acknowledgement of the impossibility of identifying the object with our own state should have as its result just the recognition of the independent reality of the object as we know it. Ultimately, no doubt, as I have said, if the larger idealism is to be maintained, the independence attributed to the material world cannot be taken as the assertion of its existence as a brute fact per se. It must be seen as an element in a whole, with a specific function within that whole. But how this real system of externality, on which as finite spirits we depend, is related to or included in an absolute experience, is necessarily dark to us; for to answer such a question would mean to transcend the very conditions of our separate individuality. We can but dimly apprehend that, to such an experience, nature cannot be external in the way in which it necessarily is to the finite minds which it shapes and fills And just because the two experiences are not in this respect in pari materia, the mode in which nature is included in the Absolute cannot be expected to throw light on the question in debate between mentalist and realist. But, at any rate, to treat the system 
of nature (as Berkeley does) as the effect in finite centres of an abstract Will, is to evade the real difficulty altogether $;^{1}$ and to figure its ultimate reality (as Green seems constantly inclined to do) as that of a system of thought-relations is so astonishingly meagre and incredible an account of the mighty fact in question that it explains Mr. Bradley's famous protest against the dissolution of the world into ' some spectral woof of impalpable abstractions, or unearthly ballet of bloodless categories'.'

And if it is unnatural and completely unconvincing to treat nature as a set of ideas or intellectual processes in a world-mind, conceived after the pattern of our own, it seems to me no less unnatural, as I argued in the previous lecture, to coin nature into the small change of an infinite number of monads or little minds. Both theories are, in fact, prompted by the same difficulty; and the expedient adopted is, in principle, identical. The difficulty is to conceive the unconscious thing with no central unity of feeling, however vague, to give it individuality and existence for itself. And it seems an easy way out of the difficulty either to put a mind-a speck, as it were, of consciousnessbehind each of the minutest atoms or ions into which physical science resolves the world, or to supply the centrality by treating the material system en bloc as the object of a cosmic mind. In both cases there is the attempt to escape from a difficulty by a general hypothesis which runs counter to the direct suggestion of the facts, and which necessarily, therefore, 'produces no conviction'-has no vital meaning, that is to say, for our experience. What relevance has either theory to the lapping of the waves, the summer rain, or the wind among the trees, to Nature's

${ }^{1}$ As Berkeley himself at a later period came to realize. He touchesthough very slightly-in Siris on the mode in which nature may be conceived as present to the divine consciousness.

${ }^{2}$ At the close of his Logic, in I883. Such an abstract intellectualism, he says, 'strikes as cold and ghost-like as the dreariest materialism'. 
aspects of impersonal vastness, of resistless power, or enduring peace-

The silence that is in the starry sky,

The sleep that is among the lonely hills?

Both theories are intended, of course, as a demonstration of the idealist contention that the ultimate reality of the universe is spiritual. In both cases, however, the stress is laid on the bare form of consciousness. But the infinite multiplication of so-called conscious centres, which are admittedly no more than the supposed inward aspect of purely mechanical reactions - the dynamics of a particle in psychological terms-is no enrichment of the content of the universe. And nothing is gained, as we have seen, by the formal abstraction of unity which figures in the mentalistic demonstrations. The content of the universe is alone worth contending for-the reality of infinite values open to appropriation and enjoyment by beings at a certain level of existence. ${ }^{2}$

'See Supplementary Note C, p. 420. 


\section{SECOND SERIES}

$$
\text { I9I2-I } 3
$$





\section{LECTURE XI}

THE ARGUMENT OF THE FIRST COURSE. THE LOWER PANTHEISM AND THE DOCTRINE OF 'DEGREES'

ThE survey taken and the results reached in last year's course were of a somewhat general nature. In the opening lecture we considered, as a kind of historical background and contrast, the remarkable discussion of theism by David Hume in his Dialogues concerning Natural Religion. Based as it was exclusively on the evidence of design in external nature, the attenuated theism of Hume's conclusion afforded, in his own language, 'no inference that affects human life or can be the source of any action or forbearance,' and this seemed scarcely what the idea of God had meant in human experience. I then sought to show that the idea of intrinsic value or worth, which Kant found in his analysis of moral experience, had been of determining influence upon the modern discussion of man's place in the scheme of things, thus shaping the view taken of the ultimate character of the universe. Kant's own presentation of the ideas of God and immortality as postulated by our ethical experience was defective, it was urged, owing to the externalism of his treatment, arising from the individualistic and consequently deistic habit of thought which he shared with Hume and the eighteenth century generally. But the consciousness of value-the assertion of the objectivity of our fundamental estimates of value-remained central for Idealism in the long controversy with Naturalism which filled out the nineteenth century, and which still remains the specific form in which the philosophic problem presents itself to the modern mind. As Höffding states it, 
it is the question of 'the relation between what seems to us men the highest value and existence as a whole". The Kantian distinction between knowledge and belief, and the restriction of knowledge to the world of sense-perception, as physical science conceives it, tended to suggest that the biological categories of life, the aesthetic perceptions of beauty and sublimity, and the implications of ethical experience were, after all, to be contrasted, as subjective interpretations and mere ideals or aspirations, with the assured objectivity of scientific knowledge and of the mechanical world-system which seemed to be its last word. Hence in many quarters the assertion of the principle of value took the form of a protest of the heart against the head, the feelings against the intellect; and in others, the demands of our ethical and aesthetic nature were opposed as a shadow-land of the poetic imagination to the harsh reality of a scientific materialism. But ideals must speedily wither if they are consciously realized to be but the cloudland of fancy; to a true idealism they are an intense vision of the foundations on which the universe is built. And we endanger the principle of value if we set one part of our nature against another in this way, and associate the principle with a campaign against 'intellectualism' or, as some go the length of saying, against Reason. Any theory which leaves us with an irreconcilable dualism between supposed conclusions of the intellect and the ethico-religious interpretation of the world is essentially a surrender to scepticism, and therefore an impossible resting-place for the human mind. Hence I urged that the vindication of human values could only become effective and convincing when accompanied by the demonstration that the conclusions of Naturalism rest on a misinterpretation of the character of the scientific theories on which it founds-that Naturalism, in short, in spite of its claims to exclusive reality, is no more than the substantiation of an abstraction or of a 
fragment that can exist only as an element in a larger whole. The principle of value, in other words, should be the informing principle of a coherent theory of reality instead of being put forward as a conviction which has, as it were, an independent root in a separate part of our nature, and which, instead of issuing from reason, is represented almost as a protest against reason.

The argument of the lectures which followed was in the main directed to establish this position. I showed in the fourth lecture how the development of biology as an independent science had demonstrated the insufficiency of purely mechanical conceptions to describe even the most elementary facts of life. In passing from physical and chemical phenomena to the behaviour of living matter we find ourselves instinctively and of necessity driven to a new range of categories, if we are, I will not say to explain, but even accurately to describe, the characteristic features of the facts before us. Such an acknowledgement, I argued, does not mean an attempt to re-introduce miraculous interferences, unbridgeable chasms and special creations. These are the apparatus of an arbitrary and external Supernaturalism, against which the protest of Naturalism was entirely justified. Science and philosophy alike support the demand for order and continuity. But nature, I said, is not the less nature, because it exhibits a scale of qualitative differences; the principle of continuity is misinterpreted, if it is supposed to imply a reduction of all the facts of experience to the dead level of a single type. It is important, I suggested, to distinguish between the lower and the higher Naturalism. The lower Naturalism is that which seeks to merge man in the infra-human nature from which he draws his origin-which consistently identifies the cause of any fact with its temporal antecedents, and ultimately equates the outcome of a process with its startingpoint. A higher Naturalism will not hesitate to recognize 
the emergence of real differences where it sees them, without feeling that it is thereby establishing an absolute chasm between one stage of nature's processes and another. What we have to deal with is the continuous manifestation of a single Power, whose full nature cannot be identified with the initial stage of the evolutionary process, but can only be learned from the course of the process as a whole, and most fully from its final stages. Although the appearance of life is a peculiarly impressive instance of a synthesis which refuses to be analysed into the merely physical and chemical facts which were its apparent antecedents, it is by no means the only one. Scientific thinkers, fighting against the theological doctrine of special creation, have pointed to the phenomenon of crystallization as similarly inexplicable by the unguided forces of gravity and cohesion. And within the realm of life there is the passage from the vegetable to the animal, and in the realm of consciousness the passage from instinct and association to the conceptual reason. In all these cases, questions of historical origin or of transitional forms are philosophically irrelevant. The philosophical point is that in each case we do pass to a new plane or level of existence, qualitatively different from the preceding. and opening up, through that difference, a new range of possibilities to the beings which it includes.

It is between the human intelligence and its antecedent conditions, between nature and man, that the idea of a chasm or absolute break is most deeply rooted, both in philosophy and in ordinary thought. But it was the central contention of the later lectures of the course that man must be taken as organic to nature. If we consistently apply in this case the twin principles of continuity and immanence, I said, and steadily refuse to characterize the nature of the world till we have all the facts before us, some of the most persistent difficulties of modern thought will be found to disappear. The nature of the Power at work 
in any process is only revealed, as has just been said, in the process as a whole, and the world is not complete without man and his knowledge. The idea of nature as a completed system and of man as a spectator $a b$ extra is essentially false. The intelligent being is rather to be regarded as the organ through which the universe beholds and enjoys itself. From the side of the higher Naturalism, I sought to emphasize man's rootedness in nature, so that the rational intelligence which characterizes him appears as the culmination of a continuous process of immanent development. This organic point of view delivers us, I contended, from the difficulties which so sorely afflict modern philosophy as to the relativity, or subjectivity, or phenomenality, of knowledge, and the impossibility of knowing things as they really are. These difficulties depend on the conception of the world as a finished fact independently existing, and an equally independent knower with a peculiar apparatus of faculties which inevitably colour and subjectify any fact on which they are brought to bear. Such a conception errs also, I insisted, by treating the function of intelligence as purely cognitive, in the sense of simply mirroring or duplicating external facts, whereas all knowledge is an experience of the soul, which, as such, has necessarily its feelingvalue; and the existence of such living centres capable of feeling the grandeur and beauty of the universe and tasting its manifold qualities is what is alone really. signifi cant in the universe. All values are in this sense conscious values; and so it is that the sentient and, still more, the rational being appears as the goal towards which Nature is working, namely, the development of an organ by which she may become conscious of herself and enter into the joy of her own being.

While rejecting, therefore, the relativity of knowledge in the usual sense of that doctrine, I emphasized the essential relatedness of nature and mind as the guarantee of the 
naturalness of the knowledge-process and the truthfulness of the result. I applied this specially to the case of the secondary qualities which are usually regarded as the stronghold of the relativistic theory. Popular science and popular philosophy take the physical scheme of moving particles or ethereal vibrations as the reality of nature as an objective system, all the rest being merely subjective appearance to finite subjects. But the objectivity of the secondary qualities as predicates of reality is affirmed both by common sense and by a ripe philosophy. The physiological process through which knowledge is attained does not invalidate the result. There is no explanation possible of the evolution of the sense-organs unless we assume the reality of the new features of the world to which their evolution introduces us. The organism is developed and its powers perfected as an instrument of Nature's purpose of self-revelation. And what is here claimed for the secondary qualities holds good also of the aspects of beauty and sublimity which we recognize in nature and those finer insights which we owe to the poet and the artist. These things ought not to be regarded as arbitrary fancies, subjective glosses upon nature's text-on the contrary, they give us a deeper truth than ordinary vision, just as the more developed eye or ear carries us farther into nature's beauties and refinements than the less perfect organs of a lower species.

I applied the same idea of organic relatedness to the consideration of the ethical and social qualities which we recognize as constituting our humanity. For if the stigma of subjectivity can be attached with any semblance of justice to our knowledge, it will seem to apply with still greater force to the world of values in which our inmost and most personal nature finds expression. And, as a matter of fact, it is between man's nature as an ethical being and the apparently non-moral nature of the world 
from which he springs, that the breach of continuity-not to say the apparent opposition-has been most keenly felt. I drew attention, in this connexion, to the sharp expression of this dualism between man and nature in the Religion of Humanity, one of the most characteristic products of the nineteenth century, in its combination of a lofty ethical and religious idealism with an ultimate metaphysical agnosticism. Comte was right, I urged, in the stress he laid on the distinctively human qualities as alone fitted to call forth the emotions of love and worship-as alone, therefore, in a true sense, divine. His error lay in supposing that a purely subjective synthesis, as he called it, is possible - in other words, that it is possible to isolate humanity from the universe as a whole, and to treat it as a self-contained organism, evolving all its properties and engineering all its advances in its own strength and out of its own particularity. The specifically human experiences cannot be taken as an excrescence on the universe, or as a self-contained and underived world by themselves with no root in the nature of things. Man is, after all, the child of nature and it is on the basis of natural impulses, and in commerce with the system of external things, that his ethical being is built up. Hence the characteristics of the ethical life must be taken as contributing to determine the nature of the system in which we live. According to the principle of value and the distinction between lower and higher ranges of experience, they should, indeed, carry us nearer to a true definition of the ultimate Life of which we are partakers than categories which suffice to describe, at most, the environmental conditions of human existence.

The further analysis which I undertook of the Agnosticism which forms one strand in the Comtian theory, and which meets us in so many shapes in modern thought, consisted of little more (as, to my mind, it can consist of little 
more) than an exposure of the fundamental absurdity of the demand to know a substance otherwise than through its qualities, a cause otherwise than through its effects, reality otherwise than through its appearance or manifestation. The phenomenon is the noumenon so far as it has manifested itself. "The power manifested to us through all existence,' an 'Infinite and Eternal Energy manifested alike within us and without us', to which 'we must ascribe not only the manifestations themselves but the law of their order' (those are Spencer's own words) can hardly be fitly designated by that barren abstraction, the Unknowable. The designation is due, in part at least, to a failure on Spencer's part, as on Sir William Hamilton's before him, to distinguish between the inaccessible, that which is, by its very nature, cut off from knowledge, and that which is unfathomable or inexhaustible by any finite mind; and it was doubtless the positive elements, acknowledged or unacknowledged, in his conception which invested the Unknowable in Spencer's eyes with a genuine religious halo, and made it appear to him the suitable residuary legatee of the religious sentiments of mankind. But, while he rightly condemned the attempt of the Positivists to isolate Humanity and treat it as a kind of finite God-while he rightly contends that the veneration and gratitude which Comte claims for Humanity are due in the last resort, if due at all, to 'that ultimate Cause, that great stream of Creative Power' as he calls it in the same context, 'from which Humanity individually and as $\exists$ whole, in common with all other things, has proceeded 'he strangely fails to see that it is only so far as the character of that Power is taken to be revealed in the highest human qualities that it can call forth either veneration or gratitude. And so the worship of the Unknowable and the worship of Humanity, each untenable in itself, are found to owe their vitality (as we might have expected) to the partia! 
and complementary truths which they respectively enshrine, and which are only kept apart by a distorted conception of the relation of reality to its appearances.

The main purpose of last year's argument might be fairly described as an attempt to establish a true metaphysic of that relation. Agnosticism of the ordinary type depends on the sheer separation of what is given together and cannot be conceived apart. But the Absolute, if we are to use the modern term, is not unknown. According to a fine phrase of Professor Laurie's which I quoted, 'its predicates are the worlds'; we read its nature in the system of its appearances. God as immanent-the divine as revealed in the structure and system of finite experiencethis may be said to have been the text of last year's discourse and the outcome of my argument. And in the philosophical interpretation of phenomena everything depends, I argued, on keeping the whole range of experience in view. Naturalism and kindred theories result, as we saw, from prematurely closing the record, instead of following out the evolutionary scheme to its obvious culmination in mind-mind that knows and appreciates, and thus rounds and completes what were otherwise a broken arch. There is no system, no whole of being, no real fact at all, till the external gathers itself up, as it were, into internality, and existence sums itself in the conscious soul.

The view thus indicated commits us, it was urged in the two concluding lectures, ${ }^{1}$ neither to a monadistic construction of the universe nor to any form of subjective idealism or mentalism. But it enshrines the conviction which Mr. Bradley expressed, in replying to certain of his critics, that "that which is highest to us is also in and to the universe most real, and there can be no question of its

- These are to be considered as, in some respects, an appendix to the general argument contained in the first eight lectures. 
reality being somehow upset'.' Some such view of the systematic character of reality is taught in every constructive philosophy; and, short of such a conviction, we cannot be said, I think, to have either a philosophy or a religion in the ordinary sense.

'God as immanent,' it has just been said, might be described as the text of our last year's discourse. In the more abstract language of recent philosophical discussion, our conclusion might also be expressed as 'the reality of appearances'. Mr. Bradley, in the title of his great book, and in his wholesale condemnation of the successive phases of our experience as 'mere appearances', or as 'illusory', 'self-contradictory' and 'unreal', has laid himself open to the charge of reviving in a subtler form the old agnostic contrast between reality and its appearances. But such is not, as. I understand him, Mr. Bradley's real intention or his deepest thought. He reminds us, at all events, emphatically that 'appearances exist, and whatever exists must belong to reality.'; consequently whatever conclusion we may ultimately reach as to the nature of reality, we may at least 'be certain that it cannot be less than appearances'.2 The universe, in short, or its informing principle, is ' good for' as much as our experience actually shows it to contain. So expressed, this may appear a trivial result, and, as we shall immediately see, it leaves many questions still unanswered. But when we consider the almost incorrigible tendency of human thought to interpret the relation of appearance and reality as one of opposition or negation, it is very far from being as unimportant as it looks. In its original and legitimate sense, the antithesis in question is perfectly intelligible, and is constantly verified in everyday practice. It means the contrast between the first view of a thing or situation-the first imperfect and probably more or less erroneous impression-and the

$$
{ }^{2} \text { Appearance and Reality (second edition), p. } 560 . \quad \text { 'Ibid., p. } 132 .
$$


corrected view that is the result of further examination. The contrast is, in short, between the thing as it first appears, and the thing as it eventually appears in the light of a fuller experience. But a misguided philosophy transfers this practical distinction between false and true within experience to the relation between our experience as a whole and a reality, which it is usually, and rightly, supposed to reveal, but which is now set over against all its appearances as something inaccessible and unknowable. For the progressive criticism of imperfect conceptions inherent in the advance of knowledge, and systematically carried out in philosophical reflection, there is substituted, more or less explicitly, a condemnation of knowledge as such, because to be known is to appear to the knower. Hence the importance of the contention that in the appearances we already grasp the nature of reality and that we can attain to it in no other way.

This was, perhaps, the main thought in Lord Haldane's First Series of Gifford Lectures at St. Andrews, as indicated in their title, 'The Pathway to Reality'. That pathway does not lie through and behind phenomena to some inscrutable Beyond. 'It may be', he says at the outset of his quest, " that it is just in the world that is here and now, when fully comprehended and thought out, that we shall find God, and in finding God shall find the Reality of that world in Him.' And repeatedly he uses, to enforce his meaning, the emphatic and, at first blush, almost paradoxical phrase, 'the world as it seems'. 'If the standpoint of these lectures be a true one,' he says towards the close of his first volume, ${ }^{1}$ 'we are free to believe in the world as it seems, and not driven to sacrifice any aspect of it. If the supposed facts of observation which we indicate by our names-life and development-are, what all plain people assume them to be, real facts, why should we strain

${ }^{1}$ The Pathway to Reality, p. 254. 
every faculty to explain human beings away into automata, or quiver with excitement when some one writes that he has found that protoplasm may apparently be reduced to a condition of chemical inertness. . . . If a thousand such results were really established, we should yet be as far as ever from exhibiting life as a mechanical arrangement of molecules.' 'We ought ', he says again, 'to be prepared to believe in the different aspects of the world as it seemslife, for example, as much as mechanișm, morality as much as life, religion as much as morality - for these belong to different aspects of the world as it seems, aspects which emerge at different standpoints, and are the results of different purposes and different categories in the organization of knowledge. And if Philosophy gives us back what Science threatened to take away, and restores to plain people their faith in the reality of each of these phases of the world as it seems, then Philosophy will have gone a long way to justify its existence.' ${ }^{1}$ Hegel's metaphysic of essence and appearance has always seemed to me, in its massive realism, one of the fundamental insights of the philosophy from which Lord Haldane draws. Hegel is the last man to bid us rest content with first views of things; rather, philosophy is to him, in its essence, the systematic criticism of knowledge. But, in his view, the process of experience is, from the beginning, the growing knowledge of a self-manifesting reality. And the most important consequence of thus emphasizing the essential truthfulness of the process of self-communication is just that it forbids any arbitrary limitation of truth to particular phases or departments of experience-forbids us, for example, to treat the practical world of sense-perception as literally and finally real, and the expressions of the religious consciousness as the illusory product of selfish hopes and fears. Our experience is nowhere infected by

${ }^{2}$ The Pathway to Reality, p. II. 
radical falsehood. Criticism of detail and reflective interpretation of the whole are necessary in all departments; but in their main affirmations the ethical, the aesthetic and the religious consciousness have at least the same prima facie claim upon our belief as any other side of our experience. And that general claim once admitted, it may well be that, on a critical review of experience as a whole, these phases of it may prove to be of more decisive importance than any others for our final conception of the world.

For it is clear, as I have emphasized from the first, that in the philosophical interpretation of phenomena everything depends on the idea of system and the scale of values which is associated with it. If every phenomenon is, so to say, as good as another, there can be no talk of a principle of the whole and no sense in seeking to determine its nature. If every event, every feature of the world, in its isolation as a particular fact just as it occurs, is referred directly to the operation of the supreme principle, that principle becomes simply the pell-mell of empirical occurrence over again. The doctrine of immanence becomes on these terms a perfectly empty affirmation; for the operative principle supposed to be revealed is simply the characterless unity of 'Being', in which the sum-total of phenomena is indiscriminately housed. The unity reached is the unity of a mere collection, and everything remains just as it was before. Such a pantheism is indistinguishable from the barest Naturalism. 'All in All,'s said Fichte in another reference, 'and for that very reason nothing at all.' This lower pantheism, as it may be called, is common in the popular cults of the East, where the immanental unity of the divine is little more than the idea of a teeming nature, and passes easily into a gross polytheism, whose deities represent and consecrate every natural force and tendency. In pantheistic thought on a higher intellectual level, one 
often meets the same tendency to press the idea of the immanence of the divine in all phenomena equally, and thereby to use the Absolute as an instrument for the obliteration of all distinctions of rank and value. Notable examples are to be found in the epigrammatic but shallow philosophy of Pope's Essay on Man:

All are but parts of one stupendous whole, Whose body Nature is, and God the soul; That changed thro' all, and yet in all the same, . . .

Lives thro' all life, extends thro' all extent, Spreads undivided, operates unspent ;

Breathes in our soul, informs our mortal part, As full, as perfect, in a hair as heart:

As full, as perfect, in vile man that mourns, As the rapt Seraph that adores and burns:

To Him no high, no low, no great, no small; He fills, he bounds, connects, and equals all. (I. $267-80$.

Sometimes (as to some extent in the lines quoted) this levelling down of finite distinctions appears as the counterpart of an insistence on the incomparable and unapproachable greatness of the divine. The tendency of mystical thought to exalt the divine above all predicates, making it literally the unnameable, the ineffable, the unknowable, leads in a similar direction; for that which-is characterlesscannot be said to reveal itself more. intimately in one aspect of experience than another; and so, as Bradley says, this empty transcendence and this shallow pantheism are seen to be opposite sides of the same mistake. ${ }^{1}$ But the 'principle of unity' which philosophers seek is not the unity of a mere collection or of a bare abstraction. It is unity of system that is clearly intended; and the idea of a systematic whole essentially involves discrimination, perspective, something like a hierarchy of means and end. The true revelation of the divine must be sought,

${ }^{2}$ Cf. Appearance and Reality, p. 55I. 
therefore, as I have contended, in the systematic structure of finite experience as a whole.

Spinoza's system is, from one point of view, an example of the logic which, in its attempt to characterize the Absolute, abstracts from all finite determinations, and is left, accordingly, with the definition of God as mere Substance or Being. Moreover, his insistence on the universal and thorough-going immanence of the divine causation exposed him to the accusation of abolishing the distinction between good and evil, and, indeed, of reducing all distinctions to one dead level of indifference. In the famous appendix to the First Book of the Ethics, he includes good and evil, right and wrong, praise and blame, as well as beauty and ugliness, order and disorder, among human 'prejudices', abstractions of the imagination, due to man's incorrigible habit of judging every fact according to its beneficial or harmful effects upon himself. "The perfection of things is to be reckoned only from their own nature and capacity '; and so regarded everything in its own place as it exists is equally perfect and equally necessary, seeing that all things follow from the necessity of the divine nature. It was sentences such as these, in entire harmony as they seemed with the whole tenor of his system, which drew upon him from one of his correspondents the charge of 'removing all the sanctions of virtue and reducing us to automata', of degrading human beings to the level of the brutes or even of plants and stones. Spinoza's patient letters in reply are important because, whether they completely turn the point of the criticism or not, they are clear proof that Spinoza did not intend his doctrine of God to override the specific differences between the parts of nature or what he would have called the 'essences' or 'natures' of things. Although God is the immanent cause of all things-that is an ontological tie which it is impossible to sever-still the divine nature is not equally manifested in 
everything: there are degrees of perfection or reality. As he quaintly puts it: 'A mouse no less than an angel is dependent on God, yet a mouse is not a kind of angel.' So again: "The wicked, it is true, do in their fashion the will of God, but they are not, on that account, in any way comparable to the good. The more perfection a thing has, the more does it participate in deity, and the more does it express God's perfection. Since, then, the good have incomparably more perfection than the bad, their virtue cannot be likened to the virtue of the wicked, inasmuch as the wicked lack the love of God, which proceeds from the knowledge of God, and by reason of which alone we are, according to our human understanding, called the servants of God. The wicked, knowing not God, are but as instruments in the hands of a workman, serving unconsciously, and perishing in the using; the good, on the other hand, serve consciously, and in serving become more perfect' (Ep. 32). Finally, he says, we can understand best the nature of God's relation to the universe 'by considering, not stocks and plants, but the most reasonable and perfect creatures' (Ep. 34).

Here, then, in Spinoza, where a priori we might perhaps have least expected it, we get the doctrine of 'degrees of truth or reality.', the emphatic assertion of which made Mr. Bradley's Appearance and Reality such an important contribution to contemporary thought. Spinoza's reply to his critics is, in effect, the acknowledgement of an objective scale of values, which reinstates the distinctions which he had apparently denied; and, inconsistent as it may seem with his thorough-going determinism, the concluding book of the Ethics sets before us the true or ideal life of man as a gospel of liberation. I have already referred to the negative argument with which this doctrine of Degrees is linked in Mr. Bradley's exposition, and we shall have occasion to return at a later stage to criticize certain of its implications. But however Mr. Bradley reconciles to 
himself apparently conflicting positions, it is sufficiently plain from his concluding paragraphs that, in his own view, the vital contention of his book is the positive doctrine that reality is revealed in the system of its appearances, and that the standards of better and higher which we apply. are themselves based on the nature of reality and dictated by it. ${ }^{1}$ With this conclusion we may intimate our agreement in advance, but the nature of our criterion of value and the justification of the objective character we attribute to it are points that still call for further discussion. This will form the subject of the next lecture. One thing, however, is already plain from all that has gone before. The standard or principle of value must be found in the nature of the system as a whole. Judgements of value, in other words, are not to be taken, like the intuitions of an older philosophy, as so many detached and mutually independent pronouncements of one faculty or another upon particular features or aspects of the world. They represent rather so many parts of one fundamental judgement in which the nature of reality, as exhibited in the system, may be said to affirm itself. Every particular judgement depends for its ultimate sanction on the recognition of its object as a contributory element to this inclusive whole.

If I might venture to illustrate my meaning by turning from nature to art, I would point to the outlook on the world which we get in the greatest poetry. Let us take the case of Shakespeare, for Shakespeare has been accused by a recent writer of being too like nature and giving us no worldview-no philosophy-of his own. Shakespeare, says this writer, "is all the world over again. Here is human life no doubt, and a brilliant pageantry it is, but human life as varied and as problematic as it is in the living. There is

" 'The positive relation of every appearance as an adjective to Reality, and the presence of Reality among its appearances in different degrees and with diverse values-this double truth we have found to be the centre of philosophy' (p. 55r). 
no Shakespearian point of view. He possessed no unitary conception of the meaning and larger relations of human life.' ${ }^{1}$ That is true, so far as it emphasizes the richness and many-sidedness of Shakespeare's nature and the dramatic character of his genius, which enables him to realize and to express sympathetically very various attitudes towards life and the ultimate problems. It is true also if it means that Shakespeare had no cut-and-dry theory of the universe. He was no precise and self-satisfied expounder of the ways of God to man: the complexity and the mystery of existence are the themes of his deepest utterances.

\section{Men must endure}

Their going hence, e'en as their coming hither ; Ripeness is all.

But on the fundamental verities his touch is sure. Shakespeare gives us the heart-shaking tragedies of Lear and Othello, full of baseness and wickedness and folly and the cruelty of things, but he gives us Cordelia and Desdemona as their centre. And, as in the old story of the three men who were cast into the fiery furnace, 'the fire had no power upon their bodies, and the smell of fire had not passed on them,' so in the case of Cordelia and Desdemona we feelthe poet makes us feel-that evil and death have no power over their radiant and triumphant goodness. The last word is with Truth and Love. That is Shakespeare's criticism of life. It is also a theory of things. And as in the world of Shakespeare's tragedies, so in the greater world, which they reflect as Shakespeare saw it, we have to take the fabric of the world as a whole, before we recognize the foundations on which it stands.

'R. B. Perry, Approach to Philosophy, pp. 32-4. 


\section{LECTURE XII}

THE CRITERION OF VALUE: ITS NATURE AND JUSTIFICATION

WE accepted at the close of the last lecture the principle that the nature of reality can only mean the systematic structure discernible in its appearances, and that this must furnish us with our ultimate criterion of value. We have accepted, therefore, in a sense in which it seemed to us intelligible and true, the criterion on which 'absolutist' writers like Mr. Bradley and Professor Bosanquet lay so much stress. But much controversy has raged round the particular form in which they express the position. It is well known that the revolt against Mr. Bradley's Absolutism was one main cause of the Pragmatist movement which has since assumed such wide dimensions. The accusation originally brought against Mr. Bradley by the Personal Idealists, who were the forerunners, and in some cases the pioneers, of Pragmatism, was based, in their own words, upon his 'way of criticizing human experience not from the standpoint of human experience, but from the visionary and impracticable standpoint of an absolute experience ', ${ }^{1}$ or, in Mr. Schiller's more drastic phraseology, 'his inhuman, incompetent and impracticable intellectualism '. ${ }^{2}$ The reference is more particularly to the way in which Mr. Bradley, in Appearance and Reality, uses his criterion to 'condemn', as he says, the world of appearances en bloc. This naturally provokes the question or retort-What knowledge have we of this Absolute, in whose name condemnation is so magisterially passed upon the world of our actual experience? And I think it must be

${ }^{2}$ Personal Idealism, Preface, p. viii.

"Ibid., p. 127 . 
admitted that Mr. Bradley's mode of procedure is unfortunate. He says repeatedly that a complete philosophy would be 'a systematic account of all the regions of appearance', in which 'the whole world of appearance would be set out as a progress, a development of principle though not in time, and every sphere of experience would be measured by the absolute standard and given a rank answering to its own relative merits and defects ' ${ }^{\prime}$ His own doctrine of degrees of truth and reality is his positive contribution to such a philosophy, and it contains, I think, most of what is valuable and likely to be permanent in the volume. But the positive doctrine is almost swamped for the reader by the copious negative polemic in which Mr. Bradley labours to expose the self-contradictory nature of the phenomenal world from top to bottom. If we are to avoid misconception, therefore, it will be necessary to examine with some care the way in which the criterion is formulated by the two authors referred to. In that way we shall best define our own position.

Mr. Bradley's statement of his criterion is familiar to us all. 'It is clear', he says, ' that in rejecting the inconsistent as appearance, we are applying a positive knowledge of the ultimate nature of things. Ultimate reality is such that it does not contradict itself ; here is an absolute criterion.' But to deny inconsistency is to assert consistency; and seeing that appearances, however contradictory they may be, still exist, and must therefore in some sense 'belong to reality', 'we may make a further advance-we may say that everything which appears is somehow real in such a way as to be self-consistent. The character of the real is to possess everything phenomenal in a harmonious form.' And to achieve such an 'inclusive harmony', 'the Reality must be a single whole', 'beyond which there is nothing'. In other words, "the Absolute is an individual and a system '.2

'Appearance and Reality, p. 455.

I Ibid., pp. 136-44. 
Returning to the subject in a later chapter, ${ }^{1}$ he defines perfection of truth and of reality as consisting in 'positive self-subsisting individuality', and recalls the two ways in which individuality appears. "Truth must exhibit the mark of internal harmony or again the mark of expansion and all-inclusiveness. And these two characteristics are diverse aspects of a single principle.' Wherever we apply it, he says, "the standard still is the same. And it is applied always under the double form of inclusiveness and harmony.' And again in the concluding pages of the volume we read, ' our criterion is individuality or the idea of complete system.'

Professor Bosanquet has emphasized his acceptance of the same formula by making it the title of his first course of Gifford Lectures: 'The Principle of Individuality and Value.' 'I chose Individuality', he says in his Preface, ' as the clue. to my subject, because it seemed to be the principle which must ultimately determine the nature of the real and its constituents, of what is complete and self-contained, and of what approximates or belongs to such a reality.' 'The supreme principle of value and reality' is ' wholeness, completeness, individuality', and 'the appeal to the whole is the same thing with the principle otherwise known as the principle of non-contradiction. . . Every true proposition is so, in the last resort, because its contradictory is not conceivable in harmony with the whole of experience.' Again, 'It is all one whether we make non-contradiction, wholeness or individuality our criterion of the ultimately real.' 'The Individual is complete and coherent, and in the ultimate sense there can be only one Individual.' And once more, almost is Mr. Bradley's words, 'The standard [' the supreme standard of value '], is positive non-contradiction, developed through comprehensiveness and consistency.' ${ }^{3}$

${ }^{1}$ Chap. xxiv, 'Degrees of Truth and Reality,' pp. 363, $37 \mathrm{r}$.

${ }^{2}$ p. 542.

${ }^{3}$ Cf. Individuality and Value, pp. vi, xxv, 44, 5I, 68, 72, 299. 
'Our result so far is this,' says Mr. Bradley: 'The universe is one in this sense that its differences co-exist harmoniously within one whole, beyond which there is nothing. Hence the Absolute is, so far, an individual and a system; but if we stop here [he admits] it remains but formal and abstract.' ' 'Can we then', he adds, 'say anything about the concrete nature of the system?' Mr. Bradley's answer is to identify existence with 'experience', or, more definitely, 'sentient experience', ' what is commonly called psychical eixstence'. This he does in language closely resembling Berkeley's. If, then, we read our former abstract definition in terms of this new position, 'our conclusion, so far, will be this, that the Absolute is one system, and that its contents are nothing but sentient experience. It will, hence, be a single and all-inclusive experience, which embraces every partial diversity in concord.' Finally, Mr. Bradley proceeds to ask whether we really have a positive idea of an Absolute, thus defined as 'one comprehensive sentience;' and he answers that, while we cannot fully realize its existence, its main features are drawn from our own experience, and we have also a suggestion there of the unity of a whole embracing distinctions within itself. This we have in ' mere feeling or immediate presentation', where we experience as an undifferentiated whole that which we afterwards proceed, in the exercise of relational thought, to analyse into the known world of self and not-self, with all its manifold objects and distinctions. Combining this primitive experience of felt unity with the later experience of known diversity, we can recognize the latter as a transitional stage, and thus reach the idea of a higher experience in which thought shall, as it were, return to the immediacy of feeling. "We can form the general idea of an absolute intuition in which phenomenal distinctions are merged; a whole become

\footnotetext{
'Appearance and Reality, p. 144 (the opening of the second chapter in Part II).
} 
immediate at a higher stage without losing any richness.' 'The relational form is a compromise on which thought stands, and which it develops. . . . [But] thought can form the idea of an apprehension, something like feeling in directness, which contains all the character sought by its relational efforts'; 'a total experience where will_and thought and feeling may all once more be one.'

We shall have to consider the conception of an absolute experience somewhat closely in the sequel. But what it is at present important to note is that Mr. Bradley repeatedly confesses, ' we have no direct knowledge of such an experience '; ' the unity after all is unknown'.' And, as a natural consequence, we are equally ignorant of how 'the bewildering mass of phenomenal diversity' is harmonized, and its contradictions reconciled in the Absolute. But 'it must somehow be at unity and self-consistent '. ${ }^{3}$ This confessed ignorance of the 'how', combined with an inextinguishable faith as to the 'somehow', has often been remarked upon, so constantly are the two repeated in Mr. Bradley's pages. 'Wecannot understand how in the Absolute a rich harmony embraces every special discord, but on the other hand we may be sure that this-result-is reached.' ' We have no basis on which to doubt that all content comes together harmoniously in the Absolute. . . . All this detail is not made one in any way which we can verify. That it is all reconciled we know, but how, in particular, is hid from us.' 'Certainly, in the end, to know how the one and the many are united is beyond our power. But in the Absolute somehow, we are convinced, the problem is solved.' 4 -.. In contrast with such passages, almost pathetic in their frequency, we have to set Mr. Bradley's emphatic, almost truculent, assurance that, "with regard to the main character of the Abso-

${ }^{1}$ Ibid., pp. 160, 180, 181.

'Ibid., pp. 468,473 . It is 'not an experience but an abstract idea' (p. 160$)$.
Ibid., p. 140.
-Ibid., pp. 192, 239, 281. 
lute', his ' conclusion is certain and that to doubt it logically is impossible'.' Or again, in a curious formula which he is fond of repeating: 'What may be, if it also must be, assuredly is.' 2 In other words, reality must be a single and harmonious whole, but for aught we know it may be such a whole, therefore it is such a whole. Surely it is obvious that this strange attempt at demonstration does not carry us a step beyond the intellectual postulate of our initial 'must': 'Reality must include and must harmonize every possible fragment of experience.' 3 And again it is clear that, unless we have at least some knowledge of the 'how', the knowledge claimed in these passages of the 'is' is not knowledge at all, in the ordinary sense, but a postulate or, if you like, a belief, an inextinguishable faith.

And I would add that the criterion of inclusiveness and harmony, taken by itself, remains entirely formal and abstract, if not, indeed, tautologous. ${ }^{4}$ It is only when applied to specific experience that the principle of non-contradiction or of internal coherence becomes more than an empty formula, and as soon as it is so applied it receives its character from the concrete material in which it works itself out. The principle itself gives no guidance as to the mode in which the harmony is realized; and it leaves us consequently at the mercy of analogies which, it is more than probable, may be quite misleading. Hence it is an inversion of the true philosophic method to try to define the Absolute on the basis of the empty principle, and from that definition to reason down to the various phases of our actual experience, and to 'condemn' its most characteristic features, root and branch, as 'irrational appearance ' and 'illusion'. The

${ }^{1}$ p. 5 18. So again (p. 536 ), ' $U$ p to this point our judgement is infallible, and its opposite is quite impossible.'

p. 199.

p. 548 .

- As I have suggested elsewhere, 'the mere consideration that the universe exists-that Being is-proves that it is in some sense a harmony. All its aspects co-exist, and the business of the universe goes on ' (Man's Place in the Cosmos, and ed., p. 127). 
only possible result of such a procedure is exemplified in Mr. Bradley's actual conclusion, namely, that in the Absolute everything is somehow reconciled, but inasmuch as we know not how, none of the predicates drawn even from our highest experiences are applicable in this ultimate reference. 'The Absolute ', he says, ' is not personal, nor is it moral, nor is it beautiful or true' 1 - a cluster of negations which, though technically true, in the sense intended, are practically more false than would have been the corresponding affirmations. It was the strong impression which Mr. Bradley produced of following this barren method that provoked (and justified) the protest above referred to, against his 'way of criticizing human experience from the visionary and impracticable standard of an absolute experience'.

Professor Bosanquet, who, as we have seen, adopts the same criterion and formulates it in almost identical terms, appears to me to realize more clearly the dangers of such a procedure and, indeed, its inherent impossibility. His frequent phrase, 'the empty form of totality,' is itself significant in this connexion; and in general he follows, as if instinctively, the path from finite experience to the Absolute, tracing the organization of the real wholes in which, in the concrete material of life, the empty form realizes itself, and seeking, by critical use of the data thus obtained, to reach some positive determination of the nature of the ultimate Whole. It is surely by this experimental and tentative method alone that we are likely to reach results of any value. What can we extract from the principle of inclusiveness and harmony apart from our experience of the concrete worlds of morality, of beauty, of love, or of the passion of the intellectual life? The specific modes in which the consciousness of value is realized must obviously in this sense be drawn from experience. They are directly apprehended; we taste and see that they are good. And only through such

'Appearance and Reality, p. 537. 
experiences can we give any concrete content to the idea of a perfect. or absolute Life. Accordingly it is upon such experiences, and within our actual experience as a whole, that the metaphysical criterion works, as Professor Bosanquet has put it in an admirable passage: 'The fundamental nature of the inference to the Absolute . . . is misapprehended if we call upon it to put us in possession of an ultimate experience which is, $c x$ hypothesi, incompatible with our limited being. What it will do for us is much more relevant to the transformation of our lives. It exhibits to us, in their relative stability and reciprocal suggestions of completeness, the provinces of experience which comprise the various values of life; it interprets the correlation of their worth with their reality, and of both with their satisfactoriness to the soul. . . What metaphysics may do, and in the hands of the masters always has done, is, starting from any datum, no matter what, to point out what sort of thing is in actual life the higher, the more stable, and what is the more defective and the more self-contradictory, and to indicate the general law or tendency by which the latter is absorbed in the former.'. We are limited, in fact, to the immanent criticism of more or less in our actual experience. The perfect or absolute is something which we feel after, whose characters we divine in the light of the best we know, taking, as Professor Bosanquet says elsewhere," 'the general direction of our higher experiences as a clue to the direction in which perfection has to be sought'. That is to say, in sum, that we do not argue-and it would be a futile procedure if we did-from the bare idea of a systematic whole, but from the amount of system and the kind of system which we are able to point to as realized in experience. From that we argue to more of the same kind, or at least on the same general lines, although it may be on an ampler and diviner scale, 'above all that we can ask or think'.

'Individuality and Value, p. 268.

Ibid., p. I8. 
It is obvious, moreover, that in transferring to the Absolute the dominant features of our own experience-in treating it as essentially the completion or perfected expression of these-we are assuming much more than is warranted by the abstract, and at best purely intellectualistic, criterion of non-contradiction and inclusiveness with which we started. And if we return to Mr. Bradley, we soon find him using non-contradiction, harmony and satisfaction as alternative terms, and disposed, accordingly, to extract from his logical principle much more than it seems capable, in its natural meaning, of yielding. His Absolute is not merely an intellectually coherent whole; it is perfect in every respect. 'I admit,' he says in the chapter introductory to the Second Book, in which he gives a preliminary description of the characteristics which Reality must possess, if it is to be accepted as the solution of the philosophical problem, "or rather I would assert, that a result if it fails to satisfy our whole nature comes short of perfection. And I could not rest tranquilly in a truth, if $I$ were compelled to regard it as hateful. . . . If metaphysics is to stand, it must, I think, take account of all sides of our being. I do not mean that every one of our desires must be met by a promise of particular satisfaction; for that would be absurd and utterly impossible. But if the main tendencies of our nature do not reach satisfaction in the Absolute, we cannot believe that we have attained to perfection and truth.' ' 'We must believe', he concludes, 'that reality satisfies our whole being. Our main wants-for truth and life and for beauty and goodness-must all find satisfaction.' ${ }^{2}$ The conclusion is reiterated in the closing pages of the volume in the famous passage: "We make mistakes, but still we use the essential nature of the world as our own criterion of value and reality. Higher, truer, more beautiful, better and more real-these on the whole count in the universe

${ }^{1}$ Appearance and Reality, p. 146.

${ }^{2}$ p. 158. 
as they count for us, and existence must correspond with our ideas.' 1

So far as I can recall, the enormous extension thus given to the formal principle of self-consistency is nowhere expressly justified, except in a piece of reasoning which has always struck me as one of the weakest in the book. 'There is no direct way', he says, 'of showing that reality is perfect. . . We cannot argue directly that all sides of our nature must be satisfied, but indirectly we are led to the same result '; for ' is it certain', he asks, 'that the mere intellect can be self-satisfied if other elements of our nature remain not contented?' 2 The argument is made to turn almost entirely on practical discord in the form of pain or unsatisfied desire. The very 'idea of a better and nonexisting condition of things must destroy theoretical rest'; and as "we are forced to assume theoretical satisfaction, to suppose that existing one-sidedly and together with practical discomfort appears inadmissible'. 'Pain, of course, is a fact, and no fact can be conjured away from the universe; but the question is as to a balance of pain', and it is only necessary to 'assume that in the Absolute there is a balance of pleasure, and all is consistent.' Surely, as an argument to prove the perfection of the universe, this transition from logical coherence or incoherence to psychical comfort or discomfort is one of the flimsiest bridges ever built by metaphysical subtlety, and I can hardly avoid the feeling of something half-hearted in the way in which Mr. Bradley puts it forward. He deals more worthily with the essentials of the question in a recent article in $\mathrm{Mind}^{3}$ one of the many to which criticism has compelled him during the last ten or twelve years. 'It is after all', he says at the close of the article, "an enormous assumption that what satisfies us is

p. 550.

2 pp. $155-8$.

'On 'Coherence and Contradiction' in Mind, October 1909, New Series, vol. xviii, p. 507 (reprinted in Essays on Truth and Reality, p. 243). 
real, and that the reality has got to satisfy us. It is an assumption tolerable, I think, only when we hold that the Universe is substantially one with each of us, and actually as a whole, feels and wills and knows itself within us. ... And our confidence rests on the hope and the faith that, except as an expression, an actualization, of the one Real, our personality has not counted, and has not gone here to distort and vitiate the conclusion. . . . And, wherever this is felt, there is little desire to insist that what we want must be real exactly so as we want it. Whatever detail is necessary to the Good we may assume must be included in reality, but it may be included there in a way which is beyond our knowledge and in a consummation too great for our understanding. On the other side, apart from the belief that the ultimate and absolute Real is actually present and working within us, what are we to think of the claim that reality is in the end that which satisfies one or more of us? It seems a lunatic dream. . . . The ideas and wishes of "fellows such as I crawling between heaven and earth," how much do they count in the march or the drift of the Universe?'

It may easily be objected that there is something circular in the reasoning here. The validity of our assertions about the universe is to depend upon the view we hold of man's place in the universe or his relations to the Real; but that is the fundamental affirmation in the case, and how are we to be assured of its validity? To this it may be answered that the view here indicated of man's relation to the Real has behind it the whole weight of a philosophical system. It is the same view so strongly urged in last year's lectures, that man, as I expressed it, is organic to the world, and conversely the world is organic to man, completing itself in him, and manifestly coming to life and expression in his experience. Neither, if we consider rightly, can be so much as conceived apart from the other. For by man is meant, of course, not merely, or even specifically, the historical denizens of this 
planet, but sentient life flowering in the rational mind, in whatever 'where' or 'when' it comes to birth. And yet, if the critic were to press his objection, L would admit that there is an assumption involved in this philosophical theory, an assumption woven into its very texture, and without which, perhaps, the theory would never have been arrived at-I mean the conviction of the essential greatness of man and the infinite nature of the values revealed in his life. Without this absolute judgement of value, how could we argue, how could we convince ourselves that, in our estimates, it is not we who judge as finite particulars, but Reality affirming, through us, its inmost nature? It is not on the mere fact of consciousness or self-consciousness that we take our stand, but on the nature of the content experience, the inexhaustible wonder and greatness of the worlds which it opens up to us. Every form of philosophical idealism appears to involve this conviction of the profound significance of human life, as capable of appropriating and realizing these values. And without such a conviction, argument about God or the universe would seem to be mere waste of time; for the man to whom his own life is a triviality is not likely to find a meaning in anything else.

When we approach the question seriously, therefore, and not in a spirit of dialectical display, we find ourselves, I think, dismissing without more ado the insinuations of naturalistic evolution that our human values are no more than the forms taken by the instinctive self-affirmation of a particular animal species, and, consequently, quite irrelevant in any discussion of the ultimate nature of reality. Glib theories of this description always remind me of Plato's account of those who have been introduced to philosophy too young, the boys who have tasted dialectic for the first time, and who delight, like puppies, in pulling and tearing to pieces with logic any one who comes near them. ${ }^{1}$ If (to

\section{${ }^{1}$ Republic, 539 .}


continue in Plato's words) we are 'resolved to discuss and examine truth, rather than to play at contradiction for amusement,' we see at once that, however gradual the transition from one stage of consciousness to another, man's attainment of conceptual thought makes him an organ of the universe in a totally different sense from that in which. any mere animal can be said to be so. As the old legend puts it, in the mouth of the Creator no less than on the word of the serpent, 'Man is become as one of us, knowing good and evil.' We need not, as Locke said, 'put ourselves proudly at the top of things,' but, with thought, we are somehow at the centre: we have become freemen of the universe. 'Souls in general', said Leibnitz in his peculiar phraseology, 'are living mirrors or images of the universe of created things, but spirits are also images of the divinity or of the author of nature himself, capable of knowing the system of the universe.' 1

'Capable of knowing the system of the universe'-science, philosophy, religion are all included in the phrase. The animal soul reacts to its particular environment, and asks no questions; but the outlook of the rational mind is universal. Man weighs in a balance the earth on which he moves, an insignificant speck; he calculates the distance, the mass, and the movements of the farthest stars; he dissolves the solid framework of material things into a whirl of invisible elements and forces; he traces the history of his own and of other worlds ' in the dark backward and abysm of time '; he foresees his own death and the death of his race. He asks the meaning of it all, and he names the name of God. Man alone philosophizes, and man is the only religious animal. The omnipresence of religion in the human race, often remarked on, however rude in origin and however gross the superstitions with which it is first associated, is a symbol of the step from the finite particulars of the senses to the

${ }^{1}$ Monadology, section 83 . 
universal of thought, It is the beginning of the quest of God, and the quest means that God is present in a new way in the creature that undertakes it. 'Spirits alone', says Leibnitz again, " are made in His image, and are, as it were, of $\mathrm{His}$ race, or like children of the house, since they alone can serve him freely and act with knowledge, in imitation of the divine nature.' 1

This view of man, it need hardly be added, is suggestive of anything else than of self-glorification. Mr. Bradley refers, in the context of the passage I have last quoted, to 'that vapouring, new or old, about Humanity, which, if it were not ambiguous, would be hardly sane'. And one recalls Comte's foolish phrase about the heavens declaring the glory, not of God, but of Kepler and Newton, or that other about ' the regency of God during the long minority of Humanity', and the echo of such things in Swinburne's 'Hymn to Man':

Glory to Man in the highest! for Man is the master of things.

And Mr. Bradley has also in view, I doubt not, the more recent excesses of some Pragmatists and so-called Humanists, those who speak ambiguously of a 'plastic' world, of man as 'making' both truth and reality, or who acclaim as the essence of modern humanity 'the desire and determination to have a voice and a vote in the cosmic councils ', ' who write articles on 'The Democratic Conception of God ', 3 in which they tell us that 'society, democratic from end to end, can brook no such class distinctions' as the effete European contrast between God and man. But in examining the Religion of Humanity last year, we saw the fallacy involved in treating humanity as a self-contained entity, a kind of Absolute on its own account. Ideals would be impossible

'Quoted in Latta's Leibniz, p. 266 (note), from Gerhardt's edition of the Philosophical Works, vol. iv, p. 461 .

${ }^{2}$ A. W. Moore, Pragmatism and its Critics, p. 72.

' H. A. Overstreet, Hibbert Journal, January 1913. 
to a self-contained finite entity. To frame an ideal and pursue it means the presence of the infinite-in the finite experience; or, from the other side, it is the mark of the finite being who is partaker in an infinite life. All claims, therefore, made on man's behalf, must be based on the objectivity of the values revealed in his experience, and brokenly realized there. Man does not make values any more than he makes reality. The soul, in Plato's metaphor, 'feeds upon 'truth, upon goodness, upon beauty; and these, being all infinite in their essence, humble, as well as exalt, the finite subject to whom they display their features.

A few words more may be added as to the nature of the assurance with which we hold our position. The logical principle of non-contradiction, or, to express it more largely, the principle of intellectual coherence, we must and do accept as absolute. We accept it as a necessity of reason involved in the possibility of knowing anything-involved therefore in all practical living as well as in the immovable belief in law or order which inspires all scientific investigation. And, needless to say, life and science alike vindicate the principle; all experience may be looked upon as its progressive verification. But if we ask what is the nature of our certainty that existence, the world of facts, is ultimately and throughout intellectually coherent-that we have to do, in short, not with a chaos but with a cosmos, a world whose laws may be infinitely complex and difficult to unravel, but which will never put us to permanent intellectual confusion-we are bound to reply that in a sense it is an unproved belief. It is unproved in the sense that we have not explored the whole of existence, and in the nature of the case can never hope to include all the facts within the net of reason. And hence it may perhaps be called a postu"late of reason, a supreme hypothesis. Many would describe it as a 'venture of faith', and as such it has been luminously 
treated, as the first step in the theistic argument, by my own revered teacher, Professor Campbell Fraser, in his Gifford Lectures on the Philosophy of Theism. In a similar spirit Lotze speaks of 'the confidence of reason in itself ' as the faith which lies at the root of all knowledge.

We have most of us, I suppose, as good moderns and children of the light, had our gibe at the ontological argument, and savoured Kant's pleasantry of the hundred dollars. But this fundamental confidence of reason in itself is just what the ontological argument is really labouring to express-the confidence, namely, that thought, when made consistent with itself, is true, that necessary implication in thought expresses a similar implication in reality. In this large sense, the truthfulness of thought-its ultimate truthfulness-is certainly the presupposition of all thinking: otherwise there could be no inducement to indulge in the operation. To that extent we all believe, as Mr. Bradley puts it in a rather incautious phrase, that 'existence must correspond with our ideas'. When I say, 'we all believe it,' I mean that it is the first and natural attitude of the mind to the world, that it never ceases to be our practical assumption, and that, although a little philosophy may lead us for a time into the wilderness of scepticism and relativism, depth in philosophy brings us back with fuller insight to the sanity of our original position. And Mr. Bradley's confidence that 'the main tendencies of our nature' must 'reach satisfaction in the Absolute', or Professor Bosanquet's readiness to 'stake [his] whole belief in reality ... on the general "trueness and being" of whole provinces of advanced experience such as religion or morality or the world of beauty or of science', is, in effect, an extension to our nature as a whole of the fundamental confidence expressed in the ontological argument. We are more or less familiar with this claim to objectivity on behalf of the deliverances of the moral faculty. The voice of conscience 
is frequently referred to in popular philosophy as the voice of God. The claim is made by modern philosophy in a more general form, and because it has been more critically sifted, it is no doubt vaguer in its outcome than the old intuitional argument used to be. Fundamentally, it is the conviction that 'the best we think, or can think, must $b e$ '-a form of statement which perhaps enables us to see the real intention of the old scholastic argument that ' a perfect being necessarily exists.'. In other words, the possibilities of thought cannot exceed the actuality of being; our conceptions of the ideal in their highest range are to be taken as pointing to a real Perfection, in which is united all that, and more than, it has entered into the heart of man to conceive.

Admittedly, however, such a conception transcends the empirical reality of man's own nature or of the factual world around him, just as the perfectly coherent intellectual whole transcends the achieved results of knowledge. And, so far, the argument seems parallel in the two cases; in both there is an aspect of faith, and in both a similar claim to objectivity. But it is idle to deny that, although the belief in ultimate Goodness and Perfection at the heart of things may be held with a more passionate energy of conviction than the more colourless postulate of the intellect, it does not present itself to most minds with the same impersonal logical cogency. 'The ultimate identity of value and existence' has been described as the great venture of faith to which mysticism and speculative idealism are committed. ${ }^{1}$ It has often been described by religious thinkers as a 'wager'. It has been treated as not in the strict sense a conclusion of the intellect at all, but a decision of character given out of a man's own moral and religious experience. Hence Fichte, who as much as any man believed in the coercive demonstrations of thought, can say, describing the great philosophical antithesis between naturalism and idealism, 'the kind of

${ }^{2}$ In an article by Dean Inge in The Times Literary Supplement, March 20, 19r3. 
philosophy we choose depends upon the kind of men we are '; and Eucken in our own day, under the name of Activism, puts forward his 'spiritual Idealism' as a problem to be worked out by each man for himself, a truth to be embraced by a supreme act of the personality, and proved true by its consequences for life. So, as we all remember, William James, in his spirit-stirring essay on the 'Will to Believe', represents a man's theoretical conclusions as to the spiritual or non-spiritual character of the universe as a personal cleaving to the one alternative or the other, an act which has its own influence in validating for the cosmos the hypothesis adopted.

But here we pass away from the point of view of religious idealism into a moral dualism or Zoroastrianism, and the discussion of such a position would lead us too far. But it may at least be said that on this path we are in danger of losing the meaning of truth altogether and forgetting the function of philosophy. Philosophy is not-an effort to help the good cause in a cosmic duel, but an attempt to find out the truth about the universe - to find out, for example, whether it is such a duel or not. Hence, whatever aspect of faith may cling to a philosophical conclusion, it must be presented as the conclusion of the reason upon a consideration of all the evidence and after due weight assigned to all the modes of our experience. It must be our reasonable faith, and I note how that expression, emphasizing both aspects of the case, occurs prominently even in a theory of Absolutism like Professor Bosanquet's, who also, as we saw in the passage quoted, adopts the familiar metaphor of 'staking our whole belief in reality' on the truth or trustworthiness of certain great provinces of our experience. 'We must believe' is Mr. Bradley's way of stating his ultimate conclusion; and if I commented on his frequent references to our ignorance of the 'how', it was not that I questioned the propriety of the confession, but because of its incongruity with other dogmatic claims and pronouncements of the author. 


\section{LECTURE XIII}

\section{THE IDEAL AND THE ACTUAL}

ACCORDING to the argument of the preceding lecture, it is from the ideals present and operative in man's life that we draw our criterion of value and, at the same time, our conviction of the nature of the system in which we live. In what follows, I wish particularly to insist that here too we are drawing upon experience. Man's experience is not limited, in the moral life, for example, to the 'is' of his actual achievement, or, in the contemplation and production of the beautiful, to the beauty which the artist has succeeded in embodying in his poem, his painting, or his symphony. In Marlowe's great words :

If all the pens that ever poets held

Had fed the feeling of their masters' thoughts, And every sweetness that inspired their hearts, Their minds and muses on admired themes:

If all the heavenly quintessence they 'still

From their immortal flowers of poesy,

Wherein as in a mirror we perceive

The highest reaches of a human wit:

If these had made one poem's period, And all combined in beauty's worthiness, Yet should there hover in their restless heads One thought, one grace, one wonder, at the least, Which into words no virtue can digest. ${ }^{1}$

And, as in the quest of beauty, so in the life of moral endeavour. The best and noblest looks up to a better and

${ }^{1}$ Cf. Sir Joshua Reynolds on the painter's ideal: 'The sight never beheld it, nor has the hand expressed it. It is an ideal residing in the breast of the artist, which he is always labouring to impart, and which he dies at last without imparting.' 
nobler; with a strange mingling of ardour and despair he strains his eyes towards an unapproachable perfection. Hence Browning's familiar paradox that life's success lies in its failures, and that the divine verdict, in contrast to the world's, is passed, not upon the paltry sum of a man's deeds and attainments, but upon the visions of goodness which were his own despair:

\section{What I aspired to be, And was not, comforts me.}

Such a passage requires, of course, to be read with understanding. The question is not of the casual inoperative wish, or the formal acknowledgement of the more excellent way, on the part of those confirmed in self-indulgence. Obviously, where there is no attempt, there can be no failure. It is the vision of goodness which has pierced a man with a sense of his own unworthiness, the ideal after which he has painfully limped-it is of these things that the poet speaks. And what I am concerned to emphasize is simply that, according to a doctrine of immanence rightly understood, man's 'reach' as well as his 'grasp' must be taken into account; for the presence of the ideal in human experience is as much a fact as any other. It is, indeed, much more; it is the fundamental characteristic of that experience.

This is frequently neglected. Philosophers are apt to treat human nature as a finite and strictly self-contained fact, exhaustively revealed in its past record or in its present achievement. This is the defect in Hume's otherwise just contention that every cause must be judged by its effects. We have no call, and no right, he argues, to attribute more intelligence or goodness to the causal principle of the universe than we find actually exhibited in the facts as we see them. But finite premisses can never prove an infinite conclusion; the limited and partial goodness of which we have 
historical experience cannot of itself justify us in treating the whole history as the operation of a Being of infinite goodness, wisdom, and benevolence. And so Cleanthes tells us, at a turn of the argument, that he has been apt to suspect the frequent repetition of the word infinite in theological writers to savour more of panegyric than of philosophy. We should get on better, he suggests, 'were we to rest contented with more accurate and more moderate expressions'. The facts, as Hume sees them, present a motley spectacle in which, to the dispassionate observer, evil may well seem on the whole predominant over good. ${ }^{1}$ But this impression may be due, I would suggest, to the external attitude of the dispassionate spectator so characteristic of Hume. Just as his general argument is based on a consideration of 'the works of nature', in which no account is taken of the characteristics of human nature, so when human phenomena do perforce come up for discussion, they are likewise judged as they would be by a spectator $a b$ extra, necessarily limited in his data to overt manifestations, and ignorant of the conditions of the inner drama of which these actions are the outcome and, as it were, the external register. But in such moral experience, finite and even paltry as the outcome in word or deed may appear, there may be an infinite factor involved. How otherwise, indeed, can we explain the human capacity of choice and man's long struggle to rise above himself? Is it not just the power of framing (and consequently of following) an ideal which constitutes man's nature as a rational creature-which makes him more than an intermittent pulse of animal desire? Man's ideals are, in a sense, the creative forces that shape his life from within. They have brought him thus far, and they confer upon him the possibility of an endless advance. As Edward Caird puts it: "Their prophecies may be truer than history, because they contain something more of the divine than history

${ }^{1}$ Dialogues concerning Natural Religion, Part XI. 
has expressed as-yet,-or-perhaps than it ever can fully. express.' 1

Whence, then, are these ideals derived and what is the meaning of their presence in the human soul? Whence does Man-pessess-this outlook upon a perfect Truth and Beauty and an infinite Goodness, the world of empirical fact being, as Bacon says, in proportion inferior to the soul? Man did not weave them out of nothing any more than he brought himself into being. "It is $\mathrm{He}$ that hath made us, and not we ourselves'; and from the same fontal Reality must be derived those ideals which are the masterlight of all our seeing, the element, in particular, of our moral and religious life. The presence of the Ideal is the reality of God within us. This is, in essentials, the famous argument for the existence of God which meets us at the beginning of modern philosophy - the argument from the fact of man's possession of the idea of a Perfect Being, which forms the centre, indeed the abiding substance, of Descartes's philosophy. This idea, Descartes reminds us, is not just an idea which we happen to find as an individual item in the mind, like our ideas of particular objects. It is innate, he says, in his old-fashioned misleading terminology. He means that it is organic to the very structure of intelligence, knit up indissolubly with that consciousness of self which he treated as his foundation-certainty-so that our experience as self-conscious beings cannot be described without implying it. 'I must not imagine', he says in the Third

${ }^{1}$ Evolution of Religion, vol. ii, p. 9. Caird is commenting upon the well-known passage in which Goethe sets the world of inner experience beside the larger cosmos revealed to us in perception, and in which he justifies the popular identification of the divine with the best that we know or can conceive :

Im Innern ist ein Universum auch,

Daher der Völker löblicher Gebrauch,

Dass jeglicher das Beste was er kennt,

Er Gott, ja seinen Gott, benennt. 
Meditation, " that the conception of the infinite is got merely by negation of the finite. . . . On the contrary I plainly see that there is more reality in the infinite substance than in the finite substance, so much so that it may even be said that my consciousness of the infinite is in some sense prior to my consciousness of the finite-or, in other words, that my consciousness of God is prior to my consciousness of myself. For how could I doubt or desire, how could I be conscious, that is to say, that anything is wanting to me, and that I am not altogether perfect, if I had not within me the idea of a being more perfect than myself by comparison with whom I recognize the defects of my nature?' The finite self, in short, with which Descartes appeared to start as an absolute and independent certainty, is not really an independent being at all. It can neither exist nor be known in isolation: it knows itself only as a member of a larger life. The idea of God, Descartes says elsewhere, ${ }^{1}$ originates along with the idea of self and is innate in the same sense as the latter. The absolutely finite, if the paradoxical expression may be pardoned, would be entirely shut up within the four walls of its independent entity: it would be a universe to itself with no consciousness of any Beyond, and of course, therefore, without the consciousness of higher or lower. But man is not finite in this sense. Man is by contrast a finite-infinite being, conscious of finitude only through the presence of an infinite nature within him. The possibility of aspiration, infinite dissatisfaction and its obverse, the capacity for infinite progressthese fundamental characteristics of the human and rational life are based by Descartes on the existence of a Perfect Being revealing himself in our minds.

We need not follow Descartes in the mechanical and external details of his theory-I mean in the separation of the idea from the fact it represents, the treatment of it as an

${ }^{1}$ Towards the end of the Third Meditation. 
effect produced in the mind by an external cause-nor need we even be perturbed if doubts invade us whether we really do possess such a positive idea of an absolutely perfect Being as Descartes seems to assert, and whether it is this idea which we use as a standard of comparison. It has been made an objection to Descartes's argument that we know only degrees of more and less, as we find them in experience, and that by a process of idealization from these examples we frame the imagination of a Being indefinitely exceeding the greatest and the best we know, whom we finally proceed to clothe with superlatives as the absolutely Perfect Being. But, in point of fact, what more do we want for the purposes of the argument than is here conceded? We may well admit that we do not rightly know in what Perfection consists. It is something which we feel towards, whose characters we divine along the lines of our own highest experiences; and our idea is, to the end, something approximative, a hint, a suggestion, a bare outline. If by a positive idea Descartes is supposed to mean a clear, precise, and adequate idea, then it is certain we possess no such idea of a Perfect Being. We should require to be God in order to construct it. But what Descartes really meant by his epithet was that the idea is not a mere negation-as if we simply clapped a 'not' before the finite, and said that the infinite is what the finite is not. The idea is positive up to the very limits of conception, including all that is real in the finite and infinitely more. But that 'more', although it is the moving spirit of life within us, we do not possess in terms of conscious experience or of thought till it is revealed to us bit by bit 'with the process of the suns', and, it may often be, in the travail of our souls.

Let it be frankly admitted, therefore, that we do not use the full-orbed conception as our direct criterion of value, because the full-orbed conception is not ours. The human idea of God or-of-perfection is, as Locke said in an apt phrase 
of our idea of infinity, 'an endless growing-idea,' ${ }^{1}$ one which grows with man's own growth, acquiring fresh content from every advance in knowledge or in goodness, opening up fresh heights and depths to him who presses honestly forward; but he who penetrates farthest will be the last to say that he has attained. We are never at the goal, but as we move, the direction in which it lies becomes more and more definite. The movement and the direction imply the goal; they define it sufficiently for our human purposes; and in direct experience we are never at a loss to know what is, higher and what is lower, what is better and what is worse.

A criticism of the ordinary form of what is called the cosmological argument leads us by a slightly different path to a similar result; for again what we have is the argument from the less to the more, from the finite to the infinite. In form, it is the ordinary argument from effect to cause, from the empirically verified existence of the world-my own existence at the very least-to God as the cause which explains that existence. So we have it in Locke, for example: 'Man has a clear conception of his own being; he knows certainly that he exists and is something. . . . If, therefore, we know that thus there is some real being, and that nonentity cannot produce any real being, it is an evident demonstration that from eternity there has been something. ... Again, a man finds in himself perception and knowledge, and as whatsoever is the first eternal being [cannot] give to another any perfection that it hath not, either actually in itself or in a higher degree, it necessarily follows that the first eternal being cannot be matter but must be an eternal mind.' 2 .

It is at this point that we are faced by Hume's rejoinder, already referred to: 'Whence can any cause be known but

'Essay, II. 17. 7. Cf. section 12: 'a growing and fugitive idea, still in a boundless progression that can stop nowhere', and, in the end, 'very far from a positive complete idea' (section I5).

${ }^{2}$ Essay, IV. 10. 2-12, 
from its known effects?' We reach along such a line of argument only sufficient power and sufficient intelligence to account for the tangled web of empirical fact; it is impossible, from finite and imperfect data as our premisses, to reach the infinite and perfect in our conclusion. But, as Hegel has justly pointed out, such a criticism of the reasoning misreads entirely the logic of religion and, indeed, the procedure of living thought in any sphere, which perpetually carries us in the conclusion beyond our premisses. Otherwise why reason at all, if there is no advance? The premisses have to be transformed, set in another light, in order to yield the conclusion. In the argument which we are considering, the finite empirical world is certainly our starting-point, but the defect of the ordinary syllogistic form, says Hegel, is that 'the starting-point is taken as a solid foundation and supposed to remain so throughout, left at last just as it was at the first . . . as if we were reasoning from one thing, which is and continues to $b e$, to another thing which in like manner is'. But 'to think the phenomenal world rather means to re-cast its form and transmute it into a universal'; and 'what men call the proofs of God's existence are, rightly understood, [just] ways of describing and analysing the active course of thought, the mind thinking the data of the senses..' Hence to the religious man the passage from the finite to the infinite does not mean that the empirical world is "anything more than the point of departure '.$^{2}$ It is, in fact, the contingence of the finite which is the whole nerve of the reasoning. As it has been put, the argument is not so much 'Because the contingent is, therefore the necessary being is '; it is, rather, 'Because the contingent is not, the necessary being is ' .3 It is because the finite facts in their dispersedness and mutability seem to be unable to stand alone, to have nothing

'Encyclopaedia, section 50.

2 Philosophy of Religion, vol. iii, p. 287 (English translation).

${ }^{3}$ Caird's Critical Philosophy of Kant, vol. ii, p. 125. 
stable or permanently satisfactory about them, and to be riddled with discord and contradiction, that the mind seeks to pass beyond them, as fragmentary appearances, to a reality which it conceives as an abiding and harmonious whole. Hence the starting-point is cancelled, so far as its independent existence is concerned. 'The apparent means or stepping-stone vanishes,' and the finite is recognized as existing only in and through the infinite. This is not to be interpreted, however, Hegel urges, as if the finite were merely absorbed. It is the nature of the infinite to express itself in the finite; and the living fact is just this unity-the realization of the infinite in the finite and the recognitiun by the finite of its own groundedness in the infinite.

The character of the reasoning is expressed in the name most commonly given to the argument-the argument $a$ contingentia mundi-and Professor Bosanquet describes it, not unfairly, as 'the essential argument of metaphysics' and as identical 'in all Idealist philosophies'.' The necessary, as opposed to the contingent in the argument, is, as he says, 'the stable, the satisfactory, the $\beta \dot{\varepsilon} \beta \alpha z o v$, and the essence of the reasoning is an 'inference from the imperfection of data and premisses'. ${ }^{2}$ It is what he calls 'the spirit of totality', working within us, which carries us forward. The same idea of the spirit of the whole is the fundamental meaning of Aristotle's great doctrine of the First Mover, operative in the universe as desire or love, and so, through the quest of satisfaction and self-completion, drawing all things to itself. It is what we desire - what we are not, but what we have the power to become - that is the moving power in all advance.

Our destiny, our being's heart and home,

Is with infinitude, and only there;

With hope it is, hope that can never die,

Effort, and expectation, and desire,

And something evermore about to be. ${ }^{3}$

${ }^{1}$ Individuality and Value, p. 262.

${ }^{2}$ Ibid., p. 267.

${ }^{3}$ Wordsworth, The Prelude, Bool: VI. 
Hence the ideal is precisely the most real thing in the world; and those ranges of our experience, such as religion, which are specifically concerned with the ideal, instead of being treated as a cloud-cuckoo-land of subjective fancy, may reasonably be accepted as the best interpreters we have of the true nature of reality, And certainly in no sphere of our experience is the implication of objectivity-the " $t$ ruthclaim ', as it has been called-more insistent, one might say, more overwhelming, than just in the moral and religious life. Reverence for the moral law, the self-humiliation caused by failure to fulfil its demands, the sense of sin, the attitude of worship and utter self-surrender, are possible only if the subject feels himself in presence of a Reality beside which all else pales into insignificance. And it is to the moral and religious man himself that we must go, not to the philosopher weaving theories about him, if we are to understand his experience aright, The religious man's account of his experience may be overlaid with accretions and survivals of primitive custom and belief; and on these accessories philosophical criticism and historical research have their legitimate work to do. But the fundamental presuppositions of any experience must be accepted from the experience itself : they may be explained, but not explained away. On the evidence of the moral and religious life, therefore, we are bound to treat the ideals of that life not as devout imaginations, in which fancy has combined with desire to heighten and idealize certain features of the actual, but as having their authentic basis in the nature of the world. In Mr. Bradley's words: 'There is nothing more real than what comes in religion- To compare facts such as these with what comes to us in outward existence would be to trifle with the subject. The man who demands a reality more solid than that of the religious consciousness knows not what he seeks.'

The presence and power of the Ideal is the solution of 'Appearance and Reality, p. 449. 
the question at issue in the ever-renewed debate between immanence and transcendence. Without the acknowledgement of the Ideal, a doctrine of immanence must degenerate into an acceptance and justification of the actual, just as we find it. In Pope's shallow phrase, ' whatever is, is right '. This is the lower Pantheism, of which we spoke in the first lecture of this series; and it is to be observed that such a theory, by ascribing everything that happens to the direct or immediate agency of God, is a virtual denial of the existence of reflective self-conscious, spiritual centres, such as we know them in our own experience. For although we often talk, in a legitimate metaphor, of individuals as the vehicle or the channel of certain divine ideas or purposes, the selfconscious individual must appropriate the idea in order to transmit it; he must identify himself with the purpose in order to be its instrument. On the theory which we are criticizing, however, the metaphor is taken as literal fact, and such self-reference is no more possible to the individual centre than it is to the water-pipe in respect of the water which courses through it. We are all divine automata, with at most a passive sentience of what goes on within us, enduring the course of events as they happen. Immanence, so understood, reduces both God and man to meaningless terms, for God becomes simply a collective name for a world of things which simply exist. In such a world there is not room even for the most ordinary case of desire-prompted action; for desire, as distinguished from recurrent appetite, implies the idea of a better. And the idea of a better means the idea of the self as finding satisfaction in a state of things different from its actual situation. Paltry or evanescent as the particular satisfaction may be, we have in such simple experiences the origin of the ideal self, the conception of which, as a permanent and authoritative object of desire, it is the function of experience in the individual and in the race to develop and organize. Apart from this capacity of 
self-reference, there can be no ideals, but only bare facts. And if the lower Pantheism is justly criticized as being indistinguishable from Atheism, the reason is that there can be no true doctrine of God which is not based on a true doctrine of man. Now the essence of human nature is just, as the poet expresses it,

Effort and expectation and desire

And something evermore about to be-

the contrast between the actual present and the unrealized future, passing into the deeper contrast between the 'is' and the 'ought-to-be', and the duality of what is commonly called the lower and the higher self, with the discord and the struggle thence resulting.

The process of such a life is explicable_only through the actual presence within it, or to it, of the Perfection to which it aspires. Theories of the sheer transcendence of the divine defeat their own object, because the very exaltation of the divine into an inaccessible Beyond confers a spurious independence or self-existence upon the finite. It is treated as existing in its own right. But as soon as we begin to treat God and man as two independent facts, we lose our hold upon the experienced fact, which is the existence of the one in the other and through the other. Most people would probably be willing to admit this mediated existence in the case of man, but they might feel it akin to sacrilege to make the same assertion of God. And yet, if our metaphysic is, as it professes to be, an analysis of experience, the implication is strictly reciprocal. God has no meaning to us out of relation to our own lives or to spirits resembling ourselves in their finite grasp and infinite reach; and, in the nature of the case, we have absolutely no grounds for positing his existence out of that reference.

I have commented in a previous lecture-in connexion with Kant and Martineau-on the unworkableness of a 
purely transcendent theory, and in the sequel I hope to deal more explicitly with what I hold to be the true conception of the divine life. In the present connexion it may be sufficient to suggest that the transcendence which must be retained, and which is intelligible, refers to a distinction of value or of quality, not to the ontological separateness of one being from another. It refers, as we have seen in this lecture, to the infinite greatness and richness of the containing Life, as compared with anything as yet appropriated by the finite creature. But the creation of a soul is not comparable to the manufacture of an article, which remains throughout something separate from its maker, and which is dismissed, when finished, to do the specific work for which its designer has fitted it. It may be more fitly represented by the addition of a child to a family. But it is something nore intimate still; for the filaments which unite the finite spirit to its creative source are never severed. The ProGuctive Reason remains at once the sustaining element of the dependent life, and the living content, continually offering itself to the soul which it has awakened to the knowledge and the quest of itself. 


\section{LECTURE XIV}

THE ABSOLUTE AND THE FINITE INDIVIDUAL

The Ideal was treated in the preceding lecture as the infinite present in the finite, and we thus naturally found ourselves involved towards the close in the general question of the relation of the finite individual to the creative principle of its life. I propose, in this lecture and the one which follows, to deal with this subject-to discuss what I may call the status of the finite individual-mainly in the light of its recent treatment by Professor Bosanquet in his suggestive volume on The Value and Destiny of the Individual, with such reference as may be called for to Mr. Bradley's doctrine in Appearance and Reality and the theories of Spinoza and Hegel, in which Professor Bosanquet's treatment will generally be found to have its roots. I believe that a consideration of Professor Bosanquet's position is likely to prove especially helpful, because in both his Gifford volumes he adopts Keats's description of the world as 'the vale of soul-making', and frequently speaks in that sense as if the moulding of individual souls were the typical business of the universe, while at the same time the strong monistic trend of his thinking tends to carry him in an opposite direction-to the view that 'the formal distinctness' of finite selves is an appearance due to 'impotence' and incidental to their finitude. From this point of view the blending or fusion of individual selves in an absolute experience becomes (according as we regard it) either the consummation of their effort and apparent progress in time, or the timeless reality to which that appearance corresponds.

It will be well, at the outset, to indicate the points on which we are agreed, more especially as certain utterances 
of my own in the past have been understood as a typical and extreme expression of what I suppose Professor Bosanquet means by 'an irrational Personalism', that is, as he explains, the notion of 'the personal self as an exclusive entity, simply living out a nature of its own ',' or, again, what he calls 'the unreflecting attitude which accepts [finite selves or persons] as fundamentally isolated selfsubsistent beings, externally connected, but not in any genuine sense parts of the same stuff or elements in the same spirit'.2 Such phrases may perhaps describe accurately the old doctrine of the soul-substance as a kind of metaphysical atom, which served as substrate or point of attachment for the individual's experiences; and so far as these experiences are regarded by any thinker as subjective processes going on within this substance, as in a kind of closed internal space, so far we might characterize his conception of the self as that of an exclusive entity living out a nature of its own. Among recent treatments, Dr. McTaggart's theory of personal identity, based on identity of substance, has certain obvious affinities with the theory criticized. 'Dr. McTaggart does, indeed, expressly describe the self as 'a substance existing in its own right '; ${ }^{3}$ though he more usually speaks of it as a fundamental and eternal differentiation of the Absolute, which is treated as the unity or society of such persons, without being itself a person. Or, again, we found Martineau, in his insistence on the transcendence of the Divine as the source of obligation, speaking of the 'unitary' nature of personality as occupying one side of a given relation and unable to be also on the other, and using such phrases as 'an insulated nature', a being existing ' within the enclosure of his detached personality'.4 Such expressions, as we saw, were connected

Value and Destiny of the Individual, pp. 32-3.

'Ibid., p. 46.

- Studies in Hegelian Cosmology, p. 37.

- Cf. Lecture II, supra, pp. 36-7. 
with the externally deistic conception of God and the correspondingly individualistic conception of man which, on the whole, dominate Martineau's formal philosophy. But a closer inspection shows that these phrases are applied to the hypothetical case of 'one lone man in an atheistic universe'; and if we recall Martineau's frequent designation of God, in his philosophy of religion, as 'the soul of all souls', we see that they cannot be intended to apply in any literal sense to the relations of the divine to the human, as they exist and are experienced in the actual universe. Still, even to put forward the hypothetical case is evidence of defective philosophical insight. For the mere individual nowhere exists; he is the creature of a theory.

A self can exist only in vital relation to an objective system of reason and an objective world of ethical observance from which it receives its content, and of which it is, as it were, the focus and depositary. Apart from these it would be a bare point of mere existence. Historically, the individual is organic to society, to which he is sometimes said to be subsequent; for, in the light of history, it is not altogether unmeaning to speak, as Professor Bosanquet does, of 'the genesis'-so to speak, the 'crystallizing'-of the individual soul out of the collective soul of the primitive community; the genesis, at any rate, of anything worthy to be called self-consciousness. Apart from questions of origin, it is certainly true that it is only by a convenient (though often misleading) abstraction that we can discuss the nature and conduct of the individual apart from the social whole in which he is, as it were, imbedded, and of which he appears to be the product. And as the individual is organic to society, so in still larger philosophical reference the individual is organic to a universal life or world, of which he is similarly a focus, an organ or expression. And he cannot possibly be regarded as self-contained in relation to that life, for such self-containedness would mean 
sheer emptiness. Both his existence and his nature (his 'that' and his ' what') are derived. It is absurd to talk of him as self-subsistent or existing in his own right. He exists as an organ of the universe or of the Absolute, the one Being; and from the same source he draws his rational and spiritual content, 'feeding', as Plato says, 'on mind arid pure knowledge, the proper food of every soul' ${ }^{1}$

Hence, as Professor Bosanquet rightly, more than once, insists, 'the finite self, like everything in the universe, is now and here beyond escape an element in the Absolute'.2 Or, if we use the more concrete terms of religion, we may say that no act of creation is conceivable or possible which should extrude us from the life of God and place us, as solitary units, outside the courses of his being. The individual self, in other words, does not exist 'strong in solid singleness', like a Lucretian atom. The currents of the divine life course through it; it is open to all the influences of the universe. As we have already seen, ${ }^{3}$ how should we explain the fact of progress, if not by this indwelling in a larger life-this continuity with what is more and greater than ourselves? And it is from the fact that the finite individual is thus rooted in a wider life, to whose influences it remains throughout accessible, that those visitings of grace, of which the religious consciousness testifies, become most easily intelligible-as well as those more violent upheavals of the personality as we have known it, in which, as religion says, the man is born again and becomes a new creature. And because, so long as it exists, every self remains in principle thus accessible, the possibility of such regeneration remains open to the most abandoned or degraded. For which of us knows his own self and its possibilities, whether for good or for evil? According to the saying of M. Bergson, which Professor Bosanquet is fond of quoting, 'Nous ne nous tenons jamais

'Phaedrus, 247.

${ }^{2}$ Value and Destiny, p. 257.

\section{- Lecture II.}


tout entiers': we never possess ourselves entirely. If we could, we should be, I suppose, either the Absolute in propria persona, or Browning's ' finite clod, untroubled by a spark', the unchanging atom of a false theory.

But, to realize the presence of the universal in the individual (or the life of the individual in the universal, according as we choose to express the organic or inherent relation which unites them), it is not necessary to go beyond Professor Bosanquet's simple instance from everyday life, the bare fact of argument or discussion. 'No one ever dreams', he says, "of acting on the assumption that a mind is for itself, especially at a given moment of time, all that it is in itself. If this were the case, we should never argue or persuade. For to argue or to persuade is to rely on factors of the mind which are at the moment not explicit, and which we desire to evoke into explicitness.' ${ }^{1}$ It is the same thought which Plato expresses in the Meno in the quasi-mythical doctrine of Reminiscence, which, reduced by himself to philosophical prose, assures us that 'all Nature is akin ' and, therefore, for the rational mind any actual knowledge is so linked with other truths as to be capable of carrying us ultimately to the end of the intellectual world, that is, to the systematic knowledge of the whole. Thus any knowledge is the possibility of all knowledge, or, in his actual words, 'the soul can elicit all out of a single recollection, if a man is strenuous and does not faint'.

All this, then, is common ground, and common also is (or appears to be) the conviction that in the making of souls we have the typical business, or, as one might put it, the central interest of the universe. 'The universe', said Professor Bosanquet in the opening lecture of his first course, 'is not a place of pleasure, nor even a place compounded of probation and justice; it is, from the highest point of view concerned with finite beings, a place of soul-making. Our best

${ }^{1}$ Value and Destiny, p. 60. 
experience carries us without hesitation thus far. . . It is the moulding and the greatness of souls that we really care for.' ${ }^{1}$ And in his second volume the phrase and the idea are made central. But in spite of this, there is at various points in the book, as I have already hinted, something curiously grudging in his treatment of what he calls 'the formal distinctness of selves or souls ' ${ }^{2}$ The term is used always, I think, with a tone of depreciation, as if this were a feature which one is, indeed, forced to recognize, but rather as a limitation to be overcome than as part of the fundamental structure of the universe-what one might perhaps term the fundamental method of creation. 'No one', we are told, " would attempt to overthrow this formal distinctness-consisting in the impossibility that one finite centre of experience should possess, as its own immediate experience, the immediate experience of another.' But it is suggested that it 'depends on what are at bottom unessential limitations, such as the fact of differences of vital feeling, depending as a rule on the belonging of different selves to different bodies'; and 'if the hindrance against two selves having the same immediate experience could be removed, the result involved would be the coalescence of the two selves into one'. So, again, we are told that this formal distinctness is 'no doubt inevitable on the assumption that there are to be finite individuals, because, if the centres ceased to have the different bases of feeling that keep them from merging, they would be one without distinction and there would be no two experiences to blend'. Nevertheless, 'its nature seems not wholly fundamental nor irreducible'. And later the conclusion is reached that "while we may venture to say that we see a use and convenience in this system of finite experiences ... . we are aware of its precarious and super-

${ }^{1}$ Individuality and Value, p. 26.

${ }^{2}$ Value and Destiny, p. 47 (in the second lecture, where this grudgingness is specially noteworthy throughout). 
ficial nature'. 'A completer unity of finite minds in one would bring us at once to a partial Absolute, and necessitate a transformation of the differences which now suffice to keep finite minds distinct'; but this, it is indicated, would not serve the purposes of 'everyday life'. 'But, again (he repeats), we are aware of the precarious and superficial nature of their distinctness, and at every point we meet with indications that something deeper and more real underlies them.' ${ }^{1}$

The attitude revealed in such expressions, and the constantly recurring conception of blending or merging, as the superior ideal or goal, seem to me very significant as bearing on the ultimate outcome of a rigidly absolutist theory, and I will return to consider them in that reference. But we must first, in justice both to Professor Bosanquet and to ourselves, take note of the main considerations on which he bases this view of the unimportance of the distinctness of selves and, as it would seem, its progressive disappearance. These considerations are indicated in the reference in the passage last quoted to something deeper and more real which underlies the individual selves. And in what has already been said about the universal in which the individual lives, and from which he draws his sustenance, I have emphasized in advance my adhesion to the valuable truth which Professor Bosanquet enforces. What I deny is its relevance to the suggested view of finite selfhood as a vanishing distinction. Professor Bosanquet's polemic is directed against the tendency to over-emphasize the exclusiveness of the self, as if it were in the assertion of its bare self-identity and difference from others that the self realized its true being; and it is characteristic of his argument that he construes any statement of the focal difference or separateness of selves as implying the denial of any common aims or common content, in short, the denial of any common life in the whole. And as against such a view he has no difficulty in showing that the

${ }^{2}$ Value and Destiny, pp. 47, 48, 54, 58. 
value of a self, or, in his own phrase, its reality, lies in its content, and that this depends just on the extent to which it appropriates a common heritage of ideas and interests. The life of the finite individual, as it builds up its true self, is thus a continual process of self-transcendence; its true per-. sonality or individuality does not lie in unshareable feelings, but in the richness and variety of its thoughts and interests. It is not an abstract point of particularity; it is, or rather, it makes itself, a little world, a microcosm. But the contents of such a self-and every actual self is in its degree such a self-are essentially shareable. In social interests and purposes the individual becomes one with his fellows; and in science and philosophy, religion and art, he shares those universal interests which are the common heritage of humanity-which in the most literal sense make us men. It is obvious, therefore, that there must be an identity of content in all selves, and that the extent of this identity may vary indefinitely as between different selves, "large numbers of consciousnesses' being indeed, as he says, ' completely coincident for the greater proportion of their range'-so much so as to suggest the difficulty of understanding " what was to be gained by so immense a multiplication of contents all but identical '. In this reference we may quite intelligibly talk, as Professor Bosanquet does, of 'the overlapping of intelligences', inasmuch as 'the formal diversity of finite centres is not at all thoroughly sustained and reinforced by a coincident diversity of the matter of their experience '.' But to add, as he does, that the formal diversity is 'in some degree reacted on and impaired ' by the partial identity is, I submit, to state what may be true as the author intends it, in a form which opens the way to serious error. For it is quite clear that the formal distinctness of selves is not at all ' impaired '-not affected at all-by the extent of the knowl-

${ }^{1}$ Ibid., p. 56. Cf. p. 53: 'Their contents overlap in the most irregular and fluctuating way.' 
edge they have in common, or of the sympathies they share. The fabric of two minds may, as Professor Bosanquet has suggested, be so nearly identical that the one seems to reduplicate the other rather than to supplement it, and yet they remain two minds to the end of the chapter. Finite centres may 'overlap' indefinitely in content, but, ex vi termini, they cannot overlap at all in existence; their very raison d'être is to be distinct and, in that sense, separate and exclusive focalizations of a common universe.

It is not conceivable, of course, that Professor Bosanquet means to deny such a commonplace. He allows, indeed, at the outset, that 'individuality or personality has an aspect of distinct unshareable immediacy, [although] in substance, in stuff and content, it is universal, communicable, expansive'. But the suggestion of the argument throughout is the unimportance of this aspect. It may be a necessary condition of finiteness, but finiteness, we are distinctly told, ' lies in powerlessness '; and we noted how the expansion of the self and its identification of itself with other selves in common interests and movements repeatedly suggested to the author the idea of blending or merging as the consummation of the process of enlargements and a kind of emancipation from the de facto limitations of individuality as we know it. This is brought out still more strongly, if possible, in the author's summary of the lecture. 'There is no rule as to how far "persons" can overlap in their contents. Often a little change of quality in feeling, it seems, would all but bring them into one. It is impotence, and no mysterious limitation that keeps them apart. At their strongest they become conflucnt, and we see how they might be wholly so.'

'Ibid., p. xxi (italics mine). Cf. again in one of the summaries of the previous volume: "There would be no gain in wiping out the distinction between one self and another in finite life; our limitations themselves no doubt have a value. Still, in principle, our limitations are merely de facto; there is no hard barrier set that can make our being discontinuous with others or with the perfect experience' (Individuality and Value, p. $\mathrm{xxxi}$ ). 
The whole stress is laid, in this chapter and again in Chapter IX where 'the destiny of the finite self' is discussed, upon the objective and impersonal content as distinguished from the personalities in which it is focused or realized. 'The social fabric or any of the great structures in which spiritual achievement takes shape, e. g. knowledge, fine art, historical continuity of the constitutional system of a country'-'solid fabrics' or 'organic structures' such as these- ' are the certain, intelligible and necessary thing', the 'something deeper and more real' of which he spoke as underlying the 'precarious and superficial' system of finite experiences. ${ }^{1}$

My argument does not require me to deny what is true in this way of putting the case. These great supra-individual creations impress us all with a sense of permanent, or at least, of age-long reality. The structure of a national civilization and the traditions which constitute a nation's life seem real in a sense which transcends and overshadows the reality of any individual citizen of to-day, or any of the nameless generations of the past, of whose lives it is, as it were, the abiding product. The time has gone by when it was possible to speak of such things as mere abstractions: it is the individual who is apt to appear an abstraction when set over against them. And so he is when set over against them; for, as we have abundantly seen, it is only in themas participating in them-that he has any concrete reality. But if we are not to forget the fundamental structure of the world, the counter-stroke must also be delivered. The universal is no less an abstraction, if it is taken as real, or as possessing substantive existence, independently of the individuals whose living tissue it is. They realize themselves through it; it realizes itself in them. Thus a social whole is the sustaining life of its individual members, but it

${ }^{2}$ Value and Destiny, pp. 53-4. 
melts into thin air if we try to treat it as an entity apart from them. Exclusive emphasis on the one side or the other is the explanation of the perennial duel between individualistic and organic theories of society or between nominalism and realism, pluralism and monism, in the wider field of philosophy. Now, although Professor Bosanquet certainly would not challenge the Aristotelian doctrine of the concrete universal just enunciated, the strongly monistic trend of his thought leads him, as we have seen, to treat the individual, qua individual, almost as a negligible feature of the world, and in the issue, consequently, as we shall see later, to treat the finite self as a transitory phenomenon.

But this, I venture to urge, is entirely to mistake and to underrate the place which individuation holds in the structure of the universe, and, consequently, as I suggested, to be untrue to the position apparently adopted, which treats soulmaking as the essential business of the universe. It is no doubt true, as Professor Bosanquet remarks," that 'we cannot expect to give a reason for the scheme of the universe '; but we ought, at least, to be able to see a reason or a reasonableness in it, if our philosophy is to carry us through. And to leave the whole question of "why the finite world exists' as, in the main, a mystery, would seem to indicate some defect in the conception either of the individual or of the Absolute, or perhaps of both.

Let us consider first, then, what is meant, or what we ought to mean, by an individual. I will start from an incidental remark of Professor Bosanquet's, in which he protests against the phrase 'numerical identity', commonly used in this connexion. In the sentence I refer to, he speaks of accentuating 'the positive self of content, at the expense of formal distinctness, or what I call under protest numerical identity '.2 If I understand Professor Bosanquet's objection to the phrase, I take his contention to be that individuality is

${ }^{2}$ Value and Destiny, p. $6 \mathrm{r}$.

Ibid., p. 287. 
ultimately a matter of content, and that individual differences, consequently, must be so explained. Form is not like an empty case into which a certain content may be put: it is the structure and organization of the content itself. Individuals are formally distinct, therefore, not because a more or less identical content has been thrust into so many empty cases which have afterwards had a numerical label, or a proper name, attached to them for convenience of reference. Individuals of a species are not comparable to articles turned out by a machine, each of which seems an exact repetition of its predecessors. They are formally distinct, because they are really different; and, no doubt, if we made our analysis fine enough, the manufactured articles also would turn out to be only practically and approximately identical in quality and structure. For I accept the principle of the identity of indiscernibles as necessarily true of all real existences. Things are distinguished by their natures; they are different wholes of content. And even if we make space and time the principium individuationis and try to reduce the formal distinctness of individuals to difference of position in the spatio-temporal series, such difference of position means a changed relation to the rest of the universe, an exposure to different influences and a consequent difference in the resulting nature. And space and time may be regarded ultimately as only a mode of expressing the general fact of individuation-the fact that there are finite centres at all.

It follows, then, that every individual is a unique nature, a little world of content which, as to its ingredients, the tempering of the elements and the systematic structure of the whole, constitutes an expression or focalization of the universe which is nowhere exactly repeated. Appearances to the contrary are due to superficial observation and want of interest in the object observed. To take the common instance: the sheep which to the 
ordinary passer-by are only so many numerable units, are known as real individuals, by differences of feature and character, to the shepherd who lives with his flock and enters into their life. And the higher we go in the animal scale, the more this uniqueness of the individual life is emphasized. It is expressed with rare beauty and pathos in Matthew Arnold's lines on the death of his little dachshund :

And not the course

Of all the centuries yet to come, And not the infinite resource

Of Nature, with her countless sum

Of figures, with her fullness vast

Of new creation evermore,

Can ever quite repeat the past

Or just thy little self restore.

And when we pass to man, a Nietzsche may consign the masses of the race 'to the devil and statistics' 1 as 'blurred copies on bad paper and from worn-out plates', but mankind, it has been more finely said, 'is all mass to the human eye, and all individual to the divine '. ${ }^{2}$ If not to Nietzsche's diseased extent, we are all prone to something of the same feeling. Most of us, I fancy, have had our moods of depression before the vast monotony of human conditions and human types, and have felt ourselves glutted by nature's endless fecundity. But that may be our mistake, as suggested in the saying just quoted. It needs, in fact, only a little sympathy and imagination to see, as Wordsworth says,

into the depth of human souls,

Souls that appear to have no depth at all

To careless eyes.

William James, in a delightful paper in his Talks to Teachers, entitled 'On a certain Blindness in Human Beings', discourses, with the aid of a famous quotation from Stevenson,

'In the essay on History in his Unzeitgemässe Betrachtungen.

- Mozley, University Sermons, p. 121, at the close of a sermon on War. 
on our ordinary lack of this imaginative sympathy, which makes our fellow-beings mere outsides for us; and in his essay on Human Immortality he returns to emphasize the narrowness and stupidity of such an attitude, in particular the stupidity of imposing upon the universe or upon God our own incapacity, our limited sympathy and interest. And, in fact, there is nothing more characteristic of the religious attitude that the sense of a Divine Companion, whose perfect comprehension is the pledge of a sympathy as perfect, a sympathy to which we appeal with confidence even where we might hesitate in regard to those nearest to us and most dear.

But this is carrying us away from our immediate point, which was the nature of the individual as a whole of content, constituting a unique focalization or expression of the Absolute, and thus making its unique contribution to the life of the whole. The line of thought into which we have glided has seemed to suggest that this uniqueness of function or contribution might carry with it the conservation or permanence of the finite whole as such. But Professor Bosanquet, although in objecting to the phrase numerical identity he appears to emphasize the qualitative uniqueness of the individual, and although he frequently speaks of the 'contribution' made by the finite self to ultimate reality (it is indeed one of his favourite expressions), seems constantly to imply that this is to be conceived as the contribution of an 'element' or quality, some peculiar flavour or tang, to a universal experience-not as consisting in its own total living reality as a specific incarnation, a centre into which the Absolute has poured its own being. And it is in accordance with this view that the finite individual is represented as yielding its contribution like a perfume exhaled in the very dissolution of its private being.

Odours, when sweet violets sicken,

Live within the sense they quicken.

This is clearly stated in an important new chapter in the 
second edition of his Logic, ${ }^{1}$ which is in the nature of a reply to criticisms by Professor Stout and Professor Taylor. It is true that the statement to which I refer is made of the animal mind, but animal minds are expressly taken as ' an extreme case' of 'the imperfect individual' in general, that is to say, of 'all finite individuals'; and what is said of the dog applies in principle to every finite subject. 'No one who has loved a dog ',' says Professor Bosanquet, 'can doubt that its mind has a value of the same kind, if remotely the same, as his own. No one, on the other hand, can well suppose that it has the distinctness and organization of content which we should expect of anything that is to have a permanent place of its own as a separate member of the system of reality. Surely the solution must be of the general type which conceives this partial mind as contributing a character, some intensification of loyalty and affection, to some greater existence, and not claiming in itself to be a unique differentiation of the real.' It is, no doubt, in the light of such phrases here as 'a separate member', ' a unique differentiation', that one must understand the pointed refusal made twice over, in the chapter on 'the destiny of the finite self ', to entertain the term ' member' in reference to such selves. 'The finite self [he says there in the text], like everything else in the universe, is now and here beyond escape an element in the Absolute'-to which we have the foot-note: "I do not say "a member of" the Absolute. Such an expression might imply that it is, separately and with relative independence, a standing differentiation of the Absolute.' And again, à propos of the same point, we have another note, fourteen pages later, in which the same distinction is punctiliously reasserted: 'We are sure, to begin with, of our eternal reality as an element-I do not say a member-in the Absolute.' And it is in harmony with the

'The chapter on 'The Theory of Judgment in relation to Absolutism'.

'Logic, and ed., vol. ii, p. 259. 
spirit of the distinction that the conclusion of the chapter offers us 'the eternal reality of the Absolute as that realization of our self which we instinctively demand and desire '.'

We are not at present discussing the specific problem of human immortality, although the argument may have important bearings on such a question. What I wish to challenge is Professor Bosanquet's whole view of the self or the finite individual-a view which is brought to a point in such a distinction as $I$ have just quoted (between ' member' and 'element'), but which runs from end to end of his system and determines its whole structure. The too exclusive monism of the system depends, it seems to me, on a defective idea of what is meant by a self or by the fact of individuation in general. If one were inclined to put it strongly, one might almost say that Professor Bosanquet's theory does not contain the idea of self at all : the world is dissolved into a collection of qualities or adjectives which are ultimately housed in the Absolute. And again, just because of the failure to appreciate the meaning of finite selfhood, it is difficult to say whether even the Absolute is to be regarded as a self or not-that is to say, whether what is called the absolute experience possesses the centrality or focalized unity which is the essential characteristic of a self, and, in its degree, we may say, of everything that is real.

The doctrine of the one perfect individual is, of course, the overt thesis of Professor Bosanquet's first Gifford volume on 'Individuality and Value'; but the foundations on which the argument rests are more clearly exposed in the chapter of the Logic to which I have already referred. It is there quite unequivocally stated, in connexion with the theory of the judgement, that the only ultimate subject of predication is 'the one true individual

${ }^{1}$ Value and Destiny, chap. ix, pp. 258, 272, 288. So again in the summary of the same chapter ( $p$. xxxi) the conclusion is suggested that 'it is rather $a$ personality than our personality that is essential'. 
Real', all finite individuals being 'in ultimate analysis connexions of content within the real individual to which they belong', and of which they are therefore 'ultimately predicates '.' Here we come, I think, definitely to the parting of the ways, and yet, in reading Professor Bosanquet's chapter, one has the hopeless kind of feeling which so often oppresses us in philosophical controversy-a sense of despair at seeing the one party accumulating proofs, and reiterating assertions, of what it has never occurred to the other to deny. The question is whether finite individuals possess a substantive or an adjectival mode of being-whether, that is to say, they must be taken as substances in the Aristotelian sense of $\pi \rho \omega^{\prime} \eta \eta$ ov $i \alpha$, that which cannot stand in a judgement as predicate or attribute of anything else, the individual thing or being, in short, of which we predicate the universals which constitute its nature. But what Professor Bosanquet elaborately contends is that the finite individual is not a substance in the Spinozistic sense, not 'wholly independent and self-subsistent', not a 'true individual', not, in short, the Absolute. And, of course, as Locke said in a similar connexion, 'it is but defining substance in that way and the business is done'. Taking substance in this sense, Professor Bosanquet naturally finds it 'quite astonishing that an appeal in favour of a doctrine of independent substances should be made on the ground of our experience of ourselves'. That experience seems to him, on the contrary, ' of all things the most fatal' to such a doctrine. 'What all great masters of life have felt this [experience] to reveal has been a seeking on the part of the self for its own reality, which carries it into something beyond.' 2 But the misunderstanding is almost wilful, for the appeal to which Professor Bosanquet is replying is not to the self as complete and self-explaining, but expressly to 'the unique individuality of the self as a centre of immediate experience'. Its

'Logic, vol. ii, pp. 258-9 (italics mine).

2 Ibid., pp. 254-5. 
edges may be as ragged as you please; our experience may, as it does, carry us on all sides beyond ourselves till we bring in the whole context of the universe. But, as Mr. Bradley himself testifies: ' My way of contact with Reality is through a limited aperture. For I cannot get at it directly except through the felt this. . . Everything beyond, though not less real, is an expansion of the common essence which we feel burningly in this one focus. And so, in the end, to know the universe, we must fall back upon our personal experience and sensation.' ${ }^{1}$ Of course, as he proceeds to explain, this does not mean that we start with an Ego conscious of its own states; it does not mean that we start with an idea of the Ego at all, for such a consciousness is admittedly a later growth of reflective interpretation. What it affirms is simply the fact on which developed selfhood is based-the fact that experience takes place in finite centres, and that all construction, all knowledge, rests on the basis of what Mr. Bradley calls 'the this and the mine '.2 Such presentation, he says, 'is the one source of our experience, and every element of the world must submit to pass through it. . . . The "this" is real for us in a sense in which nothing else is real.' 3

If we now ask how it is that Mr. Bradley, in spite of his emphasis on the fact of individual subjects as separate 4 centres of immediate experience, proceeds nevertheless, in his favourite phrase, to 'merge' these subjects, and to treat them as adjectives of the one Reality, which he makes the

${ }^{2}$ Appearance and Reality, p. 260.

${ }^{2} \mathrm{Cf}$. Professor Stout, Proceedings of the Aristotelian Society, 1902-3, p. 19: "The consciousness of self is a complex product of mental development, and even in its simplest phases it always includes a reference beyond immediate experience. All that we are justified in affirming is that the primary psychical reference implicit in all judgement is the ultimate point of departure of the growth of self-consciousness, and that it always continues to be its essential basis and presupposition.'

'Appearance and Reality, p. 225.

- They are considered, in some sense, to own an exclusive character. And that this character, in part, is exclusive cannot be denied' (ibid., p. 227). 
ultimate subject of all predication, the only intelligible answer seems to be that the assertion is intended as a denial of a final and unmediated pluralism, i. e. of the doctrine of ultimately self-subsistent, independent and unrelated reals. The best insight into a writer's meaning is often gained by considering what he is attacking or, to put it more precisely, his conception of the alternative to his own point of view. Now both Mr. Bradley and Professor Bosanquet appear to assume that such a pluralism is the only alternative to their own position. We have seen how this runs through Professor Bosanquet's statement. In almost identical terms, Mr. Bradley tells us that every finite fact is ' infected with relativity' - it is 'given as existing by reference to something else'. 'It is adjectival on what is beyond itself.' ' But such a use of the word adjectival, though intelligible, and perhaps forcible, is none the less confessedly metaphorical. Things are not adjectives of one another. A shoe is not an attribute of a foot, and a son is not an attribute of his father, though in both cases the one fact transcends itself, and carries you to the other. Reduced to plain prose and ordinary English usage, the 'adjectival' theory of the finite is simply the denial of unrelated reals; and, so understood, I at least should have no quarrel with it. If no finite fact can either exist or be understood by itself, then the true view of Reality must be that which conceives the universe as an inclusive system of interrelated facts which, as so included and interrelated, are to be regarded as constituent members of a single whole. This is the conception suggested by Professor Bosanquet's doctrine of the disjunctive judgement as the complete or perfect form to which the categorical and the hypothetical forms lead up. As readers of his Logic will recall, the disjunctive judgement, so interpreted, means not the bare 'either-or' of formal logic, but the system of subordinate and mutually exclusive forms into which any given

${ }^{2}$ Principles of Logic, pp. 70-1. 
whole differentiates itself. And, in point of fact, we find him, in the course of the present discussion, repeatedly employing such expressions as ' members of a system', 'members within a whole', 'membership within a concrete universal', to cover the meaning formerly conveyed by the terms adjective and predicate, while still pertinaciously maintaining the formal point that such members are logically to be regarded as predicates of the whole. ${ }^{1}$

It might seem, therefore, as if it became merely a verbal question whether we are to speak of an individual as a member or as a predicate of the Absolute. But unless there is some real distinction, how are we to account for Professor Bosanquet's punctilious and repeated rejection, in his Gifford volume, of the term 'members of the Absolute' as applied to finite selves? The rejection is, of course, verbally inconsistent with the phrases just quoted from the Logic, and one passage, at least, might be quoted from the Gifford volume itself ${ }^{2}$ in which the term 'membership' occurs. But, even if not consistently adhered to, the fact of the deliberate rejection of the one term implies that, when taken in bitter earnest (to use a favourite phrase of his own), the idea of membership suggests another conception of the nature and function of individuation than that which dominates Mr. Bradley's and Professor Bosanquet's metaphysics. In the next lecture I shall try to indicate what I take the difference between the two conceptions to be.

${ }^{1}$ Cf. Logic, and ed., vol. ii, p. 257.

'Value and Destiny, p. 204. There is a more important passage which I have since discovered, in which, speaking of 'the part', he says: 'it is, in truth, more than a part, it is a member or an aspect'. This occurs (p. 298) in the fine concluding chapter of the same volume, 'The Gates of the Future', and indicates at any rate a change of emphasis. 


\section{LECTURE XV}

\section{THE ABSOLUTE AND THE FINITE INDIVIDUAL}

\section{(Continued)}

I HAVE dwelt at some length in the preceding lecture on Professor Bosanquet's tendency to rebel against what he called the 'formal distinctness' of finite selves, and I cannot help finding a similar significance in the admission, so curiously recurrent in Mr. Bradley, of the 'inexplicability' of the finite individual. 'That experience should take place in finite centres, and should wear the form of finite "thisness ", is in the end inexplicable.' Again, 'Why there are finite appearances, and why appearances of such varied kinds, are questions not to be answered;' and, once more, in the closing pages, 'We do not know why or how the Absolute divides itself into centres, or the way in which, so divided, it still remains one." ${ }^{\prime}$ And I quoted in the last lecture a passage from Professor Bosanquet in which he refers in the same spirit to the question 'why the finite world exists ', dismissing it with the remark that 'we cannot expect to give a reason for the scheme of the universe'. It would seem, then, as if the unity with which the system concludes tends to abolish the plurality of centres from which it starts. Their individual and, so far, separate existence cannot, of course, be denied as a fact of experience; but it is represented as ' appearance' or illusion, due to the impotence of our finite point of view, and quite unreal ' from the side of the Absolute'. 'It may be instructive', says Mr. Bradley, 'to consider the question [of souls] from the side of the Absolute. We might be tempted to conclude that these souls are the Reality, or at least must be real.

'Appearance and Rcality, pp. 226, 511 , 527. 
But that conclusion would be false, for the souls would fall within the realm of appearance and error. They would be, but, as such, they would not have reality. They would require a resolution and a recomposition, in which their individualities would be transmuted and absorbed. The plurality of souls in the Absolute is, therefore, appearance, and their existence is not genuine. . . . To gain consistency and truth it must be merged, and recomposed in a result in which its specialty must vanish.' ${ }^{\text { ' }}$ 'Taken together in the whole,' he says again in his final chapter, 'appearances, as such, cease.' ${ }^{2}$ The equivocation here and elsewhere between appearance and mere appearance or illusion (the unconscious passage, I mean, from the one to the other) is, I venture to think, characteristic of Mr. Bradley's whole position; but, applied in this way to the existences which form the necessary starting-point of the whole speculation, it clearly involves a circle in the reasoning. There cannot be illusion or mere appearance, unless souls or finite selves really exist as such, to be the seats or victims of this illusion. The plurality of finite centres is, therefore, a true appearance; that is to say, the Absolute really does appear, or differentiate itself, in that way. ${ }^{3}$ One might infer from Mr. Bradley's account that the Absolute had no cognizance, so to speak, of the existence of finite centres at all, in its 'single and all-absorbing experience' ${ }^{4}$ What I wish to contend, on the contrary, is that the existence of such centres is a fact as true and important "from the side of the Absolute' as from the point of view of the finite beings themselves-nay, that this differentiation or creation (according as we name it) constitutes the very essence and open secret of the Absolute Life.

This is apparently implied, as we saw at the outset,
Ibid., pp. 304-6.
2Ibid., p. 511 .
'Cf. Professor Stout's argument, Proceedings of the Aristotelian Society, 1902-3, p. 28.
Appearance and Reality, p. 272. 
in Professor Bosanquet's emphatic description of the universe as a place of soul-making. But on looking more closely at his language, a qualification may be noted, which at first is apt to pass unobserved. 'The universe', he says, ' is not a place of pleasure . . . it is, from the highest point of view concerned with finite beings, a place of soul-making.' I confess that it was a long time before the insertion of the proviso which I have italicized struck me as a significant limitation of the general statement. But I observe that it is carefully repeated in the summary of Lecture III of the second course, where the moulding of souls is described as 'the main work of the universe as finite'. One is forced to conclude, therefore, that the qualification is important in Professor Bosanquet's own eyes; and it is perhaps worth noting that in the second instance the phrase occurs after the mention of the passage from Keats. 'Keats's suggestion', says Professor Bosanquet, 'is expressed so as to imply the pre-existence of something to be developed into souls, and a survival of souls in a further life after being moulded in this life. Accepting the conservation of all values in the absolute, I do not think these special assumptions necessary. But the view that the moulding of souls is the main work of the universe as finite seems to contain an unquestionable truth.' This seems to imply that ultimately, or for the Absolute, the moulding of souls does not possess the central value or importance which is attributed to it from the finite point of view. Unless the souls are conserved as souls, it is hardly intelligible to speak of their moulding as in any sense the end or meaning of the world-process. But the whole drift of the two volumes is against the idea of individual survival; 'values' survive in the Absolute, but not persons. 'The destiny or conservation of particular centres', he tells us in his opening lecture, 'is not what primarily has value; what has value is the contribution which the particular centre-a representative of certain 
elements in the whole-brings to the whole in which it is a member.'

This idea of 'contribution', as we have seen, runs through Professor Bosanquet's treatment, and it is an attractive idea, and true if rightly understood. But what if our contribution to the Absolute just lay in being ourself, our particular, imperfect, but developing, self, the unique individual whom it has taken such pains to fashion? The contribution cannot lie in any of the qualities of the individual taken separately, for these are all universals, and as such must be already fully represented in the perfect experience of the Absolute. The uselessness of such contributions from the side of the finite is aptly symbolized in the beautiful but strangely heartless parable with which Professor Royce closed his first exposition of the Absolute philosophy. 'At worst', he says, 'we are like a child who has come to the palace of the King on the day of his wedding, bearing roses as a gift to grace the feast. For the child, waiting innocently to see whether the King will not appear and praise the welcome flowers, grows at last weary with watching all day and with listening to harsh words outside the palace gate, amid the jostling crowd. And so in the evening it falls fast asleep beneath the great dark walls, unseen and forgotten; and the withering roses by and by fall from its lap, and are scattered by the wind into the dusty highway, there to be trodden under foot and destroyed. Yet all that happens only because there are infinitely fairer treasures within the palace than the ignorant child could bring. The King knows of this, yes, and of ten thousand other proffered gifts of loyal subjects. But he needs them not. Rather are all things from eternity his own.' ${ }^{2}$ Professor Royce has moved since then, and in his Gifford Lectures in this University ${ }^{2}$ he has expounded a

1 The Religious Aspect of Philosophy, p. 483.

${ }^{2}$ The World and the Individual. 
very different view of the place and destiny of the finite self in the Absolute life, and his later view is founded, I think I may say, just on the uniqueness of meaning or purpose in each individual life. To adopt the style of his own parable, it is not flowers, gifts out of the common stock of nature, which the child brings to the King, but the gift of himself, an offering which only he can make, and which, we would fain believe, is precious, as nothing else can be, in the eyes of the King.

But all the metaphors in which Mr. Bradley so abounds, expressive of the blending and merging of finite selves in the Absolute, depend on the assumption that the selves, as such, in their finite integrity, if one may so speak, possess no value for the Absolute. In the final chapter of Appearance and Reality, Mr. Bradley has occasion to consider a view which 'suggests', he says, 'that in the Absolute finite centres are maintained and respected, and that we may consider them, as such, to persist and to be merely ordered and arranged'. 'But not like this', he proceeds, ' 'is the final destiny and last truth of things. We have a re-arrangement not merely of things but of their internal elements. We have an allpervasive transfusion with a re-blending of all material. And we can hardly say that the Absolute consists of finite things, when the things, as such, are there transmuted and have lost their individual natures.' Professor Bosanquet is not so copious in his metaphors or so peremptory in his way of putting the case; but his view of "the final destiny and last truth of things', as we have already partly seen, is, in all essentials, the same. He also tells us that the content of the imperfect individual has to be 'transmuted and re-arranged ', the result being 'the contribution of some modifying element to the experiences which come together in the Absolute ' ${ }^{3}$ And, as Mr. Bradley talks of the finite self as being

'Appearance and Reality, p. 529.

'Value and Destiny, p. 259.

=Logic, and ed., vol. ii, p. 258. 
'embraced and harmonized ' in the Absolute through its being 'suppressed as such', so Professor Bosanquet speaks of 'the expansion and absorption of the self'. ${ }^{1}$ With more audacious irony Mr. Bradley speaks of the perfection and harmony which the individual attains in the Absolute as 'the complete gift and dissipation of his personality' in which 'he, as such, must vanish'. 'The finite, as such, disappears in being accomplished.' ${ }^{2}$ And again, 'the process of correction' which finite existence undergoes in the Absolute may ' entirely dissipate its nature'. 'Transmuted' is the word most favoured by both; but synonyms plentifully scattered through Appearance and Reality are 'merged', 'blended', 'fused', 'absorbed', ' run together', 'transformed', 'dissolved in a higher unity', and even the more sinister terms 'suppressed ', 'destroyed', and 'lost'.

Mr. Bradley's famous metaphor of the window-frames as expressing the condition of finite selfhood significantly indicates his conception of the process and its final consummation. "My incapacity to extend the boundary of my "this", my inability to gain an immediate experience of that in which it is subordinated and reduced-is my mere imperfection. Because I cannot spread out my window until all is transparent, and all windows disappear, this does not justify me in insisting on my window-frame's rigidity. For that frame has, as such, no existence in reality, but only in our impotence. . . . There is no objection against the disappearance of limited transparencies in an all-embracing clearness.' $^{3}$ The Absolute is, in short, 'a whole in which all finites blend and are resolved '.4 And in Professor Bosanquet's account, it seems to be through some such conception of the disappearance of the finite selves, as such, and the 're-distribution' or 're-adjustment' ${ }^{5}$ of their material in

Ibid., p. 263.

Ibid., pp. 253-4 (italics mine).

"Value and Destiny, p. xxix.

'Appearance and Reality, pp. 419-20.

- Ibid., p. 429. 
the perfect experience, that evil, which is said to be simply good in the wrong place, disappears, as such, in the Absolute. The contents or qualities of the different selves are, as it were, shaken up together, and neutralize and supplement one another. The metaphor is Professor Bosanquet's own. 'How constantly we hear it said,' he writes, " "They will do capital work together; A's failing will counteract B's," or " if A and B could be shaken up in a bag together, they would make a perfect man." The Absolute is a limiting case of such a process.' 1 But if such an 'all-pervasive transfusion' (to go back to Mr. Bradley's phrase) is the goal or, more strictly, the eternal reality which only our impotence disguises from us, then certainly we need not wonder that the existence of finite centres at all seems on the theory inexplicable and, one might even say, uncalled for. Why should the blessed harmony of the perfect experience be disturbed even in appearance?

But, in fact, the whole conception of blending and merging, as applied to finite individuals, depends on the failure to recognize that every real individual must possess a substantive existence in the Aristotelian sense. Both $\mathrm{Mr}$. Bradley and Professor Bosanquet, as we saw in the preceding lecture, insist on taking the individual as an adjective, thereby reducing it to a conflux of universals or qualities. But it is a trite observation that no number of abstract universals flocking together can give you the concretely existing individual. To exist means to be the subject of qualities, to have or possess a nature. This is recognized in the current distinction between existence and content, between the 'that' and the 'what'. And although, as we have already partly seen in another connexion, ${ }^{2}$ this is a distinction which easily lends itself to erroneous statement, we must be on our guard against a counter-error. It is certain that the 'that' of a thing, the substantive in it, is

'Value and Destiny, p. 217.

${ }^{2}$ In Lecture IX. 
not to be thought of as a solid core of being, a grain, as it were, of reality-stuff, ${ }^{1}$ to which, as a support, the qualities are attached. It cannot be taken out and exhibited as something over and above the qualities. But reaction from such errors easily leads to an exclusive stress on the content or nature as constituting and differentiating the individuals. Here again, it will be remembered, we have acknowledged the truth which lies in such a mode of statement. Individuals, it may be quite truly said, are ultimately differentiated by their nature, that is to say, by their specific content, including therein, of course, the peculiar arrangement or make-up of the content-what we may call its peculiar organization or system. But this way of stating the case is true only so long as it does not obscure the fact that we are dealing, in each case, with a concrete existent. There is a subtle danger in the term content-a suggestion that the individual is simply a very complex group of universals. But if, as we are agreed, the individual is not to be regarded as put together, so to speak, out of the abstract universal, in the shape of so many qualities, and the abstract particular in the shape of a point of existence, neither can it be regarded as simply an intricately mingled group of universals-a highly complex adjective. So to think of it is to confound the abstractions of knowledge with the concrete texture of reality; it is entirely to overlook the unity and centrality which is the characteristic of concrete existence, and is what we mean by individuation. Such centrality is acknowledged by our authors in the phrase 'finite centres'. But we have seen how 'precarious and superficial' Professor Bosanquet pronounces such formal distinctness to be. And when the whole stress is laid on content, the content comes to be regarded as somehow detachable from the centres, and capable of being re-arranged and finally shaken up into perfect harmony in the Absolute. As Mr. Bradley puts it:

\footnotetext{
${ }^{2}$ Lotze's phrase. Cf. his Metaphysic, Book I, chap. iii, section $3 \mathbf{3}$.
} 
'We found no reason why such feelings, considered in any feature or aspect, should persist self-centred and aloof. It seemed possible, to say the least, that they all might blend with one another, and be merged in the experience of the one Reality. And with that possibility, given on all sides, we arrive at our conclusion. The "this" and "mine" are now absorbed as elements within our Absolute.' 1

But such a conception does no more justice to the substantive unity of every existent than did the old associationist dissolution of the self into atomic states or ideas, the doctrine which Mr. Bradley himself so mercilessly caricatured in his Ethical Studies. 'Mr. Bain collects that the mind is a collection. Has he ever thought who collects $\mathrm{Mr}$. Bain?' So runs one of the notes that sticks in the memory. But now Mr. Bradley's own conception of the self seems open to the same retort. To use one of his own illustrations, the qualities or different elements of content in a centre seem as loose and independent as marbles in a bag, and when the string of the bag is loosened the marbles escape, as it were, into the empty space of the Absolute, to group themselves afresh. Or, seeing that the bag, as a receptacle, is ultimately a fiction, or an accommodation to popular thought, we ought rather to speak of temporarily cohering marbles detaching themselves from their groups and being swept into new combinations. But not so must we think of any self or soul or, indeed, of anything that actually exists, not even of the Absolute itself, if it is to be more than an abstraction, if it is really, as it is said to be, an experience.

The term 'centres of experience' involves, of course, a spatial metaphor, but, try as we may, we cannot get rid of such metaphors; and the term centre, or the essentially similar term focus, which Mr. Bradley, we have seen, occasionally uses as a variant, expresses, as happily as we can hope to do, the characteristic nature of the individual or 
the concrete universal as (formally at least) a self-contained world, in which a certain manifold of content acquires an internal unity as a single self or subject. The self or subject, as we have already said, is not to be conceived as an entity over and above the content, or as a point of bare existence to which the content is, as it were, attached, or even as an eye placed in position over against its objects, to pass them in review. The unity of the subject, we may agree, simply expresses this peculiar organization or systematization of the content. But it is not simply the unity which a systematic whole of content might possess as an object or for a spectator. Its content, in Professor Bosanquet's phrase, has 'come alive'; it has become a unity for itself, a subject. This is, in very general terms, what we mean by a finite centre, a soul or, in its highest form, a self.

The origin of such centres is, perhaps, the only fact to which we can fitly apply the term creation, for they necessarily import into the universe an element of relative independence and separateness which is not involved in the notion of externality as such. Externality, i. e. the general system of nature, cannot be really separated from the foci in which it finds expression; to make this separation, as we argued in the first course, is to hypostatize an abstraction. But if we try to imagine a purely mechanical system without any such living centres, it might seem possible to conceive it as simply the object of an absolute percipient. And the abstraction may help us to realize, by force of contrast, that a being which exists in any degree for itsclf, as a conscious subject, rounds itself thereby to an individual whole, and acquires in so doing an independence which we should not attribute to a mere object. To understand the process of such creation is necessarily beyond us; we can barely describe its phases without involving ourselves in contradictions. In one aspect, the soul appears to be the product of the general system of things; in another aspect it appears to be self- 
created by its own action, to presuppose its own existence at every stage of its progress-so that it has been said paradoxically, there is no first moment of self-consciousness, but only a second.

Professor Bosanquet, in his careful and suggestive chapters on 'The Moulding of Souls ', describes the origin of life as consisting essentially in the existence of 'a centre sensitive to a more concrete environment than that to which physical matter reacts', and 'capable', he adds, 'of maintaining, combining and transmitting adaptations, so as to build up a series of adapted creatures. In a word, what is needed is a centre of unification, differentiated by the externality which it unifies, nothing more in principle than this.' And by 'the sculpturing process of natural selection' everything else is added, 'the content of life and mind [being] elicited by the bare principle of totality or non-contradiction' from the environment or 'range of externality' which constitutes the 'circumference' of the living or intelligent centre. It is a process, as he rather strikingly puts it, of 'eliciting our own souls from their outsides'.' 'Elicit', however, as he remarks himself, a little later, 'is a useful word, but covers an almost miraculous creation, which it does not explain.' 2 For, of course, 'centre' must be understood as an active centre of response, not simply as a focus in which a certain range of externality reflects itself into unity. Professor Bosanquet's quasi-metaphorical phrases sometimes seem to suggest the latter idea, and his remarks on the origin of life, taken together with the exclusive stress laid on the function of the environment, seem unduly to minimize the momentous difference between a responsive centre 'capable of maintaining, combining and transmitting its adaptations', and the mass-points which serve the physicist as the substrata of the scheme of mechanical movements. The mass-point is a theoretical abstraction; the responsive centre is a practical

'Value and Destiny, pp. 74, 78-9.

2 Ibid., p. 97. 
and living reality. In his first volume he lays a similar stress on the physical basis of mind and the intimate correlation of the organism with its environment, but he reminds us, in a phrase which I made use of in an earlier lecture, ${ }^{1}$ that all we can ultimately mean by such assertions of the dependence of mind on organic conditions is to conceive the soul or self as 'a supervenient perfection'; ' a perfection granted by the Absolute according to general laws upon certain complex occasions and arrangements of externality'. In the conscious being, he adds, 'the Absolute begins to reveal its proper nature through and in union with a certain focus of externalities' $\because$ Lotze, to whose phraseology Professor Bosanquet refers, while emphasizing the inevitable mystery involved in the process, brings out more clearly the peculiar nature of the product. 'How it can be brought about,' he says, "or how the creative power of the Absolute begins to bring it about, that an existence is produced which, not only in accordance with universal laws produces and experiences effects and alterations in its connexion with others, but also, in its ideas, emotions and efforts, separates itself from the common foundation of all things, and becomes to a certain extent an independent centre-this question we shall no more attempt to answer than we have others like it. Our business is not to make the world, but to understand the inner connexion of the world that is realized already; and it was this problem that forced us to lay down our limiting idea of the Absolute and its inner creation of countless finite beings. This idea we found it necessary to regard as the conception of an ultimate fact.' ${ }^{3}$

Lotze's statement is important, because it is just the partial independence of the finite centre, the way in which it 'separates itself from the common foundation of all things',

${ }^{1}$ Cf. supra, p. 99.

Individuality and Value, pp. 189-93.

- Metaphysic, section 246 (English translation, pp. 432-3). 
which constitutes the essential mystery of the fact. Monistic writers are too apt, after accepting the fact (as in some sense, of course, they must), to proceed to obliterate or explain away its characteristic features. But if the individuals are simply pipes through which the Absolute pours itself, jets, as it were, of one fountain, there is no creation, no real differentiation, and, therefore, in a sense, no mystery. A self which is merely the channel or mouthpiece of another self is not a self. It is of the very nature of a self that it thinks and acts and views the world from its own centre: each of us, as it has been said, dichotomizes the universe in a different place. No supposed result of speculative theory can override a certainty based on direct experience-the certainty, namely, that it is we who act and we who think. We are not simply an ideal (i.e. an imaginary) point through which the forces or ideas of the universe cross and pass. This primary conviction is not inspired by the ulterior motive of introducing pure contingency and overthrowing the idea of law and system. ${ }^{1}$ No doubt it excludes a fatalistic determinism a tergo, which is simply the denial of selfhood altogether; but it forces itself upon us apart from any outlook upon consequences. It is, in a sense, a direct certainty, but it is based also on an insight into the contradictory nature of any counter-hypothesis. The creation of creators, says Professor Bosanquet dogmatically, is a mere self-contradiction; and, no doubt, that would be so, if the term creator were understood in a literal and absolute sense. But the meaning which the epigrammatic phrase is intended to convey is just that the selves are real centres of existence and not points of intersection or radiating centres of a single force. As already said, there is no creation in the case, no otherness at all, unless the selves have some kind of independent status conferred upon them. And to say, as Professor Bosanquet does in the same breath with his accusation

'As Professor Bosanquet always seems to imagine. 
of self-contradiction, that "there cannot be genuine freedom unless the divine will is genuinely one with that of finite beings in a single personality', is, to my mind (unless we are speaking of the ethical and spiritual harmony of the two wills), to furnish a much more glaring instance of a selfcontradiction, for it is to deny that there are two wills at all.

Professor Bosanquet is fond of appealing to the great experiences of life-to love, to the religious consciousness, to social union-as carrying us out of the quasi-legal world of selfish claims and individualistic justice into a world of deeper spiritual membership, where such claims disappear in the intimate consciousness of union with our fellows, with the beloved object, or with God. And again this is true, beyond question, of all private and exclusive or, as we say, purely selfish desires and claims. But I appeal confidently to the same great experiences to prove the absolute necessity of what I will call 'otherness', if they are to exist at all. It takes two not only to make a bargain; it takes two to love and to be loved, two to worship and to be worshipped, and many combined in a common purpose to form a society or a people. Surely, as the poet says, sweet love were slain, could difference be abolished; the most self-effacing love but ministers to the intensity of a double fruition. As in the love of man and woman, so in a great friendship the completest identification of interests and aims does not merge the friends in one; the most perfect alter ego must remain an alter if the experience is to exist, if the joy of an intensified life is to be tasted at all. Selfhood is not selfishness. And, passing to the instance of society, it is an insidious fallacy to speak as if, with the growth of social solidarity, there was formed ' an individuality' in which particular centres 'tend to be, as particular centres, transcended and absorbed'.' Surely the better the society-the more pervasive the spirit of membership-the more fully does each member realize

${ }^{2}$ Value and Destiny, p. 92. 
and enjoy his own individuality. It is an individual foci that the common life burns: it is reflected to us from the countenances of our fellows.

And when we come finally to the religious consciousness the same necessity holds. I will take Professor Bosanquet's own account of that experience, to which both he and $\mathrm{Mr}$. Bradley assign-and rightly assign-such central significance. The religious consciousness is expressly defined by Professor Bosanquet as self-recognition," the recognition by the finite of its 'true being' and of its ' union with the whole'; the insight into 'the impossibility of its finding peace otherwise than as offering itself to the whole'. Or, again, 'the primary principle of religion' is said to be found ' in devotion and worship, such that in them the self not merely, as in all action, passes beyond itself, but consciously and intentionally rejects itself as worthless, because of the supreme value which it attaches to the object with which it desires and affirms its union '.2 Similarly, in the concluding chapter, the experience is described as 'self-identification with perfection'; ' accepting perfection as real while admitting that he cannot attain it in his own right'; ' his identification by faith with the greatness of the universe'. 3 The description is, I think, beyond challenge, but every phrase of it surely implies that reality of difference for which the system, in its letter at least, appears to leave no room. If the specific religious insight is the recognition of dependence, it is only inasmuch as we have a certain independent status that we can recognize and affirm the dependence. When the religious man identifies himself with the perfection of the whole, and, as it were, appropriates it to himself, the very act of self-identification implies the individual difference of the self that makes it. Otherwise the whole

"Self-recognition, as we shall see, is another phrase for the religious consciousness' (Value and Destiny, p. 18; cf. p. 20).

'Ibid., p. 303. Cf. the Summary, p. xxxii.

"Ibid., p. 26 . 
thing is a puppet show, and we fall back on the vulgar pantheism which makes the Absolute the direct agent in everything that is done:

And patiently exact,

This universal God

Alike to any act

Proceeds at any nod,

And quietly declaims the cursings of himself. ${ }^{1}$

The religious attitude-all that we mean by worship, adoration, self-surrender-is wholly impossible, if the selves are conceived as telephone wires along which the Absolute acts or thinks. As it has often been remarked, the system of Spinoza has no room in it for Spinoza himself and 'the intellectual love of God' with which he closes his Ethics. That sublime acquiescence, that ardour of self-identification with the spirit of the universe, is possible only to beings who are more than mere modes of a divine Substance-whose prerogative it rather is to become the sons of God.

The relation of the Absolute to finite individuals cannot, in fact, be properly stated in terms of the old metaphysic of substance. The essential feature of the Christian conception of the world, in contrast to the Hellenic, may be said to be that it regards the person and the relations of persons to one another as the essence of reality, whereas Greek thought conceived of personality, however spiritual, as a restrictive characteristic of the finite-a transitory product of a life which as a whole is impersonal. ${ }^{2}$ Modern Absolutism seems, in this respect, to revert to the pre-Christian mode of conception, and to repeat also the too exclusively intellectualistic attitude, which characterizes Greek thought in the main. But no solution of the problem of God and man can be reached from a consideration of man as a merely cognitive

'Empedocles on Etna.

"Fraser, Philosophy of Theism, vol. i, p. 77, 'the profound personalism of Christianity'. Cf. Windelband, History of Philosophy, p. 238 (English translation). 
being. Bare will is certainly an abstraction; but so is knowledge, if it is not regarded as the moving and determining force in a personality, shaping its attitude to the world and all the action which is the outcome of that attitude. In this sense it is the character, or spiritual will, that is the concrete personality. It is as such a will that man is independent. To be a self is to be a formed will, originating its own actions and accepting ultimate responsibility for them. For in all questions of moral causation the person is necessarily, in our explanations, a terminus ad quem or a terminus a quo. He is the source of the action: we cannot go behind him and treat him as a thoroughfare through which certain forces operate and contrive to produce a particular result. The person is certainly not a fixed and unchangeable unit. $\mathrm{He}$ is open to moral education and spiritual regeneration: he may change so much as to become, in the expressive phrase of religion, a new creature. But although he is thus open to all the influences of the universe, these do not act on him like forces $a b$ extra. They make their appeal to him, but he must give the response. He cannot be driven, he must be drawn. And, therefore, the process of transformation is always, in a very real aspect of it, his own act, his deliberate choice. We may believe in the ultimately constraining power of the Good, ${ }^{1}$ but a moral being cannot be commandeered; he must be persuaded, and the process may be long. - Behold, I stand at the door and knock : if any man hear my voice and open the door, I will come in to him, and sup with him, and he with me.' Even the divine importunity will not force an entrance. This freedom belongs to a self-conscious being as such, and it is the fundamental condition of the ethical life; without it we should have a world of automata.

${ }^{2}$ Cf. Emerson's lines, 'The Park':

Yet spake yon purple mountain,

Yet said yon ancient wood,

That Night or Day, that Love or Crime

Leads all souls to the Good. 
No doubt the creation of beings who are really selves, with this measure of 'apartness' and independent action, is the ' main miracle' ${ }^{1}$ of the universe. It is, in the very nature of the case, impossible that we should understand the relation (if one may even use such a finite term as relation) between a creative Spirit and its creatures, whether as regards the independence conferred or the mode in which the life-history of the finite being still remains part of the infinite experience. Finite beings know one another from the outside, as it were, the knower being ipso facto excluded from the immediate experience of any other centre. But there can be no such barrier, we may suppose, between the finite consciousness and the Being in which its existence is rooted. It must remain open and accessible-it must enter into the divine experience in a way for which our mode of knowing hardly furnishes us with an analogy. It is, I say, in the nature of the case, impossible that we should understand, and be able to construct for ourselves, the relation in question; for to do so would be to transcend the conditions of our own individuality, to get, as it were, behind the conditions of finite existence and actually repeat the process of creation and realize the absolute experience. Accordingly, when we do try to schematize the fact for ourselves, we either eliminate the characteristics of selfhood by making the individual simply a vehicle of transmission or, on the other hand, we lose hold of the creative unity altogether by treating the individuals as independent, self-subsistent units. But because such is the inevitable fate of any attempt to describe the fact in terms devised to express the relation of one finite fact to another, and only there appropriate, it by no means follows that such creation is impossible for the Absolute. And certainly no theoretic difficulties in conceiving how we

1 This main-miracle, that thou art thou,

With power on thine own act and on the world.

Tennyson, 'De Profundis'. 
can be free should prevent us from recognizing that we are free. In asserting freedom we are not asserting anything additional and extraneous about our experience; we are simply describing its nature, as we know it from within. And we are applying, in this supreme instance, the principle which has guided us throughout, the principle of the reality of appearances.

So far as we are concerned, individuation, in the sense explained, appears to represent the fundamental method of creation, or, to put it otherwise, the fundamental structure of the actual world. And when we turn to the Absolute and try to figure to ourselves 'the art of world-making' ${ }^{1}$ from that standpoint, the same suggestion seems strongly emphasized. 'We are finite,' says Professor Bosanquet in a fine passage of his introductory lecture, 'we are finite, which means incomplete, and not fitted to be absolute ends. . . . We must have something greater than our finite selves to contemplate. We want something above us, something to make us dare and do and hope to be.' ${ }^{2}$ 'The unit ', he says in another place, 'looks from itself and not to itself and asks nothing better than to be lost in the whole.' ${ }^{3}$ Nothing could be truer. It is the familiar paradox of the ethical and religious life, dying to live, self-realization through self-sacrifice, self-development through absorption in objective interests and in the currents of the universal life. The individual who would find his end in the culture of his own personality, whether as a moral work of art or in the wider fields of literature and taste, suffers the same defeat as the voluptuary who pursues pleasure for pleasure's sake. He goes in danger of the doom figured by Tennyson in 'The Palace of Art'. But although the individual may not make himself his own End, the world of finite individuals may well constitute the End of the Absolute. How

${ }^{2}$ As Hume calls it.

${ }^{2}$ Individuality and Value, p. 25.

'Value and Destiny, p. 153. 
can we ascribe to the Absolute, as many theologians have done, the self-centred life, the contemplation of $\mathrm{His}$ own glory, which spells moral death in the creature? Is it reasonable to deny of the fontal life of God that giving of Himself and finding of Himself in others, which we recognize as the perfection and fruition of the human life? This would be, under pretext of exalting the divine, to place it lower than the best we know. More reasonable is it to suppose that the infinite reality reflects itself in the finite nature, and that, in the conditions of mortal perfection,

Our souls have sight of that immortal sea Which brought us hither-

repeating in the process of their own experience the flux and reflux of the cosmic life.

The idea of end or purpose may not be literally applicable in such a sphere, but we may at least say that just 'from the side of the Absolute' the meaning of the finite process must lie in the creation of a world of individual spirits; for to such alone can $\mathrm{He}$ reveal himself, and from them receive the answering tribute of love and adoration. The coming into being of such internalities means 'eliciting', in Professor Bosanquet's phrase, out of the common fund of externality a new world of appreciation, of mutual recognition and spiritual communion, to which the former now assumes a merely instrumental function, a circuit made by the Absolute towards the formation of beings capable of spiritual response, which enrich thereby the life from which they spring. Only for and in such beings does the Absolute take on the lineaments of God. This world of self-conscious personalities is the Civitas Dei, described by St. Augustine and by Leibnitz; it is the Kingdom of the Spirit of which theologians speak as the great consummation. The yearning of the divine for fellowship is the idea of the well-known 
lines of Schiller with which Hegel closes his Phcnomenology:

Friendless was the mighty Lord of worlds,

Felt defect-therefore created spirits,

Blessed mirrors of his blessedness ...

From the chalice of the world of souls

Foams for him now infinitude.

But if we project our imagination thus into the vacancy before the world was, nay, before God was truly God, we must remember that we are merely translating into terms of time, as in a Platonic myth, the eternal fact of the divine nature, as a self-communicating life. The divine Eremite, as a pre-existent Creator, is a figure, if one may so speak, of the logical imagination: it indicates what God is not, it does not tell us what $\mathrm{He}$ once was.

NOTE ON PROFESSOR BOSANQUET'S USE OF THE SOCIAL ANALOGY

Professor Bosanquet himself, on more than one occasion, suggests that in the conception of society we have the best analogy of the absolute experience. So far as there is formed 'a social mind', he says, 'the particular centres begin to be adapted as members of an individuality transcending their own. . . Their qualities begin to be reinforced by others, their deficiencies supplied, in a word, their immanent contradictions removed by readjustment and supplementation, so that the body of particularised centres begins to take on a distinct resemblance to what we know must be the character of the absolute.' 1 So, again, he speaks of 'the social whole and civilisation' as 'a realised anticipation of the absolute.' ${ }^{2}$ 'Ultimate reality is for [the metaphysical] argument', he says, ' what the social collectivity is for the social student.' ${ }^{3}$ But there is the same wavering of point of view which we have noted throughout, due to the defective sense of personality. It is the supra-individual and, as it were, impersonal character of the social mind or the social collectivity that seems to commend
${ }^{2}$ Value and Destiny, p. 90.
'Ibid., p. 142.
Ibid., p. II. 
it to Professor Bosanquet as an analogy. He speaks, in the context of the passage first quoted, of the tendency of the social process as being 'towards an individuality in which centres, formed and further formed by such a process, tend to be, as particular centres, transcended and absorbed'. And, on the other hand, inasmuch as the social collectivity has no self-consciousness, no centralized existence of its own, apart from the particular centres in which it is realized, the suggestion of the analogy, when thus applied, is that the Absolute also is not to be regarded as a self-centred life. In that way the personality both of the finite centres and of the Absolute tends to disappear. But, as we have seen, the development of society, so far from 'absorbing' its individual members, is a continual development of their self-consciousness, and furnishes no grounds, therefore, for inferring their disappearance, as particular centres, in the Absolute. And if we take the idea of centrality or individuation 'in bitter earnest' as the characteristic of everything that is concretely real, we shall not speak or think of the Absolute as 'a vast continuum' of which 'finite self-conscious creatures' are 'fragments',' but rather as the focal unity of a world of self-conscious worlds, to which it is not only their sustaining substance but also the illumination of their lives. Society, taken by itself, is an abstraction hypostatized, but the idea of a divine Socius has been one of the most abiding inspirations of religious experience. ${ }^{2}$

1 We approach the study of finite self-conscious creatures, prepared to find in them the fragments of a vast continuum ' (Value and Destiny, p. I1). Cf. p. 12, 'the continuum of the whole'.

${ }^{2}$ See Supplementary Note D on Lectures XIV and XV, p. 426. 


\section{LECTURE XVI}

\section{THE IDEA OF CREATION}

Ar the close of the last lecture we found ourselves insensibly involved in criticism of a certain conception of Creation. The word Creation recurs so constantly in philosophical and theological discussions of the relation of God to the world that it is desirable to submit the idea to a somewhat more careful examination, in order to discover the meaning, or meanings, which have been attached to the conception. This should enable us to determine whether, in any of its senses, it is to be taken as expressing or pointing to a philosophical truth.

The idea forms a natural part of any theory which treats God deistically as a purely transcendent Being-a Cause or Author of the universe, entirely distinct from an effect which is spoken of metaphorically as "the work of his hands'. But it occurs also in theories which claim to be immanental, and in some of its forms it may not be incompatible with such a doctrine. Historically, the idea carries us back to a primitive stage of pictorial thought like that of the Zulus, mentioned by Tylor, who trace their ancestry back to Unkulunkulu, the Old-old-one, who created the world. It meets us with something of a sublime simplicity in the opening words of Genesis-' In the beginning God created the heaven and the earth.' Such a statement yields a temporary satisfaction to the craving for causal explanation, though it is not necessary to go beyond the child's question, 'Who made God?', to become aware of its metaphyșical insufficiency. As it has been not unjustly said,"

'Von Hartmann, Philosophy of the Unconscious, iii. I96 (English translation). 
'Contentment with the regress to a God-creator or some similar notion is the true mark of speculative indolence.'

The first feature in the ordinary idea of creation to which I wish to draw attention is that creation is regarded as an event which took place at a definite date in the past, to which we can remount by a temporal and causal regress. The old chroniclers in their naive fashion record the event methodically with the other entries that seemed to call for notice, such as the death of a monarch, an invasion of the enemy, a plague, or an exceptionally bad winter. We know that the date was long fixed by Biblical chronology as the year 4004 B. C. And so it remained till the rise of geological science brought about a vast extension of cosmic time. Theology accommodated itself, not without some friction; to the demands of the new science; but, although the actual date was thrust back, the view of creation as an event that happened at some definite period in the past still continued to be held by ordinary theological thought. Perhaps I should say still continues to be held, for I find so able a theologian as the late Professor Flint telling us, in his lectures on Theism, that 'the question in the theistic argument from causality' is 'to prove the universe to have been an event-to have had a commencement. . . . Compared therewith, all other questions which have been introduced into, or associated with, the argument are of very subordinate importance.' ${ }^{1}$ And accordingly, in order to answer the question, he proceeds to an examination of the universe ' in order to determine whether or not it bears the marks of being an event'. And because such an examination reveals mutability stamped upon every particular fact in the universe, even its apparently most stable formations-so that each may be treated as an event dependent on a preceding event, a phase in a universal process of transformation-we have the extraordinary conclusion drawn that

${ }^{1}$ Theism, 8th ed., p. ror. 
the universe as a whole is an event or effect in the same sense. But surely such an argument is an example in excelsis of the fallacy of Composition. A little later the author is found grasping at Lord Kelvin's then current deductions from the theory of heat. 'If this theory be true,' he says, 'physical science, instead of giving any countenance to the notion of matter having existed from eternity, distinctly teaches that creation took place, that the present system of nature and its laws originated at an approximately assignable date in the past.' ' But Sir William Thomson's speculation, based on the ultimate dissipation or, rather, degradation of energy-an end or running-down of the cosmic mechanism, implying a beginning or start of the same within a measurable time-entirely depended on the conception of the universe as a finite closed system, and therefore begged the whole question. It has ceased to agitate the scientific world, as the conditions of scientific theorizing have come to be more clearly realized; and the recent discovery of the immense quantities of energy generated through the disintegration of radium, by completely upsetting the basis of the calculation, has made men more than ever disinclined to draw definite and final conclusions from theories which are in a process of continual revision. In this connexion it is a significant fact, on which I cannot help remarking, that, although the whole face of physical science has been changed by the remarkable discoveries of the last twenty years, there has been no attempt to exploit the changes either in a theological or an antitheological interest.

It is difficult to understand the importance attached by many theologians to a temporal origin of the physical universe, if we have once abandoned the geocentric hypothesis and its corollaries. The spectacle of the birth and death of worlds may actually be secn by the astronomer as

'Theism, p. 17. 
he scans the heavens, and in that sense the earth and the solar system to which it belongs undoubtedly had a beginning and may be expected to have an end. These, however, are but local incidents of the distribution of the cosmic forces; what passes away here is being born, or is ripening to fruition, elsewhere. The universe, as it has been said, ${ }^{1}$ has no seasons, but all at once bears its leaves, fruit, and blossom. In Professor Flint's case, the stress laid on origin 'at some assignable date in the past' is the less easy to understand, because in the next section of the same lecture he proceeds to argue that secondary, that is to say, physical, causes are not, strictly speaking, causes at all; each merely transmits to its consequent what it has received from its antecedent. 'A true cause is one to which the? reason not only moves but in which it rests, and except in a first cause the mind cannot rest.' And this is described as 'a single all-originating, all-pervading, all-sustaining principle. . . . All things must consequently "live, move and have their being" therein. It is at their end as well as at their origin; it encompasses them, all round; it penetrates them, all through. The least things are not merely linked on to it through intermediate agencies which go back an enormous distance, but are immediately present to it, and filled to the limit of their faculties with its power.' ${ }^{2}$ Obviously we have passed here to a different range of ideas altogether, ${ }^{3}$ to a frankly immanental view of causation where 'first', in the expression 'first cause', has no reference to antecedence in time, but is employed propter excellentiom, as the Scholastics say, to signify that what is so. designated is the true and only cause. As Kant no less than Spinoza clearly saw, God cannot be reached at the farther

${ }^{1}$ Bradley, Appearance and Reality, p. 500.

Theism, pp. 124, 127.

This is noted by Adamson in his Shaw Lectures On the Philosophy of Kant, p. 224. 
end of any chain of phenomenal antecedents and consequents. To imagine that $\mathrm{He}$ could be reached in that way is to treat God and the divine action as a particular fact, one more phenomenon added to the series. But to talk of a ' first' cause in that sense is a contradiction in terms; once embarked on the modal sequence we are launched upon the infinite regress. God is cause only in the sense of ground, that is to say, the Being whose nature is expressed in the system as a whole. ${ }^{1}$ In other words, God is cause only when causa = ratio; for the reason or ultimate explanation of anything is only to be found in the whole nature of the system in which it is included.

The idea contained in Professor Flint's second account, that the existence of the universe depends upon a continuous forth-putting of divine power was recognized by mediaeval thinkers in the doctrine, which Descartes takes over from them, that "the conservation of a substance in each moment of its duration requires the same power and act that would be necessary to create it, supposing it were not yet in existence'? This they held, even while maintaining at the same time the theory of the original creation of the universe at a definite period in the past. But the more thoughtfully we consider the idea of creation as a special act or event that took place once upon a time, the more inapplicable does it appear. It represents the universe as in no way organic to the divine life. On the contrary, God is conceived as a pre-existent, self-centred Person to whom, in his untroubled eternity, the idea of such a creation occurs, one might almost say, as an afterthought. The inspiration is forthwith put into execution; the world is

${ }^{1}$ God, in Spinoza's terminology, is not (except in a very technical sense which he explains) the causa remota of anything, but $\mathrm{He}$ is the causa immanens of all things, inasmuch as 'all things which come to pass, come to pass solely through the law of the infinite nature of God, and follow from his essence' (Ethics, i. 15, Scholium).

'Meditations, iii. 
created 'by the word of his power'. A universe is summoned into existence and stands somehow there, as shapes and figures might appear at a sorcerer's word of command, or as temples and towers rise like an exhalation before the eyes of a dreamer. The act is an incident in God's existence, and the product stands somehow independently outside him and goes by itself; so that his relation to the subsequent unfolding of the cosmic drama is at most that of an interested spectator.

It is somehow thus, I think, that popular thought envisages the relation of God to the universe in creation, though it, no doubt, naïvely attributes a much greater importance to the incident and its consequences than they could reasonably be supposed to have for such an eternally self-involved Deity. But such a conception of creation belongs to the same circle of ideas as the waving of a magician's wand. It has no place either in serious thinking or in genuine religion. It was an old gibe of the Epicureans, familiar in Cicero's day, to ask what God did before He created the heavens and the earth, and how $\mathrm{He}$ came to choose just then to create them, after forbearing to do so for so many ages-a flippancy, no doubt, but a flippancy provoked in some measure by the shallow anthropomorphism of the doctrine assailed. St. Augustine, who twice addresses himself to meet the criticism, wins a technical victory by the argument that time itself was created along with the world of moving things by which its duration is measured, so that there could be no lapse of unoccupied time before the creation, there being in eternity neither before nor after. ${ }^{1}$ But, in so far as he still regards creation as a unique event, an event, that is, which took place once-an act of God's will, but not grounded in his nature-he does not meet the real difficulty. The world, on his theory, still had an absolute

${ }^{1}$ Cum tempore, non in tempore is Augustine's distinction; the world was not created in time but together with time. So Plato in the Timaeus, 38, 'Time, then, was created with the heaven.' 
origin; and, even if it had never existed at all, the selfexistent being of God would have been in no way affected. And this external and almost accidental relation between the two is inevitably implied in phrases which speak of a divine existence 'before the world was'. But this solitary, ante-mundane Figure is the residuum of a primitive and pictorial fashion of thinking, a magnified man, but rarefied. to bare mind, after the analogy of Aristotle's pure thinking upon thought, and left standing apart from the world he is invoked to explain. A God so conceived is an Absolute in the old bad sense of a being existing by itself with no essential relations to anything else. But if God is the principle through which the world becomes intelligible, His relation to the world cannot be of the merely incidental character indicated. If the universe is to be understood through God, the nature of God must no less be expressed in the universe and understood through it.

Hence more speculative minds, both before and after Augustine, thinkers both Christian and non-Christian, have insisted that creation must be regarded as an eternal act, an act grounded in the divine nature and, therefore, if we are to use the language of time, coeval with the divine existence. Such was the doctrine of Origen, the early Father. God, says Spinoza, is the cause of all things, per se, not per accidens. God is not more necessary to the world, says Hegel, than the world to God. Without the world, God were not God. 'God is the creator of the world,' he says, repeating Spinoza's thought, 'it belongs to his being, to his essence to be Creator. . . . That he is Creator is moreover not an act undertaken once for all; what is in the Idea is an eternal element or determination of the Idea itself.' 1 And lest these latter testimonies should be in any way suspect, I will quote to the same effect from Ulrici,

${ }^{1}$ Werke, vol. xii, p. I8I (in the second volume of the Philosophy of Religion). 
prominent half a century ago as a defender of Theism against all that he deemed pantheistic error. 'The creation of the world ', says Ulrici, 'is certainly to be understood as the free act of God. But his freedom is nowise an arbitrary freedom (Willkiihr) which at its mere good pleasure might act so or otherwise, might act or refrain from acting. . . . In truth God is not first God and then creator of the world, but as God he is creator of the world, and only as creator of the world is he God. To separate the two ideas from one another is an empty and arbitrary abstraction, affirming in God an unmeaning difference which contradicts the unity of the divine nature.' 'Hence,' he concludes, ' just as God does not become creator of the world but is from eternity creator of the world, so the world too, though not eternal of itself, exists from eternity as the creation (or act) of God.' 1

But if the world is thus co-eternal with God, how does the doctrine differ, it may be asked, from the Greek doctrine of the eternity of matter, in opposition to which the Christian dogma of 'creation out of nothing' was primarily formulated? The difference is indicated in the last phrases quoted from Ulrici: it is eternal not of itself, but as the eternal creation of God. The doctrine of matter in the Platonic and Aristotelian theories is a somewhat obscure question. To Plato, who hardly uses the actual term at all, matter was the element of Non-Being, with which the pure Being of the Ideas is mingled so as to produce the phenomenal world of sense-experience; and he is commonly understood to be thinking chiefly of space (the unlimited, the great and small, as he calls it) considered as a principle of individuation and multiplication. To Aristotle, from whose philosophy the opposition of matter and form is derived, matter is the idea of mere potentiality not yet actual - an idea which appears to be involved in any process

${ }^{1}$ Gott und Welt, pp. 531-2. 
of development. Neither, therefore, understood by the term what it means in our ordinary usage and in modern philosophy generally - the elemental structure of the-physical world. Both, however, regarded it as a limitation of the purposive action of the ideal or formal principle. It is the $\dot{\alpha} v \dot{\alpha} \gamma \boldsymbol{\gamma} \eta$, or mechanical necessity, which imports into the world of experience an element of contingency or casualty, and prevents it from being a perfect realization or embodiment of reason. Thus in Aristotle, as well as in Plato, the cosmic process is regarded 'ultimately under the analogy of the plastic artist who finds in the hard material a limit to the realization of his formative thought '. ${ }^{1}$ Careful examination might show that Plato and Aristotle in such expressions do little more than formulate the conditions which appear to be involved in the existence of an individuated or differentiated universe at all, conditions which modern philosophy also is forced, in one fashion or another, to recognize. But looked at roughly-and especially if we read into the doctrine of matter the ordinary associations of the word, and think, as the Christian writers mainly did, of the world-artificer in the Timaeus-ancient thought appears to leave us with a dualism of two independent and co-eternal principles, the one of which is conceived as hampering and limiting the divine activity.

It was against this dualistic conception that the Christian doctrine of creation out of nothing was directed. All the dogmas of the creed, it has often been pointed out, were formulated as counter-statements directed against some error or heresy; and hence it is from what they deny, rather than from what they affirm, that their true meaning or intention is to be gathered. The doctrine of creation out of nothing is accordingly the denial that the world was merely shaped by God out of a pre-existing material. God is creator, not artificer; in him.is to be found the sole explana-

${ }^{2}$ Windelband, History of Philosophy, p. 144 (English translation). 
tion of the existence of the world, as well as of its detailed arrangements. There are not two principles, but one. Creation, moreover, was expressly defined as an act of will, in opposition to the many then current theories of emanation and evolution, in which the derivation of the world from its ultimate principle is conceived, by the aid of plentiful, and often gross, physical analogies, as a process undergone, so to speak, by the ground of things without its intelligent concurrence, much like the fission, for example, by which the lowest organisms propagate themselves. The importance of the doctrine, negatively, in these two directions, and its greater relative truth may therefore be freely acknowledged. But the precise positive meaning to be attached to the formula was necessarily a subject for further philosophical analysis.

Creation was, doubtless, originally conceived by early Christian thinkers in the quasi-magical fashion already described, as an act of bare will, and the world as a mere effect, a separate, externally posited, existence. But this kind of factual externality, if asserted of material objects, could not long be maintained in regard to the spiritual creation, though just here, from another point of view, the independence involved in real creation is, as we have seen, most marked. Already, in the old Hebrew story, man is made in the image of God, and it is through the breath of God that he becomes a living soul. And the direct ethicoreligious relation of man to God, which was the essential. characteristic of the new religion-the idea of the heavenly Father, which was the burden of the teaching of Jesusmade it impossible to treat the divine and the human simply. on the footing of cause and effect. While the doctrine of the Word made flesh, which so soon became the central dogma of the faith-asserting with a stupendous simplicity that God became man-made an end, in principle, of mere monotheistic transcendence. Hence in Origen, the first 
philosophical theologian of the Church in any larger sense, we have, as already mentioned, the doctrine of an eternal creation, which, as the continual product of the changeless divine will, becomes an expression of the divine nature rather than the outcome of will in the sense of choice. Origen applies this conception primarily to the world of free spirits which he describes as 'surrounding the Deity like an ever-living garment'. He gives a more fantastic account of the material world, but he rightly regards it as secondary to the existence and function of the spiritual creation. On similar lines modern idealism, as represented by Professor-Bosanquet, while treating the whole universe as organically one, regards the material world fundamentally as that 'through which spirit attains incarnation'-'a system by which the content of finite minds is defined and their individuality manifested '-the instrument, as it were, through which the only real creation, that of minds, is worked out. And thus, although finite minds exist only through nature, nature in the last resort ' exists only through finite mind $\because$

On such a general view, the idea of creation tends to pass into that of manifestation-not the making of something out of nothing, but the revelation in and to finite spirits of the infinite riches of the divine life. It was in this sense that theologians and the makers of creeds and confessions came to speak of 'the glory of God' as the supreme end and meaning of creation. The phrase has proved in some respects an unfortunate one, in so far as it tends to suggest the idea of self-glorification and display, as of a despot feeding on servile adulation. But in its religious intention it is to be interpreted in this sense of self-communication, intensification of life through realization of the life of others. In this sense we may take Plato's great words in the Timaeus: 'Let me tell, then, why the

${ }^{1}$ Individuality and Value, pp. $133,135,37 \mathrm{r}$. 
Creator created and made the universe. He was good . . . and being free from jealousy he desired that all things should be as like himself as possible.' It is in this spirit, too, that Hegel so often tells us that the Christian, that is to say, in his view, the final religious, idea of God is that of the self-revealing or self-imparting God. And this again is the philosophical meaning of the saying that God is Love.

We begin to see, then, that creation cannot be understood unless in reference to the subjects or conscious existences in which it terminates. The objective world is a creation, or rather, as we have said, a revelation in and to them, 'there being', as Berkeley once put it, 'nothing new to God'. Such a position need not, however, involve us in the subjective or individualistic idealism of Berkeley; all that it means is that we refuse to take one element or moment in a process and treat it statically as a fact on its own account. And we must be in earnest with this principle throughout; for it applies to God and finite minds, the apparent beginning and end of the process, just as much as to nature, the intermediary or connecting term. They also cannot be substantiated as static units apart from the process in which they live or which constitutes their life. In the case of the finite conscious being this is fairly obvious, for he plainly receives his filling from nature and is reduced at once to a bare point or empty focus if we attempt to lift him, as an independent unitary existence, out of the universal life from which he draws his spiritual sustenance. But it is apt not to be so obvious in the case of God. And yet, in this ultimate reference, it is equally essential to be clear on the point, if we are not to involve ourselves in meaningless speculation. Hardly any philosophy has avoided such speculation or at least the appearance of it. Even a theory like Hegel's, which insists so strongly on the idea of creation as an eternal act or an eternal process, seems repeatedly by its form of 
statement to suggest just that prior existence of the bare universal which it is the essence of the theory to deny.

The misleading suggestion referred to may be illustrated by the more naive statements of Janet, to whom, however, by reason of his doctrine of final causes, it was more than simply a defective form of expression. "The insoluble problem ', says Janet,' ' is this: Why is there anything but God? Whether it be held that God produced the world by a necessary emanation or that he created it freely, the difficulty still remains - why did he create it, why did he not remain wrapped up in himself?' 'We conceive', he says again," 'two periods in the divine life, whether historically or logically distinct does not here much concern us. In the first period, God is in himself, collected, concentrated, gathered in himself in his indivisible unity. This unity is ... the absolute concentration of being: it is the plenum, God being thus conceived as the absolute unity, act and consciousness. Creation commences when God comes out of himself, and thinks something else than himself.' The cause of the universe, he says once more, ' is beforehand, entirely and in itself, an absolute '.3 Hence it is that we are confronted with the old difficulty, "the wherefore of creation '." Now such a problem is certainly, as he says, insoluble, but we have created the difficulty for ourselves by substantiating God as a solitary unit apart from the universe in which he expresses himself. As Ulrici puts it, God is known to us as creator of the world; we have no datum, no justification whatever, for supposing his existence out of that relation, 'wrapped up in himself,' as Janet puts it, 'entirely and in himself an absolute'.

And yet thinkers much more profound than Janet appear to be embarrassed by the same kind of problem. The whole systematic structure of German idealism in Fichte

'Final Causes, p. 447 (English translation).

Ibid., p. 375.

2 Ibid., p. 437.

'Ibid., p. 445. 
and Hegel might almost be cited in evidence. Think only of Fichte's laborious and futile attempts in the Wissenschaftslehre to deduce the Non-Ego or object from the Absolute Ego or bare subject with which he starts. The Absolute Ego, he says, "is absolutely identical with itself . . there is nothing here to be distinguished, no multiplicity. The Ego is everything and is nothing, because it is nothing for itself.' Yet he proceeds to represent it as an infinite outward striving, which somehow manages at the same time to throw an obstacle in its own way, by impinging against which it is driven back upon itself. By this reflection or return upon itself it attains to self-consciousness, that is to say, first becomes an Ego in any real sense of the word. The purely illusory character of this attempt to conjure bare object out of bare subject is obvious. It is hopeless to try to construct a concrete self-consciousness out of the interaction of these abstractions; and, when challenged, Fichte tells us, as we might expect, that he never contemplated what would be comparable to the absurdity of writing a man's biography before his birth. 'Consciousness', he declares, ' exists with all its determinations at a stroke, just as the universe is an organic whole, no part of which can exist without all the rest-something, therefore, which cannot have come gradually into being, but must necessarily have been there in its completeness at any period when it existed at all.' He tells us, in other words, that he has not been narrating what ever took place, but giving a logical analysis of self-consciousness into its distinguishable but inseparable moments or aspects.

We must accept the disclaimer, and yet the start with an abstract One, and the persistent attempt to make it posit its own other and thereby generate all the multiplicity of the world 'out of the unit of itself' 1 is significant of a deepseated tendency of thought. We meet it again in Hegel's start with the pure Idea which 'passes over', or 'lets itself ${ }^{2}$ A phrase of Martineau's, applied by him, however, in another reference. 
go', into Nature in order to return thence and be at home with itself as Spirit. We meet it even more unmistakably in the elaborate construction of the divine nature in his Philosophy of Religion. What Hegel is really doing, of course, or intending to do, is to emphasize the truth that if we start reflectively with a One, we find that it inevitably involves a Many, for it is only as the unity of a multiplicity that you know it as one; or, similarly, the idea of subject implies an object of which it is conscious-through which alone it can be a subject. In the world of reality, therefore, there is no possibility of a start with a mere One or a mere subject, for these are the abstractions of reflective analysis. The Hegelian principle of logical implication is, in short, when applied to the case of God and the world, the demonstration of the very principle of eternal creation for which we have contended. God exists as creatively realizing himself in the world, just as the true Infinite is not a mere Beyond, but is present in the finite as its sustaining and including life. Hence Hegel's recurring polemic against the God of Deism, whom he styles, in so many words, the unknown God. And yet, adopting for his own purposes the old Platonic idea of the Logos, as developed by Alexandrian and Christian thinkers into the doctrine of a trinity in the divine nature, he is led in the course of his exposition, not infrequently, to use expressions which involuntarily recall the old conception of a succession of stages in the divine reality-what Janet calls 'periods in the divine life'. He tells us, for example, that 'the starting-point and point of departure' is 'the absolutely undivided self-sufficing One'; or, again, 'Eternal Being, in and for itself, is something which unfolds itself, determines itself, differentiates itself, posits itself as its own difference ' ${ }^{1}$ In the same sense he speaks of ' the advance of the Idea to manifestation'. The constant use of the term 'posit' in this connexion, and the recurring expression

${ }^{2}$ Philosophy of Religion, vol. iii, p. 35 (English translation). 
'diremption', have the same suggestion of the bare subject producing its object or of the pre-existing unit opening itself out into a multiplicity. Philosophical reflection on the implications of thought is hypostatized in such passages into an actual process generative of reality.

This deceptive priority finds, of course, striking expression in the historical doctrine with which Hegel connects his philosophical exposition, the eternally begotten Son of the Father. If we recognize that we are not talking here of two separate individuals, two Gods, then the origination of the one by the other, even when stated to be an eternal act, is plainly a figure of speech. The Father, in theological language, knows himself in the Son, that is to say, the Son is the object without which a divine self-consciousness were impossible. Or, again, we are told, God utters himself, first becomes articulate, in the Son, who is called on that account, the Word. But there is no existence of God at all without self-consciousness, without such self-articulation. The Father consequently, if conceived even ideally as prior, is simply the abstraction of the empty subject; and, as handled in the metaphysical creeds, the idea may be said to represent the inveterate tendency of our thought to try to get beyond or behind the ultimate, to project a more abstract God behind the living God, as somehow bringing the latter into being. This is still more apparent in the form in which the doctrine first specifically appeared in Philo of Alexandria. To Philo the Logos is expressly 'the second God', and, as immanent, is knowable; but God himself, or the transcendent Deity, is exalted above determination by any of the predicates known to finite intelligence. He is. ärozos. The kindred speculations of the Neo-Platonists show us the same tendency and the same result. Plotinus teaches that Mind, as already containing plurality in its unity, must have come forth from the One, which precedes all thought and being. Proclus, who devises an intermediate principle to bridge 
the gulf between the two, describes the transcendent Source as a principle in its nature completely ineffable ( $\dot{\alpha} v \tau \eta$

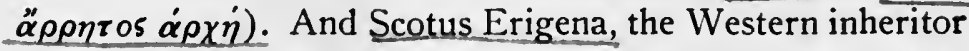
of their philosophy, declares that "on account of his supereminence God may not improperly be called Nothing'.' Thus thought, grasping at the transcendent, and seeking something more real than reality, overleaps itself and falls into the abyss of absolute nothingness. 'Abyss,' indeed, was one of the names which the Gnostics gave to this imaginary prius of the rational cosmos.

God, then, becomes an abstraction if separated from the universe of his manifestation, just as the finite subjects have no independent subsistence outside of the universal Life which mediates itself to them in a world of objects. We may conceive God as an experience in which the universe is felt and apprehended as an ultimately harmonious whole; and we must, of course, distinguish between such an infinite experience and the experiences of ourselves and other finite persons. But we have no right to treat either out of relation to the other. We have no right to suppose the possibility of such an infinite experience as a solitary monad-an absolute, in the old sense of the term already condemned, self-sufficient and entirely independent of the finite intelligences to whom, in the actual world which we know, it freely communicates itself. Coleridge, it is true, represents this as the fundamental difference between Spinozism and the Christian scheme, that whereas to Spinoza the world without God and God without the world are both

'In Meister Eckhart, the devout mystic, there is a similar distinction between 'God', the knowable Creator, and the original ground, beyond Being and Knowledge, which he calls 'the Godhead', and which he also characterizes by predilection as the Nothing, or 'unnatured nature', not only unknown and unknowable to man, but unknown also to itself. The Godhead, as he says in the extremity of his paradox, dwells in the nothing of nothing which was before nothing, and it is apprehended only in the knowledge that is a not-knowing. (The passage is quoted in Ueberweg's History of Philosophy, vol. i, p. 474, English translation.) 
alike impossible ideas ( $\mathrm{W}-\mathrm{G}=0$ and $\mathrm{G}-\mathrm{W}=0$ ), for Christian thaught the world without God is likewise an impossibility, but God without the world is the self-subsistent $(W-G=0$, but $G-W=G)$. I may quote in reply the comment of my old teacher, on this ingenious play of symbols. 'This is applicable to the Christian scheme only as popularly understood,' comments Fraser, ' not a few thoughful Christians holding by the absolute correlation of God and the world as an inference necessarily deducible from the moral nature or personality of God.' ' 'We may not take for granted', he says again, 'that the Divine Source of the life in which we now are, is not eternally the Source of light and life to intelligences, active and responsible for their actions, like ourselves.' 2 Creation, in short, if it is taken to mean anything akin to efficient causation, is totally unfitted to express any relation that can exist between spirits. Spirits cannot be regarded as things made, detached like products from their maker; they are more aptly described, in the Biblical phrase, as 'partakers of the divine nature' and admitted to the fellowship of a common life. But if so, there can be no ground for the supposition of a pre-existent Deity, not yet crowned with the highest attribute of Goodness or self-revealing Love. God's 'glory' (in the theological phrase already referred to) is not something adventitious, subsequently added to the mode of his existence; it is as eternal as his being. The divine life is essentially, I have contended, this process of self-communication. Or, to put it in more abstract philosophical language, the infinite in and through the finite, the finite in and through the infinite-this mutual implication is the ultimate fact of the universe as we know it. It is the eternal fashion of the cosmic Life.

How is such a position distinguishable, it may be asked, from the Pluralism advocated by thinkers like Professor

'Essay on 'M. Saisset and Spinoza', North British Review, vol. xxxviii, p. 463 .

${ }^{2}$ Ibid., p. 487. 
Howison or Dr. McTaggart? In denying any priority of the infinite to the finite, our view seems in danger of attributing an independent reality to the latter, and thus resolving the universe into a collection of self-subsistent individuals. That is, in fact, the conclusion at which Professor Howison arrives, in revulsion from a Monism which, by making the Absolute the sole determining agent in whatever happens, leaves no place in its scheme for the existence of self-active moral persons. Now it is the essential postulate of morality, as we have ourselves seen, that the acts of the self-conscious individual are his own acts, not to be fathered on any ' nature of things ', and that every self-conscious being is in this sense a free and originative source of activity. But, says Professor Howison, 'no being that arises out of efficient causation can possibly be free. . . . Not even Divine agency can give rise to another self-active intelligence by any productive act.' And therefore he concludes to 'an eternal Pluralism' - a ' society of minds' or ' circle of self-thinking spirits', in which God is indeed 'the central member' but 'only as primus inter pares'. 'The members of this Eternal Republic have no origin but their purely logical one of reference to each other. . . . They simply are, and together constitute the eternal order.' 1

With all that Professor Howison says about 'thinking in terms of spirit' and discarding the 'old efficient-causal notion of Divine being and function', I feel the greatest sympathy, as also with his insistence on what he rather happily terms the inherent 'sourcefulness' of self-consciousness. I have also already adverted to the contradiction which appears to be involved in the origin of a self. Such origin is inconceivable as the result of action from without, and hence the self appears to us as its own creation; but to make it the result of its own action is obviously to presup-

'The Limits of Evolution and other Essays illustrating the Metaphysical Theory of Personal Idealism, pp. 332-4, 289, 277, 256, 359, 337. 
pose the very existence we are seeking to explain. Nevertheless, every child which grows to manhood exemplifies anew the fact of origination which we find it so difficult to formulate. And again, from the nature of the case, we cannot get behind the 'sourceful' Ego, and therefore none of us can imagine either a beginning or an end of his existence; the knowing self seems as eternal as the universe. Yet this apparent eternity of the intellect is combined in our experience with a conviction of utter dependence; for which of us, as Descartes asks, feels himself able to guarantee his own continuance in existence from one moment to another? I cannot agree, then, that because a self is a genuine source of activity, it is therefore necessarily eternal and self-subsistent. Nor do I think that Professor Howison's too subjectively Kantian view of the a priori legislative function of the mind in the 'making' of Nature can be regarded, even if it were true, as a convincing proof of the thesis for which he is arguing. Professor Howison does not hesitate to speak of man and other finite intelligences as ' nature-begetting minds'. We are 'ourselves the causal sources of the perceived world and its cosmic order'; 'the laws of nature must issue from the free actor himself, and upon a world consisting of states of his own consciousness, a world in so far of his own making.' He makes a point, indeed, of this 'Pluralistic Idealism', as contrasted with 'the idealistic monism that has so long dominated philosophical theism'. ' Not God only, but also the entire world of free minds other than God, must condition Nature.' In fact, the finite minds are alone 'directly and productively causal of it, while God's conditioning of it can only be indirect and remote; namely, by the constant reference to him which these naturebegetting minds spontaneously have '.'

But surely under cover of this indirect causation-this constant reference to a divine centre-we give the whole

'I bid., pp. 302, 325-6. 
pluralistic case away. We are reinstating in such phrases the objective system of nature-the common world-of which the independent action of so many individual minds offers no manner of guarantee. Professor Howison tells us that the finite minds 'spontaneously have' this reference, and he talks elsewhere of 'the benign consensus of the whole society of minds'. ${ }^{1}$ But if we are not to treat such a consensus as the miraculous result of chance, what other explanation of it can we give than that the plurality is based upon a deeper unity of system? Professor Howison's scheme appears to work only because he postulates an identical content or system of reason common to all his self-active intelligences. The society of which he speaks is described by himself as 'a universal rational society', or, more explicitly still, as ' an association of beings united by a common rational intelligence'. This community of nature extends not only to the abstract categories of the pure intellect, but also to the governing conceptions of ethical and aesthetic experience. Speaking of God and human souls, he says, 'As complete reason is his essence, so is reason their essencetheir nature in the large-whatever may be the varying conditions under which their selfhood, the required peculiarity of each, may bring it to appear. Each of them has its own ideal of its own being, namely, its own way of fulfilling the character of God. . . . Moreover, since this ideal, seen eternally in God, is the chosen goal of every consciousness, it is the final-not the efficient-cause of the whole existing self.' The relations between the Divine and the human indicated by such phrases as a common essence and an immanent ideal ${ }^{2}$ are of a character so intimate and so unique as to make the metaphor of a 'republic'-the whole

p. 276.

2 pp. 339-40. Cf. Preface, p. xxx. "The theistic ideal of God immanent in the world by the activity of his image in the mind of Man, the only Divine Immanence compatible with the moral freedom of the soul.' 
idea of an association of independent individuals-totally inapplicable to the facts.

I think I understand the motives of Professor Howison's insistence on a certain equality of status among all persons, as such, consequently even as between the human self and God. He has clearly perceived that a self-conscious being is, by his very nature, raised above the sphere of efficient causality as that operates in a world of things. Such a being is inaccessible to force or action from without: nothing can be effected in a self except through the personal will of the agent himself. A person cannot be coerced, he can only be persuaded; and if he is effectually persuaded, his decision becomes the expression of his whole nature. Short of such ratification we have gained nothing, for, as the adage has it, a man convinced against his will is of the same opinion still. In such a sphere, then, the only causation is final causation, the causation of the ideal, as it is expressed in Aristotle's doctrine of the prime mover, or again, in the language of Christianity, ' I, if I be lifted up from the earth, will draw all men unto myself'. 'Hence the divine love', as Professor Howison happily puts it, ' is a love which holds the individuality, the personal initiative of its object sacred. . . The Father of Spirits will have his image brought forth in every one of his offspring by the thought and conviction of each soul itself. ... [Accordingly] the moral government of God, springing from the Divine Love, is a government by moral agencies purely. . . . Leaving aside all the juridical enginery of reward and punishment, it lets his sun shine and his rain fall alike on the just and the unjust, that the cause of God may everywhere win simply upon its merits.' ${ }^{1}$ This central conception of the inviolable nature of personality is likewise the gist of the phrase of which Professor Howison makes important use, both in the careful summary of doctrine prefixed to his book and elsewhere-' the mutual

${ }^{2}$ pp. 257-8. 
recognition of all minds'. 'This mutual recognition is involved', he says, 'in the self-defining act by which each subsists, and is the condition of their co-existence as a moral order.' But it holds not only between one finite spirit and another; it characterizes equally, as we have just seen, the divine attitude to the human self. In truth the moral recognition of the world of spirits by God is the intelligible meaning of the metaphor of creation, and it is an eternal act or fact, Professor Howison urges, which is the expression of His own nature as a perfect moral being. ${ }^{1}$

With such a statement of the case I have not much fault to find; it is, indeed, practically identical with the conception of creation which we have ourselves adopted. But it is pluralism only so far as it is a protest against the completely non-ethical idea of God as a solitary unit. The notion of God is indeed inseparable from that of a spiritual community. But so long as we apply the terms infinite and perfect to God and speak of Him, with Professor Howison, as ' the fulfilled Type of every mind and the living Bond of their union', such a view is misrepresented by phrases which seem to make God one individual mind among a number of equally self-subsistent individuals, which 'spontaneously', but inexplicably, coincide in certain characteristics and in certain ideals. However impious and intolerable one may feel the image of the potter and the clay, however certain one may be that the integrity of the self-conscious being is involved in the very perfection of the divine nature, still the relation between the finite spirit and its inspiring source must be, in the end, incapable of statement in terms of the relation of one finite individual to another. To treat God as no more than primus inter pares is to lose touch both with speculation and religion. Professor Howison, in the phrases to which I

${ }^{2}$ Preface, pp. xiii-xvii. Cf. p. 355: 'An absolutely perfect mind, or God, whose very perfection lies in his giving complete recognition to all other spirits, as the complement in terms of which alone his own selfdefinition is to himself completely thinkable.' 
refer, seems to use the idea of self-consciousness entirely as a principle of separation and exclusion, which finitizes even what he calls 'the Supreme Instance', the 'absolutely perfect mind, or God'. Substantiating the selves in their mutual exclusiveness, he is further led to insist on the essen. tial eternity of every self as such, and to represent the universe as consisting of a definite number of such permanent finite souls plus God. With consequences like these, however, we pass from philosophical theism to a real pluralism, such as is more consistently represented by Dr. McTaggart's atheistic Absolute or by the doctrine of a finite God. The discussion of such theories, so far as it is called for after the establishment of our general position, falls in another place. 


\section{LECTURE XVII \\ TELEOLOGY AS COSMIC PRINCIPLE}

THE idea of Purpose meets us in all the ordinary theological accounts of the relation of God to the world of finite things and persons; while philosophers are often found contending that the contrast between a teleological and a mechanical theory of the universe is the most radical of philosophical distinctions, and that a spiritual view of the world stands or falls with a teleological interpretation. We have seen, in the opening lecture, the central position assigned by Hume to the 'argument from design' in its older form. Although, as a philosopher, he denies its coercive force, yet Philo, speaking to Cleanthes as man to man, frankly admits the difficulty of escaping from it. 'In many views of the universe and of its parts, particularly the latter, the beauty and fitness of final causes strikes us with such irresistible force, that all objections appear (what I believe they really are) cavils and sophisms.' In very similar terms Kant, in his classical criticism of the traditional proofs of the existence of God, although he exposes the limitations of the argument, refers to it as "the oldest, the clearest, and that most in harmony with the common reason of mankind'. Purposive activity is, indeed, the central feature of our human experience; reason seems to operate in that experience characteristically under the form of End. Nevertheless there are manifest difficulties in transferring the conception of Purpose or End to the action, if we may so call it, of the Absolute, and in using it to describe the relation existing between God and the world 
of his creatures. These difficulties have been so pressed by thinkers of the first rank that it is incumbent upon us to examine carefully whether the teleological point of view can be maintained in such a reference, and, if so, in what sense precisely the affirmation of Purpose is to be understood. Certain features of finite purpose, it is to be presumed, must fall away; but when these are dropped, there may still remain a fundamental attitude of will (perhaps even of desire) which cannot be more fitly designated in mortal speech than by the time-honoured category of End or Purpose.

It will, I think, again be convenient if I connect the discussion with Professor Bosanquet's treatment of the same subject; ${ }^{1}$ for although in the opening or programme lecture of his first Gifford course he lays it down that 'a Teleology cannot be ultimate', ${ }^{2}$ and returns at the conclusion of the volume to repeat the position that 'it seems unintelligible for the Absolute or for any perfect experience to be a will or purpose', he will be found, in a later handling of the subject, endeavouring to make room in his final conception for the essential core of the idea which he had rejected.

The idea of Purpose, as we meet it in experience, appears to imply ( I) desire for an as yet non-existent state of affairs, (2) the conception of a plan for bringing the desired state of affairs into existence by selection of appropriate means, (3) the act of will proper, which realizes or carries out this plan. The final stage or aspect of the process may involve more or less difficulty, but it seems in any case to involve the adaptation of means to an end. Purpose in this sense is thus essentially a feature of a life in time, and also, it would seem, characteristic of a finite individual in

${ }^{1}$ Especially in Individuality and Value, Lecture IV, 'The Teleology of Finite Consciousness'. Cf. Appendix I to Lecture X, pp. 39r-3.

${ }^{2}$ p. 16. In the lecture devoted to the subject he begins with a disparaging reference to "that popular principle of ethical and theistic idealism known in general as Teleology'. 
an orderly universe where connexion of means and end can be ascertained and relied upon. There is no reason, in short, to object to Professor Bosanquet's description of 'de facto purpose' as 'a psychological, temporal, and ethical idea':' Our question, then, is, Do these features of the idea disqualify it utterly as a principle of cosmic interpretation? Some of them we easily recognize as inapplicable in such a sphere. But because the conception is derived, like all our ideas, from the facts of our own experience, is it therefore essentially or exclusively a finite category? We have argued in these lectures throughout from the structure of experience, and it has been my contention that no other procedure is reasonable or possible. In the case, then, of an idea so central as that of purpose, may we not expect that, when purged of demonstrably finite accompaniments, it will still help us to characterize truly the nature of the infinite Experience?

Familiar criticisms of 'the argument from design' already indicate some of the features of finite activity which must be eliminated in speaking of a divine purpose. Thus the idea of contrivance-the skilful adjustment of means to end-so prominent in the traditional form of that argument, evidently implies a pre-existing or independently existing material whose capabilities limit and condition the realizing activity. At most, therefore, the proof would yield us, as Kant points out, an architect of the world, a kind of demiurge, ' not a creator to whom all things are subject'. J. S. Mill puts the same point more strongly: " It is not too much to say that every indication of design in the cosmos is so much evidence against the omnipotence of the designer. . Wisdom and contrivance are shown in overcoming. difficulties, and there is no room for them in a Being for whom no difficulties exist. The evidences therefore of Natural Theology distinctly imply that the author of the

'Individuality and Value, p. 217. 
cosmos worked under limitations: that he was obliged to adapt himself to conditions independent of his will and $t_{1}$ attain his ends by such arrangements as those conditions admitted of.' 1 And, as is well known, this dualistic position was the solution which Mill was on the whole inclined to adopt. In truth the traditional form of the argument seems to represent the Creator as originating a material which has no relation to his purposes-which has no formative nisus in itself-and which has therefore to be moulded into accordance with his ends, and directed in its course, by a supplementary exhibition of the divine wisdom. It is as if the existence of the material were referred simply to the divine power-treated as a result of the fiat of omnipotence - the superinduction of order and plan being a subsequent operation of the divine wisdom, specially calculated to serve as a proof of the divine existence. But apart from the criticism that this comes perilously near to creating difficulties in order to solve them with credit, it is obviously inadmissible to treat matter and form in this way as initially unrelated to one another. Yet it is this contingent relation which forms the nerve of the argument from design, as Kant three times emphasizes in the course of his short statement. 'This arrangement of means and ends is entirely foreign to the things existing in the world-it belongs to them merely as a contingent attribute.' So Janet writes more recently: 'What essentially constitutes finality is that the relation of the parts to the whole is contingent: it is just this that is finality.' Janet goes on to imply that the alternative to such finality is 'blind necessity'. 'If it be admitted that matter, obeying necessary laws, must perforce take the form of an organism fit for a certain function, the idea of finality must be sacrificed and only blind necessity be admitted.' ${ }^{2}$ And Kant similarly indicates that the

1 Three Essays on Religion, pp. 176-7.

${ }^{2}$ Final Causes, pp. 436-7. 
argument depends on the contrast between 'a free and intelligent cause' and 'a blind all-powerful nature, producing the beings and events which fill the world in unconscious fecundity'.

But, on fuller reflection, can anything be more illegitimate than to treat one stage of the divine action as essentially unrelated to those which are to follow-to substantiate mechanism or, in Janet's phrase, ' nature obeying necessary laws', as if it were in no sense the vehicle or medium of the divine manifestation but almost a rival and hostile power, so that whatever mechanism can do is not 'of God' but the outcome of 'blind necessity'. We cannot treat the substructure of the universe in this way as going by itself, and introduce purposive intelligence at a later stage to effect more delicate adjustments and shape the cosmos towards its finer issues. The process of the universe-and we are looking at it now as a process-must be taken as a whole, in which the spirit of the whole is everywhere present. Hence, the strong emphasis which Professor Bosanquet lays on the principle of continuity commands our sympathy, even although it seems to lead him to champion mechanism against teleology, and makes him express his conclusions at times in an almost naturalistic form. As he points out, "the processes of inorganic nature are physically continuous with and essential to the processes of life, and if the latter are teleological, the former can hardly be less so. . . . Much of the work done by inorganic forces, e. g. the change of rock into soil, are obvious conditions of the adaptation of the earth to life. . . The continuity of the earth's geological structure with social and historical teleology is obvious. They plainly and essentially belong to the same process.' Taking the case of a flower, he indicates the two extremes we have to avoid. 'On the one hand it is ridiculous to say that such a product arises by accident; that is, as a by-product of the interaction of 
elements in whose nature and general laws of combination no such result is immanent.' On the other hand, we must not ascribe to the flower ' an end or idea somehow superinduced upon the course of [its] elements by a power comparable to finite consciousness, operating as it were $a b$ extra and out of a detached spontaneity of its own. . . . In the structure and being of the flower the natural elements behave according to what they are.' But 'we must interpret the nature of nature as much by the flower as by the law of gravitation :

This is the position so strongly insisted on throughout our first series of lectures, more especially in dealing with the phenomenon of life; and the modern theory of organic development seems to me strikingly to support such a view. Much controversy, of a more or less intelligent kind, has raged round the doctrine of evolution and the argument from design. Many have proclaimed on the housetops that the idea of purpose has been definitively exploded by the modern theory of natural selection; while others have contended that the evolutionary process does but broaden and deepen the conception of a cosmic teleology. The scientific doctrine, or, one may quite fairly say, the scientific facts, do, it seems to me, deal a fatal blow to the 'artificer' idea, which is the pivot of the argument from design in its familiar form. The eye certainly suggests the idea of special contrivance more forcibly, if we look simply at the complex and delicate mechanism of the perfected organ in the higher animals, than if we view its structure as a gradual refinement, through countless intermediate stages, upon the pigment spots which serve some of the lowest organisms to discriminate roughly between light and darkness. But

${ }^{1}$ Cf. Individuality and Value, pp. I46-9.

${ }^{2}$ Dr. Chalmers in his Natural Theology refers the origin of organic structure to 'the finger of an artificer'-the direct 'fiat and interposition of a God' (Institutes of Theology, vol. i, pp. 79-81). 
to bring in the operation of natural selection through environmental conditions, and to regard an organ as thus fashioned from rude beginnings by the cumulative action of such factors in the past, is not to eliminate teleology. Rather, by relating the development of the organ to the general course of things, it is to bring both organ and environment within the scope of one 'increasing purpose'. This was clearly put by Huxley as early as I 869 in criticizing the youthful extravagances of Haeckel. 'No doubt it is quite true', he says, 'that the doctrine of Evolution is the most formidable opponent of all the commoner and coarser forms of Teleology. But perhaps the most remarkable service to the philosophy of Biology rendered by $\mathrm{Mr}$. Darwin is the reconciliation of Teleology and Morphology, and the explanation of the facts of both which his views offer.' 1

The modern scientific view thus tends to coincide with the ideal outlined by Kant at the close of the Critique of Pure Reason- 'the systematic unity of nature', conceived as ' complete teleological unity.' ${ }^{2}$ This ideal,' essentially and indissolubly connected with the nature of our reason and prescribing the very law of its operation', 3 impels us 'to regard all order in the world as if it originated from the

${ }^{2}$ Collected Essays, vol. ii, 'Darwiniana', p. I09. Cf. Professor Asa Gray's statement: 'Let us recognize Darwin's great service to natural science in bringing back to it Teleology : so that instead of Morphology versus Teleology, we shall have Morphology wedded to Teleology' (quoted in Darwin's Life and Letters, vol. ii, p. 189), and the statement of Francis Darwin (in the same volume, p. 255): "One of the greatest services rendered by my father to the study of natural history is the revival of Teleology. The evolutionist studies the purpose or meaning of organs with the zeal of the older teleology but with far wider and more coherent purpose. He has the invigorating knowledge that he is gaining not isolated conceptions of the economy of the present, but a coherent view of both past and present.'

"Vollständige zweckmässige Einheit.

'Gesetzgebend. Or, as he otherwise expresses it, this unity is "not merely an economical device of reason, of hypothetical validity. Reason here does not request but demand.' 
intention and design of a supreme reason'. But, as he wisely adds, 'the agency of a Supreme Being is not to be invoked by a species of ignava ratio to explain particular phenomena, instead of investigating their causes in the general mechanism of matter. This is to consider the labour of reason ended when we have merely dispensed with its employment, which is guided surely and safely only by the order of nature and the series of changes in the world-which are arranged according to immanent and general laws. This error may be avoided if we do not merely consider certain parts of nature from the point of view of finality, such as the division and structure of a continent, the constitution and direction of certain mountain chains, or even the organization existing in the vegetable and animal kingdoms, but look upon this systematic unity of nature in a perfectly general way in relation to the idea of a Supreme Intelligence. If we pursue this advice, ... . we possess a regulative principle of the systematic unity of a teleological connexion, which we do not attempt to anticipate or predetermine.' 'We cannot', he repeats, 'overlook the general laws of nature and regard this conformity to aims observable in nature as contingent or hyperphysical in its origin. .. The whole aim of this regulative principle is the discovery of a necessary and systematic unity in nature, and hence, when we have discovered such a unity, it should be perfectly indifferent whether we say God has wisely willed it so or nature has wisely arranged this.'

The whole ideal thus sketched constitutes an emphatic repudiation, on Kant's part, of what he had himself signalized as characteristic of the old argument-the view of purpose as external and contingent, super-induced upon the facts and manifested only in particular contrivances of nature. Kant transfers the idea of purpose to the whole as a systematic and intelligible unity. And in applying his principles, in the Critique of Judgment, to the special case of the 
organism, he points out that it is just because the peculiar unity which characterizes such a whole and its members appears to us contingent with reference to the general laws of matter, that we seek to explain it by a pre-conceived plan or purpose, that is to say, by the idea of the whole in some mind prior to the actual existence of the whole in question. But this mode of explanation, he repeatedly suggests, may well be due to the nature of our understanding which, as a faculty of notions, dependent upon sensibility for its material, proceeds always from the parts to the whole, and consequently regards the connexion of the parts in that particular fashion as contingent. 'We can, however, conceive of an understanding, not discursive like ours but intuitive, which proceeds from a synthetical universal (the intuition of a whole as such) to the particular, i. e. from whole to parts.' Such an understanding would see 'the possibility of the parts as dependent on the whole in regard to both their specific nature and their interconnexion'. Here, therefore, there would be no such separation as we popularly make between means and end; the whole would not appear as an end, and the parts as means adapted to realize it. The relation of means and end in the ordinary sense would vanish; for the whole would appear as the necessary unity of its members, and the members as the necessary differentiation of the whole. Hence Kant holds that the mechanical and the teleological explanation of the facts are not ultimately contradictory, although the teleological remains the final or inclusive point of view. And when we analyse our real meaning in the light of Kant's suggestion, we see clearly that, in attributing purposiveness to the universe or any lesser whole, what we are concerned about is the character of the reality in question and not the pre-existence of a plan of it in anybody's mind, A teleological view of the universe means the belief that reality is a significant whole. When teleology in this sense is opposed to a purely mechani- 
cal theory, it means substantially the assertion of an intelligible whole as against the idea of reality as a mere aggregate or collocation of independent facts. When Trendelenburg, ${ }^{1}$ for example, speaks of the teleologists as asserting the priority of thought, and their opponents the priority of what he calls blind force, what he means by such priority is not a bare mind existing first and calling matter into being, but simply the inherently intelligible nature of reality. According to his own illustration, the universe has not chanced on its present apparently intelligible structure as the result of infinite castings of the cosmic dice, much as the Iliad or the tragedy of Hamlet might be supposed to be a collocation of letters accidentally arrived at in the course of infinite shufflings of the alphabetic symbols. Rationality is not a lucky accident of this description; it is the fundamental feature of the world. Intelligibility, as we actually discover it, and as we everywhere presume it, means that the world is the expression or embodiment of thought. In this sense mens agitat molem; reason is present at every stage as the shaping spirit of the whole.

If we discard, accordingly, in a cosmic reference the idea of a preconceived plan and the whole conception of contrivance or skill in the overcoming of difficulties, with the separation of means and end which it involves, we seem furnished with an answer to another of Professor Bosanquet's criticisms, namely, that teleology, 'in the sense of aiming at the unfulfilled, gives an unreal importance to time and to the part of any whole - it may be a relatively trivial part-which happens to come last in succession'. To proclaim the End as the true principle of explanation, we may reply, is no more than to insist, in Hegel's phrase, that the True is the Whole. Taken from the point of view of process, the principle says 'await the issue ', see what it all comes

\footnotetext{
${ }^{1}$ In his essay, Ueber den letzten Unterschied der philosophischen Systeme.
} 
to. Do not attempt to thrust things back upon their first beginnings, or try to take these beginnings out of relation to what has followed from them. It is the characteristic of Naturalism thus to substantiate the antecedents in abstraction from their consequents. But, as I have already insisted, the true nature of the antecedents, that is to say, of the apparent cause, is revealed only in the effects; and in this sense all ultimate or philosophical explanation must look to the end. Obviously, to such a teleology it is not the temporal sequence which is the important thing. The end, indeed, must not be taken in abstraction any more than the beginning; it must not be severed from the process of its realization. The last term is only important because in it is most fully revealed the nature of the principle which is present throughout. It is precisely this linkage of the first term with the last and, to that extent, the transcendence of the mere timesequence in the conception of an eternal reality, that seems to me to be expressed by the profound Aristotelian idea of $\tau \hat{\varepsilon} \lambda$ os or End.

But it is plain, as Professor Bosanquet argues, that the idea of Purpose or End, when we thus divest it of its finite incidents, tends to pass into that of Value. It is, as I have already said, the character of the whole which we have in view-not the historical fact of its having been purposed, but its nature as something worthy of being purposed, something fit, in short, to be the End of a Perfect Being. And it is in harmony with this sense of the term that theologians are wont to speak of the fundamental features of the universe as 'the eternal purpose' of God, And the same sense reappears in the test case of Spinoza's system, which apparently strides across the historical antithesis of mechanism and teleology. Spinoza passionately denounces the metaphysical use of the idea of Purpose or End, and appears therefore as the defender of mechanical necessity. But it would be a strange ruling which refused to see in Spinoza's 
system one of the great presentations of philosophical idealism. After all, it is an external teleology, and especially a teleology too narrowly centred in man, which Spinoza repudiates, and for which he substitutes the idea of a selfrealizing system. And Spinoza's necessity, we must remember, is always the necessity of the divine nature, that is to say, it is the expression of the nature of the whole. We shall not do justice to his thought, therefore, unless we interpret it in the light of his goal rather than in the light of his startingpoint-not by the formal definition of God as Substance but by the amor intellectualis Dei with which he closes, the intellectual love of the mind towards God, which is part of the infinite love with which God loves himself. Spinoza's conclusion brings into full light the element which we have just found to be the essential characteristic of the teleological conception. From the ultimate stage of philosophical insight, at which the mind realizes the system of the whole and its own oneness with God, there springs, says Spinoza, 'summa, quae dari potest, mentis acquiescentia, hoc est laetitia'; and beatitudo is the note upon which he closes. Acquiescentia - the highest contentment of mind, Pollock translates; acceptance as good, we might say. It is the human echo of the verdict put into the mouth of the divine Labourer - 'And God saw everything that he had made, and behold it was very good.' Or again, Spinoza says, this 'acquiescence ' is not really distinguished from 'glory'. In this striking array of terms there is the same undertone of mystical exaltation as in Plato's famous words at the close of the Timaeus, in which he celebrates the world he has described as 'a god perceptible, greatest, best, fairest and most perfect, the one only-begotten universe'. In these terms Spinoza enshrines his conviction that the world is not only one, but it is good: it is not only a system which we can understand, but one with which we can identify ourselves, and obtain thereby the highest satisfac- 
tion of which our nature is capable. This idea of satisfaction forms an integral part of any teleological view of the universe. The conception of a realized purpose involves the idea that the end is something worthy of attainment, an achievement in which the rational being can see the fulfilment, and far more than the fulfilment, of 'all the main tendencies of his nature '.

We meet here again, in short, the idea of value to which so much prominence was given in the first series of lectures and also in the earlier lectures of the present series. The idea is sometimes, I think, obscured in Hegelian arguments by the exclusive stress laid on the idea of unity and system. A principle of unity - the phrase which occurs so often in Caird for example-is in the end as bald and abstract a description of God or the Absolute as the much-derided 'Being' or 'Substance' of earlier philosophies. Hegel's own statements, in dealing with this very subject of teleology, also weary us by their persistent harking back to the fundamental formula of the One and the Many or identity in difference. But it is not any whole or system, any manyin-one, as such, which is capable of being looked at philosophically as an End. Such phrases, unless we read into them a specific content from our own experience, suggest no more than fitting together the parts of some intellectual puzzle. We have already seen, ${ }^{2}$ in criticizing Mr. Bradley's and Professor Bosanquet's formulation of the principle of value, how both these writers are obliged in practice to supplement the purely logical criteria of inclusiveness and non-contradiction by reference to 'the provinces of experience which comprise the various values of life', ${ }^{3}$ or, still more explicitly, to 'our main wants-for truth and life and for beauty and goodness'.4 The importance of the idea of purpose and its

${ }^{2}$ Mr. Bradley's phrase.

'In Lecture XII, on 'The Criterion of Value'.

- Individuality and Value, p. 268.

-Appearance and Reality, p. 158. 
correlate, satisfaction, is that they recall us to the aspects of feeling and will, which are incontestable marks of any experience known to us, and apart from which value is an unmeaning phrase. Value in some theories is specially connected with the facts of feeling, but satisfaction means more than can be expressed in terms of pleasure and pain, considered merely as passive states of the soul. Satisfaction is inseparable from conation, and successful conation is the self-fulfilment of the creature. In its highest form, such conation means realized purpose, and the supreme values are those which represent the realization of our most sustained purposes and the satisfaction of our deepest and most permanent desires. Value, it is not too much to say, becomes an abstraction when dissociated from the idea of purpose and realization.

But do not all these ideas bring us back, it may still be urged, to the region of finite effort? If purpose implies the ideas of conation and satisfaction, can we apply such a conception to reality as a whole without exposing ourselves to Spinoza's criticism that it implies defect in God, and explains his activity as a means to remove that defect, or to achieve a perfection which he previously did not possess? This fundamental difficulty is faced by Professor Bosanquet at the close of his contribution to an instructive Symposium on Purpose and Mechanism, ${ }^{1}$ of a later date than his Gifford. Lectures; and his suggestions towards a solution, if admittedly vague, seem to me, as coming from him, of unusual interest. In the Gifford volume, as we have seen, he appears, both at the outset and at the close, to reject the whole teleological point of view as applied to the Absolute. But in the lecture specifically devoted to the subject we find him acknowledging (or rather contending for) a 'teleology below consciousness' and a 'teleology above finite consciousness'. 'Nature,' in short, 'below conscious intelligence and Providence, if we like to call it so, above, can achieve without 'Published in the Proceedings of the Aristotelian Society, 1911-12. 
the help of a relevant explicit consciousness, results of the same general type as those which are ascribed to the guidance of conscious minds.' 1 It is not, therefore, the purposiveness of the whole which he denies, but the ascription of that purposiveness exclusively to the conscious guidance of finite individuals or of a God individualistically and externally conceived. In the more recent discussion to which I have referred, he proposes, in order to make this position plainer, to use teleology as a third term distinct both from mechanism on the one hand and purpose on the other, purpose being now identified with what he had called in his lectures 'the teleology of finite consciousness'. 'Teleology', he says in this symposium, ' as a character applicable to the universe, is got at primarily by freeing the idea of end from some incidents of finite purpose which cannot apply to a true whole.' But, he proceeds (and this is the point of interest to which I alluded), does teleology in this cosmic application ' transcend finite purpose in every way? Or must not, as we anticipated at starting, some special characters of finite purpose be carried on into teleology and establish a kinship between the two? In other words, are we not to unite the conative attitude and the correlative idea of satisfaction? Now, to unite conation with accomplished fruition -with the idea of a whole in which end and process are one-is not easy; on the other hand, to separate perfection from value, and value from satisfaction, and satisfaction from a conative attitude, is also not easy.' 'The difficulty begins', he adds, 'when you attempt to explain to whom the perfect whole is to be satisfactory'; and he is so impressed by this difficulty that he attempts to get round it by substituting the term satisfactoriness for satisfaction. 'I believe that value lies deeper, and is not conferred by de facto satisfying a conation, but is in satisfactoriness rather than satisfaction-in the character of completeness and positive non-contradiction which gives 
the power to satisfy conations, because it belongs to what unites all reality in itself.'

But surely this is an evasion of the difficulty, not a solution; for why is anything called satisfactory, unless because it satisfies some one? The same question therefore arisessatisfactory to whom? The suggestion would seem to be that the satisfaction is experienced distributively by individual finite beings. And that is no doubt an element in the case, for, after all, it is we who pronounce those judgements of ultimate value, and apart from such human valuations we possess no magical access to the secrets of the Absolute. But it is precisely because, in such judgements, there is no question of the realization of any merely individual or selfish purpose, or of any number of finite purposes, that we are prepared to stake our all upon them. We should not experience the satisfaction, if we did not believe that we were judging sub specie unizexsi or from the standpoint of the whole. Our finite judgements, therefore, seem to postulate a satisfaction of the Absolute itself, if I may so put it, which as heirs of reason and freemen of the universe we are capable of sharing. But in substituting satisfactoriness for satisfaction, and then translating satisfactoriness into purely logical characteristics, Professor Bosanquet seems to yield to the subtle temptation to detach the content and structure of truth, as logic does, from the concrete whole in which it is enjoyed, and to treat it as a self-existent entity. But the abstraction which is permissible and intelligible in logic or in any special science becomes meaningless in metaphysics. In an ultimate account of things, the logical criteria themselves-completeness, harmony, coherence, any term we like to use-imply, as much as any ethical or aesthetical criterion, the reference to a conscious experience appreciative of value. Because it is purged of all private by-ends and selfish interests, we sometimes think of truth as typically impersonal, but Aristotle's 
account of the divine felicity is sufficient to remind us that truth is not a logical abstraction but a supreme value.

The point which interests me, however, is that, in the end, Professor Bosanquet refuses to surrender the idea of satisfaction which he had seemed inclined to give up on account of its difficulty. The sentence which I have criticized is not, in point of fact, consistent with what he immediately goes on to say: it seems to reflect a temporary discouragement. In the very next sentence he reiterates the conviction which gave rise to the difficulty. 'Yet', he says, "in the purposiveness which is perfect and inclusive satisfaction, something must remain which represents the facts of conation.' Or, as he puts it in the following sentence still more strikingly, "the contradiction of a conation co-existing with fruition must be realized' ${ }^{-1}$ "This is not the place', he adds, 'to offer suggestions how this can be, but the singularly intimate unity which characterizes the teleological whole must be distinguished from the abstract unity of mechanism by something akin to a conation of all towards all, though its timeless unity seems a meeting of extremes with the mechanical ideal.'

The realization of a contradiction is a strange phrase on Professor Bosanquet's lips, but the paradoxes or apparent contradictions of religious thought have often been remarked on. A recent writer ${ }^{2}$ has observed in that connexion that, ' at our level of thought, the inclusion of an element of contradiction seems to be a sign of reality and of largeness of view rather than of error'. The paradox of religion may be truer, in short, than the dilemma, the 'Either-or', of the logical understanding. So it may be here in dealing with

'In the Appendix to Individuality and Value, in the immediate context of the statement that 'it seems unintelligible for the Absolute or for any perfect experience to be a will or purpose', he adds, 'To say that the reality as a whole may contain an untold number of finite purposes, and must itself include a satisfaction in which purpose and fulfilment are one, is another thing'.

${ }^{2}$ W. H. Moberly in Foundations, p. 520. 
the conception of an absolute experience. It seems at least certain that if nothing remains in that experience to represent the facts of conation and fruition, the Absolute is assimilated, as it is in Spinoza's formal theory, or as it sometimes appears to be in Hegel, to a timeless system of abstract truth, or, as Professor Bosanquet here suggests, it becomes indistinguishable from 'the mechanical ideal'. If we return for a moment to consider what is true and what is false in Spinoza's denials, it may serve to illuminate our conclusion. He denies both intellectus and voluntas to God. But his fierce polemic against 'absoluta voluntas' must be taken as his protest against transferring the idea of choice to a sphere where it is inapplicable, and thus founding the universe and its constitution upon a groundless act, upon the abstraction of contentless will. And this protest must be emphatically sustained. When he denies voluntas to God, it is this freedom of choice which he means, and when he denies intellectus it is the schematic and partial knowledge of things from the outside, the knowledge which proceeds by the piecing together of parts and the inferring of the unknown from the known-intellect, the deviser of means towards ends, of plans of action for the satisfaction of wants-it is this characteristically finite procedure which he refuses to carry over into his conception of the divine nature or the divine activity. And again it is obvious that the refusal is just. And yet there is a danger in Spinoza's denials; for although the discursive and scheming intellect is rightly denied, intelligence in some larger, directer form-of which we may have hints and anticipations in our own experience-must be affirmed, if we are not to treat that which is highest as lower than ourselves, and to assimilate it to unconscious nature. And with intelligence goes will, not as a meaningless freedom of choice but in the sense of continuously affirming and possessing one's experience, which is the characteristic, or at least the ideal, of the self-conscious 
individual. So far as Spinoza appears to deny these characteristics to his ultimate Individual, he abandons the principle of interpretation by the highest we know, and in that case, or so far as he does so, necessity, even the necessity of the divine nature, tends to suggest not the inwardly affirmed movement and rhythm of a concrete experience or life, but a kind of abstract destiny imposed on the universe. It is the idea of the divine necessity as a self-affirmed life, and not as a blind force acting within the universe like a fate which it undergoes, that constitutes the differentia between a theistic and a non-theistic doctrine.

The terms we have just used, however, do not carry us, of themselves, beyond the contemplative felicity of Aristotle's eternal thinker. But if we revise our idea of perfection-if we keep in view the conclusion to which we were led in the two preceding lectures, and definitively abandon the conception of God as a changeless and self-sufficient unitthe movement to the finite and the realization of the infinite in the finite must be taken as the fundamental character of the divine life. And if so, what term could be devised more fitting to describe the relation of the time-world and its process to the divine totality than to speak of it as 'the eternal purpose' of God? Like every term of our mortal speech, it retains the associations of time. The End appears as a 'far-off divine event', a consummation delayed; and beyond doubt the finite point of view cannot be transferred literally to an Absolute Experience. But so far as the ideas of process and ultimate achievement embody the conception of effort-nay, of difficulty-they may be accepted as truer to the great Fact of the universe than the language even of a philosopher like Hegel when he speaks of the Absolute Life as the eternal play of love with itself." In

'Philosophy of Religion. I am, of course, well aware that at other times Hegel emphasizes the element of strain in the cosmos. Many passages might be quoted. 
short, if the finite world means anything to God, the ideas of activity and purpose are indispensable. If he is not himself active in the process, he is no more than the Eternal Dreamer, and the whole time-world becomes the illusion which many absolutist systems pronounce it to be. Founding, as I do, on the verities of the spiritual life, it would be waste of time for me, at the stage we have now reached, to combat such a view. But the relation of the temporal to the eternal is so old a metaphysical problem, and one so much in the foreground at present, that it demands consideration in a special lecture. 


\section{LECTURE XVIII \\ TIME AND ETERNITY}

It was the apparent inseparability of the idea of Purpose from the future or the ' not-yet' that constituted the diffculty in applying it to the action of the Absolute or to the universe as a whole. We are thus led directly to a more general consideration of the problem of Time in its relation to the Absolute, or, as it is sometimes otherwise expressed, the question of the ultimate reality or unreality of Time. Adopting Plato's figure of the successive waves of a philosophic argument, we may well say that this is the most mountainous and formidable of the breakers we have to encounter. Greek speculation in any profounder sense may be said to have begun, in Heraclitus and Parmenides, with the problem of time and change; and the same problem is the fundamental issue in the latest contemporary philosophies of Mr. Bradley and M. Bergson. 'Nothing perfect, nothing genuinely real, can move,' says Mr. Bradley, 'uttering in one weighty Parmenidean phrase the burden and the underlying assumption of his whole philosophy; while duration, as we know, is to M. Bergson, in his own words, "the very stuff of reality'. ${ }^{2}$ The persistence of the problem need not surprise us if, as Professor Royce says, ${ }^{3}$ ' any rational decision as between a pessimistic and an optimistic view of the world, any account of the relation between God and Man, any view of the sense in which the evils and imperfections of the universe can be comprehended or justified, in

'Appearance and Reality, p. 500 . So again, p. 270, 'In any case there is no history or progress in the Absolute'.

${ }^{2}$ Creative Evolution, p. 287.

- The World and the Individual, vol. ii, p. I12. 
brief, any philosophical reconciliation with religion and life, must turn in part upon a distinction between the Temporal and the Eternal, and upon an insight into their unity in the midst of their contrast'. 'A philosophical position', says Professor Bosanquet in the same spirit, 'is definitely characterized by the attitude adopted to the course of time.' 1

Nothing is perhaps more remarkable, if we consider the intimacy and the omnipresence of the experience of change, than the general refusal of speculative and, it may be added, of religious thought, to regard this universal characteristic of human experience as an ultimate predicate of reality. The phenomenon is all the stranger seeing that, from the nature of the situation, it is impossible for us to emancipate ourselves from the temporal way of thinking and speaking; and, consequently, despite our best endeavours, we can only describe the supposed timeless or eternal reality by analogies and metaphors borrowed from our time-experience.

In the latest philosophical encyclopaedia the article 'Eternity' ${ }^{2}$ distinguishes three main senses in which the term is employed: ( $\mathrm{I}$ ) to denote an unending extent of time, (2) to denote that which is essentially timeless, and (3) to denote that which includes time but somehow transcends it. ${ }^{3}$ The first is the popular idea, taking its stand on the ordinary conception of time without trying to transform it in any way, but simply extending it quantitatively-adding more time at both ends. The helplessness with which this endless progress and regress afflicts the mind, the contradictions in which it involves us, if it is offered as a final statement

${ }^{2}$ Value and Destiny of the Individual, p. $29 \mathrm{r}$.

${ }^{2}$ By Professor J. S. Mackenzie in Dr. Hastings's Encyclopaedia of Religion and Ethics.

- Similarly, Dr. McTaggart notes 'three distinct senses: to denote unending time, to denote the timelessness of truths, and to denote the timelessness of existences' (in an article on 'The Relation of Time and Etẹrnity , Mind, N. S., vol. xviii, p. 343). 
of the nature of existence, have led many philosophers to insist on the essentially timeless nature of reality. They speak as if the time-view of the world were a pure illusion, embodying no characteristic feature of the universe, and therefore simply to be set aside in any attempt at an ultimate statement. But although this may be a natural revulsion from the popular conception, it is, I propose to argue, an over-statement, which is entirely contrary to sound principles of interpretation, and which necessarily lands us in a false position. The eternal is not timeless in the sense in which we might say that moral qualities are not spatial magnitudes; the eternal and the temporal are essentially correlative conceptions, so that it is only through the characteristic features of time-through some transformation of these features-that we can form any intelligible conception of the eternal. That is the principle of interpretation which we have followed throughout. Appearances are our only clue to the nature of reality. It is in developing what we find there, not in passing away from it and condemning it as illusion, that we may hope to form some conception of an absolute or perfect life. If we adopt the other method, we pass, of necessity, into the region of the completely unknown, where we can only speak in negatives. The third sense of the term mentioned by the writer of the article seems therefore the direction in which we should look for a solution of our difficulties.

The second sense, absolute timelessness, to which perhaps the term timeless might be most fitly restricted, covers the timelessness which is commonly said to belong to truths, or laws, or a conceptual system. The knowledge of any truth is, of course, an event in time; it is part of the history of some mind. Or, if the contemplation of a system of truths is supposed to be the occupation in which a divine mind realizes its eternal felicity, this activity of contemplation may still be distinguished, as a mode of existence, from 
the content of truth contemplated. The timelessness of truth as a logical content was the discovery of Plato. It is the profound thought which inspires his theory of the changeless world of Ideas, the world of true Being, as contrasted with the world of things and events, the world of $y^{\prime} v \varepsilon \sigma 15$ or Becoming. 'The conceptions through which we think things have no part in the mutability which we attribute on account of their changes to the things of which the qualities are the predicates.' ${ }^{1}$ A sweet thing may become sour, or a white thing may become black, but sweetness does not become sourness or whiteness blackness. Every concept is a meaning timelessly identical with itself and timelessly related, by relations of contrast or resemblance or otherwise, to other concepts in the world of knowledge. Here, then, we have a world of meanings, related or interconnected with one another, possessing a kind of reality, different from the reality which we attribute to an existent thing or to an event that happens, but still a reality which we instinctively acknowledge, for 'we all feel certain in the moment in which we think any truth that we have not created it for the first time, but merely recognized it; it was valid before we thought of it, and will continue so without regard to any existence of whatever kind'. It matters not whether it is ever exemplified in the structure of the actual world or is ever realized in the thought of a mind.

This kind of reality modern philosophy would designate, as Lotze says, by the term validity. The truths, we. say, are valid, they hold good, and, as entirely independent of time, we say they are timelessly or eternally valid. They do not belong to the world of things and events; they do not belong to what we ordinarily call the real world at all. Yet the kind of reality which they possess is so striking especially on its first discovery, that we can sympathetically

'I utilize here and throughout this paragraph Lotze's excellent account of this ideal world in his Logic, Part III, chap. ii. 
understand Plato's descriptions of the world of the Ideas as the world of true reality, in contrast with the world of things subject to change. For the changing things seem to possess any definite reality only so far as they are clothed with one or more of these eternal predicates-in Platonic phrase, so far as they participate in the Ideas. It may well be, as Lotze suggests, that Plato's description of the Ideas as possessing no local habitation, as visible only to the mind, as a world of pure intelligence, a heaven beyond the heavens, and many other glowing metaphors, were intended to guard against that very hypostatization of the Ideas as actual existences or substances which became the traditional interpretation of Plato's theory. But besides the dangerous influence of poetic metaphor upon more prosaic minds, it must be remembered that Plato had only the one term Being (ovi ía or $\tau o^{\prime} o^{\prime} v$ ) to express reality of whatever sort. It was almost inevitable, therefore, that the two kinds of reality should be assimilated-that the Ideas should have an existential status conferred on them, and on the other hand that the reality at the foundation of the existent world should be conceived after the fashion of the timeless validity of truths. Whatever his intention may have been, this, as a matter of history, was Plato's legacy to philosophical thought; and M. Bergson is right in pointing out that, in spite of Aristotle's polemic against Plato's substantiation of the Ideas, his own doctrine of God as a Being apart from the process of the world, defined as a thinking upon thought, is simply Plato's Ideas 'pressed into each other and rolled up into a ball'. 'The Aristotelian God is the Idea of Ideas or the synthesis of all concepts in a single concept', and the eternal divine thinking is conceived entirely on the analogy of a timeless system of abstract conceptions. ${ }^{1}$

As moderns, we may probably best understand the time${ }^{1}$ Creative Evolution, p. 339 (English translation). 
lessness which belongs to the notion of meaning or validity by thinking, not of concepts or Ideas, but of truths or laws. We naturally go for our examples to what are often called necessary truths-the laws of logic or mathematics-which, although suggested by observed facts, are recognized as in no way dependent on such observations. But the inductively established laws of the physical and other sciences, if true at all, are timeless truths on exactly the same footing. And it may be said that the same holds good of any proposition whatsoever. It may be only a statement about a particular event, but 'once true, always true'. Thus, as Locke says, 'Seeing water at this instant, it is an unquestionable truth to me that water doth exist; and remembering that I saw it yesterday, it will be always true that water did exist July I0, I688, as it will also be equally true that a certain number of very fine colours did exist, which at the same time I saw upon a bottle of that water'. But clearly timelessness in this sense is not calculated to throw light on what may be meant by eternity, as predicated of any concrete experience, and, as we have already seen in another connexion, it was just because Green's theory of an eternal consciousness, based as it was on the logical analysis of knowledge, tended to treat that consciousness as simply the logical unity of the subject involved in every judgement, or as the ideal focus of a system of intelligible relations, that we found it impossible to accept this abstract principle of unity as an eternal or divine Self operative in our individual experience. The timelessness of the subject, in Green's theory, is the abstract timelessness of the system of relations of which it is, as he says, the 'medium and sustainer'. If, therefore, we were free to fix our own terminology, it would, as I have already suggested, be better to restrict the predicate timeless to the world of truth as logic conceives it, and, in speaking of the concretely real, to employ the opposed but, as it may perhaps be shown, 
essentially correlative conceptions of the temporal and the eternal.

The original meaning of the eternal is, of course, not that of the timeless, but that which lasts or endures through time. In the grand old English word, it is the everlasting; or, in the Latin phrase, it is the permanent, that which ' remains' while other things 'change and pass'. Eternal, aeviternus, is, by etymology, age-long. And, popularly, all these terms are originally applied, not in the strict sense of lasting through all time, but in a superlative and honorific sense, as compared with human measures by years and generations. So we read of 'the everlasting hills'; and the old phrase seems not out of place, although we know that they are subject to a perpetual transformation through nature's agencies of frost and sun and rain.

The hills are shadows and they flow

From form to form, and nothing stands;

They melt like mist, the solid lands,

Like clouds they shape themselves and go.

But whether lasting an immensely long time, or being literally without beginning or end, our original conception of the eternal plainly has its roots in our temporal experience. Yet when we look more closely, it is equally plain that the meaning of the term is not exhausted-in fact does not primarily consist -in the idea of mere continuance or the indefinite prolongation of existence. Such a merely quantitative eternity adds nothing of worth or dignity to the thing in question. It belongs by hypothesis to the physical elements, and it might belong to the most casual and indifferent of their combinations. But the term eternal and its equivalents are charged with emotional value; and if we consult the language of religion in order to discover the source of that value, we find that what is expressed is the indestructible confidence of the worshipper in the perma- 
nence of the divine character and in the constancy of the divine purpose of righteousness as revealed in the government of the world. God is the Father of lights, with whom is no variableness, neither shadow of turning'; it is his righteousness, his truth, and above all, his mercy, which 'endureth for ever'. This is the 'living will' ${ }^{1}$ which binds past and future together in the unity of a single omnipotent purpose, and which therefore in a sense transcends such distinctions. The generations arise and pass away-all flesh is as grass-' 'but the word of the Lord endureth for ever'. And even when the term is applied to physical objects, as to the hills, it is not, I think, the idea of passive continuance which we wish to express, so much as the feeling they inspire of steadfast power to resist the disintegrating agencies of the seasons and the years.

Such being the original associations of the term, an analysis of our actual time-experience may probably help us towards a truer view of the antithesis we are considering. Many, perhaps most, arguments on the subject are based on the conception of absolute or mathematical time. Now, mathematical time-'duration in itself', as Locke called it - is ' considered as going on in one constant equal uniform course'. It is, in fact, the abstraction of mere succession-a system of positions in which we can arrange events as before or after one another. This pauseless flow is conceived as a succession of instants; but the mathematical instant has itself no duration, just as the mathematical point of the geometer is commonly defined as possessing no spatial magnitude. Both are ideal or limiting conceptions: 'philosophers', Reid tells us, 'give the name of the present to that indivisible point of time which divides the future from the past'. But just as it is impossible to regard the line or the surface as

${ }^{1} \mathrm{O}$ living will, that shalt endure

When all that seems shall suffer shock.

In Memoriam, cxxxI. 
a sum of such points, so it is impossible to construct the consciousness of real time out of the succession of such timeless units. In fact, if we follow out the conception to its logical results, the present, which we otherwise think of as 'the living present', interposed between a past which no longer exists and a future whose existence has not yet begun, is itself deprived of factual reality, and the whole real content of experience disappears.

Our past is clean forgot, Our present is and is not, Our future 's a sealed seed-plot, And what betwixt them are we? ${ }^{1}$

The older psychology did, in point of fact, endeavour to derive our consciousness of time or duration from the succession of ideas or mental states, regarded as discrete events, no one of which possesses duration in itself. Thus Locke tells us that, if it were possible for a waking man to keep only one idea in his mind without variation and the succession of others, the perception of duration would be 'quite lost to him', as much so as it is in sound sleep; though, with characteristic honesty, he returns to tell us that in point of fact, he does not himself think this feat is possible. ${ }^{2}$ Reid has no difficulty in demonstrating the impossibility of deriving a consciousness of duration from the succession of non-durational units. If, as Locke seems to say, it is the intervals between the ideas which yield us the consciousness, ${ }^{3}$ then the intervals between the first idea and the second and the intervals between any two subsequent ideas (although, according to the hypothesis, no succession of ideas takes place in such an interval) must

'D. G. Rossetti, 'The Cloud Confines'.

${ }^{2}$ Essay, II. 14. 4 and 13 .

3 The distance between any parts of that succession, or between the appearance of any two ideas in our minds, is what we call duration.' 
each of them possess duration for the mind. Otherwise we should be asked to believe that the multiplication of nothing may produce a definite quantity. ' I conclude, therefore,' he says, "that there must be duration in every single interval or element of which the whole duration is made up. Nothing, indeed, is more certain than that every elementary part of duration must have duration, as every elementary part of extension must have extension. . . We may measure duration by the succession of thoughts in the mind, as we measure length by inches or feet; but the notion or idea of duration must be antecedent to the mensuration of it, as the notion of length is antecedent to its being measured.' 1

But Reid appears still to cling to the idea of a succession of non-durational units, separated from one another by blocks of duration in which no events take place and in which, therefore, no succession is perceived. In other words, our experience is treated as consisting of discrete units of content (perceptions or ideas) separated from one another by periods of completely empty time. But empty time-a time in which nothing happens-is a conceptual

${ }^{1}$ Essays on the Intellectual Powers, Essay III, chap. v. In spite of this excellent conclusion, Reid's own doctrine is not entirely free from the confusion which he censures, for he still treats our perceptions (as well as what Locke calls ideas of reflection) as momentary in the mathematical sense. He concludes, accordingly, that, 'if we speak strictiy and philosophically, no kind of succession can be an object either of the senses or of consciousness [i. e. Locke's reflection] ; because the operations of both are confined to the present point of time, and there can be no succession in a point of time. . . . Hence it is easy to see that, though in common language we speak with perfect propriety and truth when we say that we see a body move and that motion is an object of sense, yet when, as philosophers, we distinguish accurately the province of sense from that of memory, we can no more see what is past, though but a moment ago, than we can remember what is present; so that, speaking philosophically, it is only by the aid of memory that we discern motion or any succession whatever. We see the present place of the body, we remember the successive advance it made to that place; the first can then only give us a conception of motion when joined to the last.' Cf. per contra, Mr. Wildon Carr's masterly treatment of this very phenomenon, 'the sensation of movement ', in his address to the Aristotelian Society on 'The Moment of Experience', Proceedings, 1915-16. 
abstraction which has no place in real experience. Form without matter nowhere exists. A completely empty time would be simply equivalent to the suspension or standstill of time. Our actual consciousness of time and its lapse is entirely dependent on the continual change of the experienced content. And the content, though parts of it are punctuated by a more vivid interest, is not to be conceived as a series of illuminated points from one to another of which we stride, so to speak, across an interval of darkness. The content is a moving and gradually changing whole. The change is in the strictest sense ceaseless and continuous-a continuous flow or melting of one moment into the next. This movement, of which we are directly conscious in its progress, constitutes the concrete reality of time-the durée réelle which $\mathrm{M}$. Bergson so impressively expounds. 'Duration', as he vividly puts it, 'is the continuous progress of the past which gnaws into the future and which swells as it advances.' 1 And, as he goes on to argue, time as it thus reveals itself in experience, is the very essence of life and of self-conscious existence.

The continuous and 'overlapping ' character of conscious experience, as well as our direct apprehension of the temporal relations involved, is emphasized by recent psychology in its doctrine of 'the specious present' or the 'span' of consciousness. William James's statement of the doctrine in his Principles of Psychology is probably the best known, but within the last few months the position has been very ably re-stated and defended by $\mathrm{Mr}$. Wildon Carr in his paper on 'The Moment of Experience'. 'The practically cognized present', says James, 'is no knife-edge, but a saddle-back with a certain breadth of its own on which we sit perched, and from which we look in two directions into time. The unit of composition of our perception of time is a duration, with a bow and stern, as it were = a rear-

${ }^{1}$ Creative Evolution, p. 5 . 
ward and a forward-looking end. It is only as parts of this duration-block that the relation of succession of one end to the other is perceived. We do not first feel one end and then feel the other after it, and from the perception of the succession infer an interval of time between, but we seem to feel the interval of time as a whole with its two ends imbedded in it.' " The content of the duration thus steadily perceived is in a constant flux, events dawning into its forward end as fast as they fade out of its rearward one, and each of them changing its time-coefficient from "notyet " or " not-quite-yet " to " just-gone" or "gone" as it passes by. Meanwhile the specious present, the intuited duration, stands permanent, like the rainbow on the waterfall, with its own quality unchanged by the events that stream through it. Each of these, as it slips out, retains the power of being reproduced. Please observe, however, that the reproduction of an event, after it has once completely dropped out of the rearward end of the specious present, is an entirely different psychic fact from its direct perception in the specious present as a thing immediately past. A creature might be entirely devoid of reproductive memory, and yet have the time-sense; but the latter would be limited, in his case, to the few seconds immediately passing by.' 2

${ }^{1}$ Principles of Psychology, vol. i, pp. 6o9-10.

${ }^{2}$ Ibid., pp. 630-I. Similarly, Mr. Carr, dealing with our perception of the luminous line described by a falling star, repudiates the explanation of the line as a fusion of quite recent memory-images with the actual sensation of a luminous point. 'By every criterion of sensation the line is sense, not memorized. The whole series is within the moment of experience and therefore a present sensation. A point or instant is not past because it is before another which is present, nor is it present only when the preceding member of the series is not present. It is present while it remains within the moment of experience. . . The moment of experience has within it no distinction of past and present, but it has within it the distinction of before and after. The limit of its duration is where memory takes the place of sensation.' I would refer also to Professor McGilvary's article on 'Time and the Experience of Time' in the Philosophical Review, March, 19I4. 
Our primitive and basal experience of time is thus characterized by a togetherness of parts or elements which lifts us above the aspect of mere succession, exclusively emphasized in the older accounts : as when Locke describes duration as 'perishing distance, of which no two parts exist together, but follow each other in succession '. 1 In contrast with temporal experience, conceived as pure succession, theologians have described the nature of the divine knowledge as a totum simul, an intuition in which the human distinctions of past and future disappear in an eternal present. But if this is to be accepted as an indication of the meaning of eternity, it is clear from what has been said of the real nature of our time-consciousness that the contrast between human and divine knowledge is not a sheer or absolute contrast between the mere successiveness of mutually exclusive moments and the compresence of all these moments in a single experience. For it cannot be too strongly emphasized that the experience of succession itself would be impossible if the successive items were not directly apprehended together as stages of a single process, parts within a single whole of duration. In the compresence which is thus an essential feature of our consciousness of time we therefore already realize, though doubtless on an infinitesimal scale, the nature of an eternal consciousness. 'In principle,' as Professor Royce says, 'we already possess and are acquainted with the nature of such a consciousness, whenever we do experience any succession as one whole.' ${ }^{2}$ And the principle is not affected by the narrow limits of our human span. 'A thousand years in thy sight are but as yesterday when it is past, and as a watch in the night.' It is possible, on the basis of our own experience, to imagine a consciousness to which the whole content of time is known at once in the same way in which a finite being knows the specious present.

'Essay, II. 15. 12. 'The World and the Individual, vol. ii, p. 142. 
Professor Royce has laid great stress on this similarity of structure-this anticipation, as it may be termed, of the eternal in the temporal. And sometimes he seems to say that the difference between the two modes of consciousness consists simply in their difference of span. "The eternal insight', we read for example, 'observes the whole of time and all that happens therein, and is eternal only by virtue of the fact that it does know the whole of time.' ${ }^{1}$ But it is clear that if the totum simul means no more than this, it is not enough. We clearly do not mean by an eternal consciousness one which simply contemplates the world as a series of events, but is somehow able to include the whole series in its span. Such a consciousness could not be said in any important sense to transcend time; for, regarded simply as events that happen, the perceived content possesses no internal unity which would permit of its being grasped as a whole. The very defect of the temporal order, as merely temporal, is the inherent absence of unity and totality - the completely inorganic level at which its contents remain; and in an eternal consciousness this defect is supposed to be corrected or overcome. But a consciousness which is merely a totum sinul would be no better than an epiphenomenon or accompaniment of the endless succession. Or, as Professor Bosanquet puts it, we should have 'only a fixed panorama of exactly the same occurrences which form a diorama for the man who goes through them'.2 The real intention of Professor Royce's argument must be gathered, therefore, from the alternative wording he more usually employs-to know the process 'as a whole'-and by the illustration, to which he constantly recurs, of the musical phrase or melody. For here we are dealing, not simply with

1 Ibid., p. I 44 .

"Individuality and Value, p. 388 (Appendix). Cf. Taylor, Elements of Metaphysics, p. 264: 'The direct insight of the Absolute Experience into its own internal meaning or structure cannot be adequately thought of as mere simultaneous awareness of the detail of existence.' 
a longer or shorter succession of sounds, but with a series which is significant and in a proper sense a whole; and although the successive order is an essential factor in the result, the consciousness of the melody as an aesthetic fact, or, for the matter of that, the perception of the meaning of any sentence, is an immediate perception different in kind from that in which we contemplate a series of events. The notes of the melody succeed one another in time, and the sentence is resolvable into separate words, and these again into syllables, no one of which co-exists, as a physical fact, with any other. Yet it is, in truth, only subsequent reflection of a scientific kind which, abstracting from the intellectual or musical meaning, enables us to isolate the elementary constituent sounds as successive events, occupying each its exclusive moment of conceptual or physical time. In the consciousness of such a significant whole, therefore, we have an example of a consciousness which may be called eternal, not in the sense of a maximized consciousness of time, but as an apprehension different in type, in which the temporal facts appear simply as the vehicle of a meaning or value.

Moreover, it is only fair to remember that the epiphenomenal or purely 'spectator' theory entirely misrepresents the nature even of finite consciousness. No consciousness falls asunder into a series of events that simply pass in time, any more than time itself can be resolved into a series of discrete or mutually exclusive instants. Past, present, and future are not to be conceived as separate sections of a line, or as if they were lengths cut off an unwinding ribbon, related to one another merely as different and mutually exclusive sections of an impersonal sequence. Time is not an element in which consciousness passes, or - a procession which passes before consciousness; it is simply the abstract form of the living movement which constitutes the reality of conscious life. If there is anything that a sound psychology teaches us, it is 
the essentially conative structure of that life. And in conation or active striving, past, present, and future are organically related to one another in the unity of a single experience. Activity, as I am now using the term, is the characteristic of the living and the conscious being alone; any application of the term, or any transference of its associations, to the happenings of physical nature and the causal relations between one phenomenon and another is rightly branded as anthropomorphism. In the older psychology (as well as in some more recently fashionable psychologies) physics may be said to have revenged itself for this intrusion; for in these systems our mental experience is constructed out of the interplay of static entities, called sensations, percepts, images, etc., conceived as the 'objects' of a consciousness which is simply an eye beholding their evolutions. The temptation so to conceive the mental life is naturally strongest in dealing with perspective or specifically intellectual processes; but to yield to it is to forget that, regarded thus statically, these facts or objects are only convenient abstractions from a concrete process which has its active basis in the facts of interest and attention. Mental experience is, in every phase of it, a process; and that process is not an impersonal movement or flow, but a movement towards an end of some sort. The facts of life and of mind cannot be truly described, in short, except teleologically, that is to say, as activity directed towards some end. To speak of end or purpose is to employ too developed and too complex terms, if we are supposed to intend by them an object of desire clearly conceived and deliberately pursued. The end may be in the creature rather than consciously present to it. Hence conation-a term wide enough to include a striving which may be almost blind-is possibly better adapted even than the term activity to express what is meant, viz. that at every point the process of consciousness is -interpretable as a self-directed movement towards some end, and can be 
intelligibly interpreted in no other way. Time and its direction are, as it were, the transcript of this movement; in it they acquire a concrete significance. The future towards. which man's face is set is primarily the end towards which he strives, but which is not yet within his grasp. As soon as it is grasped or enjoyed, it becomes the starting-point of a new pursuit and so recedes into the past. The words of the Apostle describing his own attitude of moral endeavour are, in fact, an apt description of this universal aspect_of human experience - ' forgetting those things which are behind, and reaching forth unto those things which are before?.

The consideration of Time has thus brought us back to the idea of Purpose or End, and it will be remembered that it was precisely the difficulties connected with that idea, as an ultimate category of explanation, that led to our present analysis. I cannot but think that the compass we have thus fetched carries with it an instructive moral. Purpose was condemned as essentially a temporal category. This is true, but the relation of the two terms is now reversed, for purposive activity is seen to be the concrete reality of which time is merely the abstract form. Time is the abstraction of unachieved purpose or of purpose on the way to achievement. Now, if this is so, it seems certain that an intelligible meaning of eternity will be found, not by abandoning the idea of purpose, but by following it out. The eternal view of a time-process is not the view of all its stages simultaneously, but the view of them as elements or members of a completed purpose. Then only can we be said to see them ' as a whole'.

As we have so often had occasion to observe, this transcendence of mere succession is exemplified in every application of the idea of growth or development. The impossibility which we experience of explaining later phases of such a process exhaustively by reference to the earlier is a proof that there is more in the process than appears at any given stage. The burden of our first series of lectures may be said 
to have been the exposure of the so-called scientific explanation, which seek the whole cause of a complex effect in certain simpler temporal antecedents, and, by pursuing this illusory quest from stage to stage, eventually arrives at the physical scheme of moving particles as the reality of the universe. We feel that such an analysis offers no explanation of what was the very point to be explained, the difference between one stage and another, the growth in richness and complexity, the increment of being, so to speak, as we pass from the lower to the higher. And that is why we pass from the mechanical to the teleological mode of explanation. In so doing we may be said to supplement the causality of the past by the causality of the future, explaining the evolv-: ing subject not only by what it has been, but, still more vitally, by what it is not yet, but is on its way to become. This we call the Idea or the End realized in the process. The nature. of the Idea or End is, of course, only gradually disclosed in the course of the process, and can be fully or positively. known only at its conclusion; so that it does not enable us, in the case of a subject still evolving, to predict the nature of . the future stages. It was, in fact, just the unpredictableness of the later-stages from the standpoint of the earlier that . drove us to this teleological mode of explanation. We are' wise, as it were, after the event; and from the standpoint of : the later stage we think of the earlier as containing in itself. the potentiality of all that actually followed upon it, although no analysis of the earlier by itself is capable of making the presence of the later in the earlier palpable to us.

But to think of the End as performed or prefigured in the beginning, and to think of it as operative while still an unrealized idea in the future, are both unsatisfactory modes. of statement due to our human position in mediis rebus,: in the middle of an uncompleted process. The fact with which we are faced is the breakdown of causal explanation through the antecedent in time. But to bring in the 
future, as teleology seems to do, to make good the defects of the past, is really an imperfect way of saying that we are dealing with a systematic whole, and that the complete explanation, or, in the technical language of logic, the ground of any phenomenon is to be found only in the nature of that system or whole. As Professor Taylor well puts it, "The succession of stages is welded into a unity by the singleness of the plan or law which they embody. The series of successive states which make up the history of a thing are the expression of the thing's nature or structure. To understand the thing's structure is to possess the key to the succession of its states, . . . It is evident that in proportion as our knowledge of any thing or system of things approaches this insight into the laws of its structure, the processes of change acquire a new meaning for us. They lose their appearance of paradox and tend to become the self-evident expression of the identity which is their underlying principle. Change, once reduced to law and apprehended as the embodiment in succession of a principle we can understand, is no longer change as an unintelligible mystery.'

But if time may be said to be thus transcended in the idea of a teleological process as an organic whole, words like ' law' or 'plan', 'structure' or ' system ', must not mislead us into thinking of the whole as timeless in the sense which we began by discarding, that is to say, as an abstract logical content. This sense, we decided, could have no meaning as applied to reality, for reality must be an experience not a theorem. As the Eleatic Stranger exclaims in the Sophist, when brought face to face with the blank eternity of the concept, "Can we ever be made to believe that motion and life and soul and mind are not present in absolute Being? Can we imagine Being to be devoid of life and mind, and to remain a venerable, holy, mindless, unmoving fixture?'? Movement, activity, process, is for us the very differentia of

'Elements of Metaphysics, pp. 162-3.

'Sophist, 249. 
concrete reality from the abstractions of science or of logic; and therefore, so far as this involves time, time must be retained in any conception we can form of an Absolute Experience. . The 'eternal act' by which the universe subsists can only be thought of by us as process continually renewed; and although, to the synoptic view, the end cannot be separated from the beginning, as it is to the finite individual within the process, the type of experience suggested is not one in which the stages are viewed side by side as in a fixed picture, but one in which the whole is felt in every part, and every part is real as an element in the whole.

Hence it is, I think, that the analogy of a work of art-a great drama or story-often seems to bring us nearest to what we feel must be the truth. For here, too, there is no such thing as a detached event, a mere present. In a great tragedy everything that happens is organic to the whole; the action which passes on the stage at any moment depends for its significance on all that has gone before, and we forefeel in it the future issues which are being decided. When we read or witness a play for the first time, and the course of the action is unknown to us, this sense of the solidarity of the whole, the prescience of an immanent destiny working itself out in individual scenes-in a word or a glance-naturally grows as we proceed, and reaches its maximum of intensity as we approach the close. The infinite pathos of Othello is all uttered in the parting cry, 'No way but this'. But in the case of Greek tragedy, where the legendary basis was familiar to the spectators, or in the case of any modern masterpiece where the end and the outline of the plot are known to us beforehand, this perception of the meaning of the whole as articulated in the individual incidents is present to the reader or the spectator of the piece from the very outset. And the same thing is true when we hear the opening chords of a well-known symphony; we hear them not as single chords but as elements in a great musical structure, 
prophetic, as it were, of all the thought and emotion that is to follow. The former case,-where-the-End is-gradually disclosed to us-divined by us-as we proceed, represents our human, finite attitude towards the future; the second, which may be supposed to reproduce that of the original poet or composer, is perhaps the nearest analogue we have to the divine apprehension of the temporal. What is common to both is the perception of the meaning as resident in the whole, and the impossibility, therefore, of taking any stage by itself, even the last. In reading the last scene of a tragedy, or as we move towards the close of some great poem, we feel perhaps more profoundly than in any other way the truth of Hegel's well-known saying that the End is not something that can exist, or can be understood, by itself. For art, as for philosophy, the End is inseparable from the process of its accomplishment. The End is not the final stage which succeeds and supplants its predecessors; it is the meaning or spirit of the whole, distilled, as it were, into each individual scene or passage.

The same principle applies to the history of a life. To take it as 'pure history' is to rob it of all significance. We involuntarily regard it as the unfolding of a specific nature, the moulding of a mind and character in the play of circumstance or the stress of passion. We regard it, in the phrase so often used already, as the making of a soul, The external observer can but dimly apprehend the stages and the factors in the drama, his interest and his insight being alike superficial; but even he can appreciate to some extent the quality of the product. Oftenest, perhaps, under the transfiguring touch of death, does the informing spirit of a beloved lifeits 'idea', as Shakespeare calls it '-stand revealed, lighting up the significance of individual acts or sayings, half-for-

' The reference is to the beautiful lines in Much Ado about Nothing (Act IV, sc. i) :

The idea of her life shall sweetly creep.

Into his study of imagination: 
gotten, as glimpses of a single soul. So, but far more intimately, we may conceive a human mind and life to be realized as a divine idea or an individual purpose in the Absolute. Far more intimately, for to the tenderest finite sympathy the 'idea' must retain much of the abstractness of a construction from the outside; but whatever independence of will we may attribute to the creature, we cannot think of him, in relation to the creative and informing Spirit, as dwelling in an inaccessible sphere of his own. 'All things are naked and opened unto the eyes of him with whom we have to do.' The divine idea of 'a mind and life ' 'sould therefore be the very life itself, experienced as significant because experienced as a whole, and, what is more, as part of the meaning of the all-inclusive whole,

Somewhat in this fashion we may perhaps conceive that the time-process is retained in the Absolute and yet transcended. Retained in some form it must be, if our life experience is not to be deprived of all meaning and value. The temporal process is not simply non-existent from the Absolute point of view; it is not a mere illusion, any more than the existence of the finite world, of which, indeed, it is the characteristic form and expression. I have urged consistently in these later lectures that the existence of that world must represent a necessity of the divine nature and must possess a value for the divine experience. Hence the timeprocess must enter somehow into that experience.

It may be objected that, in the view suggested, time really vanishes altogether in the Absolute. The characteristic features of a life in time are the 'not yet' and the 'no more', and for these there is no place in a complete experience. As

And every lovely organ of her life

Shall come apparell'd in more precious habit,

More moving delicate, and full of life,

Into the eye and prospect of his soul,

Than when she lived indeed.

1 'The shape and colour of a mind and life' (Tennyson, Elaine). 
Professur McGilvary urges ${ }^{1}$ : "The time-order in which experienced events stand is an order into which they come. Now the Absolute experiences the order in which events stand; but it fails to experience anything as novel or to feel any loss. Into the all-inclusive present of the Absolute nothing can enter: everything is already there. His time is therefore untimed time. The very entirety of his vision detemporalizes what he sees. ... To look forward with bated breath or to stand on tiptoe of expectation; to strain our eyes for the first blush of dawn after our sorrows have endured through a long night; to watch by the bedside of a friend, sick it may be unto death, and have our hearts rise and fall with each unforeseen turn-such are the crises in which for all of us the experience of time culminates. The Absolute can have no inkling of what lies on the inside of such experiences. To see all at once is to fail to feel the temporal sequence as genuinely temporal.' But however poignantly we may feel the truth of such a passage, we must remember that just such a contrast is a necessary result of the situation:

We that are not all,

As parts, can see but parts, now this, now that, And live, perforce, from thought to thought, and make One act a phantom of succession: thus

Our weakness somehow shapes the shadow, Time.

But it is an unreasoning procedure to seek to transfer this attitude to a universal Spirit. We must conceive, and we can in some sense understand, the temporal process as a necessary condition of the existence of partial minds, to which their content has to be communicated, which have to be made, or to make themselves, in commerce with the mighty whole. Time, in such a view, becomes an appearance incident to their partial nature. Time (and space) are

1'Time and the Experience of Time,' Philosophical Review, vol. xxiii, p. I44. Professor McGilvary's criticism is perhaps directed more particularly against Professor Royce's view of eternity as merely an allinclusive view of the contents of time. 
to be regarded, in short, as the principia individuationis, the forms of finite individuation, but as somehow transcended in the ultimate Experience on which we depend. Philosophers sometimes speak as if we could ourselves transcend these conditions. The mind, it is said, is not in space, and as knowing succession, some thinkers like to speak of it as itself timeless. But although the philosopher may constitute himself, in Plato's phrase, spectator of all time and all existence, his timelessness or spacelessness is only in a manner of speaking; for he views all time from his own 'Now' and all space from the 'Here' of his own body. It is his anchorage to a definite ' here' and 'now'.' that makes him a creature of time and place, that shapes his view of the world for him, and makes him incapable of realizing any other experience except as an abstract suggestion, or at most as a divination. In our attempts at description it is a case, as St. Augustine says, wel nosse ignorando vel ignorare noscende. But it does not follow, as Professor McGilvary suggests, that the containing experience is without 'an inkling of what lies on the inside' of the doing and suffering of the creatures of time. The author also knows the end from the beginning, at least in the sense that the ground-plan of his story and its conclusion stand before him, so that he contemplates all the actions of his characters as steps in a destiny; yet he must himself feel, and make the reader enter into, the temporal outlook of his figures at each crisis of their fate. And if it be objected that this is intelligible because the author is himself, like the characters he creates, a creature of time, it may be retorted that it is everywhere the mark of the higher and wider experience to comprehend the lower and narrower, whereas the contrary is excluded by the very nature of the case.- So the human intelligence can appreciate the dumb strivings of the animal mind, or a parent can sympathize with the ephemeral joys and unreasoning sorrows of his child. May we not extend the analogy?

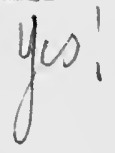




\section{LECTURE XIX}

\section{BERGSONIAN TIME AND A GROWING UNIVERSE}

TIME, then, seems one with the existence of the finite; and although the experience and the relations of time must be represented in the infinite Experience, this must be in a way which transcends our human perspective. So we might summarize the argument of the preceding lecture. It was a silent presupposition of the argument that time cannot be taken (in the current phrase) as ultimately real; that is to say, time, with all its implications of development and progress, is an aspect of facts within the universe,-an aspect of central significance, we have contended, but still an aspect within the whole-not, as it were, a containing element in which the Absolute or the All exists, and through which it advances, garnering new being and perfections as it proceeds. The idea of an absolute experience in which time is transcended is undoubtedly difficult, and the conception of a growing universe may seem, on a first statement, much easier; yet, as often as the conception has presented itself, we have set it aside as intrinsically incredible. A finite individual grows by appropriation from its environment-grows, in the last resort, by appropriation of the riches of the whole; but we feel that, while we may properly speak of such processes within the whole, it is not less than unmeaning to speak of the whole itself as such a process. Yet that is what is supposed to be involved in M. Bergson's theory of 'creative' evolution, and it is certainly the meaning of the ' unfinished universe ' of William James and other Pluralists. The idea calls, therefore, for a more careful examination than we have hitherto given it.

We have freely acknowledged the value of M. Bergson's 
exposition of the true nature of duréc réclle as the fundamental characteristic of conscious life, and as distinguished from the spatialized time of physical theory and of ordinary reflective thinking, dominated as that is by spatial images. We habitually figure the course of time to ourselves under the image of a line. But, as M. Bergson insists, there can be no greater contrast than that between the continuity or flowing of real time-the mutual interpenetration of its parts with the conservation of the past in the present-and the static image which we construct for ourselves of conceptual time, as consisting of separate and mutually exclusive moments arranged in an order of juxtaposition, like the parts of a line in space. Thinking of time thus, it is no wonder that we cannot see our way through the paradoxes of Zeno about the impossibility of movement ; for we have conveyed into the fluent moments of time the same immobility and separateness which belongs to points of space, and so, as Zeno says, ' the flying arrow is always at rest '.

In his first book, on Time and Free Will, M. Bergson has worked out impressively the influence of this spatialized idea of time in producing the peculiar illusion of determinism which represents us as the slaves of our own past, figured as a kind of external destiny. It is again the image of the line, giving an artificial permanence and externality to the circumstances or actions of the past. But the past has no operative reality save as fused in the agent's present, and we have no right to transport ourselves in imagination to some point in the past and treat our future course of action as performed or predetermined there. As William James says, ' the whole feeling of reality, the whole sting and excitement of our voluntary life, depends on our sense that such things are really being decided from one moment to another, and that it is not the dull rattling off of a chain that was forged innumerable ages ago ' ${ }^{1}$ But, if we banish the associations

'Principles of Psychology, vol. i, p. 453. 
of the spatial image, we have in the self a development which is real at every point. The self is making itself continually by its own actions, and each of these actions is free in the ethical sense required. Hence, as M. Bergson says, the self 'lives and develops till the free action detaches itself from it like a fruit overripe'. There is no necessity here to revive the idea of the liberum arbitrium, nor does M. Bergson appear to do so. It is enough that every act of moral choice is, in its very idea, free, and is recognized by the agent as such to the end, however settled in certain courses of actions he may have become. The ethical point obscured by the false conception of time is simply, as Professor Bosanquet expresses it, 'that nothing past, nothing external, is operative in the agent's choice. It is all gathered up and made into the agent himself.' Hence, 'nothing but the agent determines the act, and there is no sense in applying to him any " must" or "cannot help it" except in the sense that everything is what it is '."

We are subject to the same spatial illusion in thinking of the course of the world as a whole. We project the content of the universe into the past, and conceive all that follows, in James's phrase, as 'the dull rattling off of a chain forged innumerable ages ago'-a kind of destiny which the generations have to undergo, or a programme which they have to work out as passive instruments. If we embody this fixed fate in a mechanical system of material elements and forces, we have the common naturalistic creed; but it may also take a theological form, as in doctrines of divine predestination where 'the purpose of God ' appears as a 'doom assigned'. There is also the idealistic form, in which the course of the world appears as the pre-determined evolution of a principle eternally perfect and complete. In all these cases, if the idea of complete determination is taken seriously, a paralysis tends to creep over the life of moral effort and practical

'Individuality and Value, p. 355. 
activity. And we may agree with Bergson that it is practically indifferent whether we adopt the naturalistic or the teleological alternative, that is to say, whether we regard the course of events as predetermined by the collocations of brute matter or by some divine Idea. Radical mechanism and radical finalism (so he calls the two theories) are in this respect at one, that in both, according to his favourite phrase, tout est donné, everything is given once for all. Finalism is, in this respect, "only inverted mechanism; it substitutes the attraction of the future for the impulsion of the past. But succession remains none the less a mere appearance.' 1

And here again, I think, we must agree with Bergson's analysis of the illusion, though we may not follow him in all the consequences which he draws from its rejection. If we transfer all real action to the past, action in the present becomes a hollow show. Our life in the present is no longer real; it comes to resemble a dance of marionettes or a procession of shadows. But it is the past which is the shadow-a shadow cast by our human reflection; the present alone is real, in the sense we are considering, whether we take it, with Bergson, as the growing-point of an advancing reality or as the temporal appearance of a reality which is in itself complete and eternal. Action therefore is real here and now, whether it is man's action or God's; all the great issues are being really decided. It is wrong to place divine action in the past or in the future; but it is not, in the same way, wrong to place it in the present. The past and the future are essentially relative, and indeed negative, conceptions, the no-more and the not-yet; but the 'is' of 'the present, if we take it as we do in action and in all direct experience, is not infected by the same relativity, and hence there is in it something comparable to eternity. If we speak of the divine activity as an eternal act, that means for us, if we throw it, as we must, into terms of time, an act which is

\footnotetext{
${ }^{2}$ Creative Evolution, p. 42.
} 
being accomplished now, and which we are helping to accomplish. And it is quite in accordance with this view that theologians find it necessary (as we saw in a previous lecture) to supplement the doctrine of a creation once for all, by saying that the continuance of the world in existence is equivalent to a continually repeated act of creation-a statement which completely transforms the original doctrine. The passage from the one statement to the other represents the effort of the mind to emancipate itself from the spatialized form of time. To place the creative act in the past is rightly felt to be making it a mere event in time; to treat it as the present act which sustains the universe is felt, with equal right, to lift it out of the temporal sequence and so to justify the predicate eternal. Every statement of religious truth must undergo the same transformation. Christ must die daily; the world is redeemed as well as created continually, and the whole life of God is poured into what we call our human 'Now'.

But the same spatial illusion, which he so successfully exposes in the case of the past, seems to beset M. Bergson himself when he comes to deal with the future. As is well known, the stress which he lays on the unpredictability, the unforeseeableness, of the future has led to his being regarded in many quarters as the apostle of pure contingency and irrationality. He develops his own account of 'creative' evolution in contrast with the two rival theories of mechanism and finalism, punctuating his statement chiefly by reference to the ordinary teleological view. The essence of his theory seems included in the following statement: 'Reality appears as a ceaseless upspringing of something new. ... This is already the case with our inner life. For each of our acts we shall easily find antecedents of which it may in some sort be said to be the mechanical resultant. And it may equally well be said that each action is the realization of an intention. In this sense mechanism is everywhere, and 
finality everywhere, in the evolution of our conduct. But if our action be one that involves the whole of our person and is truly ours, it could not have been foreseen, even though its antecedents explain it when once it has been accomplished. And though it be the realizing of an intention, it differs, as a present and new reality, from the intention, which can never aim at anything but recommencing or re-arranging the past. Mechanism and finalism are, therefore, here only external views of our conduct.' The same thing holds of organic evolution. 'It would be futile to try to assign to life an end in the human sense of the word. . . . Of course when once the road has been travelled, we can glance over it, mark its direction, note this in psychological terms, and speak as if there had been pursuit of an end. But of the road which was going to be travelled, the human mind could have nothing to say, for the road has been created pari passu with the act of travelling over it, being nothing but the direction of the act itself.' In short, ' reality is undoubtedly creative, i.e. productive of effects in which it expands and transcends its own being. These effects were therefore not given in it in advance, and so it could not take them for ends, although when once produced, they admit of a rational interpretation. . . The future appears as expanding the present: it was not, therefore, contained in the present in the form of a represented end.' ${ }^{1}$

Now if we take these statements simply as an account of the phenomenal process as it appears to a finite spectator or to an agent engaged in the process, their fidelity to the facts is beyond dispute. It is obvious that to the evolving subject the end is not present in the form of idea: as regards organic nature, the perception of this is the basis of the whole doctrine of unconscious teleology, so general since Kant. And in the case of psychical activity, such as that of human beings, where the agent can really set before himself a defi-

${ }^{2}$ Creative Evolution, pp. 49-55. 
nite plan of action, it is equally true that the result is never exhaustively explained by reference to his intention. His intention, as M. Bergson acutely puts it, can reach only to the repetition or re-arrangement of what he already knows; but the result of his reaction upon the situation may be something veritably new. On the large scale, this disparity between intention and result is a commonplace of the poets and moralists. 'Man proposes, God disposes.'

There's a divinity doth shape our ends,

Rough-hew them how we will.

And the story of Saul, the son of Kish, who went out to seek his father's asses and found a kingdom, has long been a favourite parable with idealist writers. The whole idealist view of history as a process of unconscious reason depends, indeed, on the recognition of this disparity. It meets us in all the details of political and social action. The fabric of civilized society or of a nation's institutions was not made according to any pattern consciously present as idea, but is the cumulative result of actions taken to relieve pressing needs, and successively modified in view of unforeseen effects till a tolerable modus vivendi was arrived at. The path, as M. Bergson puts it, is created pari passu with the act of travelling over it. And yet, although so little apparently is due to definite human foresight, we instinctively feel, when face to face with the result, that some greater Reason has guided the process to ends so august. In artistic creation, again, the finished work of art is not explicable as the deliberate expression or embodiment of a clearly formed idea. The first idea in the mind of the poet, the painter, the sculptor, the musician, is vague, more like a feeling flashing into a visual or auditory image; but, as he works it out, it takes definite shape and colour from the exigencies and felicities of the material in which he works. It evolves itself step by step, and the artist would be puzzled to say how much of the final result was included in his original conception, and how 
much has added itself as he went along, in the silent commerce with his materials.

$\mathrm{He}$ builded better than he knew, The conscious stone to beauty grew.

And once more, in the development of ideals, as was insisted in an earlier lecture, we possess at the outset no adequate and full-orbed idea of perfection. Our idea grows from less to more in the stress of life and in intercourse with the manysided world. New features disclose themselves as we proceed, and the baser and ruder elements fall away, till the link of identity between the first stage and the last is worn almost too thin for recognition.

Everywhere, therefore, in experience we have this phenomenon of the unpredictability of the consequent from its apparent antecedents. In this respect M. Bergson's contention has a manifest affinity with the principle which Professor Bosanquet so often enforces, that in logic and life we constantly do pass beyond our premisses. The stream is constantly found rising above its source, despite the adage, for only so can any real advance be accounted for. But the idealistic tradition which $I$ have followed in the main in these lectures regards this advance as taking place in the finite evolving subject, or from the point of view of such a subject, not from the point of view of the whole, as if the ' expansion and transcendence of its own being' in unforeseen directions represented the experience of the Absolute itself. It was, indeed, a main thread in our argument that only through the presence in the finite of an infinite Perfection was such advance and self-transcendence on its part possible. But M. Bergson's followers and acclaimers, if not M. Bergson himself, apply this idea of growth or progress in time to the universe as a whole; and in the new possibilities, the new horizons, which it opens up they celebrate their deliverance from what James calls 'the rationalistic block- 
universe' or 'the static, timeless, perfect Absolute '.' And to James certainly novelty means pure indetermination or contingence. 'That genuine novelties can occur,' he says, ' means that from the point of view of what is already given, what comes may have to be treated as a matter of chance.' ${ }^{2}$ The question in regard to new being is, 'Is it through and through the consequence of older being or is it matter of chance so far as older being goes-which is the same thing as asking: Is it original, in the strict sense of the word?' 3 So again, praising Renouvier as his deliverer from 'the Monistic superstition' under which he had grown up, he says that Renouvier on his own principles 'could believe in absolute novelties, unmediated beginnings, gifts, chance, freedom, acts of faith'.4 M. Bergson himself, although he repudiates the idea of caprice, ${ }^{5}$ lays great stress, as we have seen, on 'the absolute originality and unforeseeability of the different stages in a process of living evolution' ${ }^{6}$ In the same context he uses the expression, "There is radical contingency in progress, incommensurability between what goes before and what follows, in short, duration'. So he speaks in another place of 'putting duration and free choice at the base of things '." "If time', he says, 'is not a kind of force, why does the universe unfold its successive states with a definite velocity? . . . Why is not everything given at once, as on the film of the cinematograph? The more I consider this point, the more it seems to me that, if the future is bound to succeed the present, instead of being given alongside of it, it is because the future is not altogether determined at the present moment . . . it is because in the time taken up by this succession there is unceasingly being created in the concrete whole something unforeseeable and new.' 8

'A Pluralistic Universe, pp. 318, 327.

${ }^{2}$ Problems of Philosophy, p. 145; italics his own.

Ibid., p. 145.

Ibid., p. 30.

- Ibid., p. 164.

'Ibid., p. 29 I.

- Creative Evolution, p. 50.

Ibid., pp. 358-9. 
But the stress thus laid upon contingency is surely due to the persistence of the spatial illusion in regard to time from which M. Bergson claims to deliver us. He emancipates us from the spectre of fatalistic determination of the present by the past, by showing the fallacy involved in substantiating past acts and states like external forces in space. But if we cease to hypnotize ourselves by the projected image of the past-if we recognize that every being acts from its own living present-why should we involve ourselves in precisely similar difficulties by projecting the future as a similar line in the opposite direction, and thinking of the present as fatally and externally determining the future beforehand, in such a way as to deprive future actions, when they occur, of their proper reality? It was the determination of the present beforehand that was felt to be intolerable, and just that determination constituted the illusion; and now it is the same illusion transferred to the future, from which we try to escape by the assertion of contingency at every step. But if we are true to the doctrine of real duration, we have nothing to do with this phantom future any more than with the other phantom of the past. We live and act only in the present; and every action has its own reality and, in the case of conscious action, its own freedom, just as the divine activity which sustains and guides the world is to be thought of as the expression of a present mind and will, not as the consequence of past decrees which bind God himself like a fate. The whole deterministic difficulty in its ordinary form arises from our taking time in this spatial perspective. If we avoid the error $a b$ initio, therefore, the dilemma of determinism or freedom does not arise, and consequently there is no temptation to safeguard freedom by the introduction of contingency. If, as M. Bergson says, we act now with our whole past, and yet are free, why should this be otherwise in the future, when what is now present will constitute part of the past which we carry with us? 
But if we identify reality, as has been suggested, with a living present, it must not be forgotten that the mere present is just as much an abstraction as the dead past and the nonexistent future. From our human point of view we instinctively think of the life of the world as concentrated in a very special sense in the present; and it is legitimate to do so, because we, also instinctively, take the present as rooted in an eternal reality, of which it is a partial expression. If it were not for this eternal background, we should be reduced to the intolerable paradox of identifying the reality of the universe with what is shown in our empirical present. 'Is the history of the world really reduced ', Lotze asks, 'to the infinitely thin, for ever changing, strip of light which forms the Present, marching between a darkness of the Past, which is done with and no longer anything at all, and a darkness of the Future, which is also nothing?' Even in these expressions, as he truly says, he is yielding to the imaginative tendency which seeks to soften the incredible. 'For these two abysses of obscurity, however formless and empty, would still be there, would still afford a kind of local habitation for the not-being, into which it might have disappeared or from which it might come forth. But let any one try to dispense with these images and to banish from thought even the two voids, which limit being: he will then feel how impossible it is to get along with the naked antithesis of being and not-being, and how unconquerable is the demand to be able to think even of that which is not as some unaccountable constituent of the real.' ${ }^{1}$

This unconquerable demand means that we instinctively treat past, present, and future as organic to one another; in dealing with any present phenomenon, we interpret its nature both by what it has been and by what it has in it to become. Just so far as we succeed in this interpretation, do we conceive ourselves to understand the reality operative

${ }^{2}$ Metaphysic, Book II, chap. iii, section 157 . 
in the phenomenal series; and to understand the timesequence in this way is, I have argued, in an important sense to transcend its temporal aspect. But in M. Bergson's theory, as we know, the temporal aspect is exclusively emphasized, and his critique of teleology comes very near a denial of any eternal principle in the development. Hence, I think, arises the want of balance, on which I have conmented, between his treatment of the past and his treatment of the future. It would be unfair to accuse M. Bergson of treating the present as a 'mere present'; for his insistence on the conservation of the past in the present and its operation there as character and tendency is, as we have seen, one of the luminous insights of his philosophy. But with the present the reality of the universe seems, in his account to come to a stop. The process up to date is treated as if it could stand alone, and were intelligible by itself; and the future appears, therefore, not as an inseparable part of the same development, but, as it were, something tacked on, a realm of the unknown, and consequently the appropriate home of the contingent. But to regard the future in this inorganic fashion as something entirely new, in which anything may happen, ${ }^{1}$ is to desert the principle which has already been acknowledged in the relation of past and present. And it is also to forget the essentially anticipatory character of conscious action, as purposive, and all that is implied in the causality of the ideal. In point of fact, by placing the fountain of reality entirely in the past and treating it as a vis a tergo, M. Bergson really comes nearer to the determinism which he attacks than is the case with a more frankly teleological point of view. 'Harmony', he says, ' is rather behind us than before. It is due to an identity of impulsion and not to a common aspiration. It would

'Recall James's phrases, 'genuine novelties', 'unmediated beginnings, gifts, chance, freedom', and M. Bergson's own assertions, already quoted, of a 'radical contingency in progress, incommensurability between what goes before and what follows'. 
be futile to try to assign to life an end in the human sense of the word.' 1 When he makes this statement-emphasizing it as 'the point in which finalism has been most seriously mistaken'-he is speaking at the biological level; but from life M. Bergson continually passes to consciousness, and consciousness is, as a matter of fact, his all-inclusive term. If it were necessary, however, to choose between placing the vis directrix in the past or in the future, it would be more consonant with the structure of consciousness, as we have already seen, to place it in the future-not, indeed, as a clearly conceived end, but as glimpses of a fairer and a better, the 'Gleam' which we follow, the Good, in short, ' which every soul pursues as the end of all its actions, divining its existence, but perplexed and unable satisfactorily to apprehend its nature'.2 $\quad$ But to force such a choice upon us is a mistake; the source of reality dwells neither in the past nor in the future. The three dimensions of Time (if I may so call them) are rather our human ways of refracting the Eternal Nature in which we live and on which we draw.

In the absence of such a Nature, everything reduces itself to pure contingency; for, as a prius or mere beginning, the élan vital is mere indeterminateness. It is comparable to the infinite outgoing activity with which Fichte proposed to start. Fichte supplied his activity with an Anstoss against which to break itself ; and M. Bergson, impelled by the same necessity, offers us a deduction of matter as the refractory element into which the principle of life or free consciousness ${ }^{3}$ has to infuse itself-the realm of mechanical necessity which it seeks, in his own phrase, "to penetrate with contingency'. But if life, in its contact with matter, is thus comparable to an impulsion or an impetus, regarded in itself,

${ }^{1}$ Creative Evolution, p. 54 .

Plato, Republic, 505.

" For want of a better word we have called it consciousness. But we do not mean the narrowed consciousness that functions in each of us.' "If our analysis is correct, it is consciousness or rather super-consciousness, that is at the origin of life' (Creative Evolution, pp. 250, 275). 
he reminds us, it can only be described as 'an immensity of potentiality' (virtualité). And in its action there is 'properly speaking neither project nor plan'. The anxiety to 'transcend finalism' thus leaves the nature of the creative principle a complete blank. Freedom in the negative sense of indetermination or contingency appears to be the only predicate applicable to it, and the only description of the ends which it seeks to realize. ${ }^{1}$ If so, it is impossible not to sympathize with Mr. Balfour's feelings of 'a certain incongruity between the substance of such a philosophy and the sentiments associated with it by its author. Creation, freedom, will-these doubtless are great things; but we cannot lastingly admire them unless we know their drift. We cannot, I submit, rest satisfied with what differs so little from the haphazard; joy is no fitting consequent of efforts which are so nearly aimless. If values are to be taken into account, it is surely better to invoke God with a purpose, than supraconsciousness with none.' ${ }^{2}$

Just at this point, however, M. Bergson leaves us in uncertainty as to his final teaching. Accused of preaching an atheistic monism, he has claimed that his doctrine is not only not inconsistent with Theism, but points directly to that conclusion. In a letter printed in 1912 he tells us that the arguments of his three books should leave us with 'a clear idea of a free and creating God, producing matter and life at once, whose creative effort is continued, in a vital direction, by the evolution of species and the construction of human personalities'. The letter is quoted by M. Le Roy at the close of his appreciative sketch, A New Philosophy; and M. Bergson expressly endorses M. Le Roy's protest, in the

1 'It seizes upon matter ... and strives to introduce into it the largest possible amount of indetermination and liberty.' (p. 265.) 'A living being represents a certain sum of contingency entering into the world.' (p. 276.)

'Hibbert Journal, October I9I, at the close of a sympathetic appreciation, entitled 'Creative Evolution and Philosophic Doubt'. 
context, against the habit of 'asking an author continually to do something other than he has done, or, in what he has done, to give us the whole of his thought'. He accepts M. Le Roy's description of his method of proceeding, in his successive volumes, from problem to problem, and dealing with each according to its specific and original nature, and acknowledges the possibility, consequently, of further developments of his doctrine upon the basis of an analysis of moral and religious experience. ${ }^{1}$

If we give the Philosophy of Change such a theistic background, it becomes perhaps a less striking doctrine, but it ceases to present the fundamental incredibility of which I complain. 'Reality is undoubtedly creative, i. e. productive of effects in which it transcends and expands its own being.' ${ }^{2}$ Taken in a phenomenological reference, there is no difficulty in recognizing the truth of such a statement. The 'creative' aspect of the evolutionary process in this respect, and the 'increment of being' which successive stages bring with them, was frequently emphasized in our

"In this direction I should myself say exactly what you have said' (letter to M. Le Roy, quoted in his Preface). M. Bergson, in the original letter in reply to his critics, had himself referred to the fact that he had not yet dealt with the problems of morality. It is, I think, permissible to mention that at a discussion in the Edinburgh University Philosophical Society in May 1914, during the delivery of his first course of Gifford Lectures, M. Bergson somewhat surprised the members of the Society by saying, when pressed on this ultimate question, that he did not profess to have a metaphysical system. Each of his volumes represented his concentration upon a specific problem, for which he had sought to find an appropriate solution by soaking his mind, as it were, in the relevant facts. In this way he had been led from one problem to another, while other important problems remained unexplored. But he was inclined to distinguish between philosophy as the outcome and solution of such definite problems and the more or less 'hypothetical' views one might hold on larger and more ultimate questions. The whole account of Life and its creative evolution, with " the ideal genesis of matter ', he appeared prepared, accordingly, to regard as the rationale of a phenomenal process, while accepting (as a hypothetical belief in the sense just indicated) the idea of a Creator, the end of whose action was 'the creation of creators'.

${ }^{2}$ Creative Evolution, pp. 49-50. 
first series of lectures, as well as the unforeseeableness of each new stage from the standpoint of the old. Such progress or advance appeared a fundamental and undeniable fact; and we found it intelligible on the assumption of an absolute source of the perfections successively revealed. 'The incredibility only arises, if we take 'reality' in an allinclusive sense to designate the All, and to include, therefore, the God of whose progressive activity the advancing wave of life is the expression.

I do not wish to snatch a verbal victory by playing on the word Universe or Infinite or the All-by arguing, I mean, that what is, by definition, all-inclusive and complete is not susceptible of growth, addition, or improvement. It is possible to deny the existence of a universe in the sense of a single systematic whole. Pluralism, for example, means, I suppose, that the universe is, in the last resort, an aggregate; although a certain amount of system or coherence may be traced among its separate facts, and this order may be extended by the mind and will of human and other intelligencies. But even if the universe be taken as a mere fact or sum of facts, it is there, once for all, in its nature as it is. The 'Being is' of Parmenides is, in this reference, the last word that can be said about it. It is impossible to get away from the existent fact and its nature. Whatever combinations may result within it, whatever qualities it may exhibit, must be due to its own inherent constitution. It is easy for a critic to appeal to material and social combinations or syntheses, where we get qualities in the compound or the social group which are not to be found in the elements or members separately. But the novelty in such cases is not, as it were, a creation or a spurt out of nothing; it is the result of the togetherness of existing elements and the mutual reactions grounded in their natures. So far as it goes, it is proof that the universe does not consist of bits of unrelated stuff lying about, but is a fact with a certain amount of 
systematic structure discernible among its parts. Qualities, therefore, which are educed by reaction to an environment, physical or social, cannot be regarded as extraneous to the universe as a whole. Moral progress might seem the most plausible case of such real novelty through the creation of fresh values. But, as we have seen, the verdict of the moral consciousness on its own advance emphatically repudiates the idea suggested that it is actually creating these values and raising the moral level of the universe. The reality of the ideal and its infinite transcendence of finite attainment is the very note of moral and religious experience.

I am confirmed in my view of the impossibility of regarding the universe as a growing whole, by observing that those who hold to the idea of what James calls " the strung-along unfinished world in time ', ${ }^{1}$ and who advocate the creed of 'Meliorism', do not make it clear, and apparently are not themselves clear, whether the idea of progress and betterment is to be applied to the universe as a whole or only to certain beings in it. M. Bergson's somewhat ambiguous attitude we have just considered. It is not clear whether he regards the creative source of the life-movement as also growing from less to more in the process of experience. William James falls back upon the notion of a finite God. He distinguishes sharply between God and the Absolute. God is not the All, but, as he puts it in a characteristic phrase, 'one of the eaches', an individual in the universe, 'finite, either in power or in knowledge, or in both at once', ' having an environment, being in time and working out a history just like ourselves'.2 But again it is not clear whether this God is morally perfect to begin with-in which case the development and progress would consist simply in the moral enlightenment and betterment of human beings and similar

${ }^{1} \mathrm{~A}$ Pluralistic Universe, p. 128. Cf. Pragmatism, p. 264: 'the whole spread-out and strung-along mass of phenomena'.

${ }^{2} A$ Pluralistic Universe, pp. $44,311,318$. 
races in other regions of the universe-or whether the finite God is himself conceived as growing in insight and in moral wisdom through the lessons of experience, and working out his own character as he proceeds with his beneficent work. In the latter case, one is at a loss to see why the title of God should be bestowed on an individual essentially of the human type, though, no doubt, on a larger scale and at a higher stage of development; and one is bound to conclude that such a developing demigod would give the same account of his own development as the moral and religious man among ourselves. He would describe it as a new insight into the nature of things, due to the leading of a higher God, who would be God indeed. It seems to me impossible to override the testimony of the religious consciousness on this point. As we have contended, such experience is only possible to a finite being rooted in an infinite nature. And from an ultimate metaphysical point of view, it appears to me, our conclusion must be that progress is predicable only of the part which can interact with other parts, and, in such interaction, has the nature of the whole to draw upon. It is unintelligible as applied to the whole, and the temporal view of things cannot therefore be ultimate or all-inclusive. ${ }^{1}$

'See Supplementary Note E (God and the Absolute), p. 430.

NOTE ON M. BERGSON'S DOCTRINE OF TIME

There are other points in which M. Bergson's account of time seems open to criticism. He has rightly exposed the errors which result from the persistence of spatial imagery in our conceptions of time. But in his polemic against the idea of the line, with its juxtaposition of our past states as mutually external points, he comes himself very near to denying any knowledge of the past as past. 'Pure duration', we are told, would be "nothing but a succession of qualitative changes which melt into and permeate one another, without precise outlines, without any tendency to externalize themselves in relation to one another, without any affiliation with number: it would be pure heterogeneity.' According to M. Bergson's 
most frequent comparison, the sensations 'add themselves dynamically to one another and organize themselves like the successive notes of a tune by which we allow ourselves to be lulled and soothed'.' The result is comparable to the summation of slight but continuously repeated stimuli, or, again, 'this organization of units in the depths of the soul is a wholly dynamic process, not unlike the purely qualitative way in which an anvil, if it could feel, would realize a series of blows from a hammer'.2 But this qualitative survival of the past in the present does not seem to give us more than a peculiarly modified present; or, at least, the penumbra of the past suggested by the analogies is so vague as hardly to suffice for the sharp rudimentary distinction between the ' now' and the 'no longer', much less for a dated knowledge of our mental history. M. Bergson's delicate psychological analysis of the phenomena he cites in illustration seems to divert his attention from the simpler experiences of loss or deprivation and of waiting expectancy, in which the child's consciousness of the no-more and the not-yet originates. Our dated knowledge of past and future is a gradual development of this rudimentary contrast. But because our perspective becomes more definite in both directions, it surely does not lose its original temporal character.

Nor can I reconcile myself to phrases which describe time as ' the very stuff of reality'. This phrase is constantly repeated in slightly varying forms by $M$. Bergson and his followers. Thus Mr. Wildon Carr tells us that " when we consider a living being, we feel that time is the very essence of its life, the whole meaning of its reality'. 3 Or again he speaks of 'a living thing, whose whole existence is time'. There are two ways, he says, in which we may think of time, "one in which it makes no difference to reality, and the other in which it is the reality. ... The answer that philosophy must give is that time is real, the stuff of which things are made.' * Except as transparent metaphors, intended to emphasize the reality of process or change as against the eternity of the metaphysicians he is attacking, such expressions seem quite unmeaning. Change or development in time may be a fundamental feature of reality, but it cannot literally be reality, life, or conscious-

'Time and Free Will, pp. 103-4.

- Henri Bergson, p. I7 (People's Books).

-Ibid., p. I9. M. Bergson uses almost identical language in Creative Evolution, pp. 4, 41, 254, 257, 334-5. 
ness. Obviously change and duration is an empty abstraction apart from some nature or content which changes or 'dures'. An ultra-Heraclitean doctrine of universal flux, such as the literal sense of the words implies, would mean the discarding of all qualitative distinctions whatsoever. Passages might be quoted in support of the view that this is the hidden truth of the Bergsonian thought. 'Reality is a flowing,' says Mr. Carr. 'This does not mean that everything moves, changes, and becomes; science and common experience tell us that. It means that movement, change, becoming, is everything that there is, there is nothing else. . . . You have not grasped the central idea of this philosophy, you have not perceived true duration, you have not got the true idea of change and becoming until you perceive duration, change, movement, becoming, to be reality, the whole and only reality.' 1

These sentences seem based on some very Heraclitean statements in the last chapter of Creative Evolution, where M. Bergson attributes the partial fixation of the universal flux, as things and qualities, to "the cinematographical instinct of our thought'. 'But in reality the body is changing form at every moment, or rather there is no form, since form is immobile and the reality is movement.' ${ }^{2}$ But I am loath to believe that it is $M$. Bergson's genuine intention to attribute all qualitative distinction to the distorting function of the intellect, and to identify reality with the qualityless abstraction of change or movement as such. An unearthly ballet of bloodless categories would be concrete in comparison.

'Henri Bergson, pp. 28-9.

${ }^{2}$ Creative Evolution, p. 319 (italics mine). Cf. pp. 333-5. 


\section{LECTURE XX}

\section{PLURALISM}

\section{EVIL AND SUFFERING}

WE have touched in the preceding lecture on the pluralistic position and the idea of a finite God, but Pluralism in various forms is so current-I had almost said, so fashionable-at the present moment, that it seems to call for some further examination on its merits. We have already encountered it, in connexion with the idea of Creation, in Professor Howison's doctrine of eternal finite selves. Founding on the characteristic feature of a self or person, that it cannot be made or fashioned like a thing, ab extra, but seems rather to make itself, and that it acts, moreover, always from its own centre, and unhesitatingly regards its acts as its own, Professor Howison insisted, as we saw, on treating finite persons as ontologically underived, or existent in their own right. He acknowledged at the same time that, as regards their animating ideals, they all reflect the nature of a divine or central Mind, and thus constitute, together with it, a single system of reality. As in Leibnitz, a real or ontological Pluralism is thus combined with an ideal 'harmony', and the unity of the universe is supposed to be thereby saved. But again, just as Leibnitz forgets the independent self-subsistence of the monads when he treats them as created by God and speaks of them as 'fulgurations' of the divine, so we found that Professor Howison's statements as to the constant reference of the finite selves to their divine centre, and his view of the divine nature as the final cause of the development which takes place in these selves, constitute a virtual abandonment of the ontological Pluralism which he champions. 
Dr. Rashdall, inasmuch as he expressly holds the finite selves to be created, would disavow the imputation of Pluralism. But he has repeatedly introduced the idea of the finiteness of God as limited by other selves, and has contended, accordingly, for a distinction between God and the Absolute. 'The Absolute cannot be identified with God, so long as God is thought of as a self-conscious Being. The Absolute must include God and all other consciousnesses, not as isolated and unrelated beings, but as intimately related (in whatever way) to Him and to one another, and as forming with Him a system or Unity. ... God and the spirits are the Absolute-not God alone. Together they form a Unity, but that Unity is not the unity of self-consciousness.' 1 Reality is thus 'a community of persons', or in Dr. McTaggart's phrase 'a society'. ${ }^{2}$ It is true, he protests against the idea of a limitation ab extra, by a hostile power or an independent matter; the limitation in question is, in the language of the theologians, a self-limitation. But, as Professor Ward pertinently says, commenting on this phrase, 'self-limitation seems to imply a prior state in which it was absent, whereas a limitation held to be permanent-as we hold creation to be-suggests some ultimate dualism rather than an ultimate unity'. ${ }^{3}$ And if we hold, as Professor Ward says, that ' God is God only as being creative ', '

${ }^{1}$ The Theory of Good and Evil, ii. 239-40.

${ }^{2}$ Personal Idealism, pp. $39 \mathrm{I}-2$.

- Realm of Ends, p. 243.

'Ibid., p. 234. 'If creation means anything,' says Professor Ward in the same context, 'it means something so far involved in the divine essence that we are entitled to say, as Hegel was fond of saying, that "without the world, God is not God". The saying which Professor Ward thus frankly adopts, suggests to Dr. Rashdall the picture of 'God as perpetually annexed by some unintelligible fate to a world quite alien to His own inner nature as to some Siamese twin from whom He would perchance, but cannot, part' (Contentio Veritatis, p. 33). But this is inconsistent with his own subsequent description of the limitation implied in the creation of other spirits as "not an arbitrary self-limitation but one which necessarily springs from the nature and character of God' (p. 37). Why should the necessity of the divine nature be resented 
the deceptive prius disappears, and with it the wholly inappropriate conception of limitation. This was the gist of our argument in Lecture VII. Why should the creation of finite spirits be treated like a pegging out of claims in a hinterland, by each of which the rights and privileges of the original proprietor are proportionately diminished? Surely the older theologians were right in regarding the existence of spirits not as an impoverishment but as an enrichment of the divine life. The divine life is, in short, the concrete fact of this inter-communion.

In this sense there is no difficulty in accepting Professor Ward's definition of the Absolute as 'God-and-the-world ', regarcied as the single eternal Fact. But it is not quite the same with Dr. Rashdall's phrase, 'God and the spirits'; for in spite of the creative function assigned to God, the suggestion of the phrase is co-existence on terms of mutual exclusion. And this impression is strengthened when we are told that 'the ultimate Being is a single Power, if we like we may even say a single Being, who is manifested in a plurality of consciousnesses, one consciousness which is omniscient and eternal, and many consciousnesses which are of limited knowledge, which have a beginning, and some of which, it is possible or probable, have an end '.' And when Dr. Rashdall goes on to say that we may "regard all the separate "centres of consciousness" as "manifestations" of a single Being', or even as a single 'Substance which reveals itself in many different consciousnesses ${ }^{3}{ }^{3}$ we

as an unintelligible fate? Dr. Rashdall emphasizes the importance of recognizing ' a causative relation between the supreme Spirit and the other spirits' (p. 34), but if I may quote Professor Ward again in this connexion, "Creation is not to be brought under the category of transient causation. Nor can we, regarding it from the side of God, bring it under the category of immanent causation as being a change in Him, unless indeed we abandon the position that God is God only as being creative' (Realm of Ends, p. 234).

'Realm of Ends, p. 241. "2Theory of Good and Evil, vol. ii, p. $24 \mathrm{I}$.

"Philosophy and Religion, p. 105. 
feel irresistibly that by such expressions we are being committed to a view of God as 'one of the eaches', for we are treating Him not as the ultimate Reality but as one of a number of 'separate' appearances. But there is surely a singular impropriety in placing God and men in the same numerical series, and in speaking as if we and God together, in a species of joint-ownership, constituted the sum-total of existence. Dr. Rashdall speaks of 'that all-fertile source of philosophical error, the misapplication of spatial metaphors. Minds are not Chinese boxes that can be put " inside " one another'.' But we do not get away from spatial metaphors by speaking of separate and mutually exclusive centres of consciousness. And if the assertion of the personality of God is to lead us to the result that 'all the conclusions which are applicable to each particular self in his relation to another seem to be equally applicable to the relations between God and any other spirit ',2 we must reply that it is ultimately unmeaning to treat the universal as one of the particulars. To speak of God in this sense as 'one of the selves' is to justify all the criticisms which treat personality as a limitation inapplicable to the sustaining and containing Life of all the worlds. Besides the unescapable associations of spatial metaphor, the controversy seems to me to be due to the substantiation of the form of consciousness apart from its content or constituent nature. It was the substantiation of the logical form of consciousness, as I argued long ago, ${ }^{3}$ which led to the theory of the universal

${ }^{1}$ Personal Idealism, p. 388.

2Ibid., p. 386.

'In the concluding pages of Hegelianism and Personality. I have many times regretted, in view of the interpretations put upon it and the applications made of it, my use in these pages of the term 'impervious' to describe the nature of a self or personality. The exclusiveness of the self, especially in its relations to the divine, was, I have little doubt, too strongly emphasized in my argument. But the obnoxious term has to be understood in the context in which it occurs. The argument was directed against the fusion of real selves in a logical universal or (to put it in a frankly spatial metaphor) the identification of all selves at a single point of being. What I emphasized, as against this attempt, was 
Self, as an identical Subject which thinks in all thinkers. And this unification of consciousness in a single Self was fatal, I argued, to the real selfhood either of God or man. But we are equally substantiating a formal unity, if we cut loose the individual selves from the common content of the world and treat them as self-existent and mutually independent units. We are then obliged to proceed to represent the universal Life in which they share as another unit of the same type, and difficulties immediately arise as to the relation between the great Self and its minor prototypes. Thought sways between a Pluralism, disguised or undiguised, and a Pantheism which obliterates all real individuality. But by the existence of the personality of God we do not mean the existence of a self-consciousness so conceived. We mean that the universe is to be thought of, in the last resort, as an Experience and not as an abstract content-an experience not limited to the intermittent and fragmentary glimpses of this and the other finite consciousness, but resuming the whole life of the world in a fashion which is necessarily incomprehensible save by the Absolute itself. ${ }^{1}$

the uniqueness of each self. I took the self, and I still take it, as the apex of the principle of individuation by which the world exists. Hence the phrase that each self is 'impervious' - not, it may be observed, to all the influences of the universe but 'to other selves'- impervious in a fashion of which the impenetrability of matter is a faint analogue'. In other words, to suppose a coincidence or literal identification of several selves, as the doctrine of the Universal Self demands, is even more transparently self-contradictory than that two bodies should occupy the same space. Apart from crudity of expression this still seems to me obvious, and it may be considered to underlie the argument in several of the preceding lectures. But I trust there is now more justice done to the identity of content which binds the selves together as members of one universe.

' IVe call God personal because in personality is revealed the highest we know, and it is better, therefore, as Mr. Bradley says, to affirm personality than to call the Absolute impersonal. The epithet, like the statements of the creeds, is the denial of an error rather than a definitely articulated affirmation of ascertained fact. And if the affirmation of personality were taken to imply identity of conditions, then, but for its tendency to become a merely empty name, supra-personal would obviously more appropriately express our meaning. 
Equally incomprehensible from the finite standpoint must it be, how the measure of individual independence and initiative which we enjoy is compatible with the creative function or the all-pervasive activity of the divine. ${ }^{1}$ But in whatever sense or in whatever way our thoughts and actions form part of the divine experience, we know that it is a sense which does not prevent them from being ours. We were agreed that no speculative difficulties could override this primary certainty.

Dr. McTaggart presents his theory as a form of Idealism, and he also would repudiate the label of Pluralism, inasmuch as he believes the universe to be a systematic whole. But as compared with the views of Professor Howison and Dr. Rashdall which we have been considering, Dr. McTaggart's theory is more consistently and uncompromisingly pluralistic, in so far as it dispenses altogether with the centrality of reference which is signified by the conception of God. The unity of his Absolute is that of a society. His favourite analogy is ' a College ', 2 although he has the grace to admit that 'of course the Absolute is a far more perfect unity than a College'. As a unity of persons, though not itself a person, a College is 'a spiritual unity'; but, as he candidly and somewhat disconcertingly reminds us, 'every goose-club, every gang of thieves' has a similar right to the term. ${ }^{3}$ Dr. McTaggart's theory of the Absolute is in reality an immediate consequence of his view of the self as 'a substance existing in its own right'. 'This does not mean', he says, "that any self could exist independently and in isolation from all others. Each self can only exist in virtue of its connexion with all the others and with the Absolute which is their unity. But this is a relation, not of

${ }^{1}$ As I have already argued in Lecture XV. Cf. supra, pp. 285-93.

${ }^{2}$ As Mr. Marett wittily put it, "It is Trinity basking in a perpetual Long Vacation'.

${ }^{3}$ Studies in Hegelian Cosmology, p. 86.

'Ibid., p. 37. 
subordination, but of reciprocal dependence.' The Absolute is exhaustively expressed in a certain number of such ' fundamental differentiations', and is thus 'a system of individuals of which each is conscious of the other'; and such a system, he contends, cannot be accused of 'atomism', for it is 'bound together by the mutual knowledge of its parts'. 1

The Idealism which Dr. McTaggart professes is defined by himself, almost in Berkeley's words, as the doctrine 'that nothing can exist but persons-conscious beings who know, will, and feel'.2 The position is open, therefore, to the general objections which have been brought against Monadism and Mentalism. But special difficulties are created for Dr. McTaggart's variety of the theory by the absence of any central Monad or Monas Monadum; for there appears to be no self in this 'harmonious system of selves' ${ }^{3}$ which knows all the other selves. How then do we know that they form a harmonious system? Can we, indeed, reasonably speak of system or harmony at all except in view of some mind for which it exists? And again, the ordinary way in which subjective idealism meets the scientific difficulties as to the existence of things unperceived or completely unknown by any finite spirit-namely, by attributing to them an existence for an eternal and omniscient Spirit-is not open to Dr. McTaggart, whose universe accordingly dissolves into a number of fragmentary subjective worlds with no provision for their co-ordination and no guarantee that, if pieced together, the result would be a coherent whole. ${ }^{4}$ Dr. McTaggart admits that, if his theory is to work, 'it would seem to follow that every self must be in complete and conscious harmony with the whole

${ }^{2}$ Studies in Hegelian Cosmology, p. 62.

2 Some Dogmas of Religion, p. 251.

I Ibid., p. 248.

- Dr. Rashdall has urged these difficulties. Cf. Philosophy and Religion, pp. 123-6, and Mind, N. S., vol. xv, pp. 542-6. 
of the universe ', 1 and he admits likewise that this is not in accordance with the facts as known to us. But he is equal to the emergency, for the difficulty disappears if we assume that all selves are perfect; and that, he says, would seem to be 'our proper conclusion'.' 'If an opponent should remind me of the notorious imperfections in the present lives of each of us, I should point out that every self is . . . in reality eternal, and that its true qualities are only seen in so far as it is considered as eternal. Sub specie aeternitatis, every self is perfect. Sub specie temporis, it is progressing towards a perfection as yet unattained.' ${ }^{3}$ This conclusion was no doubt inevitable, seeing that each self was already defined as an Absolute. ${ }^{4}$ But such a heroic multiplication of deities appeals to me rather as a reductio ad $a b$ surdum of Dr. McTaggart's doctrine of eternal substances than as calling for further discussion. I doubt if individualism has ever been carried further than in this proposal to have as many universals as there are particulars.

But Pluralism is chiefly associated, in recent discussion, with the name of William James. He has made himself the spokesman of the tendency in a special volume of lectures; but all through his work we trace the same reaction against 'monism ' or ' rationalism ' and its 'block-universe'. And with James, as we have already partly seen, the Pluralism is uncompromising; it means a 'finite God' and an 'unfinished world'. He agrees, accordingly, with the writers we have just considered in distinguishing sharply between God and the Absolute, and he invokes the ordinary religious consciousness in support of his position. " "God" in the religious life of ordinary men is the name not of the

${ }^{1}$ Hegelian Cosmology, p. 34.

${ }^{2}$ Ibid., p. 35 .

'Mind, N. S., vol. xi, p. 388 (in a review of Professor Howison's Limits of Evolution).

'Descartes had already indicated the conclusion: "If I were myself the author of my being, anything else would have been easy in comparison; I should have bestowed on myself every perfection of which I possess the idea, and I should thus be God' (Meditations, iii). 
whole of things, heaven forbid, but only of the ideal tendency in things, believed in as a superhuman person who calls us to co-operate in his purposes, and who furthers ours if they are worthy. He works in an external environment, has limits and has enemies.' 1 And again, 'Monotheism itself, so far as it was religious and not a scheme of class-room instruction for the metaphysician, has always viewed God as but one helper, primus inter pares, in the midst of all the shapers of the great world's fate'.'

James's view is thus the expression of his intense conviction of the reality of the moral struggle, taken together with the conception he has formed of the Absolute as making that struggle unmeaning, and as being in fact 'the great de-realiser of the only life we are at home in'. Hence he transfers the moralistic attitude to the universe as a whole; the course of the world appeals to him as a struggle in which the forces of reason and goodness are at grips with Chaos and old Night. One need only recall the well-known close of the essay 'Is Life worth Living?' : 'If this life be not a real fight in which something is eternally gained for the universe by success, it is no better than a game of private theatricals from which one may withdraw at will. But it feels like a real fight-as if there were something really wild in the universe which we, with all our idealities and faithfulnesses, are indeed to redeem. . . . God himself, in short, may draw vital strength and increase of very being from our fidelity. For my own part, I do not know what the sweat and tragedy of this life mean, if they mean anything short of this.' 4 Hence he offers us as a philosophical and religious creed the doctrine of 'meliorism' or 'melioristic theism', as a mean 'between the two extremes of crude Naturalism on the one hand and transcendental Absolutism on the other'; between pessimism and an op-
${ }^{1} A$ Pluralistic Universe, p. I24.
'A Pluralistic Universe, p. 49.
2 Pragmatism, p. 298.
- The Will to Believe, p. 61. 
timism 'too saccharine', 'too idyllic' for his taste. The world we know is a 'moralistic and epic kind of universe', the hall-mark of which is progress through effort. $\mathrm{Ab}$ solutism alone, he admits, can give a sense of security, an assurance, that is to say, of the eventual, or rather of the eternal, triumph of good. But James finds himself "willing to take the universe to be really dangerous and adventurous ', ' a universe with only a fighting chance of safety'. 'The ordinary moralistic state of mind makes the salvation of the world conditional upon the success with which each unit does its part.' 2

There is no denying the stirring quality of Professor James's philosophy and the appeal it makes to our active nature. But can we hope to find in the characteristics of our own practical activity a description in ultimate terms of the fundamental nature of the universe? James began by appealing to religious usage in support of his view of a struggling deity and a progressing world. But 'moralistic', as we find, is the epithet which he tends on the whole to associate with his doctrine of Meliorism; and he admits that 'many persons would refuse to call the pluralistic scheme religious at all', reserving that word for the monistic scheme alone." He speaks himself in this sense of 'religious optimism', and of taking sides for his own part with the 'more moralistic view', and again he describes his position as 'moralistic religion'.4 Now it has been rightly said that a philosophy may be ultimately tested by its ability 'to reconcile the attitudes and postulates of morality and religion'; but it is almost a philosophical commonplace that the attitudes and postulates in the two cases are not the same. However it may be with popular religion, the deeper expressions of religious faith

'Pragmatism, chap. viii.

${ }^{2}$ Varieties of Religious Experience, p. 526.

'Pragmatism, p. 293.

•Ibid., pp. 295-6, 301. 
and emotion-the utterances of the saints, the religious experts-appear quite irreconcilable with the pluralistic conception of a finite God, an unfinished world and a dubious fight. In fact, it is not too much to say, with Mr. Bradley, that 'to make the moral point of view absolute' is to have 'broken with every considerable religion'.' The victory for which morality fights is for religion already, or rather eternally, won; and it is the assurance of this victory which inspires the finite subject with courage and confidence in his individual struggle. For it is a significant fact that the apparent contradiction between the two standpoints, on which James enlarges in his attacks on monism, is a product of philosophical reflection, and does not exist for the religious man himself. On the contrary, as experience abundantly shows, the assurance of victory won and reconciliation achieved is the most powerful dynamic that can be supplied to morality.

It may be, as James of ten suggests, that there are other than merely logical considerations involved in the decision between monism and pluralism. In an intellectual aspect, it is the alternative between the idea of a system and the idea of an aggregate, and I confess that I find it impossible to reduce the universe to a mere 'and'. Moreover, if it were possible to think of the universe as a collocation of independent facts existing each in its own right, a sheer materialism would seem the most natural form for such a view to take. To conceive a Being of transcendent intelligence and goodness as no more than one of the facts in the universe, seems to make it harder than ever to think of other facts as just happening to be there along with him - just happening to exist also, and getting in his way actively or passively. Admit intelligence or an ideal factor at all, and it seems impossible to conceive it otherwise than as central and all-explaining. It appears to me trifling with

${ }^{2}$ Appearance and Reality, p. 500. 
one's intellect to make a fancy-picture of the universe as a casual collection of independent items. That anything should exist at all, it has been said, is an unfathomable mystery. Perhaps on that account it seems impossible to think of what exists otherwise than as a single whole, referable in all its parts to a single principle. And as Beauty has been called its own excuse for being, so intelligence or Mind, of which beauty is one expression, may be said in a larger sense to furnish its own raison d'ctre.

Moreover, a Pluralism like James's, put forward avowedly as an assertion of the reality of finite experience, may be shown to be in great part due to the pre-conceived idea of the Absolute from which it is the reaction. There is no doubt much excuse for that idea in the statements of idealists, but it is nevertheless erroneous. The Absolute is conceived by James from beginning to end of his polemic as purely cognitive, not the doer and sufferer in the world's life, but an eternally perfect spectator of the play. Finite beings are always represented, therefore, as the objects of the Absolute. 'To $b e$, on this scheme', he says, 'is, on the part of a finite thing, to be an object for the Absolute, and on the part of the Absolute it is to be the thinker of that assemblage of objects.' The All-knower is one of his most frequent terms for the Absolute. The absolute mind ' makes the partial facts by thinking them, just as we make objects in a dream by dreaming them, or personages in a story by imagining them '.' All through the volume, $A$ Pluralistic Universe, we have this analogy of the dream or the story repeated. We hear of 'the cosmic novel', 'the tale which the absolute reader finds so perfect', 'the spectacle or world-romance offered to itself by the absolute', 'the sort of world which the absolute was pleased to offer to itself as a spectacle '. ${ }^{2}$ And there is a significant passage in which, with the truer view in sight, he deliberately rejects

${ }^{2} A$ Pluralistic Universe, p. 36.

${ }^{2}$ Ibid., pp. 48, 49, I18, 126. 
it, and reaffirms his own pre-conceived idea of what the Absolute must be. A critic is supposed to suggest that we, as finite minds, are 'constituents' of the Absolute, that it lives in our life and cannot live without us; but James retorts that this is 'employing pluralistic weapons and thereby giving up the absolutist case'. 'The Absolute as such', he reiterates, 'has objects, not constituents.' ${ }^{1}$ That being so, we have the familiar contrast between 'the static timeless perfect Absolute' and the moving world of real events, or between 'the stagnant felicity' of the absolute novel-reader and the stress and strain (not to mention worse things) endured by those who are personages in the plot. Or, stretching the metaphor a little, he asks why, if the spectacle offered to itself by the Absolute is in the Absolute's eyes perfect, should the affair not remain on just those terms, without having any finite spectators to come in and add to what is perfect already their innumerable imperfect manners of seeing the same spectacle. Why, in short, 'should the Absolute ever have lapsed from the perfection of its own integral experience of things and refracted itself into all our finite experiences? ' 2

The metaphor, as I say, is halting, but the question repeats the old difficulty which we discussed in connexion with the idea of creation-the question why there is a finite world at all, why God or the Idea ever issued from its antemundane self-sufficiency. And we set the question aside as based on an unjustifiable substantiation of God apart from the world of his manifestation-a substantiation for which, in the nature of the case, no evidence can be forthcoming. James's Absolute is just such a self-contained Person who, apparently out of his mere good pleasure, gives himself the spectacle of the cosmic drama-as it were pour se distraire ou pour passer le temps. It is regarded at any rate as enhancing his felicity. Now I am

'A Pluralistic Universe, p. I23.

2Ibid., pp. I18-20. 
far from denying that chapter and verse might be quoted from absolutist as well as theistic writers in support of this inhuman conception: one need not go further, indeed, than Mr. Bradley's speculation about the Absolute enjoying the balance of pleasure distilled, as it were, from the delights and agonies of finite agents, to find some justification for James's way of putting things. And we saw Mr. Bradley also at a loss to know 'why the Absolute divides itself into finite centres', seeing that in its 'single and allabsorbing experience' they entirely cease to exist as such. This, as I have pointed out, is only one of two currents of thought in Mr. Bradley's philosophical work; but it was the aloofness-the in-itselfness, as we might call it-of his Absolute, which made the stronger impression on contemporary thought. And just this feature is shared by the Absolute with the ordinary theological idea of God-the idea of a God without a universe, a pre-existent, self-centred, and absolutely self-sufficient Being, eternally realizing a bliss ineffable in the contemplation of his own perfection. No wonder that there seems no passage from such a Being to the imperfect world of our experience. But the analysis we undertook, in two previous lectures, of the ideas of creation and purpose applied to the universe as a whole led us definitely to abandon this conception of the divine; and I suggested that many of our difficulties are created for us by the abstract idea of perfection with which we start. To reach any credible theory of the relation of God and man we must, in fact, profoundly transform the traditional idea of God.

Orthodox theism is defined by Professor Flint ${ }^{1}$ as 'the doctrine that the universe owes its existence and its continuance in existence to the reason and will of a self-existent Being, who is infinitely powerful, wise and good'. But

${ }^{2}$ Theism, p. 18 (eighth edition). 
this world of ours, so scarred by suffering, so defaced by wickedness, so entangled, as it often seems, in the meshes of a non-rational contingency-how dare we trace such a world to the reason and will of a perfect Being as its sole explaining cause? Here Pluralism, in one or other of its many forms, is so obviously, on the surface, what James calls it, the line of least resistance, that one can hardly wonder at the welcome it receives. God is truly good, said Plato, and cannot be the cause of any evil. But what then of these sinister and disconcerting features? Here are the ultimate difficulties of a theistic monism. When the problem is forced upon us, Plato goes on to say, we must find out a theory to save the situation. In the case of suffering, for example, we must say that what God did was righteous and good, and that the sufferers were chastened for their profit. ${ }^{1}$ From the days of Job and his comforters, the devising of such theodicies-theories to save the situation-has been the main business of theology and theological metaphysics. Plato himself, as we incidentally saw, ${ }^{2}$ has his own way of escape from the difficulty; and it consists essentially in saving goodness at the expense of omnipotence. 'We must be prepared to deny that God is the cause of all things', he tells us in the same context; "what is good we must ascribe to no other than God, but we must seek elsewhere, and not in him, the causes of what is evil.' Put in metaphysical terms, this means that our explanation of the course of the world must take account, not only of a divine intelligence and goodness, but also of the clogging and thwarting agency of the material in which the divine Idea seeks embodiment. But this is to ascribe to matter an independent and coeternal reality, and thus to set a principle of unreason alongside of or over-against the purposive action of reason represented by the Idea of the Good. Greek thought, on the whole, represents the divine action in this way, as that of
1 Republic, 379,380.
2 Cf. supra, pp. 305-6. 
an artificer limited by the qualities of his material, and consequently surrenders the idea of the universe as a perfect and coherent whole-the active manifestation of a single principle. This way of escape is not open to ordinary theism, which represents God as creator in the fullest sense; and it is of course repudiated by Absolutism, which is precisely the assertion of a perfect and coherent whole. But the empirical facts are so hard to reconcile with such a thesis, that, in one direction or another, the need is felt to qualify the idea of absolute or abstract omnipotence by the recognition of limiting conditions.

If we turn once more to Hume, with whom these lectures began, we find the dualistic or Manichaean hypothesis of two warring principles of good and evil, which is readily suggested by the phenomena of the moral world, conclusively dismissed as inconsistent with 'the uniformity and steadiness of general laws'. But Hume makes Cleanthes grasp at the idea of a finite deity as a way out of the difficulties. "Supposing the Author of Nature to be finitely perfect, though far exceeding mankind, a satisfactory account may then be given of natural and moral evil, and every untoward phenomenon be explained and adjusted. A less evil may then be chosen, in order to avoid a greater; inconveniences be submitted to, in order to reach a desirable end; and, in a word, benevolence, regulated by wisdom and limited by necessity, may produce just such a world as the present.' ${ }^{1}$ But although Philo is invited, with something like real eagerness, to give his opinion of 'this new theory', the suggestion is not developed in the sequel of the Dialogues, and perhaps Hume means us to understand that he regards it also as inconsistent with the powerful impression of unity which the universe produces. It is, however, as is well known, the position adopted by J. S. Mill in his posthumous Essays on Religion. Omnipotence is dis-

${ }^{2}$ Dialogues, Part XI. 
missed by Mill on account of the impossibility of ' reconciling infinite benevolence and justice with infinite power in the Creator of such a world as this'. The limitation of power he considers to be most probably due to the qualities of the material with which he had to deal; for 'there is in nature no reason whatever to suppose that either matter or force or any of their properties were made by the Being who was the author of the collocations by which the world is adapted to what we consider its purposes; or that he has power to alter any of those properties'. 'If [then] we suppose limitation of power, there is nothing to contradict the supposition of perfect knowledge and absolute wisdom. . . . But nothing obliges us to suppose that either the knowledge or the skill is infinite'. Similarly of the moral attributes: ' Grant that creative power was limited by conditions, the nature and extent of which are wholly unknown to us, and the goodness and justice of the Creator may be all that the most pious believe.' But if we look simply at the general indications of the evidence available, we find that the greater part of the adaptation in nature is not directed to a moral end at all, but simply to keep the living machine going. Still, a certain balance of evidence remains in favour of a 'benevolent purpose'; 'it does appear that, granting the existence of design, there is a preponderance of evidence that the Creator desired the pleasure of his creatures'. ' But to jump from this to the inference that his sole or chief purposes are those of benevolence, and that the single end and aim of creation was the happiness of his creatures, is not only not justified by any evidence, but is a conclusion in opposition to such evidence as we have. If the motive of the Deity for creating sentient beings was the happiness of the beings he created, his purpose, in our corner of the universe at least, must be pronounced, taking past ages and all countries and races into account, to have been thus far an ignominious failure; and if God had no purpose but our 
happiness and that of other living creatures, it is not credible that he would have called them into existence with the prospect of being so completely baffled.'

The two points that stand out in these arguments-and the arguments may be taken as typical-are, in the first place, the stress laid on the idea of omnipotence, and secondly, the purely hedonistic character of the ideal contemplated. The conception of omnipotence has been much abused by controversialists. Mere power is, in any case, the earliest and crudest predicate of the divine; God is conceived as the All-powerful long before he is thought of as the All-good. The ethical attributes of justice and lenevolence are not, in fact, transferred to the deity till man himself has grasped the moral concepts in their purity, and risen to the idea of a cosmic law of right and wrong and a will untouched by envy or malevolence. Moreover, by primitive thought power is inevitably conceived in terms of physical force; and so the power of the god is simply the irresistible force with which he crushes opposition and condignly punishes the disobedient. ${ }^{1}$ His will, in the absence of any ethical content, is the abstraction of empty or arbitrary will, as such. It is the will of a despot. And we must remember how closely the associations of oriental monarchy have wound themselves round the God-idea. The popular use of 'the Almighty', as an appellation of the Divine Being, may be said, with some truth, to perpetuate the pretensions of these potentates and the flatteries of their helpless subjects. In itself, the predicate completely lacks the element of value, for it simply means able to do anything. The philosophical and theological discussion about omnipotence has its origin

\footnotetext{
${ }^{1}$ Even after the deity has come to be conceived as the executor of the moral law, the same idea of the divine power is found persisting, e.g. in Locke's account of 'the true ground of morality' as being 'the will and law of a God who sees men in the dark, has in his hands rewards and punishments, and power enough to call to account the proudest offender' (Essay, I. 3. 6).
} 
in the same circle of ideas; and just as Canute's flatterers sought to persuade him that he could command the oncoming waves, so some writers, with more zeal than knowledge, have thought to exalt the divine prerogative by representing both truth and morality as dependent, in their structure, on the arbitrary fiat of God, and by asserting his power to compass intellectual and moral contradictions. And, even in our own day, Dr. McTaggart has thought it worth his while to devote some twenty pages to the barren argument that God is not omnipotent, because $\mathrm{He}$ cannot override the laws of Identity, Contradiction, and Excluded Middle, and similar necessities of thought or action." But to affirm omnipotence in such a sense is unmeaning, and therefore to deny it is unnecessary. Omnipotence can only mean-as I find it expressed in a recent Catholic manual-the power 'to effect whatever is not intrinsically impossible'. The intrinsic necessities which govern the possibilities are not, because they are called intrinsic, to be regarded as a metaphysical fate behind God, or an impersonal system of 'eternal truths' to which $\mathrm{He}$ is forced to submit. The foundations of the intelligible universe are the necessities of the divine nature itself ; and to separate God's Being, as Power or Will, from his Nature is the ultimate form of that apotheosis of the empty Ego which we have already repeatedly condemned. - This has long been recognized by responsible thinkers, theologians as well as philosophers, in regard to the fundamental conditions of intellectual coherence; but there is not always the same clearness as regards the conditions of moral experience, although these are as inexorable as any law of thought and no less founded in the nature of things.

The failure to realize the fundamental presuppositions of the moral life is strikingly exemplified in the sequel of Mill's argument. For he goes on to comment on the fact that

${ }^{1}$ Some Dogmas of Religion, p. 202 et seq. 
man, 'by the exercise of his own energies for the improvement both of himself and of his outward circumstances', has 'the power to do for himself and other creatures vastly more than God had in the first instance done'. And his comment is that it is ' a very strange supposition to make concerning the Deity . . . to suppose that he could not in the first instance create anything better than a Bosjesman or an Andaman islander, or something still lower, and yet was able to endow the Bosjesman or the Andaman islander with the power of raising himself into a Newton or a Fénelon'. 'We certainly do not know the nature of the barriers which limit the divine omnipotence', he concludes, 'but it is a very odd notion of them that they enable the Deity to confer on an almost bestial creature the power of producing by a succession of efforts what God himself had no other means of creating.' An honest controversialist will admit the dark features of the long-drawn-out process-its severity and apparent wastefulness-features which sometimes appear to us intolerable; but as regards the general principle, how (we may reply to Mill) can we conceive a moral being to be created at all except by allowing him to make himself in the stress of circumstance and temptation? And the same thing holds of the intellectual process : how but by ceaseless effort and the conquest of difficulties can the thews of the mind be developed and strengthened? Mill's notion of outright creation-everything done by God 'in the first instance '- might give us a world of automata receiving their daily doles of pleasure, but it could give us neither the minds nor the characters we know.

The thought underlying such passages recalls us, therefore, to the second feature which we noted as common to the arguments of Hume and Mill, the curious inability of both to see beyond a purely hedonistic ideal. It is striking, when one returns upon Hume's discussion of theism, to find how completely the argument moves upon hedonistic ground- 
the 'misery' of man as inconsistent with the 'benevolence' of God. 'Why is there any misery at all in the world?' Hume asks; why did God not 'render the whole world happy', seeing that he is supposed to have the power to do so? Or again: "The course of nature tends not to human or animal felicity, therefore it is not established for that purpose. ... In what respect, then, do [God's] benevolence and mercy resemble the benevolence and mercy of men?' 1 This is put forward as clinching the argument. The felicity of his creatures being apparently the only conceivable object of a benevolent creator, the existence of suffering makes it impossible to believe in the benevolence. And this is almost more strongly marked in the parallel discussion by Mill. Evidence for 'a benevolent purpose' is, for Mill also, 'evidence that the Creator desired the pleasure of his creatures'. But, as we have just seen, effort, difficulty, hardship, pain, seem to be involved in any kind of moral world which we can really conceive, or in any world which is really worth having; and the end of such a world would seem to be, by the operation of such factors, 'the making of souls,' something very different from 'the human and animal felicity' which Hume's 'bon Dieu' is supposed to aim at. Terms like pleasure, felicity, even happiness, keep us at the level of individual and quasi-passive enjoyment. To be true to the highest and deepest experiences of life, we must substitute some larger term like satisfaction-for satisfaction, of course, there must be, even in the completest sacrifice of self. But though we may possibly feel it not inappropriate to speak of such satisfaction as happiness, we should not dream of calling it pleasure. Need I do more than recall the well-known passage at the close of Romola? -We can only have the highest happiness, such as goes along with being a great man, by having wide thoughts and much feeling for the rest of the world as well as for ourselves;

${ }^{2}$ Dialogues, Parts $\mathrm{X}$ and XI. 
and this sort of happiness often brings so much pain with it, that we can only tell it from pain by its being what we should choose before anything else, because our souls see it is good.' The universe is not perfect in the sense that it contains nothing but undiluted enjoyment. We degrade it to a child's paradise in so conceiving it. It is not perfect in the sense that there is no evil in it; for it is equally childish to imagine that good can exist for a finite creature except as the conquest of evil. ${ }^{1}$ Self-contradictory and thoughtless ideals blind us to the nature of reality. We have spoken much in the earlier lectures of the reality of ideals, as the presence of the infinite in our finite lives, carrying us beyond the 'is' of actual achievement. But the ideals that are true and fruitful are struck out, or become obvious, in the stress of actual experience, and are only the fundamental structure of reality coming to fuller expression.

What, then, is the conception of God to which our argument finally points? More than once the conclusion has been forced upon us that, if we are to reach any credible theory of the relations of God and man, the traditional idea of God must be profoundly transformed. The direction which that transformation should take must now be fairly obvious. The traditional idea, to a large extent an inheritance of philosophy from theology, may be not unfairly described as a fusion of the primitive monarchical ideal with Aristotle's conception of the Eternal Thinker. The two conceptions thus fused are, of course, very different; for power, which is the main constituent of the former, has, in the ordinary sense, no place at all in Aristotle's speculative ideal. But there is common to both the idea of a self-cen-

1 It seems strange to find Dr. Rashdall saying in a recent essay on 'The Problem of Evil': 'We see how individual character is tried and strengthened by the struggle with temptation and difficulty. with evil within and evil without. But why there should be this conditioning of good by evil we cannot say' (The Faith and the War, p. 99). The italics are mine. 
tred life and a consequent aloofness from the world. Primitive man was inured to an arbitrary despotism which uses power for selfish aggrandizement and luxury, and sees in the subject populations only the instruments of its own pomp and glory; and the attitude of the Oriental ruler to his people is half-unconsciously transferred by the worshipper to his god. And although the relationship became purged in time of its baser features, and might be characterized, as in the case of Israel and Jahve, by a singular intimacy and depth of feeling, still the conception of God remains that of a purely transcendent Being, whose own life is not involved in the fortunes of mankind. 'God is good to Israel,' and his 'graciousness' is often recorded; but his graciousness still resembles the condescension of a prince from his own princely sphere, an act of kindness which costs him nothing. And the purely intellectual character of Aristotle's ideal gives it the same aloofness we have noted from the world's life. It is the ideal of the scholar and thinker who retires into his own thoughts, and finds there his highest happiness. The life of God, Aristotle says, "is like the highest kind of activity with us, but while we can maintain it but a short time, with him it is eternal '; and as all unimpeded function is accompanied by pleasure, so, in this unbroken activity of contemplative thought, God realizes a supreme and eternal blessedness. Standing outside of the process, Aristotle's God is the world's ideal; he is said to move the world, as the object of the world's desire. But how much is left out of such a conception! The world strains after God in love and longing, but there is no word of that prior love of God to the world which is the condition of finite love and aspiration. 'We love him because he first loved us.' In his account of the relation of the world to God, it has been said : 'Aristotle seems always to move upward and not downwards. He seems always to be showing that the finite world cannot be conceived to be complete and independent, and that 
its existence therefore must be referred back to God; but not that in the nature of God, as he describes it, there is any necessity or reason for the existence of the world.' ${ }^{\text {' }}$ "The time had not yet come', says Erdmann, 'when God would be known as the God that took on himself $\pi$ ovos, labour, without which the life of God were one of heartless ease, troubled with nothing, while with it alone he is Love and Creator.' 2

Both these writers point to the deeper view of the nature of God contained in the Christian doctrine of the Incarnation. But it must be confessed that the speculative truth expressed in the central doctrine of the new religion has seldom been taken seriously-taken in bitter earnest-either in Christian theology or in the metaphysical idealism which has grown up under the same influences. The God of popular Christian theology is still the far-off, self-involved, abstractly perfect and eternally blessed God of pure Monotheism, inherited instincts combining with the potent influence of Greek philosophy to stifle what was most characteristic in the world-view of the new faith. Few things are more disheartening to the philosophical student of religion than the way in which the implications of the doctrine of the Incarnation are evaded in popular theology by dividing the functions of Deity between the Father and the Son, conceived practically as two distinct personalities or centres of consciousness, the Father perpetuating the old monarchical ideal and the incarnation of the Son being limited to a single historical individual. ${ }^{2}$ Grosser still, how-

${ }^{1}$ Edward Caird, Theology in the Greek Philosophers, vol. ii, p. I3.

${ }^{2}$ Grundriss der Geschichte der Philosophie, section 87.

' In revising these lectures I have been pleased to find strong support for the view here expressed in a suggestive paper by Dr. Streeter, "The Suffering of God' (Hibbert Journal, April 1914). Dr. Streeter points out that, although the formula of Athanasius was embodied in the creeds, "so far as the imagination of the Church is concerned it has really been the Arian who has triumphed'. Hebrew and Greek tradition combined in representing God as transcendent and impassible, and 
ever, is the materialism which has succeeded in transforming the profound doctrine of the Spirit, as the ultimate expression of the unity and cornmunion of God and man, into the notion of another distinct Being, a third centre of consciousness mysteriously united with the other two. The accidents of language have combined with the ingrained materialism of our ordinary thinking to make the doctrine of the Trinity a supra-rational mystery concerning the inner constitution of a transcendent Godhead, instead of the profoundest, and therefore the most intelligible, attempt to express the indwelling of God in man.

What was the secret of Christianity, the new interpretation of life by which it conquered the world? The answer is in a sense a commonplace. It was the lesson of self-sacrifice, of life for others, precisely through which, nevertheless, the truest and intensest realization of the self was to be attained-in the Pauline phrase, dying to live, in the words of Jesus, losing one's life to find it. This is the heavenly wisdom, which commanded the homage even of the selfcentred Goethe :

Und so lang du das nicht hast,

Dieses: Stirb und werde, Bist du nur ein trüber Gast Auf der dunklen Erde.

This conception of the meaning of life, embodied in the figure of One who spoke of Himself as being among men as accordingly 'the doctrine of the impassibility of God became a postulate of theology. ... Men still spoke of the love of God: they only really meant it when they thought of God the Son; clemency at most-a royal prerogative-was imagined of the Father.... The Christian Creed acknowledges but one God and one quality of Godhead-so far Athanasius won his cause; but the Christian imagination has been driven by this postulate of the impassibility of God to worship two. Side by side sit throned in heaven God the Father, omnipotent, unchangeable, impassible, and on his right hand God the Son, "passus, crucifixus, mortuus, resurrectus". What is this but Arianism, routed in the field of intellectual definition, triumphing in the more important sphere of the imaginative presentation of the object of the belief?' 
one that serveth, this was the victory which overcame the world. It is the final abandonment of the hedonistic ideal, through the recognition of the inherent emptiness of the self-centred life. The whole standard of judgement upon life and the purpose of the world is accordingly changed. And here the bearing of the change upon our argument becomes apparent.

For if this is the deepest insight into human life, must we not also recognize it as the open secret of the universe? That is the conclusion to which we have been led up more than once already in the course of these lectures: no God, or Absolute, existing in solitary bliss and perfection, but a God who lives in the perpetual giving of himself, who shares the life of his finite creatures, bearing in and with them the whole burden of their finitude, their sinful wanderings and sorrows, and the suffering without which they cannot be made perfect. It is the fundamental structure of reality which we are seeking to determine. For that surely is the meaning of all discussion as to the being and nature of God. In this ultimate instance, therefore, we cannot expect to gain an insight into that structure by passing altogether from the process of the finite life, treating it simply as an illusion, and defining Reality, in contrast with it, as the perpetual undimmed enjoyment of a static perfection. To do so would be to abandon the principle which has guided us throughout. We must interpret the divine on the analogy of what we feel to be profoundest in our own experience. And if so, the omnipotence of God will mean neither the tawdry trappings of regal pomp nor the irresistible might of a physical force. The divine omnipotence consists in the all-compelling power of goodness and love to enlighten the grossest darkness and to melt the hardest heart. 'We needs must love the highest when we see it.' It is of the essence of the divine prerogative to seek no other means of triumph- 
as, indeed, a real triumph is possible on no other terms. ${ }^{1}$ And thus, for a metaphysic which has emancipated itself from physical categories, the ultimate conception of God is not that of a pre-existent Creator but, as it is for religion, that of the eternal Redeemer of the world. This perpetual process is the very life of God, in which, besides the effort and the pain, $\mathrm{He}$ tastes, we must believe, the joy of victory won.

But although, from the divine point of view, the process must be thus envisaged in its completeness as an eternal deed, that is not to be taken as implying that we have to do, as James suggests, with a spectacular performance, in which the conflict is merely a make-believe and the issue a foregone conclusion. There is a well-known passage of Hegel which has always seemed to me to lend colour to such a suggestion. 'Within the range of the finite', he says, 'we can never see or experience that the End has been really secured. The consummation of the infinite End, therefore, consists merely in removing the illusion which makes it seem yet unaccomplished. The Good, the absolutely Good, is eternally accomplishing itself in the world, and the result is that it needs not wait upon us, but is already by implication, as well as in full actuality, accomplished. This is the illusion under which we live. It alone supplies at the same time the actualizing force on which the interest in the world depends. In the course of its process, the Idea creates that illusion by setting an antithesis to confront itself, and its action consists in getting rid of the illusion which it has created.' ${ }^{2}$ It will be noted that Hegel represents this illusion as the beneficent source of our interest in the world and its doings. But can we hope to preserve that interest if we admit to ourselves-

\footnotetext{
${ }^{1}$ This was finely brought out in the passage quoted from Professor Howison, supra, p. 319.

'Encyclopaedia, section 212, Zusatz (Wallace's translation, p. 352). Täuschung is the word used and four times repeated, meaning literally a 'deception' practised by the Idea upon the finite subject.
} 
even though it be only in our speculative moments-that it is all a cleverly arranged deception? The view, as Hegel here presents it, seems to me, I confess, to paralyse our energies at their source; if the antagonisms of the moral life are not real, then we have no standard of reality left. But the impression produced by Hegel's passage is due, in part at least, to the intrusion of the time-perspective. For if it is false to place the divine consummation in the future as 'one far-off divine event', it is still more fundamentally false, in a practical regard, to represent it as a finished fact in the past. All the tenses of time are required to body forth the eternal, and if we use them all frankly, we reach (we need not doubt) a practical truth. But if we attempt a more speculative statement, the statement must be in terms of the present. The universe is in no sense a finished fact; it is an act, a continuous life or process which (to speak in terms of time) is perpetually bcing accomplished. ${ }^{1}$ Professor Bosanquet has well said of the finite self that ' $a$ true self is something to be made and won, to be held together with pains and labour, not something given to be enjoyed '.2 The same must be true of the Absolute as the perpetual reconstitution and victorious self-maintenance of the spiritual whole. But if so, nothing could be more contrary to the true spirit of the situation than to speak of the end as already accomplished in the sense that 'it needs not wait upon us '; for it is in and through finite individuals that the divine triumph is worked out, and each of our actions and choices is therefore integral to the total result. Such a view contains, accordingly, all the strenuousness, the sense of uttermost reality in the struggle, on which James rightly insists.

${ }^{2}$ Cf. Lecture XIX, supra, pp. 369-70.

'Individuality and Value, p. 338 . Cf. the words which Goethe puts into the mouth of Faust a few moments before his death:

Nur der verdient die Freiheit wie das Leben,

Der täglich sie erobern muss. 
In much the same way as James tends to treat Absolutism as a creed for 'the tender-minded', Nietzsche brands Idealism in all its varieties as a 'flight from reality', a species of ' cowardice' which refuses at any price to see how reality is actually constituted. But whatever grounds there may be for this suggestion in the facile optimism of some idealistic writers, such a charge can hardly be brought against the view of God and the world which has been indicated in the preceding pages. There are features of the world-process, I have admitted, so horrible that we often feel them to be frankly intolerable. The agonies of helpless suffering from age to age and the depths of infamy and cruelty which the human record discloses-how are facts like these to be reconciled with the controlling presence of a principle of reason and goodness? Certainly if we attempt the reconciliation while clinging to the old idea of an omnipotent and impassible Creator or an Absolute in the rôle of spectator, we shall soon find ourselves exclaiming with James that 'a God who can relish such superfluities of horror is no God for human beings to appeal to '. But the whole analogy of a superhuman Person and a carefully adjusted scheme is strangely inadequate to the nature of the tremendous Fact we would explain. Creation, if the term is to be used in philosophy, must be taken, we found in a previous lecture, as expressing the essential nature of the divine life; the revelation of the infinite in the finite is the eternal fact of the universe. But the finite world, as centred in finite spirits, I have also contended, is not to be regarded as a mere appearance, existing only from the finite point of view; it is metaphysically real, as founded in the nature of God himself. The usefulness of the term creation consists, therefore, in the emphasis it lays on the distinction implied, as being more than can be rendered in terms of substance and mode. And one may recall in this connexion a phrase

'Pragmatism, p. I43. 
of Hegel's, riddled by criticism, in which he speaks of the Idea 'freely letting itself go' into the externality of space and time and so appearing to itself as Nature. Without stirring the ashes of ancient controversies, it is perhaps not altogether fanciful to read into the curious phrase some recognition of the fact that the 'otherness' of the finite is not a logical transparency, but brings with it a real difference and important consequences.

The existence of a finite world at all seems, in short, to involve the clash of individualities which tend to go their own way and seek their own ends. And if this involves an element of contingency in the world of moral action, the same would seem to be true of the world of nature which is the theatre of that action. Nature, we argued at an earlier stage, may be regarded, on the large scale of history, as the instrument of man's moral and intellectual education; but that does not mean that we are bound to take each of nature's happenings as the exponent of a particular moral purpose. The religious man will, no doubt, seek to accept whatever happens to him as from the hand of God, and by doing so he will make this account of the occurrence true, because he thereby transmutes the event into an instrument of spiritual growth. But the spirit in which he meets the experience does not, I think, imply that he traces the event, as a natural occurrence, to the operation of a particular providence. And it is needless to say that such is not the broad impression we derive from the facts of life. 'One shall be taken and another left.' Contingency is written across the face of nature-not in the sense that what happens is not determined by natural law, but in the sense that it appears to be only so determined, and cannot, in its detail, be brought within the scope of any rational or beneficent purpose. Contingency, casualty, or accident in this sense was frankly recognized by Plato and Aristotle, the great teleologists of the ancient world. But whereas they treat it 
merely as hindrance and defect, does not further reflection show that just such a world is better fitted to be a nurse of what is greatest in human character than any carefully adjusted scheme of moral discipline? Nature is more than a training-school of the moral virtues in the specific sense; it is an element, savage and dangerous, into which the human being is thrown to show what stuff he is made of-an element testing with merciless severity his powers of courage and endurance, but drawing from him thereby the utmost of which he is capable. Life for the individual in such a medium is a series of opportunities, but the use he makes of them depends on himself.

It comes upon us at first with something of a shock to find Professor Bosanquet referring to this process of the moulding of souls as 'the chapter of accidents '; ${ }^{1}$ yet that common phrase correctly enough describes the aspect of contingency in detail which seems to belong to any finite world that is more than an illusion. The contingence is, in the deepest view, contributory to-or rather an essential condition of - the perfection of the whole, but it wears the appearance of a foreign element in which, and in spite of which, the divine purpose is worked out; and it carries with it dangerous possibilities-extremities of wickedness and of suffering, which it would be hard indeed to justify, if we considered them as specific parts of a deliberate plan. It is undoubtedly a source of " the arduousness of reality', but in the arduousness is rooted most of the grandeur of the world. And if we complain of the severity of the process, we constantly forget, as Professor Bosanquet urges, that 'if we had our choice of pains, we should rule out our own greatest opportunities '.2 The sequel may show the experience in question as the very gate through

\footnotetext{
${ }^{2}$ e. g. Value and Destiny, pp. 225, 228, but the idea runs through his two volumes.

"Ibid., p. I8I.
} 
which we passed to a nobler life. And every day brings us instances of

Sorrow that is not sorrow but delight, And miserable love that is not pain To hear of, for the glory that redounds Therefrom to human kind and what we are.

No deeper foundation of Idealism can be laid than the perception which Professor Royce makes the text of his latest book-the perception of the spirit's power to transform the very meaning of the past and to transmute every loss into a gain, "finding even in the worst of tragedies the means of an otherwise impossible triumph,' ' a triumph which but for that wrong or treason had never been. This is the real omnipotence of atoning love, unweariedly creating good out of evil; and it is no far-off theological mystery but, God be thanked, the very texture of our human experience.

'The Problem of Christianity, vol. i, p. 3 Iо. 



\section{SUPPLEMENTARY NOTES}

\section{NOTE A. PAN-PSYCHISM}

Mr. C. A. Richardson, an able pupil of Professor Ward's, has challenged my criticisms of Pan-psychism in an article in Mind for January 1919, since reprinted in his volume, Spiritual Pluralism and Recent Philosophy. He seeks to invalidate the objection (urged also by Professor Bosanquet) that internality is impossible without externality, and that it is in fact as externalities and not as selves that material objects function in our experience, by drawing a distinction between the immediate data of perception and the existent entities of which these 'sense-data' are the 'appearance' or 'presentation'. 'For pluralism the object of experience does not consist of other subjects but of the appearance of those other subjects to the individual subject considered.' 'An existent entity cannot be an object of knowledge,' and 'the presented object of experience is not itself to be classed as an existent entity, though it has being in the sense that it is there.' This no doubt correctly represents the theory and also the motives which underly it, but besides apparently reducing the objects of nature, as we apprehend them, to subjective processes in the mind of the percipient, it fails to deal with the unnaturalness of the hypothesis, of which I complained in the text. Normally any phenomenon or appearance expresses the nature of the existent whose appearance it is; but, in the whole realm of the inorganic at any rate, it cannot be contended that there is anything to suggest the soul-centres which Panpsychism places behind every natural occurrence. They seem to obscure the nature of the facts rather than to render them more intelligible. "Hence the theory (I am constrained to repeat) though capable of intellectual statement, seems to me in its universal application, to be without vital meaning and, in that sense, to lack credibility.

As regards the point which I specially criticised, the at- 
tempt to treat physical laws as consolidated habits, themselves the result of evolution, Mr. Richardson concedes much of what I contended for, when he admits that 'action is impossible without environment' and that 'the monads must always have had some nature.' Hence he presents the theory in a distinctly limited form: 'By the evolution of natural laws, the pluralist simply means that the laws of nature did not always exist in their present relatively fixed form.' I quite agree with him that "laws are not, as it were, imposed upon things from without, but are merely descriptions of the way in which things behave.' But no such independent substantiation of laws was involved in my argument. What I sought to press home was that habits of action cannot be acquired except in the face of a definite system of conditions to which the creature reacts, and that the resulting response is determined by the joint nature of the interacting factors. But Mr. Peirce's theory appears to build upon a spontaneity which ignores ' natures' altogether. (The italics in my quotations from Spiritual Pluralism are Mr. Richardson's own.)

\section{NOTE B (p. 190)}

A personal disclaimer on Professor Taylor's part and a more careful examination of parallel passages in Mr. Bradley's work have convinced me that the statements quoted are not intended in a strictly Berkeleian sense. They are probably meant to emphasise the meaninglessness of a world entirely unrelated to sentience, which is substantially the argument of my sixth lecture. But the form of expression is certainly misleading.

\section{NOTE C. IDEALISM AND MENTALISM}

It may not be amiss to remind the reader that the argument of Lecture $\mathrm{X}$ is to be taken in connection with the strong emphasis laid throughout the volume on the meaninglessness, 
the nonsensicality one might say, of a world from which feeling and appreciation should be absent, and in connection also with the recurring polemic against the idea of the thing-initself apart from knowledge. Just because the centrality of intelligence, as the sole principle of explanation and unity, had been so insistently dwelt upon throughout, and most recently in the summary of the argument in the preceding lecture, I have been perhaps less careful of my phraseology in this particular discussion than I ought to have been. Nothing could be further from my intention than to treat the material world as a set of self-existent facts, which just happen to be there, and which the conscious mind-another empirical fact-just stumbles upon in the course of its lifeadventure. I do not hold the realistic creed as formulated by a recent disciple, that the universe is ' a box containing many and different contents.' I am indebted, therefore, to Professor Bosanquet for calling my attention (in his review of my book in Mind) to a phrase which, taken by itself, might seem to re-introduce the unrelated dualism against which I had contended, by speaking of the existence of things 'entirely apart from their being known.' The phrase occurred in a context which dealt primarily with the knowledge of this or that individual, but I recognise its undesirability, and words are now substituted (on p. I92) which limit my meaning and make the reference to Berkeley's instance clear. I have also modified the phraseology of a sentence on p. 200 .

The general purpose of the Lecture, I may add, was to disentangle the philosophical doctrine of Idealism from the epistemological heresy of Subjective Idealism or Mentalism, and, further, to show that philosophical arguments based on cognition alone can yield us only a formal or abstract unity. These two issues are not quite the same, although Green's view of nature as a system of thought-relations formed a natural transition from the one to the other. Perhaps it might have conduced to greater clearness, had the epistemological debate between Mentalism and Realism been more fully developed in terms of contemporary controversy and the criticism of Green reserved for another context, when more 
justice might have been done to the various aspects of his system. Historically Green's philosophy was an avowed polemic against Mentalism of the Berkeleian or Humian type. But his Kantian dualism between thought and sense and his hesitating treatment of sensation seem to lead him back to a species of subjectivism.

In an article which $I$ wrote in reply to certain criticisms (Mind, January I919), the epistemological argument is a little more fully stated, and it may be useful to incorporate a few paragraphs here. They may help to clear up the sense in which the independence of the object is asserted and the grounds on which the assertion is made. Speaking of the Berkeley-Mill-Bain analysis of matter into forms of conscious process or actual and possible experience, which one of my critics appeared to accept, I said: There is nothing which I believe to be epistemologically more unsound than this identification of the knower's knowledge or experience with the reality of the object he knows. Knowledge, experience, consciousness-all such terms-contain in their very essence a reference beyond the subjective process to a reality known or experienced in that process. They all point beyond themselves to an object whose reality is not constituted by the knowing but presupposed by it, and in that sense independent of it. This is, I hold, the irreducible truth in Realism, and it will be found that the very language used by the Mentalists often betrays the confusion on which their position rests. When, for example, Dean Rashdall says 'Matter, as we know it, can always be analysed away into a form of conscious experience,' a critic might easily retort that the proposition is in effect an identical one, for 'matter, as we know it,' is taken in it as equivalent to 'our knowledge of matter'. Or, again, we are told, that if we think of matter in the sense of the Idealist, we must think of it as 'existing only in and for Mind'. But there is, or may be, a great difference between ' in' and 'for'. An object, when sensed or in any way experienced, may intelligibly be said to exist for the mind in question or to be present to it ; but it is contrary to philosophical and scientific analysis no less than to common sense to de- 
scribe the object as in the mind. Such a form of expression really depends upon the unfounded (and, let us hope, now exploded) dogma that we cannot know a thing without actually being the thing, or unless the thing migrates over into us and becomes part of our own being. From this follows, in the first instance, the doctrine of Representative Perception, which in turn gives place to Subjective Idealism. But, if we refuse to yield to this unfounded prejudice at the outset, we shall not be tempted to sacrifice the reality of the object by reducing it to a process in the knowing mind. We shall be able to recognise that the reality of the fact known is everywhere the precondition of the fact of our knowing it and not vice versa.

This is so obvious in our own case that the second word of the Mentalist is always the retractation of his first. He hastens to assure us that the identification of the object with the mental experience is of course not true in the case of any finite mind whose experiences come and go, have a beginning and an end. To make the theorem true we have to imagine the allsustaining experience of a divine or cosmic consciousness. But if this transference of the issue appears at first sight to make the argument more plausible, that is only, as I have argued, because in our statement of the new case we have insensibly altered the conditions. Under one set of phrases or another, we attribute to such a cosmic consciousness a productive or creative activity which confers upon the objects of its thought just that stability and relative independence which we recognise in the object of our own knowledge, and in virtue of which these cosmic objects, as I may call them, are supposed to be capable of becoming common objects to any number of finite minds. But, even so, the theory immediately breaks down on closer examination; for, if we give it the meaning which makes it persuasive, it implies, in the case of any socalled object, the identity, or at least the complete resemblance, of the divine and the human mode of experience. But how can we identify our own sense-experience of the external world with the mode in which Nature enters into a divine experience? Hence the theory tends to change its form. "The object and the sensation,' are no longer taken, in Berkeley's phrase, as 'the 
same thing '; the sense-experience of the finite consciousness is represented as the immediate result of the divine Will, and the reality and independence of the object is now placed in the permanent exciting cause of the experience. But with this acknowledgment of an extra-mental reality, we have abandoned the principle on which Mentalism stands. The weakness of the new version is, moreover, that the reference to bare Will does not explain the particularitythe nature-of the occurrences. But, seeing that what is willed is supposed to be consciously willed, the character of the events and what may be called the scheme of operations as a whole must be somehow present to the divine Mind; and that raises once more the question of 'how'. When Berkeley grapples intermittently with this question in Siris, his reflections seem to be leading him to a view not far removed from Platonic Realism.

It was accordingly the epistemological falsity, as it seemed to me, of the mentalistic argument in its original form and the ambiguity of all the attempts to re-state it in cosmic termsas well as the exiguous nature of the result attainable by such a mode of reasoning, even if its validity were granted-that made me anxious to keep my own argument free from such entangling associations. But I did not on that account intend for a moment to assert the metaphysical self-existence, as I may term it, of material things. Modern Realists probably tend as a rule to do so, but the idea of the universe as a mere aggregate of independent existences, whether these existences be minds or things, is to me ultimately unthinkable; and, of course, the materialistic form of such an idea-as if the universe consisted of 'bits of unrelated stuff lying about'is the precise antithesis of everything I have ever taught. 'Essential relatedness' is the conception which I oppose to the figment of the unrelated (and therefore ultimately unknowable) thing in itself, on which I have poured unmitigated scorn. Things exist as they are known by mind, and they may be said to exist in order to be so known and appreciated. In this sense all things exist for mind, but my point is that they do exist; a thing is not itself 'a form of conscious experience,' a 
phase, that is to say, of the being of the experiencing mind. Finite minds require an environment by which they are shaped and from which they receive their content, and it is ultimately nonsensical to seek to represent the environment as a state or process of the mind itself. We do not dream of doing so in the case of the social environment; no form of Subjective Idealism has been consistent enough to 'analyse away' other selves into forms of the conscious experience of the subject by whom they are known and whom they influence. Why, then, should we so treat that other environment of external nature, which presents itself so obviously to unsophisticated people as an independent reality with which they are in relation? My natural realism consists, first of all, in refusing to obliterate this manifest distinctness in existence, as the Mentalistic argument constantly tends to do, and, secondly, in declining to follow the seductive example of the Pan-psychists who, while accepting a real independence or distinctness, transmute the apparently unconscious system of nature into a multitude of infinitesimally conscious centres. My difficulty with Pan-psychism is that if we are in earnest with the spiritual or psychic nature of the monads, we lose once more, as in Mentalism, the idea of environment, in the sense in which it seems to be involved in the existence of a finite spirit. In one sense, doubtless, it may be contended that Pan-psychism does provide an environment for the individual, to wit, the social environment constituted by all the other co-existing monads. But the social environment is, in our experience, based upon the natural. Spirits, for their individuation, self-expression and intercomunication, appear to require bodies and the system of nature in which these bodies are rooted; and to resolve these bodies and the whole material world into little minds is the beginning of an infinite progress. These little minds in turn imply some medium in which they are shaped and through which they can act. 


\section{NOTE D. THE ABSOLUTE AND THE FINITE INDIVIDUAL}

Lectures XIV and XV have been the subject of a good deal of discussion. The central question of these lectures has been defined in an apt phrase by Professor Bosanquet as 'the teleological status of finite spirits in the universe', and as such it formed the subject of debate at one of the annual Symposia of the Aristotelian Socicty in July 1918. As actually formulated for discussion, the question proposed took the somewhat technical, and, as it proved, not altogether unambiguous form, 'Do finite individuals possess a substantive or an adjectival mode of being?', but the vital issue underlying this abstract formula was (again in Professor Bosanquet's words) the 'real contrast of tendency', 'the distinction between two attitudes to life', on which I had dwelt in Lectures XIV and XV. The Symposium consisted of papers by Professor Bosanquet, myself, Professor Stout and Viscount Haldane (in the order given) concluding with a Reply by Professor Bosanquet. The first four papers are included in the volume of the Society's Proceedings for 1917-18, and the whole Symposium has been republished separately in the volume Life and Individuality, edited for the Society by Professor Wildon Carr.

I may be permitted here to transcribe a page or two from my own contribution as an extension or further enforcement of the argument in the Lectures. An illustration used by Professor Bosanquet in his introductory paper will best introduce my remarks.

- A simple analogy from knowledge (he said) supports the conception that the perfection of the finite individual would imply a change in his identity, and possibly an absorption into another's. If my philosophy were made complete and selfconsistent, I am sure my critics would admit, it could no longer be identified with that which I profess as mine; but would probably amalgamate with that of some one else, and in the end with that of all. I do not know why the same 
should not be the case with myself.' (Life and Finite Individuality, p. 99.)

The use of such an analogy could not but confirm my impression of the extent to which Professor Bosanquet's general theory depends on a too exclusive reference to the logical analysis of knowledge. But the logical analysis of knowledge (I wrote) 'yields us no more than the Kantian unity of apperception, which, as such, is no real self (whether human or divine) but simply the ideal unity of systematised knowledge. Kant himself equates the subjective unity with the idea of Nature as a 'Natur-einheit' or systematic unity. It is the idea of the unity of the universe as an intelligible system, an idea which Kant insists is a necessary idea, the necessary presupposition of any knowledge whatsoever. I am far from disparaging the importance of this conception in its proper reference in logic or epistemology; but to treat the postulate of knowledge as itself a real being-the so-called universal consciousness-is in effect to hypostatise an abstraction. And if we restrict our attention to knowledge-content, there is no ground discernible for the distinction and multiplication of personalities. These are at best only different points of viewpeepholes, so to speak-from which an identical content is contemplated. They are distinguishable, therefore, only by the greater range of content which they command and the greater coherence which they are consequently able to introduce into their world-scheme. The natural consummation of such limited points of view is to be pieced together and harmonised in the central or universal viewpoint from which, with all the facts before us, we should be able to see them all in their proper relations as a completely coherent system. The existence of finite centres at all is a superfluity for the theory, which accepts it (somewhat ungraciously) as a fact which cannot well be denied, but a distinction whose 'precarious and superficial nature' it cannot sufficiently emphasise.

My position, on the contrary, is that belief in the relative independence of human personalities and belief in the existence of God as a living Being are bound up together. Thus I interpret the meaning of creation. The process of the finite 
world means the actual origination of new centres of life and agency, not created by a magical word of evocation, but given the opportunity to make themselves. Professor Bosanquet in his chapters on the 'Moulding of Souls', describes this process suggestively as one of 'eliciting our own souls from their outsides', but he admits later that 'elicit', though a useful word, 'covers an almost miraculous creation which it does not explain'. The process is in truth not simply 'almost' but wholly miraculous, if by that is meant that, in the nature of the case, we, who are its products, cannot understand the method of our own creation any more than we can fully reconcile to ourselves the separateness and moral independence of the status achieved with the relation of creaturely dependence which is involved from the beginning and persists to the end. But the process goes on daily before our eyes in every case of the growth of a mind, and my contention is that it is to be accepted, not as an unexplained and puzzling exception to an otherwise intelligible scheme of things, but as itself the illuminative fact in which the meaning of the whole finite process may be read.

Professor Bosanquet says, 'I cannot believe that the supreme end of the Absolute is to give rise to beings such as I experience myself to be'. But to put the case in that way is hardly to put it fairly. It is not I, 'such as I experience myself to be', or, as he puts it in the previous page, the finite spirit 'as it stands and experiences itself with all its imperfections on its head', which can be conceived as the end of the Absolute (and apparently the finished result of all its pains); it is the spirit as God knows it and intends it to become, the spirit with its infinite potentialities and aspirations and the consciousness of its own imperfections, which is the fulcrum of its advance and the guarantee of a nobler future. This is what Professor Bosanquet means by the 'intentional' as opposed to the 'given' unity of the self. Our unity, he says, is 'a puzzle and an unsatisfied aspiration'-it is a 'demand', a 'pretension' which is never made good. And he takes the line of arguing that because the desire for immortality, so far as it is conceived in a religious spirit and deserves 
serious consideration, is not a desire for the perpetuation and stereotyping of my present self in all its poverty and meanness, but rather a desire to be fashioned more and more in the likeness of a perfect humanity, therefore it is not a desire for personal continuance at all, but, strictly speaking, he seems to say, inconsistent with it. It is identification with perfection which we seek, in the sense of merging our own personality altogether in that of the Perfect Being. As he puts it in his Gifford Lecture, it is not 'our' personality but ' $a$ ' personality, whose eternity the moral and religious consciousness demands, and so it is 'no puzzle', he concludes, 'no "faith as vague as all unsweet", to offer the eternal reality of the Absolute as that realisation of ourself which we instinctively demand and desire.' Surely this is to misread the situation. Because I desire to be made more and more in the likeness of God, I do not therefore desire to $b e$ God. The development of a personality in knowledge and goodness does not take place through confluence with other personalities, nor is its goal and cousummation to yield up its proper being and be 'blended with innumerable other selves' in the Absolute. In spite of Professor Bosanquet's fresh attempts at justification, and in spite of the ecstatic utterances of the mystics, I maintain that the idea of blending or absorption depends entirely on material analogies which can have no application in the case of selves. 'I surrender my soul heartily to God,' wrote Labadie, the French Pietist, in his last will and testament, 'giving it back like a drop of water to its source, and rest confident in Him, praying God, my origin and ocean, that $\mathrm{He}$ will take me unto Himself and engulf me eternally in the divine abyss of His Being.' The physical metaphor dominates the whole conception. But absorption or 'engulfment', in the case of a spiritual being, means only the extinction of one centre of intelligence and love, without any conceivable gain to other intelligences or to the content of the universe as a whole. Did Labadie suppose that he had not already his being in God, or that a union founded in knowledge and love and conscious service is not closer and more intimate by far than any which can be represented by the 
fusion of material things? Did he suppose that the engulfment of his private being could in any way enrich the fontal Life from which it sprang? Surely his value to God, or that of any other worshipping saint, must be held to lie in the personality of the worshipper. The existence of an individual centre of knowledge and feeling is in itself an enrichment of the universe, and the clearer and intenser the flame of the individual life, the greater proportionally the enrichment. To merge or blend such centres is simply to put out the lights one by one. In the society of such individuals, and in their communion with God, the supreme values of the universe emerge, and it is not personal vanity which suggests that for the Absolute such communion must possess a living value which no solitary perfection or contemplative felicity could yield.

\section{NOTE E. GOD AND THE ABSOLUTE}

Various critics have referred to the fact that these two terms are apparently used in the Lectures interchangeably. The fullest criticism of my terminology in this respect occurs in the course of a very sympathetic article by Professor H. R. Mackintosh in the Contemporary Review for December I9I7. He shows by a collation of passages that the two terms appear to be directly equated with one another, and he urges that such sheer identification is inconsistent with the ethical Theism with which my argument concludes. The apparent equation leads Professor Widgery, in the Indian Philosophical Review, No. I, to attack my position as undiluted 'Absolutism'. Professor Bosanquet and Dean Rashdall have commented, from different points of view, on the same usage. It would perhaps be more correct to say that I frequently use the terms indifferently than that I expressly identify them. And in some of the passages, as when I speak, for example, of ' a principle of explanation which we name the Absolute or God', or, again, of 'the conception of a rerum natura, whether we call it 
Nature, the Absolute, or God', the 'or' may fairly, I think, be taken as chronicling a variation in philosophical usage, which is unessential for the point under discussion, rather than as indicating a personal view of the precise equivalence of the terms. As a matter of fact, the two terms in question are plainly not precise equivalents in the sense that the one may be substituted for the other in any context; and an examination of the variations in my own usage would indicate, I believe, a growing differentiation between the two as the argument proceeds. This is partly due to the progressive nature of my argument which Professor Mackintosh rightly signalises, and on which I may be permitted for a moment to dwell. The whole of the first series of lectures was devoted to the establishment, as against Naturalism, of the general position of Idealism. The argument did not go beyond the world of finite experience: it was content to recognise in the process of that world an indwelling reason and purpose. 'God as immanent,' I said, in opening the second series, might be described as the next of the first year's lectures; but, so far, the further issue between an impersonal Absolutism and a Theism which should be at once ethical and religious remained undetermined. All the more distinctively speculative questions as to the meaning of creation, the degree of independence compatible with a derived existence, the possibility and nature of a divine experience-these and other cognate questions all remained to be dealt with in the second series. Inadequate as must inevitably be the treatment of such problems, the questions were at least faced and considered, and it seems to me on reflection that the sifting of the difficulties helped to clarify my own thought, making distinctions clearer and more explicit, and thus insensibly superseding phrases which bore an intelligible meaning in the earlier context in which they occurred. Something of this kind happened, I think, with the terms 'God' and 'the Absolute' when the fact of the divine transcendence became as obvious as the doctrine of immanence dwelt on in the earlier series. But, in spite of this differentiation, the two terms will undoubtedly be found used from time to time as interchangeable even to the end; 
and perhaps I may be able to show that the usage is defensible and need cause no real confusion of thought.

Why, it may be asked, retain at all a term like the Absolute, apparently so ambiguous in its import and so questionable in its antecedents? Dean Rashdall would prefer to dispense with it altogether and to speak simply of 'the Universe', which he would then describe as consisting of 'God and the finite centres'. There is an apparent simplification here which is attractive; but it is a simplification reached, it seems to me, by sacrificing the conception of immanence, and reverting to a purely deistic view of the relation of God to the spirits whom $\mathrm{He}$ is said to create. 'Universe' is, moreover, too cold and threadbare a term to serve as the ultimate designation of the living Fact we seek to name. Etymologically, no doubt, it was intended to imply the unity and system of the whole, as opposed to what Carlyle called a multiverse or chaos. But the implication hardly survives in ordinary usage, and the term is perhaps most commonly used not as an all-inclusive term but of the world as distinguished from God, its primary suggestion being that of the immeasurable fields of space dotted with innumerable suns and planets. In any case, its associations are with the 'bad' infinite, the endless progress; it lacks almost entirely the suggestion of a self-contained and internally organised whole, beyond which there is nothing. The latter is the true philosophical meaning of the Absolute, and it is well to have a term to express just this meaning. For any idealist or spiritual view, reality is a systematic whole of this description. Such a theory as I have tried to expound finds it impossible to take God and the world as two separate and independently existing facts. A deistically conceived God, existing in solitary state before the world was, and to whom the finite world bears only a contingent relation is, I have insisted, a figment of the logical imagination. God exists only as a self-communicating Life: in theological language, creation is an eternal act or process-a process which must be ultimately understood not as the making of something out of nothing but as a self-revelation of the divine in and to finite spirits. Such, I said, is 'the eternal fashion of the cosmic life'. This, 
then, is the true Absolute, a term which would be inapplicable to the transcendent God of an abstract monotheism, but which is not unfitly applied to the sweep of a Life which realises itself in and through the process of the finite world, as consummated in the divine sonship of man. It is always, I think, of God as thus organic to the world that the term 'the Absolute' is used in my volume, and Professor Ward's hyphened phrase 'God-and-the-world' would therefore exactly express the meaning I had intended to convey.

It is plain that the process involves a real otherness in the finite selves and this is strongly emphasised in my argument. I have protested against the monism which treats the individual selves as merely the channels through which a single universal consciousness thinks and acts-masks, as it were, of the one actor who takes all the parts in the cosmic drama. And I have protested equally against the opposite idea, which denies any divine self-consciousness except that which is realised in the finite individuals. My argument presupposes at every turn a comprehensive divine experience which is other than, and infinitely more than, that of any finite self or of all finite selves collectively, if their several contributions could be somehow pieced together. If the first view abolishes the reality of the finite selves, the second recognises them alone as real, reducing God to the status of an abstract universal. In opposition to these two extremes I maintain, as I have always maintained, the real individuality and ethical independence of the finite selves as the fundamental condition of the moral life; and I accept at the same time the reality of a divine or perfect consciousness, because the process of human experience and the possibility of progress in goodness and truth remain to me inexplicable, unless the finite creature is grounded in and illuminated by such a creative Spirit. The otherness which I recognise is, of course, most conspicuous when regarded from the side of will, but it must be admitted to hold good through the whole range of self-conscious experience. No mental experience of mine can, in the sense in which it is my experience, form part of the experience of any other mind. Uniqueness belongs to the very notion of a self or consciousness. That 
being so, it follows-follows, I might say, ex vi termini-that, as Dean Rashdall contends, it is meaningless to speak of one consciousness as 'included in another,' or to speak of 'a Mind which includes all minds', and of man as, in that sense, 'a part of God'. Even those who, like Mr. Bradley, speak exclusively of the Absolute, do not suggest that the experiences of the finite centres form part, as such, of the absolute experience, but only as, in some fashion, supplemented, transmuted, harmonised. ${ }^{1}$ They could only form part, as such, of a divine or absolute consciousness, if that consciousness is identified and equated with the collectivity of the finite centres in which it is said to realise itself; and in that case there would be no divine or absolute experience at all in the sense of the present discussion.

But while we recognise that the experiences of finite selves do not form part of the divine experience in the same sense in which they are the experiences of the selves in question, it is well to be on our guard against the implications of language which might lead us to say that 'all the conclusions which are applicable to each particular self in his relation to another seem to be equally applicable to the relation between God and any other spirit.' God means, for philosophy at all events, not simply or primarily the existence of another self-conscious Being, but rather the infinite values of which His life is the eternal fruition and which are freely offered to all spirits for their appropriation and enjoyment. Truth, Beauty, Goodness, Love-these constitute the being of God- ' the fulness of the Godhead,' brokenly manifested in this world of time. God is Love. ' 'God Himself,' said St. Bernard, 'is manifested in His wisdom and His goodness, for God consists of these His attributes.' Both God and man in fact become bare points of mere existence-impossible abstractions-if we try to separate

${ }^{1}$ Cf. Essays on Truth and Reality, p. 413, 'otherwise than in their several immediacies'.

2 Similarly in the later Neo-Platonic philosophy the supreme principle is called the Good not in the sense that good is a predicate of it: Good is it. Cf. Professor Taylor's paper on "Proclus", in the Proceedings of the Aristotelian Society, vol. xviii, p. 613. 
them from one another and from the structural elements of their common life. Hence, in speaking of God in His relation to the world, the expressions I use by preference are rather such as 'the containing life' (p. 225), 'the sustaining and containing Life of all the worlds' (p. 389), 'the ultimate Experience on which we depend' (p. 364). I speak of 'the creative and informing Spirit' (p. 363), 'the universal life' in which the finite individuals share (p. 390), 'the nature of the whole' on which they draw (p. 383), ' the fontal life of God' (p. 294), and I describe that life-metaphorically, no doubt-in opposition to Professor Bosanquet's analogy of a continuum, as 'the focal unity of a world of self-conscious worlds to which it is not only their sustaining substance but the illumination of their lives' (p. 297). Some of these expressions are doubtless open to criticism, and I do not put forward any of them as faultless, but what the phrases aim at is to keep in view at once the transcendent being of God for Himself, which we inadequately figure to ourselves as a self-consciousness or personality on the model of our own, and the creative and illuminative activity of the same Spirit in the beings which live, and are sustained in life, only through its self-communicating presence. 



\section{INDEX}

Absolute, the, 155-7, 174, 407-17; the Absolute and the finite individual, Lectures XII, XIV, XV passim; the Absolute as the unrelated, 304; purpose and activity in the Absolute, 338-4I; the Absolute and the time-process, 360-5; Dr. Rashdall's distinction between the Absolute and God, 387-9I; Dr. McTaggart's Absolute, 39I-3. William James's conception of the Absolute, 397-9.

Absolutism, 225, 242, 262, 291, 341, $401,414$.

Actual and the real, 243-55.

Adamson, Robert, 52, $301 \mathrm{n}$.

Agnosticism, 7, 5I, 58-9, II8-19, 158-75, 214-15.

Animal mind, I00-3.

Appearance and reality, 131-2, 136, I58-63, I75, 216-19.

Appearance and mere appearance, 277.

Aristotle, interpretation of development through the idea of End, 106, 154, 332 ; conception of the divine activity as the eternal thinking upon thought, II3, 304, $346,408-9$; the individual as the concrete universal, 266, 272; the common sensibles, $127 \mathrm{n}$; ; the First Mover, 25I, 319; matter and form, 305-6; casualty or accident, 416.

Arnold, Matthew, 26, 268, 291.

Athanasius, $410 \mathrm{n}$.

Augustine, St., 295, 303-4, 365.

Aurelius, Marcus, 40.

Authority and reason, 62-3.

Automatism, see Epiphenomenalism.

Bacon, 6, I52, 246.

Bain, A., 9I, 284.

Balfour, A. J., 4I, 58-64, I99, 379.

Beauty and sublimity, I27-9.

Belief, see Faith.
Benevolence, Hume and Mill on divine, 403, 406.

Bergson, 48, 69, 85, 155, 259, 342, Lecture XIX passim; on Plato and Aristotle, 346, on durée réelle, 352.

Berkeley, 5I, 228, 309, 392; his world of internal experience, II6-I8, I83, 20I-2; his satirical handling of agnosticism, I6I ; circular nature of his mentalistic a rgument, 190-3.

Biology, Lecture IV passim, 107-8, 209.

Blake, 144.

Body and Mind, 99, 124-6.

Bois-Reymond, Du, 92 n., 104-5.

Bosanquet, B., 30, I9I n., 373, 413; on body and mind, 99; on the secondary and 'tertiary' qualities, 122, I27; on statistical results, I86-8; on the criterion of value, $225-42$; on the cosmological argument, 25I; on the Absolute and the finite individual, Lectures XIV, XV; use of the social analogy, 296-7; on the function of the material world, 308 ; on the temporal and the eternal, $343,355,368$; on 'the chapter of accidents', 4I6-I7.

Bradley, F. H., I90 n., 203, 215-16, 256 , 30I, 342, $390 \mathrm{n}$., 399; on degrees of reality, 220-2; on the criterion of value, 225-42, 334; on the religious consciousness, 252.

Bridges, J. H., 150.

Browning, 27, 44, 95, II4, 142, 244, 260.

Brunetière, 64.

Bruno, I05.

Butler, Bishop, 63.

Caird, E., 136, 146, 149-50, $199 \mathrm{n}$., 245, 250, 334, 409.

Carlyle, I56, I58.

Carr, Professor Wildon, 35I-3, 384-5. 
Casualty, involved in the existence of the finite, 415-16.

Categories, right of each science to use its own, $72, .79,94,107-8$, 209; philosophy as criticism of categories, 108.

Cause-a 'first' cause, 301 ; cause as ground or reason, 302; efficient causation inapplicable to the relation between spirits, 31516.

Chalmers, Thomas, $327 \mathrm{n}$.

Chance, Mr. Peirce's derivation of laws from pure chance, 185 .

Christianity, 144, 157, 291, 306-9, 314-15, 409-17.

Clifford, W. K., I8I-2.

Cognition, misleading implication of the term, II3-I4.

Coleridge, 106, I 28, 314.

Comte, 7o, Lecture VII passim, 153, 157-8, 213-14, 238.

Conation, involved in satisfaction, 336-8; conative structure of consciousness, 356-7.

Confluence of selves, $262 \mathrm{ff}$.

Contingence and freedom, in James and Bergson, 374 .

Continuity and the emergence of real differences, 90-104.

Copernicus, 28, 82 .

Cosmological argument, 249-5 I.

Creation, 285, 288, Lecture XVI passim, 415 .

'Creative synthesis', 95 .

Creative evolution, I55, 366, 370-4, 380-3.

Criterion of value, Lecture XII.

Dante, 40-I, $104 \mathrm{n}$.

Darwin, 66, 8I-4, 328.

Degrees of truth and reality, 222-3.

Deism, 34-6, 46, 207, 298, 312.

Design, the argument from, $70 \mathrm{n}$., 76 n.; Hume's discussion, 9-16; as affected by the theory of natural selection, 322-8.

Descartes, 49, II I, I I 5, 302, 393 n. ; on the idea of a Perfect Being, 246-8.

Determinism, the illusion of, 36770,375 .

Development, philosophical meaning and implications of, 105-7, 153-6.

Dewey, Professor J., II2.
Driesch, H., 69, 72, 74 n., 77-80.

Dualism, between 'the heart' and the reason, 47, 65; Cartesian dualism, II5; between ethical man and nature, $83,132-3$; in Greek thought, 305-6.

Duration and succession, 349-54

Eckhart, $314 \mathrm{n}$.

Elan vital, completely indeterminate, 378-9.

Eliot, George, 406-7.

Elliot, Hugh S. R., I64 n.

Emerson, 292 n., 373.

End, as the ultimate category of philosophical explanation, 29, 106, 154-5, 33 I-2, 340.

Energy, supposed results of the degradation of, 300 .

Environment, significance of the term, 83 .

Epigenesis, 95.

Epiphenomenalism, 114 n., 356.

Erdmann, J. E., 409.

Erigena, Scotus, 314.

Essence and appearance, 160-6.

Eternal, Eternity, Lectures XVIII, XIX passim.

Eucken, R., 242.

Evil, $400 \mathrm{ff}$.

Evolution, of sense-organs, 126-7. Cf. Development.

Experience, relation of philosophy to, 66-7; learning by experience characteristic of the living being, 85; planes of experience, 97. 100-2, 154-5.

Explanation, scientific, 91 ; philosophical, 106, 154, 331.

External world, its instrumental or mediating function, $178,200,295$, 308.

Faith, definition of, 82; distinguished from Knowledge, 49, 55, 239-42.

Ferrier, J. F., 193-5, 199.

Fichte, 29, 38, 219, 310-11, 378.

Flint. Robert, 299-302, 399.

Fouillée, A., I30-I.

Fraser, A. Campbell, 240, 291 n., 315.

Freedom, a postulate and a fact, 3I-2, 287-8, 29I-3; Monadism and freedom, $183-7 ; M$. Bergson 
on freedom and contingency, 370-9.

Galileo, 49.

Gassendi, 49.

Geddes, Professor Patrick, 83, $108 \mathrm{n}$.

God as immanent, 37, 175-7, 21522 ; as transcendent, the source of ideals, 243-55; a finite God, see Hume, Mill, James.

Goethe, 246, 4II, 4I3 n.

Gray, Professor Asa, $328 \mathrm{n}$.

Green, T. H., I55; the formal nature of his spiritual principle, 195-9, 347; his dissolution of Nature into thought-relations, 202-3.

Haeckel, E., 84, 181, 328.

Haldane, Dr. J. S., 70, 73-5, 76 n.

Haldane, Lord, 217-18.

Hamilton, Sir William, 7, 43, 5I, I24-6, I6I-5, 214.

Harrison, Frederic, 138, 168-70.

Hartmann, E. von, 27 n., 53 n., I24, $173,298 \mathrm{n}$.

Hegel, 38, 67, 131 n., 177, 218, 256, 296, 304, 334, 339, 362, 4I 5 ; on the truth as the whole, I54, 33I ; on the logic of religion, 250-1; the Hegelian Trinity and the deduction of the many from the one, 309-13; the Absolute and the illusion of the finite, 340 , 4I2-13.

Heraclitus, 342, 385.

Hobbes, 49.

Hodgson, Shadworth, 114 n.

Höffding, 39, 144, $207,214$.

Hogg, Professor A. G., $200 \mathrm{n}$.

Howison, Professor G. H., 316-2I, $386,412 \mathrm{n}$.

Hume, Lecture I passim, 25, 34, 46, 103, I87-8, 20I-2, 207, 294, 322 ; on a finite deity, I9, 40I-2; a cause must be judged by its known effects, 18, 176, 244-5, 249; unity and relatedness as fictions of the imagination, 196; Mr. Balfour's scepticism compared with Hume's, 60 ; Hume's purely hedonistic ideal, 406 .

Humanity, Religion of, 137-58.

Humanism, 238.

Huxley, T. H., I2, I10 n., 328; on
Hume's theism, 16, 22; on the breach between the ethical and the cosmic process, 26, 83, 132-3 ; his conscious automatism, $5 \mathrm{I}$; his Berkeleian sensationalism, 81.

Ideal and the actual, Lecture XIII passim; the ideal and the real, 53, $25 \mathrm{I}-2$.

Idealism $v$. Naturalism, 38-42, I8I, 236; speculative idealism, 38,56 , 57, 409; subjective idealism, see Mentalism.

Imagination, the truth of the poetic, 127 .

Immanence, 37, 175-7, 215-16; Spinoza's doctrine of immanence, 22I ; immanence and transcendence, 253-5.

Immortality, 43-5, 269-7I.

Incarnation, the Christian doctrine of the, 144, 157, 30\%, 409-10.

Indiscernibles, identity of, 267.

Individual, the finite, Lectures XIV, XV passim.

Infinite, its active presence in the finite, 247, 25I, 254.

James, William, 4I, I17, 144, 196, $242,268,412,413,414$; on a finite God, 19, 382, 393-4; on the specious present, $352-3$; on determinism, $367-8$; on an unfinished worid and contingency, $366,373-4,377 \mathrm{n}$.; on pluralism, 393-9; on meliorism, 382, 394.

Janet, Paul, 310, 325-6.

Jennings, H. S., 74 .

Judgements of value, objectivity of, $4 \mathrm{I}, 24 \mathrm{I}-2$; not to be taken as detached intuitions, 223.

Kant, 4, 8, 2I n., Lecture II passim, 48-5I, 69, 8I, III, I47, I76, I98, $207,240,254,301,371$; on intrinsic value, $27-30$; on the nature of the organism, 70 n., $77 \mathrm{n}$.; his phenomenalism, 118-19, I31-3, I $35,153,158-60,163-4$; on the argument from design, 322, 3245, 328-30.

Kapila, $200 \mathrm{n}$.

Keats, 29, 127, 129, 256, 278.

Kelvin, Lord, 97, 300. 
Kidd, Benjamin, 63-4

Kipling, R., 142.

Kropotkin, 84 n.

Ladd, Professor G. T., 42 n.

Lange, F. A., 5I-4, 8I, I49.

Lankester, Sir E. Ray, 163.

Laurie, S. S., 122-4, 127 n., 174, $177,215$.

Leibnitz, 54, 179-8I, 188, 237-8, 295, 386.

Le Roy, 379-80.

Lessing, 29.

Lévy-Bruhl, I5I $\mathrm{n}$.

Life, question of origin of, 94-7. See Biology.

Lindsay, A. D., $49 \mathrm{n}$.

Locke, 6, 49, I10, I12, I25 n., 183, $196,237,248,272,347,403$ n. ; on the distinction betwixt man and brutes, IOO-I ; on knowledge and reality, II6-18, 158-60; on the existence of God, 249 ; on the consciousness of duration, 34950, 354.

Loeb, J., 73.

Lotze, 108, 113, 174, 177, 282-3; on naturalism and idealism, 42, 546,58 ; on the creation of finite selves, 99,287 ; on the secondary qualities, 120-I ; on the timelessness of truth, 345 ; on present, past, and future, 376 .

Lucretius, 105, 259.

McGilvary, Professor E. B., 353 n., 363-5.

Mackenzie, Professor J. S., 343.

McTaggart, J. M. E., 6 n., 19, 257, 321,343 n., 387, 391-3.

Malthus, 83 .

Mansel, 7.

Marett, R. R., 39I n.

Marlowe, 243.

Martineau, 36-7, 53, 254, 257-8, 311 .

Materialism, 40-1, 5I, 8I-2, 89, 105 . See Naturalism.

Maxwell, Clerk, 78.

Mazzini, 142.

Mechanism v. purpose, Lotze on, 54; Kant on, 70 n., 76, 77 n.; mechanistic explanation in biology, 70-7.

Meliorism, 382, 394-6.

Mentalism, 190-204.
Metaphysics, Comte's idea of, 1356; agnostic travesty of, 163-4.

Mill, J. S., 19, 94-5, 134; on design and a limited God, 324-5, 40I-3, 405-6.

Mind-stuff, 182.

Mind and Body, 99, 124-6.

Moberly, W. H., 338.

Monadism, 179-89, 203-4.

Monism, see Absolutism.

Monism (popular scientific), I8I.

Moore, Professor A. W., 238 n.

Morality and the idea of intrinsic value, 26-8; Kant's treatment of the postulates of morality, 3I-5; nature and morality, 26, 83-5, I32, 146-9; religion and morality, difference of attitude, 394- 6 .

Morgan, Professor Lloyd, 92, 98-9.

Mozley, J. B., 268 n.

Myers, F. W. H., 42 n.

Naturalism and idealism contrasted, 39-42; the naturalistic controversy during the nineteenth century, Lecture III passim; the true answer to naturalism, 65 ; ambiguity of the term, 88; the lower and the higher naturalism, Lecture V passim, 200-10.

Natural Realism, in Reid and Hamilton, 124-6.

Natural Selection, 81-2, 84; and purpose, 327-8.

Nature and morality, 26, 83-5, 132, 146-9, 212-13; nature as a realm of law, 178, 187-8; the instrumental or mediating function of nature, 200-1, 308; nature and the absolute, 202.

Neo-Kantianism, in Lange, 51-3.

Neo-Realism, I 12, I91.

Neo-Vitalism, 7I-6; defective statements criticised, 77-80.

Newton, 49, 153, 238, 405.

Nietzsche, $30,84,88,175,268,414$.

Non-contradiction, as the criterion of value, 227 .

Noumenon, the quest of the mythical, 160-4.

Numerical identity, 266-7.

Omnipotence, conception of, $400-5$, 412,417 . 
Ontological argument, Hume's treatment of, 8-9; Kant's criticisms, 8,240 ; true meaning of, 240-I.

Orders or levels of existence, 92ro8.

Organic relations of nature and mind, 122-7, 146-9, 178-9, 2 10-13.

Organism, action of, not describable in terms of mechanism, 727.

Origen, 304, 307-8.

Ostwald, $108 \mathrm{n}$.

Overstreet, Professor H. A., 238 n.

Paley, 12.

Pan-psychism, 178-89.

Pantheism, the lower, 219, 253.

Parmenides, 6 n., I73, 342, 38r.

Pascal, 47, 137.

Pathetic fallacy, $128 \mathrm{n}$.

Pearson, Karl, 72 n., 84, 92 n.

Peirce, C. S., I84-7.

Perry, Professor R. B., 223-4.

Personality, as a formed will, 29r ; place of, in Greek and in Christian thought, 29l, 307.

Personal Idealism, 225.

Pessimism, 17-18, 27, 147.

Phenomenon and noumenon, 1603.

Philo, 3 I3.

Philosophy, as criticism of categories, 67, 108; the relation of philosophy to experience, 67.

Picton, J. Allanson, I73.

Planes of experience, 92-108.

Plato, 236, 239, 259, 333, 342, 400, 415 ; on creation, $305-6,308-9$; on the Good, $55,181,378$; on time and the timeless, I54, 303 n., 345-6, 360, 365 .

Pleasure or happiness not the end of the universe, $27,403,406-7$, $4 \mathrm{II}$.

Plotinus, $3 \times 3$.

Pluralism, Professor Ward on, 95, I 83-4; Professor Howison's, 315-21, 386; William James's, 393-8.

Pope, 220, 253.

Positivism, see Comte and $\mathrm{Hu}$ manity, Religion of.

Potentiality, the meaning of, ro5-7.

Pragmatism, 22, I12, 225, 238.

Present, the specious, $352-3$; the: living present, $369-70$; the mere present, 376 .

Prichard, H. A., II2.

Proclus, 313.

Progress, predicable of parts, not of the universe as a whole, 383 .

Purpose, characteristics of finite purpose, 323-4; Professor Bosanquet on teleology and purpose, $323,335-8$; the idea passes into that of a systematic and intelligible whole, 328-3I ; purpose and the idea of satisfaction or value, 332-5; Spinoza on purpose, 332-3, 339.

Rashdall, Dean, distinction between God and the Absolute, 387-9I, 392 n., 407 n.

Realism, Professor Laurie's statement of philosophical, 122-4. See also Natural Realism, NeoRealism.

Reason, attacks on, 62-3; reason and association distinguished, 100-3.

Reflex action, 73-4.

Reid, Thomas, I24, 19I, 349-5I.

Reinke's theory of 'dominants', $77,80 \mathrm{n}$.

Relatedness distinguished from Relativity, I16, 123, 126, 164, 21 1I2.

Relevancy of response, I86-7.

Religion and the religious consciousness, 137, 237-8, 252, 259, 289-9I.

Renan, E., 89 n.

Renouvier, C., 374.

Representationism, I16-18, 201.

Reynolds, Sir Joshua, 243 n.

Ritschl, A., 56-8.

Rossetti, D. G., 87, 350.

Royce, J., 279, 342, 354-5, 364 n., 4I7.

Satisfaction and value, 30 ; the argument from 'needs' to their satisfaction, 6r ; Mr. Bradley's claim that "our main wants must all find satisfaction', $233-5$; satisfaction inseparable from conation, 332-40; not to be identified with pleasure, or even with happiness, 407.

Scepticism, as a basis of faith, 7; 
Mr. Balfour's scepticism compared with Hume's, 60 .

Schäfer, Sir Edward, 96 n.

Schiller, 52, 296.

Schiller, F. C. S., 225.

Scott, Sir Walter, $129 \mathrm{n}$.

Secondary qualities, in Locke and Berkeley, II7; their objectivity, 120-4.

Seeley, Sir John, I44.

Self, false notions of the, 257 ; Dr. McTaggart's view of selves as substances existing in their own right, 391 ; Professor Bosanquet on the 'formal distinctness' and the possible blending or merging of selves, $26 \mathrm{I}-4$, on the 're-distribution' of finite selves in the Absolute, 28I-2; Mr. Bradley's metaphors in the same reference, $280-1$; selves share a common content, but are unique wholes of content, $263,266-8$; 'adjectival' theory of the self, 27 I-4; not a complex group of universals, 283 ; the origin of finite centres, 285-8, 293 ; testimony of the religious consciousness to the relative independence or 'otherness' of the selves, 289-90.

Self-sacrifice, 294, 410-12.

Shakespeare, $142,167,362,372$; the world of Shakespeare's tragedies, 223-4.

Shekinah, man the true, I57.

Shelley, 260.

Sidgwick, Henry, 39, I9I.

Simpson, Professor J. Y., 104.

Smith, Sir George Adam, 43-4.

Society ("the social whole') and the individual, 258, 265-6, 296-7.

Soul-making, 29, 256, 260, 278.

Space and time as principia individuationis, $267,364-5$.

Span of consciousness, 352-3.

Spencer, Herbert, 30, 84, 99 ; on life, 94,99 ; on the nature of explanation, 92-3; agnosticism and the unknowable, $7,51,58-9$, I64$76,214$.

Spinoza, 6 n., 34, 49, 173, 256, 272, 29I, 339; on cause as reason, 30I-2; on degrees of perfection, 22I-2; the relation of the world to God, 304, 314; the intellectual love of God, 291, 332-3.

Statistical results, Professor Ward and Professor Bosanquet on, 186-7.

Stephen, Sir James F., I68-9.

Stevenson, R. L., 268.

Stirling, J. H., 44-5, 96, I 18, 12I, I63.

Stout, Professor G. F., 270, 273 n., $277 \mathrm{n}$.

Streeter, Rev. B. H., 409-10 n.

Struggle for existence, over-emphasized, 83-4.

Substance, the Aristotelian and the Spinozistic sense of, 272, 281 ; substance and qualities, 162.

Survival of the fittest, in Hume, I3.

Swinburne, I40 n., 238.

Taylor, Professor A. E., 190 n., 270, 355 n., 360.

Teleology, Lecture XVII passim, 358-60.

Tennyson, $35,40,44,47$, II I, I 50 , 293 n., 294, 348-9, 363-4, 412.

Theism, defined by Professor Flint, 399; Hume's theism, 14-16, 20-3; Kant's theistic postulate, 34-7; differentia between a theistic and a non-theistic doctrine, 340 ; idea of God in traditional theism, 302-4, 340, 399, 408-9.

Thomson, Professor J. Arthur, 72 n., 77 n., 84,108 n.

Time, mathematical, as mere succession, 349; primitive consciousness of duration, 350-3; time transcended in teleological explanation and in an artistic whole, 358-62 : transcended, yet retained, in the Absolute, 363 ; time as principium individuationis, 267, 364-5; spatialized time and the illusion of determinism, 367-70.

Timelessness of truths, $344-7$.

Transcendence and immanence, 253-5.

Transition from one order of facts to another, 94-108, 209-10.

Trendelenburg, A., 33I.

Trinity, the doctrine of the, 313 , 410. 
Truth as the whole, 97, 106-7, 109, $154-6,177,215,33 \mathrm{I}-2,362$.

Tylor, Sir E. B., 298.

Tyndall, John, 105.

Ulrici, 304-5, 3 I0.

Ultra-rational, appeal to the, 64 .

Uniqueness of the individual, $267-9$.

Universal Consciousness (or the All-knower), 192-200, 397-8.

Unknowable, the, 58, I64-8; $\mathrm{Mr}$. Frederic Harrison on the Unknowable, I69.

Unpredictability of the future, 370-5.

Vaihinger, H., 53.

Validity of truths, 345-7.

Value, idea of intrinsic, 27-30; judgments of value, 40-1, $56-7$,
223: cognition and value, I1314; criterion of value, Lecture XII passim; satisfaction, conation, and value, 332-8.

Vitalism, 70. See also Neo-Vitalism.

Wallace, W., 89-90, 103, $104 \mathrm{n}$.

Ward, Professor James, 95 n., 103, $183-8,387-8$.

Will, as the complement of intelligence, 339; the spiritual will as the concrete personality, 291 .

Windelband, W., 39, $29 \mathrm{I}$ n., 306.

Wordsworth, 25, I28-9, 204, 25I, 254, 268, 295.

World organic to God, 295, 304-5, 309-10, 315-16, 412, 414.

Worth, see Value.

Zeno, the paradoxes of, 367 . 


\section{SCOTTISH PHILOSOPHY}

A Comparison of the Scottish and German Answers to Hume.

Zalfour Pbilosophical Zectures.

Fourth Edition. Crown 8vo. 5s.

के

HEGELIANISM AND PERSONALITY

3alfour Ohilosophital Zectures.

(Out of print.)

छ

MAN'S PLACE IN THE COSMOS

AND OTHER ESSAYS

Second Edition, revised and enlarged. Post 8vo. 6s. net.

Contents :-Man's Place in the Cosmos-The Present Position of the Philosophical Sciences-The 'New' Psychology and Automatism-

A New Theory of the Absolute-Mr. Balfour and his CriticsThe Venture of Theism-The Life and Opinions of Friedrich Nietzsche.

\section{\$)}

\section{-THE PHILOSOPHICAL RADICALS}

AND OTHER ESSAYS.

With Chapters Reprinted on the Philosophy of Refigion in Kant and Hegel.

Post 8vo. 6s. net.

Contents:-The Philosophical Radicals-Mr. Kidd on Western Civilization-Martineau's Philosophy-Herbert Spencer, the Man and his Work-Jones's 'Philosophy of Lotze'-Dewey's 'Studies in Logical Theory'-McTaggart's 'Some Dogmas of Religion'Philosophy as Criticism of Categories.

WILLIAM BLACKWOOD \& SONS, EDINBURGH \& LONDON. 







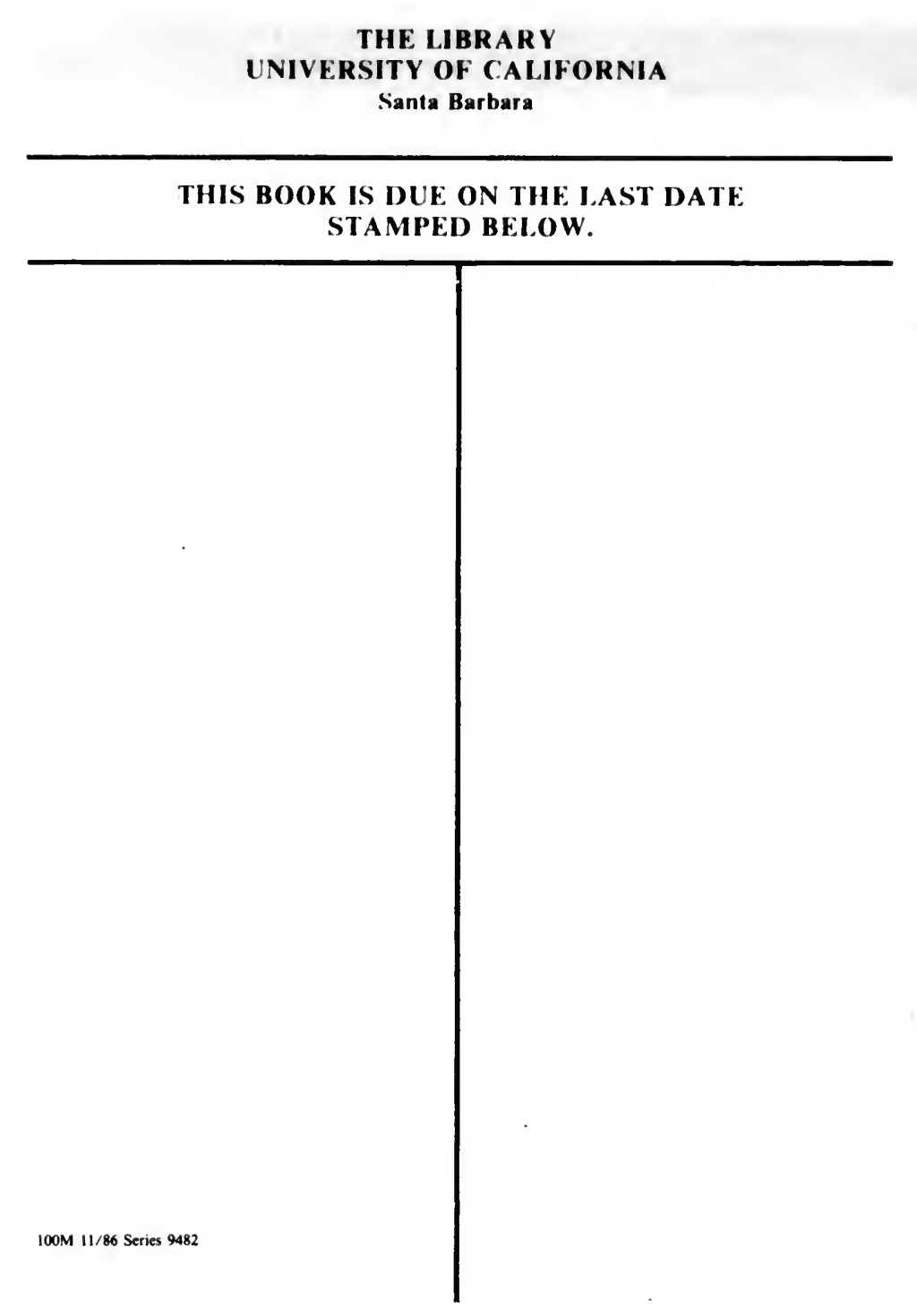




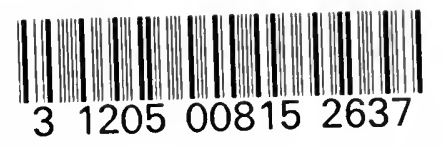

Re

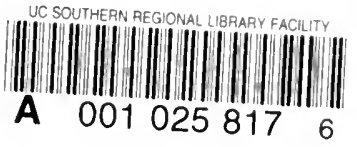


